UNIVERSIDADE DE SÃO PAULO

FACULDADE DE ECONOMIA, ADMINISTRAÇÃO E CONTABILIDADE DE RIBEIRÃO PRETO

DEPARTAMENTO DE ADMINISTRAÇÃO

VITOR EDSON MARQUES JÚNIOR

Um estudo sobre os atributos de escolha de shoppings centers pelos consumidores

RIBEIRÃO PRETO

2008 
Prof $^{a}$. Dra ${ }^{a}$. Profa. Dra. Suely Vilela

Reitora da Universidade de São Paulo

Prof. Dr. Rudinei Toledo Junior

Diretor da Faculdade de Economia, Administração e Contabilidade de Ribeirão Preto

Prof. Dr. Márcio Mattos Borges de Oliveira

Chefe do Departamento de Administração 
UNIVERSIDADE DE SÃO PAULO

FACULDADE DE ECONOMIA, ADMINISTRAÇÃO E CONTABILIDADE DE RIBEIRÃO PRETO

DEPARTAMENTO DE ADMINISTRAÇÃO

\author{
VITOR EDSON MARQUES JÚNIOR
}

\title{
Um estudo sobre os atributos de escolha de shoppings centers pelos
} consumidores

\begin{abstract}
Dissertação apresentada ao Programa de PósGraduação em Administração de Organizações da Faculdade de Economia, Administração e Contabilidade de Ribeirão Preto da Universidade de São Paulo como requisito para obtenção do título de Mestre em Administração de Organizações.
\end{abstract}

Orientador: Prof. Dr. Edgard Monforte Merlo

RIBEIRÃO PRETO

2008 


\section{AUTORIZO A REPRODUÇÃO E DIVULGAÇÃO TOTAL OU PARCIAL DESTE TRABALHO, POR QUALQUER MEIO CONVENCIONAL OU ELETRÔNICO, PARA FINS DE ESTUDO E PESQUISA, DESDE QUE CITADA A FONTE.}

\section{FICHA CATALOGRÁFICA}

\section{MARQUES Júnior, Vitor Edson}

Um estudo sobre os atributos de escolha de shoppings centers pelos consumidores. Ribeirão Preto - SP, 2008.

155 p. : il. ; $30 \mathrm{~cm}$

Dissertação de Mestrado, apresentada à Faculdade de Economia, Administração e Contabilidade de Ribeirão Preto da Universidade de São Paulo.

Orientador: MONFORTE Merlo, Edgard.

1.Varejo; 2. Atributos de Escolha. 3.Comportamento do Consumidor. 4.Shopping Center. 


\section{FOLHA DE APROVAÇÃO}

Vitor Edson Marques Júnior

Um estudo sobre os atributos de escolha

de shoppings centers pelos consumidores

Dissertação apresentada ao Programa de PósGraduação em Administração de Organizações da Faculdade de Economia, Administração e Contabilidade de Ribeirão Preto da Universidade de São Paulo como requisito para obtenção do título de Mestre em Administração de Organizações.

Aprovado em:

\section{Banca Examinadora}

Prof. Dr. Edgard Monforte Merlo

Instituição: Universidade de São Paulo

Assinatura:

Prof. Dr. Marcelo Seido Nagano

Instituição: Universidade Federal de São Carlos

Assinatura:

Prof. Dr. Paulo Sérgio Miranda Mendonça

Instituição: Universidade de São Paulo

Assinatura: 


\section{DEDICATÓRIA}

A Iara, minha esposa e mãe da minha linda Ana Clara, com amor, admiração e gratidão, por sua compreensão, carinho e constante apoio ao longo do período de elaboração deste trabalho. 


\section{AGRADECIMENTOS}

Ao Prof. Dr. Edgard Monforte Merlo, pela atenção e apoio durante o processo de definição e orientação.

Ao Prof. Dr. Marcelo Seido Nagano, pela atenção e sugestões durante o processo de qualificação.

Ao Prof. Dr. Paulo Sérgio Miranda Mendonça, pela atenção e sugestões durante o processo de qualificação.

À Faculdade de Economia, Administração e Contabilidade de Ribeirão Preto, pela oportunidade de realização do curso de mestrado.

Ao amigo Charles Dias de Almeida, em nome do qual agradeço a todos os bons amigos mestrandos da FEA, com quem, nestes dois anos, tive a alegria de conviver. 


\section{RESUMO}

MARQUES Júnior, Vitor Edson. Um estudo sobre os atributos de escolha de shoppings centers pelos consumidores. Dissertação (Mestrado) - Faculdade de Economia, Administração e Contabilidade, Universidade de São Paulo, 2008.

Embora os shoppings centers estejam em franco processo de ampliação na economia brasileira ainda são poucas as análises envolvendo shoppings centers, gestão estratégica de marcas e atributos motivadores de escolha pelos consumidores. Este trabalho tem por objetivo contribuir com estes estudos ao analisar os fatores motivacionais determinantes para a escolha de um shopping por parte dos consumidores. São analisados, portanto, a influência da gestão dos shoppings centers sobre a satisfação e o comportamento dos consumidores. A amostra deste estudo foi composta por alunos de graduação de oito cursos de Administração localizados nas cidades paulistas de Barretos, Bebedouro, Jaboticabal e Ribeirão Preto. Adicionalmente, foi realizada uma entrevista em profundidade com os gestores dos três shoppings centers da cidade de Ribeirão Preto. Para a consecução dos objetivos descritos acima, utilizou-se a metodologia de "survey" e de estudo de caso. O estudo revelou os atributos motivadores mais valorizados no processo de escolha feito pelos consumidores pesquisados. Os fatores limpeza, manutenção, segurança dentro do shopping e qualidade do serviço prestado receberam altas notas médias e alto grau de importância, atribuídos tanto pelos consumidores, quanto pelos gestores, identificando assim, nestes fatores, um aspecto de grande relevância para ambos os pesquisados. Este trabalho pretende contribuir com a compreensão da importância dos fatores valorados pelos consumidores de shoppings centers e assim sendo, fornecer material para a melhoria da gestão destes empreendimentos.

Palavras-chave: Varejo, Atributos de escolha, Comportamento do Consumidor e Shopping Center. 


\begin{abstract}
MARQUES Júnior, Vitor Edson. A study on the choice attributes of shopping mall consumers. Dissertation (Master Degree) - Faculdade de Economia, Administração e Contabilidade, Universidade de São Paulo, 2008.

Although shopping malls are in an expansion process within the Brazilian economy, few are the analyses involving shopping malls, brand strategic management and choice motivating attributes by consumers. This work is aimed to contribute to these studies analyzing the determinant motivational factors for the choice of a shopping by consumers. They are examined, therefore, the influence of shopping mall management on consumers satisfaction and behavior. The study sample was composed of undergraduate students from eight different Management Courses in cities of São Paulo state: Barretos, Bebedouro, Jaboticabal and Ribeirão Preto. Additionally, an interview was conducted in depth with the managers of the three shopping malls in the city of Ribeirão Preto. To achieve the objectives described above, a "survey" methodology was used in the case study. The study revealed the motivating attributes which are more influential in the choice made by the consumers in the research. The factors cleanness, maintenance and security in the shopping received high grade of importance and high grades, both by consumers as well as managers, identifying thus, in these factors, a point of great importance for both research. This work aims to contribute to the understanding of the importance factor of attributed by consumers for shopping malls and therefore, provide material for management improvement of these enterprises.
\end{abstract}

Keywords: Retail, Choice Attributes, Consumer's Behavior and Shopping Mall. 


\section{SUMÁRIO}

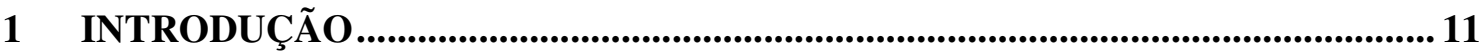

1.1 OBJETIVOS

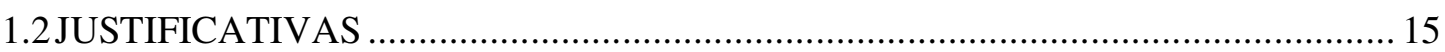

1.3 HIPÓTESE

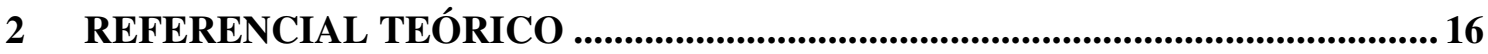

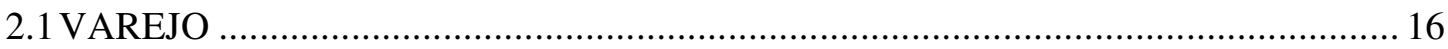

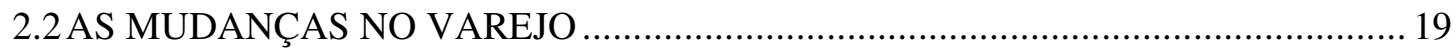

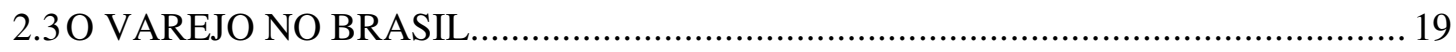

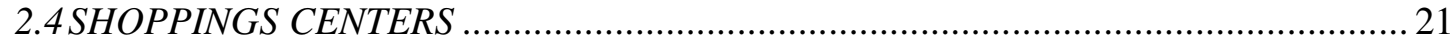

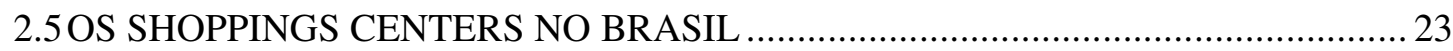

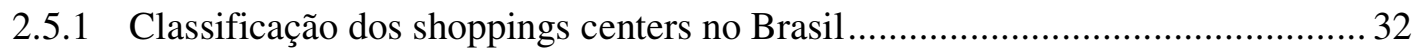

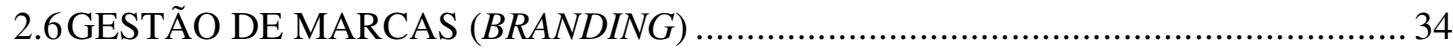

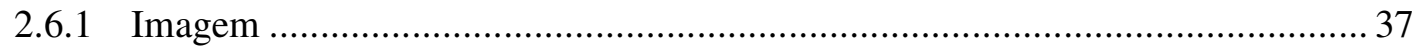

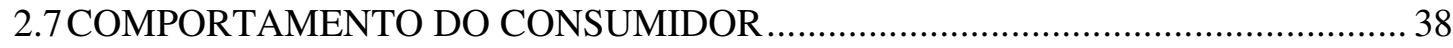

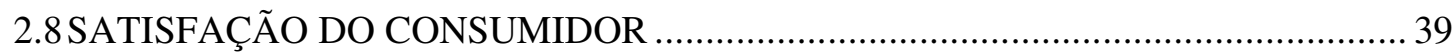

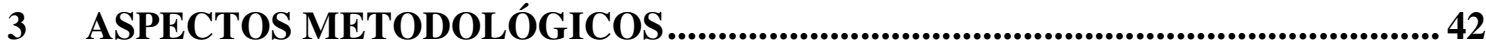

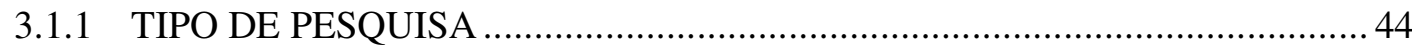

3.2PERGUNTA DE PESQUISA ………………………….................................. 48

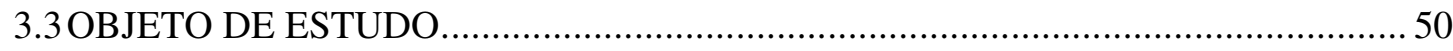

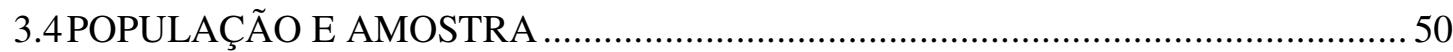

3.5 COLETA, ANÁLISE E INTERPRETAÇÃO DOS DADOS ........................................ 51

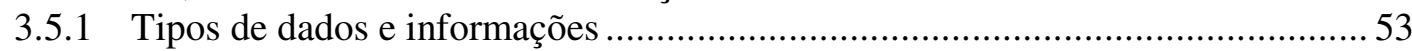

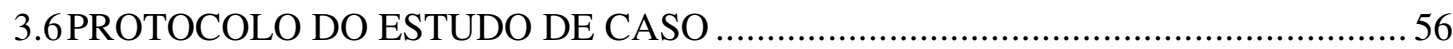

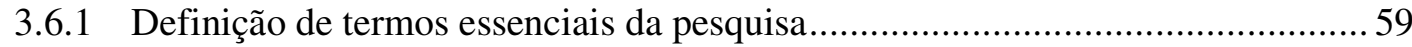

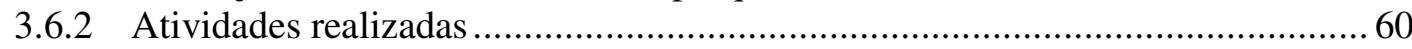

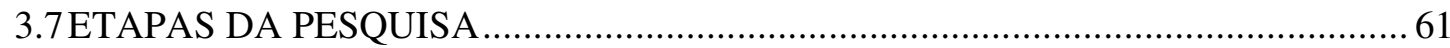

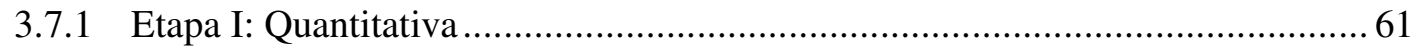

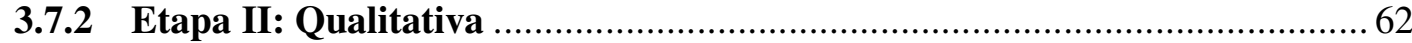

3.7.2.1 Análise de Conteúdo ............................................................................... 63

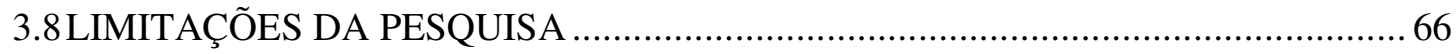

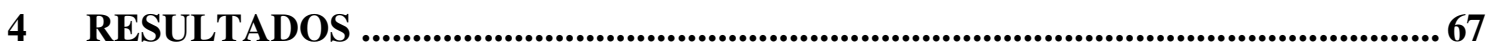

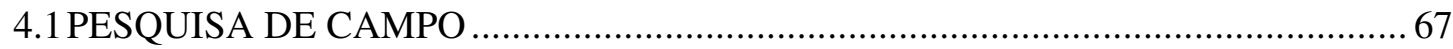

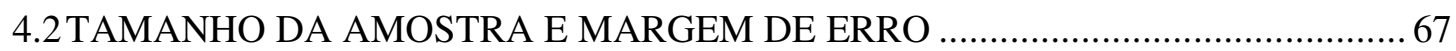

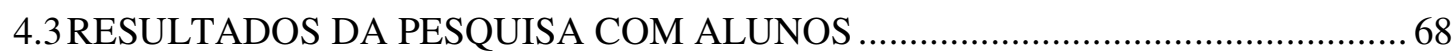

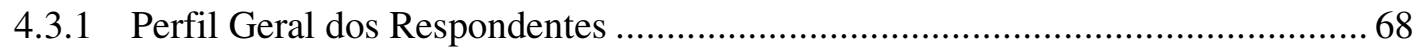




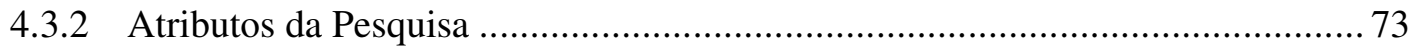

4.3.3 Atributos e Importância Alunos - Novo Shopping ….................................... 75

4.3.4 Atributos e Importância Alunos - Ribeirão Shopping ….............................. 78

4.3.5 Atributos e Importância Alunos - Santa Úrsula.............................................. 81

4.4RESULTADOS DA PESQUISA COM OS GESTORES ….................................. 84

4.4.1 Atributos e Importância Gestores - Novo Shopping .................................... 84

4.4.2 Atributos e Importância Gestores - Ribeirão Shopping ................................. 87

4.4.3 Atributos e Importância Gestores - Santa Úrsula ............................................. 90

4.4.4 TABULAÇÃO DAS PERGUNTAS DAS ENTREVISTAS COM OS

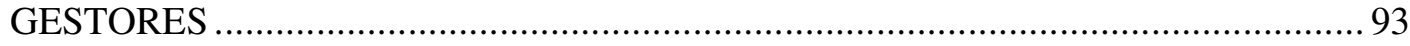

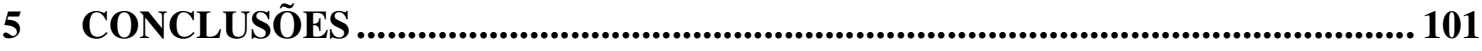

REFERÊNCIAS BIBLIOGRÁFICAS ...................................................................... 104

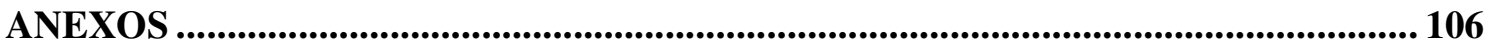

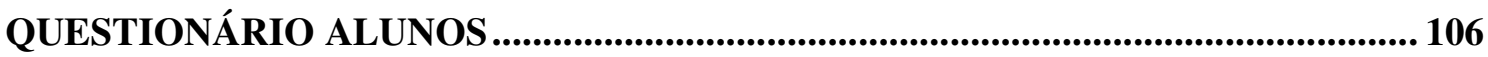

QUESTIONÁRIO GESTORES ....................................................................... 108

ROTEIRO DE ENTREVISTA COM OS GESTORES.............................................. 109

TABULAÇÃO DOS DADOS - PESQUISA ALUNOS .................................................. 111

TABULAÇÃO DOS DADOS - PESQUISA GESTORES.......................................... 150 


\section{LISTA DE GRÁFICOS}

Gráfico 2.1 - Distribuição Geográfica de shoppings centers no Brasil ......................................................... 27

Gráfico 2.2 - Evolução da distribuição de shoppings centers nas capitais x interior ..........................................28 28

Gráfico 2.3 - Evolução do número de shoppings centers no Brasil .............................................................229

Gráfico 2.4 - Evolução da Área Bruta Locável (ABL) em shoppings centers no Brasil ...................................29

Gráfico 2.5 - Evolução do número de Empregados em shoppings centers no Brasil ......................................30

Gráfico 4.1 - Importância vs Nota Média (Novo Shopping) ............................................................... 77

Gráfico 4.2 - Importância vs Nota Média (Ribeirão Shopping) ............................................................... 80

Gráfico 4.3 - Importância vs Nota Média (Santa Úrsula) ............................................................................. 83

Gráfico 4.4 - Importância vs Nota Média (Gestores Novo Shopping) …...................................................86

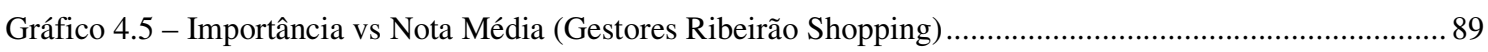

Gráfico 4.6 - Importância vs Nota Média (Gestores Santa Úrsula) .........................................................92 


\section{LISTA DE QUADROS}

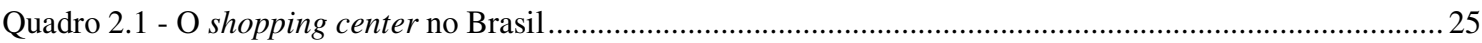

Quadro 2.2 - Distribuição dos shoppings centers por região ..................................................................26

Quadro 2.3 - Distribuição, ABL e empregos gerados pelos shoppings centers nos estados ............................. 31

Quadro 2.4- Classificação por tipo de shoppings centers (ABRASCE) …................................................. 33

Quadro 3.1 - Situações relevantes para diferentes estratégias de pesquisa ..................................................42

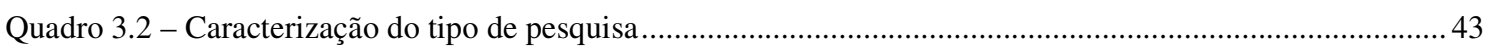

Quadro 3.3 - Complementaridade entre os métodos qualitativo e quantitativo ............................................47

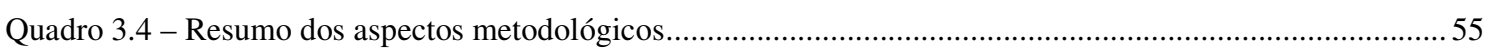

Quadro 3.5 - Protocolo do estudo de caso da etapa II - Qualitativa ............................................................58

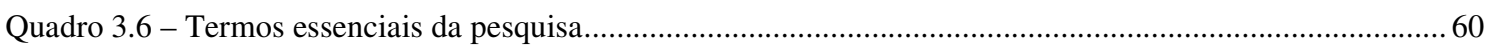




\section{LISTA DE TABELAS}

Tabela 4.1 - Faixa Etária vs Sexo .68

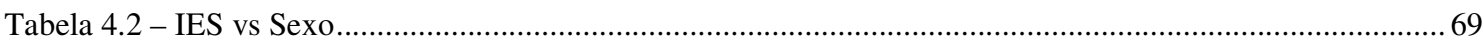

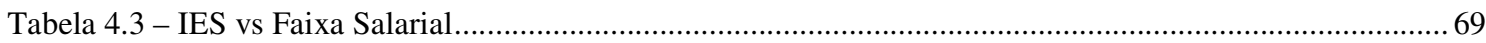

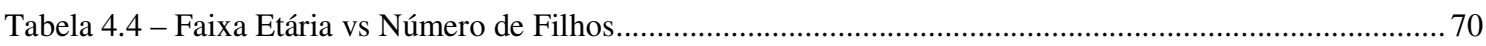

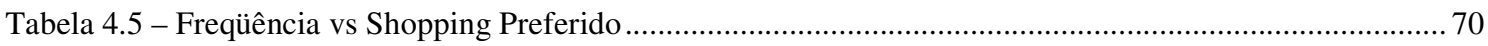

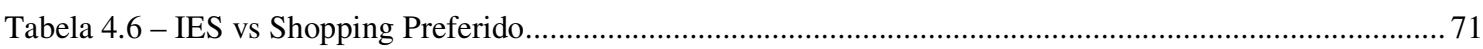

Tabela 4.7 - IES vs Shopping Preferido (Percentuais) ...................................................................... 71

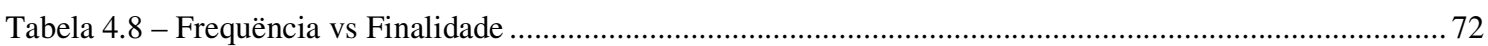

Tabela 4.9 - Freqüência (Alunos de IES de Ribeirão Preto) …............................................................ 72

Tabela 4.10 - Frequiência (Alunos de IES Fora de Ribeirão Preto) ................................................................ 72

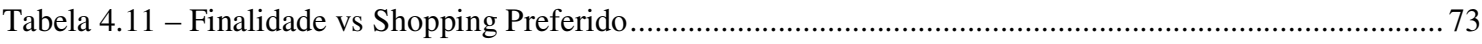

Tabela 4.12 - Finalidade vs Shopping Preferido (Percentuais) ............................................................ 73

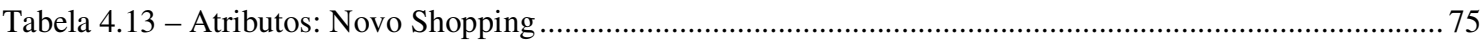

Tabela 4.14 - Atributos: Novo Shopping (Percentuais) ....................................................................... 76

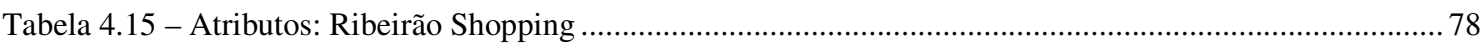

Tabela 4.16 - Atributos: Ribeirão Shopping (Percentuais) ......................................................................... 79

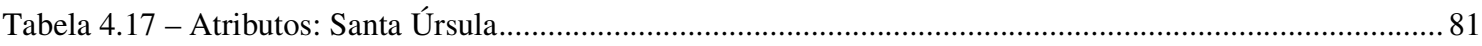

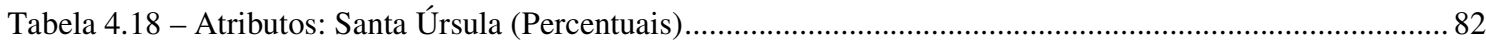

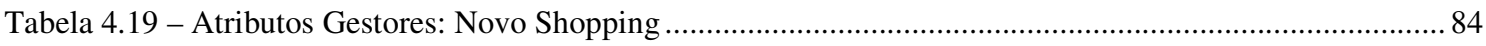

Tabela 4.20 - Atributos Gestores: Novo Shopping (Percentuais) ............................................................. 85

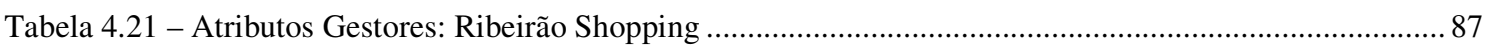

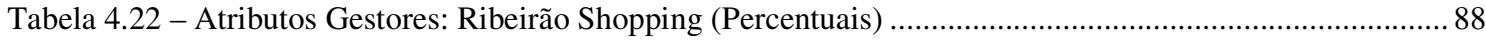

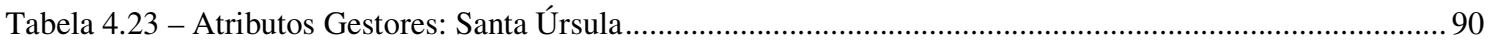

Tabela 4.24 - Atributos Gestores: Santa Úrsula (Percentuais) .................................................................. 91

Tabela 5.1 - Atributos mais valorados Alunos VS Gestores................................................................. 102 


\section{INTRODUÇÃ̃o}

Apesar de serem vários os estudos a respeito dos aspectos mercadológicos e econômicos dos shoppings centers e as relações advindas desses aspectos com seus consumidores, análises envolvendo fatores como shoppings centers, gestão estratégica de marcas, comportamento e satisfação de consumidores ainda são poucas.

Tradicionalmente, os shoppings centers têm por característica a simples oferta de áreas para o desenvolvimento de atividades de comercialização de bens e serviços aos consumidores finais, mediante a locação de espaços físicos onde o varejista encontra toda a infra-estrutura já montada para que o mesmo possa então realizar o seu negócio. Mas, ultimamente, para uma parcela cada vez maior e mais consciente de varejistas, os shoppings centers acabam sendo a melhor e mais rápida maneira de responder as várias das questões de seu ambiente competitivo, tais como a acessibilidade do negócio, a segurança e as conveniências oferecidas, tanto para os lojistas, quanto para seus clientes, bem como uma maneira eficiente de adquirir uma percepção positiva de imagem junto aos consumidores finais.

Tanto as empresas administradoras de shoppings centers, quanto os varejistas ali instalados, percebem que a imagem que os consumidores tem do seu negócio pode estar muito associada à marca projetada pelo próprio shopping center no qual eles estão inseridos.

E percebe-se, também, que parte do sucesso de um empreendimento, pode estar diretamente ligada a esta imagem da marca, sabendo que a mesma é construída e percebida pelos consumidores por meio de vários fatores e processos cognitivos.

Devido a essa quantidade e complexidade de fatores e processos que influenciam na percepção da marca por parte do consumidor, o fato de ter um varejo instalado em um shopping center que possua uma boa gestão de marca, tem se mostrado como grande fonte de 
vantagem competitiva para estes lojistas, pois, como já mencionado anteriormente, a influência dos shoppings, no despertar desta percepção de imagem da marca por parte dos consumidores, parece ser bastante significativa.

Os shoppings centers abrigam, hoje, uma ampla diversidade de atividades comerciais e de prestação de serviços especializadas no atendimento dos mais variados segmentos do mercado consumidor da região onde estão localizados. E essa especialização, parece ter feito com que, com o passar do tempo, os consumidores fossem construindo uma imagem daquele shopping center e de suas lojas. Esta imagem, positiva ou negativa, junto aos consumidores, parece ser obtida através do sucesso ou fracasso da gestão estratégica de marcas realizada por estes empreendimentos, gestão essa que deve estar aliada ao conhecimento dos fatores de satisfação destes clientes. Este conhecimento, quando transformado em especialização e adequação no atendimento oferecido aos consumidores, parece fazer com que os shoppings centers se transformem e prosperem como grandes centros comerciais, atraindo assim, cada vez mais varejistas interessados em ali se estabelecer. Sendo assim, cria-se um continuum virtuoso, pois os administradores destes começaram a perceber as vantagens econômicas que podem obter ao executarem uma gestão profissional de suas marcas.

A mesma adequação e especialização que está sendo buscada pelas administradoras de shoppings centers parecem começar agora também, de maneira mais consciente e profissional, a ocorrer por parte dos varejistas instalados nos shoppings. Pois, assim como as administradoras dos shoppings centers, os varejistas estão buscando conhecer melhor o seu cliente, para melhor se adequarem aos mesmos, posicionando seus produtos e serviços com um propósito de satisfação específico.

Hoje em dia, tanto as administrações dos shoppings centers, quanto os varejistas, estão realizando ações como: pesquisas de percepção de imagem, pesquisas de satisfação e comportamento do consumidor, entre outras, objetivando adquirir melhor conhecimento do 
seu público, para que, de posse dos resultados dessas pesquisas, possam promover um alinhamento de imagem da sua marca e de seus produtos e serviços às necessidades identificadas em seus consumidores.

Portanto, este trabalho buscou analisar o papel da gestão estratégica de marcas a ser realizada pelas empresas administradoras de três shoppings centers, situados na cidade de Ribeirão Preto, no interior do estado de São Paulo, na satisfação dos fatores motivacionais determinantes para a escolha de um deles por parte dos consumidores, e verificou se há ou não influência desta gestão de marcas nestes fatores motivacionais que determinam essa escolha.

Os consumidores escolhidos para esta análise foram alunos de graduação de oito cursos de Administração localizados nas cidades paulistas de Barretos, Bebedouro, Jaboticabal e Ribeirão Preto. Sendo pesquisados, portanto, os alunos de graduação em Administração do Centro Universitário da Fundação Educacional de Barretos - FEB (Barretos, SP), das Faculdades Integradas - FAFIBE (Bebedouro, SP), da Faculdade São Luis (Jaboticabal, SP), da Faculdade de Economia, Administração e Contabilidade - FEA/USP (Ribeirão Preto, SP), do Centro Universitário Moura Lacerda (Ribeirão Preto, SP), da Faculdade de Administração e Negócios de Ribeirão Preto - Reges (Ribeirão Preto, SP), do Centro Universitário Barão de Mauá (Ribeirão Preto, SP) e da Faculdade de Administração da Universidade Paulista - UNIP (Ribeirão Preto, SP). Também foram pesquisados os gestores dos três shoppings centers da cidade de Ribeirão Preto - SP. Os shoppings centers analisados foram: o Novo Shopping, administrado pelo Grupo Savoy, o Ribeirão Shopping, administrado pelo Grupo Multiplan e o Shopping Santa Úrsula, administrado pelo Grupo Almeida Júnior.

Tal análise foi obtida por meio da realização de uma pesquisa descritiva qualitativa (VERGARA, 2004) aplicada aos consumidores (alunos) e aos shoppings centers (gestores), bem como, através de entrevistas com os superintendentes de cada um dos três shoppings, 
sendo apresentados os resultados de um estudo que identificou os atributos que são valorizados pelos consumidores de cada um destes shoppings centers e as práticas de gestão de marcas que cada uma destas organizações adota.

Os resultados obtidos com esta pesquisa permitem identificar quais atributos realmente são importantes para a adoção de um determinado shopping center pelo consumidor e, com isso, compará-los ao papel da gestão de marcas adotadas por estes mesmos shoppings.

Esta pesquisa foi norteada pelas seguintes questões:

Quais os fatores motivacionais determinantes para a escolha de um shopping center por parte dos consumidores e qual o papel da gestão estratégica de marcas na satisfação destes fatores?

A fim de alcançar os objetivos propostos e para direcionar os rumos deste trabalho científico, foi necessário realizar um levantamento bibliográfico sobre varejo, shopping center, gestão de marcas, comportamento e satisfação do consumidor, assim como analisar dos resultados já alcançados por outras pesquisas, mesmo que não tenham sido realizadas no setor varejista de shopping center.

\subsection{OBJETIVOS}

O Objetivo Geral deste trabalho foi:

Analisar a gestão de marcas adotada pelos três Shoppings Centers de Ribeirão Preto (o Novo Shopping, o Ribeirão Shopping e o Shopping Santa Úrsula) em relação à escolha dos fatores motivacionais apontados pelos consumidores.

Os Objetivos Específicos deste trabalho foram:

1. Caracterizar o perfil dos consumidores entrevistados que preferem cada um dos três Shoppings Centers;

2. Identificar os fatores motivacionais determinantes para a escolha de um dos três Shoppings Centers de Ribeirão Preto na opinião dos consumidores e gestores; 
3. Verificar se há similaridades ou diferenças na classificação dos fatores motivacionais atribuídos pelos consumidores e gestores em relação a cada um dos três Shoppings Centers, e

4. Analisar se a gestão de marcas adotada nos Shoppings Centers de Ribeirão Preto conseguem propiciar ou contribuir para a satisfação dos fatores motivacionais de escolha considerados como determinantes pelos consumidores.

\subsection{JUSTIFICATIVAS}

No Brasil, conforme mencionado no início deste trabalho há uma carência de estudos acadêmicos que relacionem fatores como gestão estratégica de marcas com comportamento e satisfação de consumidores. E essa carência torna-se ainda mais acentuada se os estudos forem orientados para o setor de shoppings centers.

Desta forma, este trabalho justifica-se, pois tratou de avançar no estudo do comportamento do consumidor de shoppings centers e na gestão estratégica de marcas desenvolvidas por estes shoppings para satisfazer às demandas de seus clientes.

\subsection{HIPÓTESE}

Com base nas discussões levantadas nessa dissertação, pode-se destacar a consideração de que a gestão estratégica de marcas tem importante papel na satisfação, por parte dos consumidores, dos fatores motivadores determinantes no processo de escolha de um shopping center. 


\section{REFERENCIAL TEÓRICO}

Para dar embasamento teórico a esta pesquisa, o seu referencial teórico contempla quatro grandes tópicos, são eles: varejo, shoppings centers, gestão estratégica de marcas e comportamento do consumidor.

\subsection{VAREJO}

No início do que se chamava civilização, segundo Richter (1954) os povos produziam seus próprios alimentos, seu vestuário, quase não havendo nessa forma econômica a especialização do trabalho ou a necessidade de negociar. Mas aos poucos, os indivíduos foram deixando de produzir para o consumo próprio e passaram a produzir um excedente para com ele obter outros produtos que não possuíam. Esse sistema de trocas foi, de forma rudimentar, o fundador do comércio ou mais propriamente dito do varejo.

Hoje, existem várias definições para varejo, mas a sua essência continua sendo a comercialização de produtos e serviços a consumidores finais.

O mesmo Richter (1954) definia assim o varejo:

"E o processo de compra de produtos em quantidade relativamente grande dos produtores e dos atacadistas e outros fornecedores e posterior venda em quantidades menores ao consumidor final."

À época, na década de 50, esta definição parecia responder bem às características do que era o chamado de varejo. Mas com o passar do tempo, outras definições surgiram para melhor representar e definir as características atuais dessa atividade comercial, que é o varejo.

Definições pouco mais elaboradas como a de Kotler (1998), onde o mesmo propunha a seguinte explicação de varejo: 
"O varejo inclui todas as atividades envolvidas na venda de bens ou serviços diretamente aos consumidores finais para uso pessoal. Qualquer organização que utiliza esta forma de venda, seja ele fabricante, atacadista ou varejista, está praticando varejo. Não importa a maneira pela qual os bens ou serviços são vendidos (venda pessoal, telefone, correio ou máquina automática), ou onde são vendidos (loja, rua ou residência)."

Portanto, de acordo com Kotler (1998), varejo são todas as atividades envolvidas na venda de bens ou serviços diretamente aos consumidores finais para seu uso pessoal não relacionado a negócios. Muitas instituições - fabricantes, atacadistas, varejistas - fazem varejo. Mas a maior parte do varejo é feita pelos varejistas - negócio cujas vendas vêm primariamente do varejo.

Ainda segundo Kotler (1998), em todo o mundo, o varejo é uma importante atividade setorial, pois como tal, contribui nos planos econômicos, estratégicos e sociais. No plano econômico, o varejo fomenta a arrecadação fiscal, fortalecendo as economias regionais, gerando assim investimentos. Se for considerado o aspecto social, o varejo contribui para a geração de empregos e a manutenção de diversas outras fontes de sustentação da família. E por fim, no plano estratégico a contribuição do escopo varejista está intimamente relacionada ao seu papel de conexão entre o fabricante e o consumidor, pois com suas atividades promovem uma gama variada de oferta de produtos das mais distintas formatações e tipologias específicas adaptadas a cada mercado consumidor. Da mesma forma, Levy e Weitz (2000), definem varejo como sendo um conjunto de atividades de negócios que busca agregar valor a produtos e serviços, para vendê-los com o objetivo de satisfazer as necessidades de um segmento específico de consumidores, que os utilizará pessoalmente ou na família.

Para contemplar de forma pouco mais ampla este leque de definições de varejo, foi pesquisado Dias (2003) que trouxe a seguinte explicação sobre este assunto:

"O varejista é o intermediário que se encarrega de vender para os consumidores finais. Portanto, qualquer empresa que venda mercadorias ou 
presta serviços ao consumidor final para consumo pessoal ou doméstico está desempenhando a função de varejo.”

Parente (2000) destaca que dentre as teorias mais importantes, encontra-se a teoria do ciclo de vida do varejo que, além de ser um conceito clássico do conhecimento do marketing, também se aplica ao contexto do varejo. Assim como ocorre com os produtos, os formatos varejistas também atravessam os quatro estágios desse ciclo de vida. No estágio de introdução é que surgem os novos formatos de varejos e nessa fase, praticamente sem concorrência, as margens de lucro são baixas em função dos custos de desenvolvimento da estrutura e conceito do novo formato. Na fase subseqüente, a de crescimento, as vendas passam a se elevar, o modelo alcança aceitação, e o conceito se propaga com expansão também dos lucros e dos volumes. Maturidade é a terceira fase e nela o crescimento das vendas se estabiliza, pois o novo formato já alcançou aceitação nos mercados potenciais, a concorrência está muito intensa e há uma queda contínua da lucratividade. Na última fase do ciclo, encontramos o declínio, no qual as vendas e lucros do formato varejista declinam rapidamente, cedendo espaço para outro modelo bem mais estruturado e com maior nível de competência para se sustentar no mercado.

Neste estudo foi utilizada e adotada a definição de varejo de Parente (2000), por ser este um renomado autor brasileiro, especializado no assunto; e porque sua teoria de varejo é coerente com a linha de pensamento deste estudo, pois declara que varejo é caracterizado pela venda ao consumidor final por instituições que se constituem e se organizam para esse fim. 


\subsection{AS MUDANÇAS NO VAREJO}

Devido às constantes mudanças na economia mundial e as evoluções tecnológicas, conforme explica Parente (2000) houve transformações nas características estruturais da atividade comercial empresarial de varejo.

Com o advento destas novas tecnologias, por exemplo, o que antes era uma atividade de venda de bens e serviços que ocorriam, necessariamente, em uma loja, hoje pode acontecer pelo telefone, correio, internet ou outros meios.

Coughlan et al. (2002) também tenta explicar as mudanças ocorridas no varejo, conforme pode-se verificar na citação a seguir:

"o varejo moderno é extremamente competitivo, orientado para a inovação, formado por uma variedade cada vez maior de instituições e constantemente afetado por um ambiente altamente fluido."

Hoje em dia, com a globalização já estabelecida, o varejo é um dos setores mais fortes e representativos da economia mundial. E este fato tem provocado no setor varejista constantes e crescentes mudanças que estão acontecendo em intervalos de tempo cada vez mais curtos. Na verdade, as mudanças no varejo são respostas às alterações ocorridas na demografia e nas necessidades dos consumidores, que hoje estão mais informados, tem acesso facilitado a outros produtos e serviços, o que o torna mais exigente. Faz com que ele exija melhores mercadorias e serviços para suprir suas necessidades.

\subsection{O VAREJO NO BRASIL}

Como não podia deixar de acontecer, após as mudanças econômicas ocorridas no mundo e no país nos últimos tempos, principalmente depois da abertura do mercado nacional, houve uma transformação estrutural na atividade comercial empresarial do Brasil. Estas mudanças 
proporcionaram o aumento da competição não só no comércio varejista, mas também no comércio brasileiro como um todo, provocando a reestruturação interna de muitas empresas. Tais alterações foram introduzidas a partir da implementação de novos métodos gerenciais, terceirizando e introduzindo modernos sistemas de logística, ou por um processo de automação comercial baseado nas novas tecnologias de informação e comunicação.

Para melhor caracterizar o comércio varejista no Brasil e suas mudanças, este trabalho recorreu ao Instituto Brasileiro de Geografia e Estatística - IBGE, através de sua Pesquisa Anual de Comércio (PAC), que é uma publicação que reúne o mais completo conjunto de informações econômico-financeiras da atividade e estrutura do segmento empresarial do comércio atacadista e varejista brasileiro.

O IBGE divulgou, em sua recente pesquisa (PAC - 2005), que a atividade comercial, no ano de 2005, continua empregando parcela significativa da população. Segundo o Instituto, em 2005, as 1.211 mil empresas do varejo, que representavam $84,2 \%$ do total, ocuparam cerca de 5.320 mil pessoas, $75,2 \%$ do total do número de pessoas ocupadas na atividade comercial. $\mathrm{O}$ que coloca a atividade de comércio varejista como grande contribuidora na geração de empregos no Brasil.

A PAC - 2005 do IBGE estimou que a atividade de comércio varejista figurava com a maior participação nos salários, retiradas e outras remunerações, pessoal ocupado, número de estabelecimentos e número de empresas; analisou também que, no ano de 2005, o comércio varejista foi responsável por uma receita operacional líquida de $\mathrm{R} \$ 393,5$ bilhões que representava $41,9 \%$ do total da atividade comercial. O pagamento de salários, retiradas e outras remunerações foi de $\mathrm{R} \$ 33,9$ bilhões, representando $64,0 \%$ do total dos salários pagos pelas empresas comerciais. 
O Instituto Brasileiro de Geografia e Estatística destacou, nesta mesma pesquisa, outro indicador importante quando se analisa o setor comercial, que é a margem de comercialização ${ }^{1}$.

O comércio varejista apresentou o maior resultado em comparação com os demais. As empresas varejistas totalizaram $\mathrm{R} \$ 97,4$ bilhões de margem de comercialização, correspondendo a 53,1\% do total, enquanto a parcela do comércio atacadista foi de $36,5 \%$, e a do setor de veículos, peças e motocicletas foi de $10,4 \%$.

Também foi demonstrado, pelo IBGE, que o comércio varejista, sobretudo as grandes redes, passou por transformações nos últimos anos, destacando-se nesse processo: o acirramento da concorrência com a entrada de grandes empresas internacionais do setor no mercado nacional, a reestruturação patrimonial dos grandes grupos econômicos, e a rápida assimilação de inovações organizacionais e tecnologias de automação.

\subsection{SHOPPINGS CENTERS}

Os shoppings centers são empreendimentos que surgiram como possibilidade de concentrar atividades de compras em um único local, com facilidade de acesso e estacionamento disponível, evitando e minimizando o tráfego de veículos nas áreas centrais das cidades, onde normalmente existe congestionamento e falta de estacionamento.

Segundo Barret (1975), os shoppings centers foram criados para atender a demanda por ambientes com tráfego desobstruído, acesso fácil e áreas de estacionamento adequadas, procurando oferecer aos clientes um sistema com todas as facilidades de acesso e estacionamento, situando-se geralmente em locais distantes do centro.

\footnotetext{
1 Margem de comercialização corresponde à diferença entre a receita líquida de revenda e o custo das mercadorias revendidas. Refere-se ao resultado obtido pelo esforço de venda de mercadorias deduzidos de seus custos de aquisição pelas empresas.
} 
Dick apud GONÇALVES (1990, p.7), define shopping center como um empreendimento comercial que oferece as seguintes facilidades ao cliente:

- Realizar compras num mesmo local e ao mesmo tempo;

- Comparar produtos e seus preços;

- Desfrutar de um local confortável e descontraído;

- Oferta de estacionamento em local próximo e de fácil acesso

- Carregamento de produtos de maneira rápida e segura.

Conforme dados da Associação Brasileira de Shoppings Centers - ABRASCE (2007), os shoppings centers surgiram inicialmente nos Estados Unidos, em 1956, e o sucesso e a aceitação fizeram com que esses empreendimentos surgissem em outros países. Hoje, nos Estados Unidos, existem aproximadamente 50.000 shoppings centers, com incremento anual de aproximadamente 2,0\%, estando grande parte desses empreendimentos concentrada no estado da Califórnia: cerca de 7.000 unidades. O acelerado aumento de shoppings centers naquele país fez surgir, em 1957, o ICSC (International Council of Shoppings Centers) através do qual foram padronizados e classificados esses empreendimentos de acordo com a configuração arquitetônica, ramos de negócios oferecidos e tamanho do empreendimento.

Segundo Lima apud CONCEIÇÃO (1984, p. 4)

“...a classificação dos shoppings centers em relação a padrões de localização é difícil principalmente porque diferentes tipos de shoppings centers localizam-se em áreas com características iguais."

Este trabalho, por se tratar de um estudo de caso envolvendo shoppings centers no Brasil, optou pela utilização do padrão de classificação de shoppings centers adotado pela ABRASCE (Associação Brasileira de Shoppings Centers), que é o equivalente ao ICSC dos Estados Unidos. Esta classificação de shoppings centers no Brasil, será detalhada no próximo tópico. 
Para Beyard et alii (1999, p.3), os shoppings centers talvez sejam o mais bem sucedido modelo de utilização de terra, de negócio imobiliário e de concepção de varejo do século XX e tornou-se a mais poderosa e adaptativa máquina de consumo que o mundo já conheceu. Os autores assinalam que, nos dias de hoje, os shoppings centers podem assumir diversas formas, o que torna, como já dito anteriormente, bastante difícil a sua classificação.

Pode-se constatar este sucesso verificando-se a enorme quantidade de novos empreendimentos deste tipo que estão surgindo em todo o mundo. O ISCS, por exemplo, no ano de 1995, possuía aproximadamente 30.000 associados, e hoje, 12 anos depois, possui 65.000 associados. Em outros países, assim como no Brasil, conforme será demonstrado no próximo tópico, esse sucesso também está sendo constatado.

\subsection{OS SHOPPINGS CENTERS NO BRASIL}

Assim como no resto do mundo, os shoppings centers no Brasil tornaram-se, para o consumidor, pontos de encontro e pólos de entretenimento, que aliam praticidade à segurança. Conceição (1984) destaca que, atendendo aos propósitos de um empreendimento comercial que oferecesse ao cliente facilidades, tais como: realizar compras num mesmo local e ao mesmo tempo; comparar produtos e seus preços; desfrutar de um local confortável e descontraído; oferta de estacionamento em local próximo e de fácil acesso; e carregamento de produtos de maneira rápida e segura, em 1966 foi implantado o primeiro shopping center no Brasil (Shopping Iguatemi, em São Paulo), e a partir daí a sua evolução e expansão foi progressiva, tanto em termos de ABL (Área Bruta Locável), que é a área negociada (locada) pelos donos de lojas (locatários) destes empreendimentos, quanto no faturamento e empregos gerados. 
Visando os mesmo objetivos do International Council of Shopping Centers - ICSC, surgiu no Brasil, em 1976, a ABRASCE (Associação Brasileira de Shoppings Centers), que congrega empreendedores do ramo, assim como os administradores e prestadores de serviços. A ABRASCE define shoppings centers como sendo:

“[..]) empreendimentos constituídos por um conjunto planejado de lojas destinadas à exploração de ramos diversificados ou especializados de comércio e prestação de serviços, oferecendo estacionamento compatível com a área de lojas e afluência de veículos."

Atualmente, segundo a Associação Brasileira de Shoppings Centers - ABRASCE, o conjunto de shoppings centers brasileiros apresenta um nível de qualidade que se equipara ao dos países desenvolvidos. Segundo dados desta associação, existem hoje 367 shoppings no Brasil, com estimativa da ABRASCE para atingir no ano de 2008 a marca de 382 shoppings centers. $\mathrm{Na}$ década de 80 , apenas $15 \%$ desses empreendimentos estavam no interior do país. Atualmente, este percentual se elevou para aproximadamente 46\%. Ainda segundo a ABRASCE, os 367 shoppings centers totalizam uma ABL (Área Bruta Locável) superior a 8.3 milhões de $\mathrm{m}^{2}$, compreendendo 55.087 lojas satélites, de 1.400 lojas âncoras e 1.970 salas de cinema e teatro. Desses empreendimentos, 170 shoppings centers são filiados a essa entidade (ABRASCE), que segue, conforme já mencionado, o padrão e experiência americana, em concordância com o ICSC.

Informações da ABRASCE apontam para uma evolução, nos últimos dois anos, do resultado das vendas do conjunto dos shoppings em operação (de R\$ 40,0 bilhões em 2005 para R\$ 44,0 bilhões em 2006 e 56 bilhões em 2007). Estas vendas, em 2007, representaram 18\% do faturamento de todo o varejo nacional, excluído os setores automotivo e de derivados de petróleo. Se junta a estes dados, os mais de 629.700 empregos diretos que são gerados pelos shoppings centers, demonstrando assim a grande vitalidade deste setor que desempenha 
importante papel na economia brasileira. Tal importância poderá ser melhor visualizada nos quadros, tabelas e gráficos a seguir.

\begin{tabular}{|l|l|}
\hline \multicolumn{1}{|c|}{ O shopping center no Brasil (2008) } \\
\hline Número Total de Shoppings & 367 \\
\hline Área Bruta Locável (em m2) & 8.204 .066 \\
\hline Área Construída (em m2) & 61.223 .800 \\
\hline Vagas para Carros & 488.677 \\
\hline Lojas Satélites & 55.087 \\
\hline Lojas Äncoras & 1.400 \\
\hline Salas de Cinema / Teatro & 1.970 \\
\hline Empregos Gerados & 629.700 \\
\hline Tráfego de Pessoas (milhões por mês) & 203 \\
\hline Vendas em Relação ao Varejo Nacional ${ }^{*}$ ) & $18 \%$ \\
\hline$\left({ }^{*}\right)$ Excluido setor automotivo & \\
\hline
\end{tabular}

OBS: Estão considerados os shoppings com lojas locadas, que tenham administração centralizada, lojas âncoras, vagas de estacionamento e $\mathrm{ABL}$ acima de $5.000 \mathrm{M} 2$, além de todos os shoppings associados à

Abrasce.

\section{Quadro 2.1 - O shopping center no Brasil}

Fonte: Site da ABRASCE (http://www.abrasce.com.br/gr_numeros.htm) em 28/01/08.

O quadro 2.1, acima relata bem a pujança desta atividade varejista que se encontra em franca expansão. O fato da "industria do shopping center" empregar quase 630.000 e representar $18 \%$ do total de vendas do varejo nacional só vem corroborar sua importância no cenário econômico brasileiro.

Essa expansão dos shoppings centers no Brasil, cada vez aumentando mais sua presença no território brasileiro, fica mais clara se forem observados os gráficos, quadros e tabelas a seguir. 
Distribuição dos shoppings centers por Região (2008)

\begin{tabular}{|c|c|c|c|c|}
\hline Regiões & No. de Shoppings & $\%$ do Total & $A B L$ & $\%$ do Total \\
\hline Norte & 9 & $2,5 \%$ & 213.361 & $2,6 \%$ \\
\hline Nordeste & 51 & $13,9 \%$ & 1.173 .412 & $14,3 \%$ \\
\hline Salvador & 10 & $2,7 \%$ & 287.864 & $3,5 \%$ \\
\hline Fortaleza & 9 & $2,5 \%$ & 205.796 & $2,5 \%$ \\
\hline Recife & 5 & $1,4 \%$ & 156.177 & $1,9 \%$ \\
\hline Natal & 5 & $1,4 \%$ & 106.297 & $1,3 \%$ \\
\hline São Luis & 2 & $0,5 \%$ & 37.731 & $0,5 \%$ \\
\hline João Pessoa & 3 & $0,8 \%$ & 64.780 & $0,8 \%$ \\
\hline Aracajú & 2 & $0,5 \%$ & 68.089 & $0,8 \%$ \\
\hline Teresina & 2 & $0,5 \%$ & 40.629 & $0,5 \%$ \\
\hline Centro-Oeste & 33 & $9,0 \%$ & 671.775 & $8,2 \%$ \\
\hline Brasília & 13 & $3,5 \%$ & 268.110 & $3,3 \%$ \\
\hline Goiania & 8 & $2,2 \%$ & 130.532 & $1,6 \%$ \\
\hline Cuiabá & 3 & $0,8 \%$ & 80.285 & $1,0 \%$ \\
\hline Campo Grande & 1 & $0,3 \%$ & 28.168 & $0,3 \%$ \\
\hline Sudeste & 201 & $54,8 \%$ & 4.903 .429 & $59,8 \%$ \\
\hline SP (estado) & 122 & $33,2 \%$ & 3.339 .826 & $40,7 \%$ \\
\hline SP (capital) & 51 & $13,9 \%$ & 1.792 .123 & $21,8 \%$ \\
\hline RJ (estado) & 49 & $13,4 \%$ & 992.177 & $12,1 \%$ \\
\hline RJ (capital) & 32 & $8,7 \%$ & 767.816 & $9,4 \%$ \\
\hline MG (estado) & 27 & $7,4 \%$ & 497.099 & $6,1 \%$ \\
\hline B.Horizonte & 14 & $3,8 \%$ & 281.178 & $3,4 \%$ \\
\hline Sul & 73 & $19,9 \%$ & 1.242 .089 & $15,1 \%$ \\
\hline Curitiba & 12 & $3,3 \%$ & 276.079 & $3,4 \%$ \\
\hline Porto Alegre & 13 & $3,5 \%$ & 267.186 & $3,3 \%$ \\
\hline Florianópolis & 4 & $1,1 \%$ & 83.169 & $1,0 \%$ \\
\hline Total & 367 & $100 \%$ & 8.204 .066 & 100 \\
\hline
\end{tabular}

Quadro 2.2 - Distribuição dos shoppings centers por região

Fonte: Site da ABRASCE (http://www.abrasce.com.br/gr_numeros.htm) em 28/01/08 
Pode-se observar no quadro 2.2, da página anterior, como também no gráfico 2.1, abaixo, o cenário detalhado de como os shoppings centers estão distribuídos pelas regiões do Brasil.

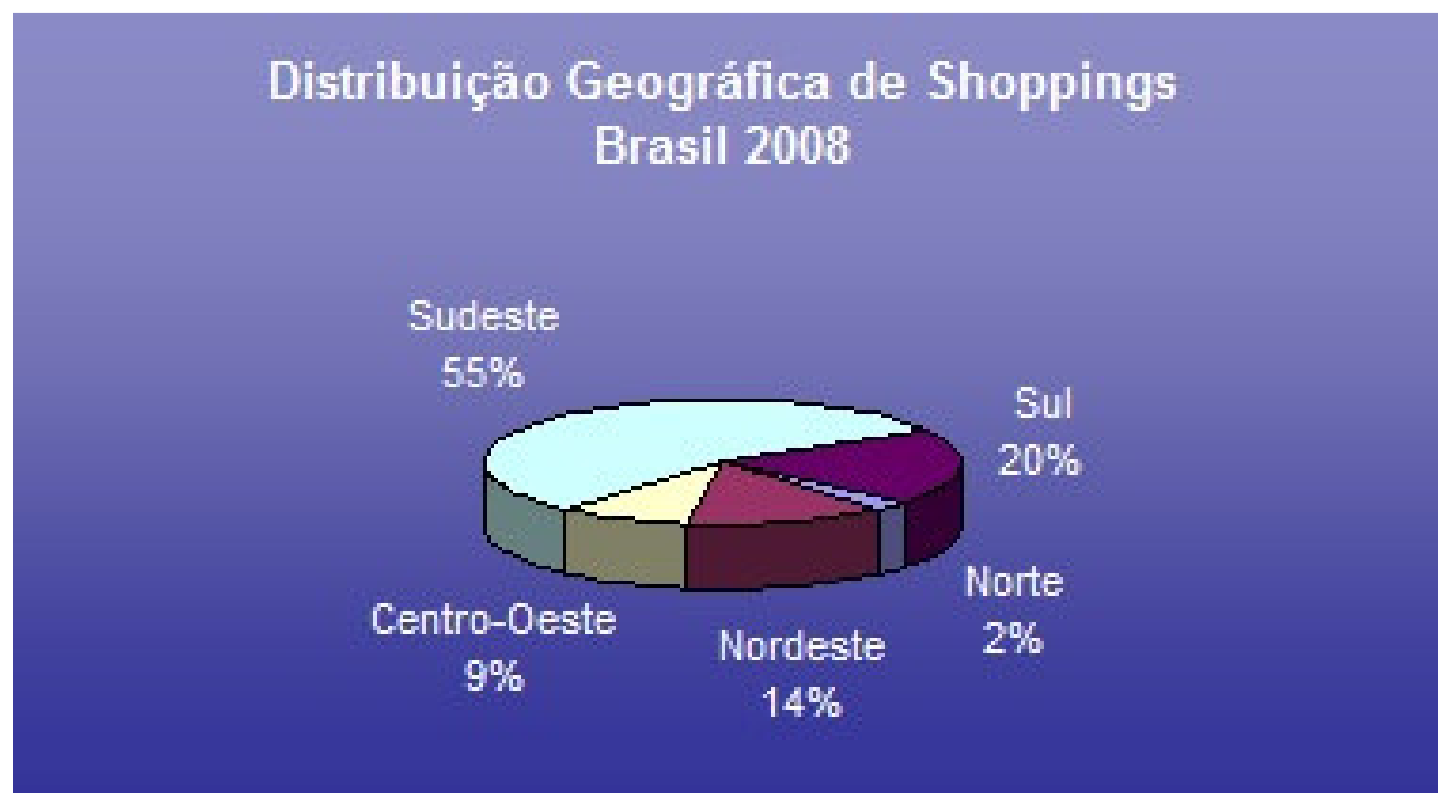

\section{Gráfico 2.1 - Distribuição Geográfica de shoppings centers no Brasil}

Fonte: Site da ABRASCE (http://www.abrasce.com.br/gr_numeros.htm) em 28/01/08.

Fica claro, pelas informações dadas acima, que as regiões mais desenvolvidas do Brasil, que são as regiões Sul e Sudeste, concentram a maior parcela desses empreendimentos, ou seja, 75\% dos shoppings centers do Brasil estão localizados nestas regiões. Destaca-se também a região Nordeste, com a concentração de $14 \%$ do total desses empreendimentos.

Veja nos gráficos, tabelas e quadros a seguir, mais informações sobre a evolução brasileira dos shoppings centers. 


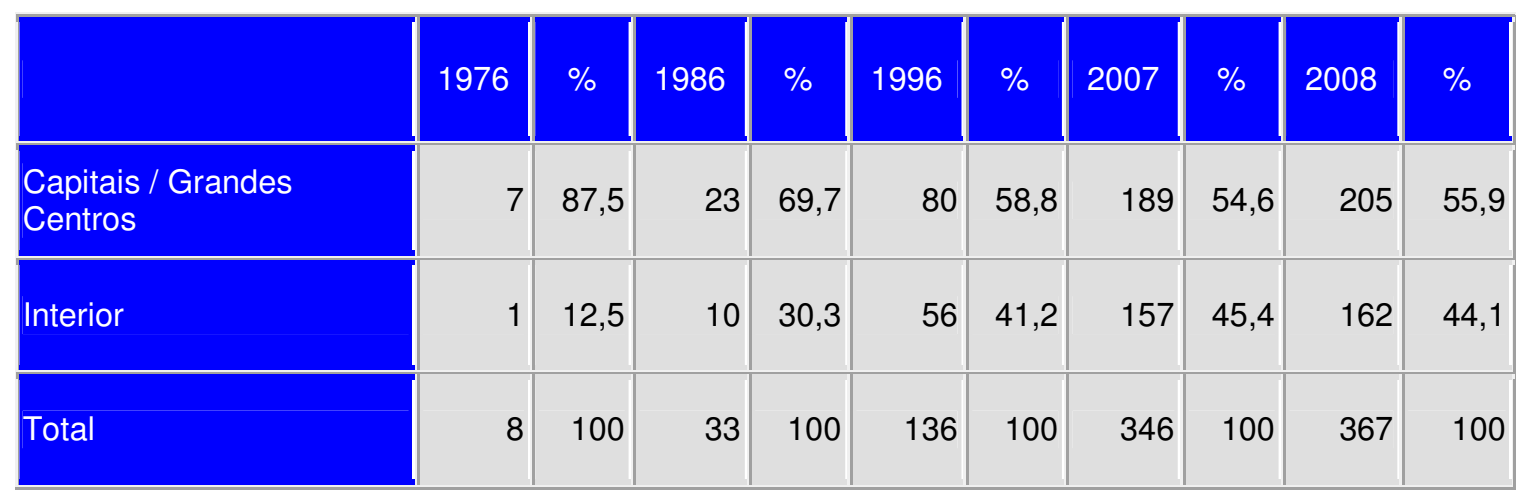

Gráfico 2.2 - Evolução da distribuição de shoppings centers nas capitais x interior

Fonte: Site da ABRASCE (http://www.abrasce.com.br/evo_setor.htm) em 28/01/08

Conforme mencionado anteriormente, a expansão dos shoppings centers não está localizada apenas nos grandes centros e capitais, pois como pode ser observado no quadro acima (gráfico 2.2) a proporção de shoppings localizados no interior dos estados vem crescendo significativamente, tendo chegado hoje a significativos $44,1 \%$ desses empreendimentos sendo localizados em cidade no interior dos estados brasileiros. O cenário visto hoje é bem diferente do que foi no passado, quando se tinha quase $90 \%$ dos shoppings localizados nos grandes centros. Isso é um demonstrativo de que as cidades do interior do Brasil estão se desenvolvendo e com isso demandando e sustentando novos tipos de varejo.

Nos gráficos a seguir o leitor encontrará ainda mais subsídios que tornaram mais claras a evolução deste tipo de negócio varejista no Brasil. 


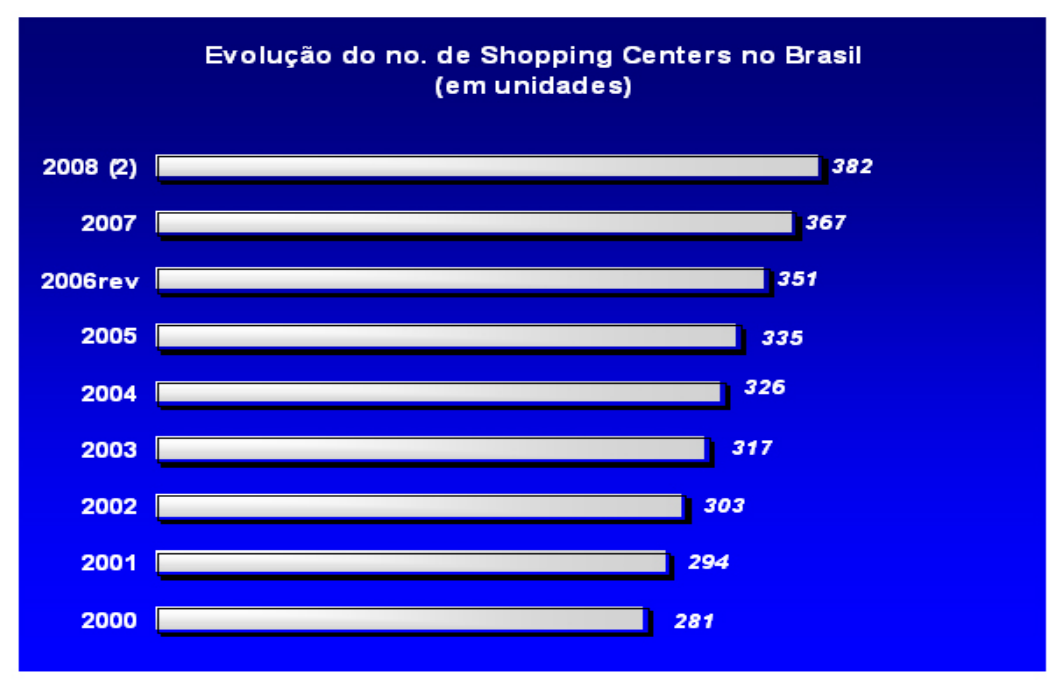

Gráfico 2.3 - Evolução do número de shoppings centers no Brasil

Fonte: Site da ABRASCE (http://www.abrasce.com.br/evo_setor.htm) em 28/01/08

O gráfico 2.3 mostra a crescente evolução do número de shoppings centers no Brasil, analisando dados do ano de 2000 até hoje. Já o gráfico 2.4 demonstra a evolução da Área Bruta Locável (ABL), que é a área que os shoppings centers tem efetivamente disponíveis para serem locadas aos comerciantes. O aumento desse índice é coerente com a expansão dos shoppings e com a percepção, por parte dos lojistas, de que esse tipo de empreendimento é viável comercialmente.

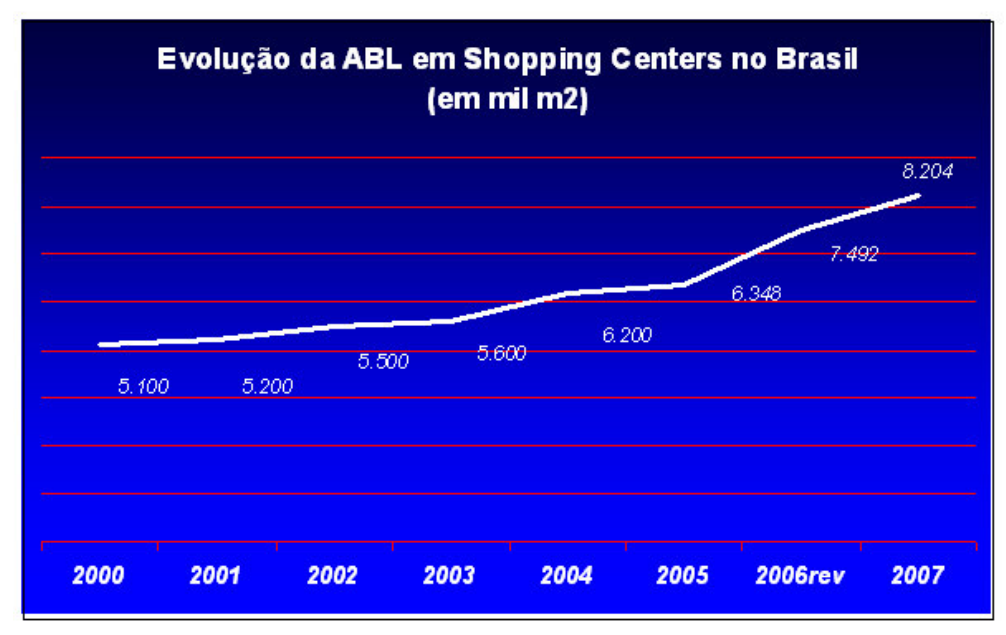

Gráfico 2.4 - Evolução da Área Bruta Locável (ABL) em shoppings centers no Brasil

Fonte: Site da ABRASCE (http://www.abrasce.com.br/evo_setor.htm) em 28/01/08 


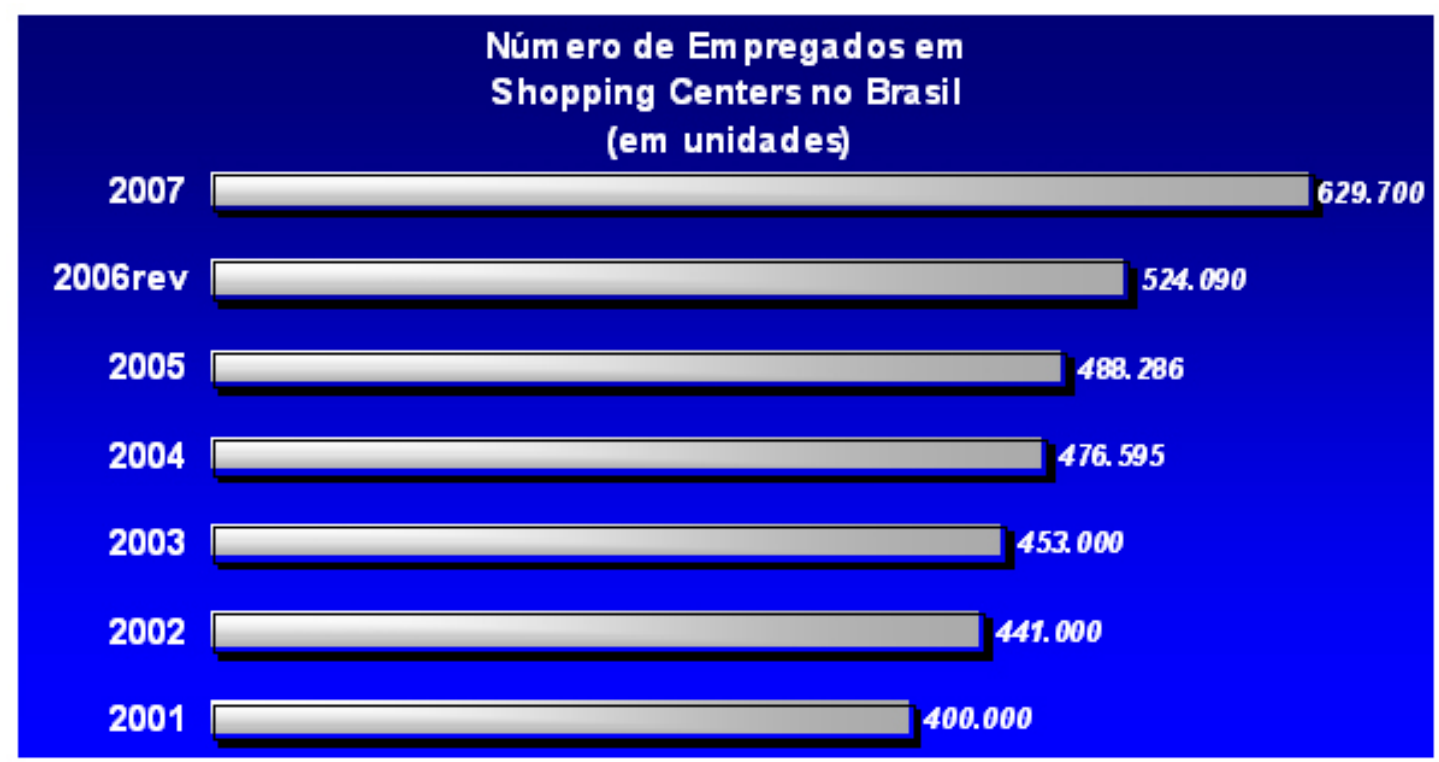

Gráfico 2.5 - Evolução do número de Empregados em shoppings centers no Brasil

Fonte: Site da ABRASCE (http://www.abrasce.com.br/evo_setor.htm) em 28/01/08

O gráfico acima (gráfico 2.5) e a quadro a seguir (quadro 2.3) demonstram, conforme já descrito anteriormente, a importância que esse tipo de empreendimento tem para a economia nacional, pois ele próprio gera cerca de 630.000 empregos que estão espalhado por todas as regiões do Brasil, o que certamente é um forte indicador do potencial destes empreendimentos para o desenvolvimento do País.

A seguir, no quadro 2.3, é demonstrada a distribuição dos shoppings centers nos vários estados brasileiros, com suas respectivas quantidades de unidades, os índices de área bruta locável (ABL) e a quantidade de empregos gerados por esta modalidade de comércio. 
Distribuição dos shoppings centers nos estados ( 2008)

\begin{tabular}{|c|c|c|c|}
\hline & s nos estados ( 2008 & & \\
\hline UF & No. de Shoppings & $A B L(e m ~ m 2)$ & Empregos \\
\hline Alagoas & 1 & 33767 & 2.500 \\
\hline Amazonas & 5 & 83.146 & 6.300 \\
\hline Bahia & 16 & 335809 & 26.000 \\
\hline Ceará & 11 & 226.240 & 17.500 \\
\hline Distrito Federal & 16 & 320.924 & 24.600 \\
\hline Espírito Santo & 3 & 74.327 & 5.700 \\
\hline Goias & 11 & 195.432 & 15.000 \\
\hline Maranhão & 2 & 37.731 & 2.900 \\
\hline Minas Gerais & 27 & 497.099 & 38.000 \\
\hline Mato Grosso & 4 & 92.251 & 7.100 \\
\hline Mato Grosso do Sul & 2 & 63.168 & 4.900 \\
\hline Pará & 2 & 70.215 & 5.400 \\
\hline Paraíba & 4 & 78.471 & 6.000 \\
\hline Pernambuco & 8 & 246.379 & 18.900 \\
\hline Piauí & 2 & 40.629 & 3.100 \\
\hline Paraná & 27 & 502.032 & 38.600 \\
\hline Rio de Janeiro & 49 & 992.177 & 76.400 \\
\hline Rio Grande do Norte & 5 & 106.297 & 8.200 \\
\hline Rio Grande do Sul & 30 & 468.130 & 36.000 \\
\hline Rondonia & 1 & 33.000 & 2.500 \\
\hline Santa Catarina & 16 & 271.927 & 20.900 \\
\hline Sergipe & 2 & 68.089 & 5.200 \\
\hline São Paulo & 122 & 3.339 .826 & 256.000 \\
\hline Tocantins & 1 & 27.000 & 2.000 \\
\hline Total & 367 & 8.204 .066 & 629.700 \\
\hline
\end{tabular}

Quadro 2.3 - Distribuição, ABL e empregos gerados pelos shoppings centers nos estados

Fonte: Site da ABRASCE (http://www.abrasce.com.br/gr_numeros.htm) em 28/01/08. 


\subsubsection{Classificação dos shoppings centers no Brasil}

Este estudo optou por adotar a classificação de shopping center definida pela ABRASCE.

A ABRASCE (2007) classifica os shoppings centers no Brasil em seis principais tipos, são eles: Shopping Regional, Shopping Comunitário, Shopping de Vizinhança, Shopping Especializado, Outlet Center e Festival Center.

Os principais determinantes levados em conta para se classificar estes centros são orientação mercadológica, tipo de produtos e serviços oferecidos e tamanho do empreendimento.

Portanto, veja a seguir a definição/classificação dos shoppings centers adotada neste trabalho:

- Shopping regional - Empreendimentos que oferecem mercadoria em geral (alta porcentagem de vestuário) e serviços completos e variados. Apresentam como atração principal lojas ãncoras tradicionais, lojas de departamento de desconto e/ou hipermercados. É geralmente fechado, com as lojas voltadas para um pátio interno.

- Shopping de vizinhança - Empreendimento projetado para oferecer conveniência na compra de necessidades diárias dos consumidores. Tem como âncora um supermercado. A âncora tem o apoio de lojas oferecendo outros artigos de conveniência.

- Shopping comunitário - Empreendimentos que geralmente oferecem grande sortimento de vestuário e outras mercadorias. Entre as lojas âncoras mais comuns estão os supermercados e lojas de departamento de descontos, encontrando-se algumas vezes varejistas de "off-price" vendendo itens como roupas, objetos e móveis para casa, brinquedos, artigos eletrônicos e/ou artigos para esporte.

- Shopping especializado - Empreendimentos que apresentam um mix específico de lojas de um determinado grupo de atividades, tais como: moda, decoração, náutica, esportes ou automóveis. 
- Outlet centers - Empreendimentos que apresentam lojas de fabricantes vendendo suas próprias marcas com desconto, além de varejistas de "off-price".

- Festival center - Empreendimentos basicamente voltados para atividades de lazer, com restaurantes, fast-food, cinema e outras diversões. Localiza-se geralmente em áreas turísticas.

Cabe notar, que a classificação de shoppings centers aqui apresentada somente faz referência aos diversos ramos de negócios oferecidos, não considerando a sua localização, área de influência e oferta de estacionamento. Este último no que diz respeito à configuração e tamanho, segundo a definição de shoppings centers, deveria ser compatível com a configuração e o tamanho do empreendimento.

Classificação por tipo de shopping: ABRASCE (fev. 2007)
\begin{tabular}{|l|l|l|}
\hline Tipos & No. de shoppings & $\%$ \\
\hline Regional & 101 & 63 \\
\hline Vizinhança & 27 & 17 \\
\hline Comunitário & 20 & 12 \\
\hline Especializado & 10 & 6 \\
\hline Outros & 3 & 2 \\
\hline
\end{tabular}

Quadro 2.4- Classificação por tipo de shoppings centers (ABRASCE)

Fonte: Site da ABRASCE< http://www.abrasce.com.br/gr_numeros.htm.> em 03/10/07.

O shopping center necessita administrar uma série de aspectos para seu funcionamento. Dada à crescente competição que vem ocorrendo com o aumento do número de shoppings centers, um aspecto de grande importância é o gerenciamento da própria marca do shopping center. Assim sendo a seguir este aspecto será mais detalhado. 


\subsection{GESTÃO DE MARCAS (BRANDING)}

Empresas e outros tipos de organizações, segundo Keller (2006), estão de maneira crescente se dando conta de que um de seus principais ativos, talvez o mais valioso deles, é a associação da sua marca aos produtos e serviços que comercializa.

Especialmente, considerando o novo cenário complexo e competitivo em que vivemos atualmente, onde as escolhas que podem ser feitas pelos consumidores são cada vez maiores e o tempo para fazê-las cada vez menor. E o fato de que embora muitas vezes seja possível copiar processos e produtos, as crenças e atitudes estabelecidas na mente dos consumidores nem sempre podem ser copiadas. Daí se percebe a inestimável importância e capacidade que uma marca forte tem de simplificar o processo de decisão do consumidor, reduzir riscos e ameaças e definir expectativas.

Executar a gestão estratégica de marcas (branding) é proporcionar a criação de marcas fortes que cumpram o que prometem. Nos dias de hoje, tornou-se obrigatório, para todos os tipos de organização, promover a manutenção e o aprimoramento da força dessas marcas ao longo do tempo.

No intuito de esclarecer e firmar os conceitos de produtos, marcas e gestão de marcas, foram, a seguir, citados e comentados vários autores e instituições, que são verdadeiras referências nestes assuntos.

O primeiro deles é Keller (2006) conceitua branding (gestão de marcas) como sendo o ato de dotar produtos e serviços de brand equity. E o conceito de brand equity ainda segundo Keller (2006) é o de fornecer aos profissionais de marketing um denominador comum para interpretar os efeitos potenciais de diferentes estratégias para suas marcas. Fundamentalmente, esse conceito enfatiza a importância do papel da marca nas estratégias de marketing. Ele se refere ao fato de que se chega a diferentes resultados do programa de 
marketing de um produto ou serviço por este ser identificado por uma marca. Ou seja, brand equity representa o valor agregado a um produto como resultado de investimentos anteriores em uma marca.

Segundo o Marketing Science Institute:

"brand equity é o conjunto de associações e comportamentos da parte de clientes, membros do canal e empresa controladora da marca que permite à marca ganhar maior volume ou maiores margens do que conseguiria sem o nome de marca e que lhe dá uma vantagem forte, sustentável e diferenciada sobre os concorrentes."

Por sua vez, David Aaker (Universidade da Califórnia em Berkeley), afirma que:

"brand equity é o conjunto de ativos e obrigações vinculados a uma marca, seu nome e símbolo, que são somados ou subtraídos do valor proporcionado por um produto ou serviço a uma empresa elou aos clientes dessa empresa”.

A palavra marca, segundo Ferreira (1999), numa de suas muitas definições, é um substantivo feminino que significa categoria, qualidade, espécie ou tipo.

Keller (2006) explica que a utilização e a aplicação de marcas existem há séculos como meio de diferenciar os bens de um fabricante dos bens de outro. Ainda segundo Keller, a palavra brand (marca, em inglês) derivou do nórdico antigo brandr, que significa "queimar". Isso porque as marcas a fogo eram, e de certa forma ainda são, usadas pelos proprietários de gado para marcar e identificar seus animais.

Por outro lado, segundo a definição da American Marketing Association (AMA),

"marca é um nome, termo ou símbolo, desenho ou uma combinação desses elementos que deve identificar os bens ou serviços de um fornecedor ou grupo de fornecedores e diferenciá-los dos da concorrência”. 
Portanto, segundo Keller (2006), sempre que um profissional de marketing cria um novo nome, logotipo ou símbolo para um novo produto, ele está criando uma marca.

Faz-se necessário, para o bom entendimento deste trabalho, que diferenciemos o que é marca do que é produto. Segundo Kotler (2000)

\begin{abstract}
"Produto é qualquer coisa que possa ser oferecida a um mercado para apreciação, aquisição, utilização ou consumo e que possa satisfazer uma necessidade ou um desejo. Assim, o produto pode ser um bem físico (cereal, raquete de tênis ou automóvel), um serviço (linha aérea, banco ou seguradora), uma loja de varejo (loja de departamentos, loja de especialidades ou supermercado), uma pessoa (político, artista ou atleta profissional), uma organização (ONG ou grupo de teatro), um lugar (cidade, estado ou país) ou uma idéia (causa política ou social).”
\end{abstract}

Já uma marca, segundo Keller (2006), é um produto, mas um produto que acrescenta outras dimensões que o diferenciam de algum modo de outros produtos desenvolvidos para satisfazer a mesma necessidade. Segundo Keller (2006), essas diferenças podem ser racionais e tangíveis - relacionadas com o desempenho de produto da marca - ou mais simbólicas, emocionais e intangíveis - relacionadas com aquilo que a marca representa.

Para Kapferer (2003), a marca não é o produto; ela define o seu significado, define sua identidade no tempo e no espaço. A empresa descobre que esse capital da marca deve ser administrado, alimentado e controlado.

Este estudo optou por adotar, para suas análises e considerações, as definiç̧ões de produto defendidas por Kotler (2000) e de marca definidas por Kapferer (2003). 


\subsubsection{Imagem}

A palavra imagem está muito ligada à marca e é definida por Ferreira (1999) como conceito genérico resultante de todas as experiências, impressões, posições e sentimentos que as pessoas apresentam em relação a uma empresa, produto, personalidade etc. Ainda segundo o mesmo Ferreira (1999), Imagem é aquilo que evoca uma determinada coisa ou tem com ela semelhança ou relação simbólica; símbolo.

Pessoas e empresas podem beneficiar-se muito do potencial que a gestão estratégica de marcas pode proporcionar à imagem percebida do negócio. Entre outras coisas, a boa imagem da marca pode alavancar e decidir negócios, potencializar qualidades e virtudes, suprir deficiências, fazer a diferença, encurtar caminhos, aumentar a produtividade, em suma, gerar vantagem competitiva. E, do outro lado, a má gestão de marcas, por parte de pessoas ou empresas, pode também acarretar em sérios prejuízos.

\section{Aquela empresa não têm boa imagem perante a população.}

Este produto tem um sério problema de imagem associado à marca.

A imagem que esta marca projeta no mercado é a de uma empresa eficiente.

As frases acima são produzidas, hoje, de forma corriqueira. Isso também acontecia há algum tempo atrás. Mas, atualmente, vem ocorrendo com mais intensidade, pois percebeu-se o enorme potencial que a imagem projetada pela marca pode trazer para os negócios.

Segundo Neves (1998), imagem é o conjunto de fatores objetivos e subjetivos que envolvem o produto, o serviço ou a empresa que os oferece. Alguns desses fatores emanam da própria marca, como, por exemplo, a garantia de qualidade, de inovação tecnológica etc. Outros se constroem de forma autônoma no imaginário do cliente/consumidor em função de seus próprios valores e perfis; podendo até não refletir a realidade. 
Em empresas prestadoras de serviços, os atributos relacionados à própria instituição crescem de importância dia após dia. Empresas que são reconhecidas como éticas, sérias, que tratam bem os empregados, que respeitam o consumidor, que não se metem em transações ilegais, que tem preocupações sociais, que apóiam as artes, que não agridem o meio ambiente, etc, são, por conta desta imagem, bastante valorizadas, e acabam convertendo e transferindo as vantagens dessa boa imagem para a sua marca, para a marca do seu negócio.

\subsection{COMPORTAMENTO DO CONSUMIDOR}

Nos dias de hoje, a maioria das empresas sabe dos benefícios obtidos por entender como o consumidor irá se comportar. Portanto, o claro entendimento do comportamento desse consumidor/cliente será a chave para o sucesso da empresa, pois oferece os conhecimentos básicos necessários para decisões empresariais eficientes e eficazes.

Segundo Sheth (2001), entender o comportamento do consumidor/cliente irá tornar-se ainda mais importante para o sucesso de qualquer empresa, esteja ela onde estiver.

Ainda de acordo com Sheth (2001), o comportamento do consumidor/cliente é definido como as atividades físicas e mentais realizadas por consumidores/clientes de bens e serviços que resultem em decisões ou ações, como as de comprar, utilizar e pagar por estes bens e serviços. De acordo com Kotler (2000), o comportamento do consumidor é influenciado por quatro fatores: culturais (cultura, subcultura e classe social), sociais (grupos de referência, família e papéis e status), pessoais (idade, estágio no ciclo de vida, ocupação e circunstâncias econômicas, estilo de vida e personalidade e auto-imagem) e psicológicos (motivação, percepção, aprendizagem e crenças e atitudes). A pesquisa de todos esses fatores pode fornecer sugestões sobre como alcançar e servir aos clientes mais efetivamente.

Ainda segundo Kotler (2000), para se entender como os consumidores realmente tomam suas decisões de compra, os profissionais de marketing devem identificar quem fornece as 
informações para a decisão de compra. As pessoas podem ser iniciadoras, influenciadoras, decisoras, compradoras ou usuárias, e as diferentes campanhas de marketing devem ser dirigidas a cada tipo de pessoa.

Este trabalho adotou a definição de comportamento do consumidor oferecida por Kotler (2000), por entender que sua teoria responde melhor e de maneira mais completa às diversidades étnicas e culturais que são características da população Brasileira.

O motivo de se buscar entender como o consumidor se comporta, tem um objetivo claro que é o de buscar atender plenamente às necessidades destes clientes e com isso promover sua satisfação. E sabe-se que um cliente satisfeito é um cliente com alto potencial de repetir sua visita para adquirir novos produtos.

A satisfação do consumidor será melhor detalhada no próximo tópico à seguir.

\subsection{SATISFAÇÃO DO CONSUMIDOR}

A satisfação do consumidor é, hoje em dia, tema de vários estudos científicos. A fidelização e retorno do cliente à empresa têm estimulado os pesquisadores a desenvolver suas pesquisas no sentido de descobrir as razões de satisfação e de insatisfação dos consumidores.

Segundo CHAUVEL (1999), a satisfação é uma avaliação (um julgamento); efetuada $a$ posteriori; relativa a determinada transação.

Os pensadores contemporâneos mais conhecidos que debruçaram sobre estas discussões foram Evrad, Oliver, Spreng, MacKenzie e Olshavsky (apud CHAUVEL, 1999). Estes autores questionam os parâmetros utilizados para o julgamento da satisfação, o conceito e influência da dissonância cognitiva, expectativas dos consumidores acerca da oferta da empresa no mercado e outros diversos fatores encontrados na realidade "satisfação do consumidor", quando este se relaciona com as organizações. 
Outros autores como Singh e Pandya (1991); Woodruffe (1997), Wensley (1998) (apud CHAUVEL, 1999) e Kotler (2001), focaram seus esforços de pesquisa de satisfação do consumidor em pontos diferentes dos estudados pelos autores acima citados, formando uma outra corrente de pensamento. Eles procuraram compreender a satisfação através do enfoque da insatisfação e seus mecanismos.

Em geral, dois caminhos foram observados para a expressão da insatisfação: tomada de ações públicas ou tomada de ações privadas. É tarefa dos pesquisadores de Marketing compreender o mecanismo de ação de seus consumidores e desenvolver programas mercadológicos para o melhor aproveitamento destas ações, reforçando determinado comportamento do consumidor julgado positivo ou eliminando um comportamento julgado negativo.

Segundo Peter F. Drucker (1973), criar e manter clientes satisfeitos é o grande propósito de qualquer negócio. É certo que toda empresa tem que ganhar dinheiro e isto é uma necessidade e não um objetivo. Na realidade, ganhar dinheiro é o resultado final, um efeito desejável, de se criar um cliente satisfeito.

De acordo com Sheth (2001), o fato de uma empresa ganhar dinheiro não é um motivo legítimo para que a sociedade a sustente. Uma sociedade sustenta as empresas porque elas servem seus membros suprindo suas necessidades, deixando-os satisfeitos. Ainda de acordo com Sheth (2001), se um número suficiente de clientes ficarem insatisfeitos, não só eles deixarão de comprar da empresa, mas toda a sociedade a condenará e poderá até penalizá-la a ponto de provocar sua extinção.

Cada vez mais conscientes disso, empresas e seus funcionários estão passando a tratar seus clientes de modo diferenciado, objetivando a contínua satisfação do mesmo.

O tipo de atitude, em prol da satisfação do cliente, já está sendo conhecida como "cultura do cliente". Esse nome dado, "cultura do cliente", nada mais é do que incorporar a satisfação do cliente como parte integrante de todos os processos da organização. Ela se vale da 
compreensão do comportamento do consumidor como matéria-prima para todas suas estratégias de marketing.

Este estudo escolheu a teoria definida por Sheth, por pensar que ela é a que melhor traduz o conceito de satisfação do consumidor, se for considerado o consumidor brasileiro. 


\section{ASPECTOS METODOLÓGICOS}

Vergara (2004) classifica as pesquisas quanto aos fins e quanto aos meios. Observando-se os conceitos de Richardson (1999, p. 22), constata-se que "método é o caminho ou a maneira para se chegar a determinado fim ou objetivo, e metodologia são os procedimentos e regras utilizadas por determinado método".

Considera-se que, para se alcançar o objetivo proposto neste trabalho, é necessário adequar uma estratégia metodológica para o tipo de pesquisa adotada. De acordo com Gil (2006) "método significa caminho para se chegar a um fim" e Yin (2003) apresenta três condições que ajudam a definir a estratégia a ser utilizada: (a) o tipo de questão de pesquisa proposta, (b) a extensão de controle que o pesquisador tem sobre eventos comportamentais e (c) o grau de enfoque em acontecimentos históricos em oposição aos contemporâneos. O quadro 3.1 apresenta as situações relevantes que devem ser consideradas para as diferentes estratégias de pesquisa.

\begin{tabular}{|c|c|c|c|}
\hline \multirow{2}{*}{ Estratégia } & $\begin{array}{c}\text { Forma da questão de } \\
\text { pesquisa }\end{array}$ & Exige controle sobre eventos & Focaliza acontecimentos \\
\hline Experimento & Como, por que & Sim & Sim \\
\hline Levantamento & Quem, o que, onde, & Não & Sim \\
\hline Análise de & Quantos, quanto & Sim/Não \\
arquivos & quantos, quanto & Não & onde, \\
\hline Pesquisa & Como, por que & Não & Não \\
histórica & & & Sim \\
\hline Estudo de caso & Como, por que & Não & \\
\hline
\end{tabular}

Quadro 3.1 - Situações relevantes para diferentes estratégias de pesquisa

Fonte: COSMOS Corporation apud (YIN, 2001, p. 24) 
As questões tratadas no quadro 3.1 permitem que o pesquisador delimite qual o tipo de estratégia de pesquisa deve adotar, os principais pontos a serem alcançados e qual o melhor caminho para se atingir aos objetivos propostos no início de sua pesquisa.

\begin{tabular}{|c|c|}
\hline Característica & Fundamentação \\
\hline Exploratória & $\begin{array}{l}\text { Por sua principal finalidade desenvolver-se, esclarecer e modificar conceitos e idéias } \\
\text { tendo em vista a formulação de problemas mais precisos ou hipóteses pesquisáveis para } \\
\text { estudos posteriores. Habitualmente envolvem levantamento bibliográfico e documental, } \\
\text { entrevistas não padronizadas e estudos de caso (GIL, 2006). }\end{array}$ \\
\hline Quantitativa & $\begin{array}{l}\text { Em função de ser caracterizada como método que utiliza parâmetros quantificáveis, } \\
\text { tanto para a coleta de informações quanto para o tratamento dos dados que se realiza } \\
\text { com o emprego de técnicas estatísticas (RICHARDSON, 1999). }\end{array}$ \\
\hline Qualitativa & $\begin{array}{l}\text { Segundo Richardson (1999), a pesquisa qualitativa é caracterizada como uma tentativa } \\
\text { de compreensão detalhada dos significados e das características situacionais } \\
\text { apresentadas pelos entrevistados, em lugar de produção de medidas quantitativas de } \\
\text { características ou comportamentos. Já Martins (2006) relata que a avaliação qualitativa } \\
\text { é caracterizada pela descrição, compreensão e interpretação de fatos e fenômenos, em } \\
\text { contrapartida à avaliação quantitativa, denominada pesquisa quantitativa, onde } \\
\text { predominam mensurações. }\end{array}$ \\
\hline Estudo de caso & $\begin{array}{l}\text { Por permitir um estudo empírico que investiga um fenômeno atual dentro do seu } \\
\text { contexto de realidade, quando as fronteiras entre o fenômeno e o contexto não são } \\
\text { claramente definidas e no qual são utilizadas várias fontes de evidência (YIN, 2001). }\end{array}$ \\
\hline Survey & $\begin{array}{l}\text { Pois é um procedimento para coleta de dados primários a partir de indivíduos. Os dados } \\
\text { podem variar entre crenças, opiniões, atitudes e estilos de vida até informações gerais } \\
\text { sobre a experiência do indivíduo, tais como gênero, idade, educação e renda, bem como } \\
\text { as características de uma empresa, como lucro e número de funcionários (HAIR } \\
\text { JUNIOR et al., 2005). }\end{array}$ \\
\hline
\end{tabular}

Quadro 3.2 - Caracterização do tipo de pesquisa

Fonte: (AUTOR) 


\subsubsection{TIPO DE PESQUISA}

Partindo das definições de Richardson (1999, p. 22), percebe-se que "ao realizar uma pesquisa científica, faz-se necessário estabelecer claramente quais são os procedimentos metodológicos que serão utilizados". Neste sentido, para atingir os objetivos propostos, esta pesquisa foi de natureza exploratória qualitativa e quantitativa, utilizando-se do método de estudo de caso do tipo multicaso ou casos múltiplos, para as etapas qualitativas e o método de survey (levantamento) na etapa quantitativa. Este estudo foi realizado junto aos gestores e consumidores dos três shoppings centers da cidade de Ribeirão Preto.

A estrutura desta pesquisa pôde ser considerada do tipo pesquisa exploratória, pois sua principal finalidade foi desenvolver esclarecer e modificar conceitos e idéias, tendo em vista a formulação de problemas mais precisos ou hipóteses pesquisáveis para estudos posteriores. Segundo Gil (2006), habitualmente, pesquisas exploratórias envolvem levantamento bibliográfico e documental, entrevistas não padronizadas e estudos de caso. Utilizou-se aqui, também, uma abordagem qualitativa, pois este tipo de abordagem auxilia o pesquisador ao entendimento do fenômeno, segundo a perspectiva dos participantes da situação estudada, propiciando uma interpretação própria do fenômeno por parte do pesquisador (NEVES, 1996); nesta mesma visão, Richardson (1999, p. 79) "afirma que a abordagem qualitativa justifica-se, sobretudo, por ser uma forma adequada para entender a natureza de um fenômeno social".

Conforme relatado acima a estratégia de pesquisa adotada neste trabalho foi o estudo de caso. O método estudo de caso permite avaliações profundas, exaustivas e comparativas de um ou poucos objetos (GIL, 2002). Segundo Yin (2003), o método de estudo de caso deve ser

utilizado quando se estudam eventos contemporâneos, em situações nas quais os comportamentos relevantes não podem ser manipulados, mas onde é possível fazer observações diretas e entrevistas sistemáticas. Deve-se ressaltar que o estudo de caso, como 
experimento, não representa uma "amostragem", e o objetivo do pesquisador é expandir e generalizar teorias e não enumerar freqüências (generalização estatística), ou ainda, o objetivo único do caso é fazer uma análise “generalizante” e não "particularizante” (YIN, 2001).

O estudo de caso é uma estratégia que realiza uma investigação empírica sobre fenômenos dentro de seu contexto real, onde o pesquisador não tem controle sobre os eventos ou as variáveis. Neste caso, o pesquisador busca apreender a situação sob estudo e, criativamente descrever, compreender e interpretar a complexidade de um caso concreto (MARTINS, 2006).

Segundo Gil (2006, p. 73), o estudo de caso vem sendo utilizado com freqüência cada vez maior pelos pesquisadores sociais, visto servir a pesquisas com diferentes propósitos, tais como:

- explorar situações da vida real cujos limites não estão claramente definidos;

- descrever a situação do contexto em que está sendo feita determinada investigação; e

- explicar as variáveis causais de determinado fenômeno em situações muito complexas que não possibilitam a utilização de levantamentos e experimentos.

Como estratégia de pesquisa, utiliza-se o estudo de caso em muitas situações: política, ciência política e pesquisa em administração pública; sociologia e psicologia comunitária; estudos organizacionais e gerenciais; pesquisa de planejamento regional e municipal, como estudos de plantas, bairros ou instituições públicas; e supervisão de dissertações e teses nas ciências sociais - disciplinas acadêmicas e áreas profissionais como administração empresarial, ciência administrativa e trabalho social (YIN, 2003).

Os estudos de caso colocam mais ênfase em uma análise contextual completa de poucos fatos ou condições e suas inter-relações. Embora as hipóteses sejam freqüentemente usadas, basearse apenas em dados qualitativos torna o suporte ou a rejeição mais difícil. A ênfase nos detalhes fornece informações valiosas para a solução de problemas, avaliação e estratégia. Esse detalhe é obtido de fontes múltiplas de informação. Permite que as provas sejam verificadas e evita a perda de dados (COOPER; SCHINDLER, 2003). 
No caso deste estudo, optou-se, mais precisamente, pelo estudo de caso do tipo multicaso ou casos múltiplos, que é uma variação dentro da mesma estrutura metodológica do estudo de caso. Segundo Yin (2003), projetos de pesquisa que fazem uso da estratégia de estudo de caso, do tipo multicaso, permitem um estudo empírico que investiga um fenômeno atual dentro do seu contexto de realidade- quando as fronteiras entre o fenômeno e o contexto não são claramente definidas e no qual são utilizadas várias fontes de evidência. Ainda segundo Yin (2003), projetos de casos múltiplos apresentam vantagens e desvantagens distintas em comparação aos projetos de caso único. Yin afirma que "as evidências resultantes de casos múltiplos são consideradas mais convincentes, e o estudo global é visto, por conseguinte, como algo mais robusto".

Conforme relatado acima, este estudo fez, também, uso da análise quantitativa, que de acordo com Richardson (1999) é caracterizada como método que utiliza parâmetros quantificáveis, tanto para a coleta de informações quanto para o tratamento dos dados, que se realiza com o emprego de técnicas estatísticas; obtendo informações para a análise por meio do procedimento chamado survey (levantamento), que é um procedimento de coleta de dados primários a partir de indivíduos. Segundo (HAIR JUNIOR et al., 2005), os dados podem variar entre crenças, opiniões, atitudes e estilos de vida até informações gerais sobre a experiência do indivíduo, tais como gênero, idade, educação e renda, bem como as características de uma empresa, como lucro e número de funcionários.

Richardson (1999, p. 88), diz que embora existam diferenças profundas entre os métodos qualitativo e quantitativo, pode-se identificar três instâncias de integração entre ambos os métodos: no planejamento da pesquisa, na coleta dos dados e na análise das informações, conforme quadro 3.3 . 


\begin{tabular}{|c|c|c|}
\hline $\begin{array}{l}\text { INSTÂNCIAS DE } \\
\text { INTEGRAÇÃO }\end{array}$ & $\begin{array}{l}\text { APORTE DO MÉTODO } \\
\text { QUALITATIVO AO QUANTITATIVO }\end{array}$ & $\begin{array}{l}\text { APORTE DO MÉTODO QUANTITATIVO } \\
\text { AO QUALITATIVO }\end{array}$ \\
\hline $\begin{array}{l}\text { Planejamento } \\
\text { pesquisa }\end{array}$ & $\begin{array}{l}\text { A discussão com o grupo que participará } \\
\text { da investigação, o uso de entrevistas e a } \\
\text { observação podem melhorar a formulação } \\
\text { do problema, o levantamento de hipótese } \\
\text { e a determinação da amostra }\end{array}$ & $\begin{array}{l}\text { A utilização de um questionário prévio no } \\
\text { momento da observação ou entrevista pode } \\
\text { contribuir para delimitar o problema estudado } \\
\text { e a informação coletada, permitindo } \\
\text { identificar casos representativos ou não } \\
\text { representativos em nível grupal ou individual }\end{array}$ \\
\hline Coleta dos dados & $\begin{array}{l}\text { Entrevistas, observações e discussões em } \\
\text { grupo podem enriquecer as informações } \\
\text { obtidas, particularmente pela } \\
\text { profundidade e pelo detalhamento das } \\
\text { técnicas qualitativas }\end{array}$ & $\begin{array}{l}\text { Na coleta de dados, o questionário prévio } \\
\text { pode ajudar a evitar perguntas rotineiras e a } \\
\text { identificar características objetivas, como por } \\
\text { exemplo, geopolíticas de uma comunidade, } \\
\text { que podem influir no contexto da pesquisa }\end{array}$ \\
\hline $\begin{array}{l}\text { Análise } \\
\text { informações }\end{array}$ & $\begin{array}{l}\text { As técnicas qualitativas permitem } \\
\text { verificar os resultados dos questionários e } \\
\text { ampliar as relações descobertas }\end{array}$ & $\begin{array}{l}\text { As técnicas estatísticas podem contribuir para } \\
\text { verificar informações e reinterpretar } \\
\text { observações qualitativas, permitindo } \\
\text { conclusões menos objetivas }\end{array}$ \\
\hline
\end{tabular}

Quadro 3.3 - Complementaridade entre os métodos qualitativo e quantitativo

Fonte: Adaptado de Richardson (1999).

Para definir o papel da gestão estratégica de marcas na satisfação dos fatores motivacionais determinantes no processo de escolha de um shopping center foram utilizadas abordagens qualitativas e quantitativas e realizou-se uma pesquisa descritiva. Segundo Richardson (1999), a pesquisa qualitativa é caracterizada como uma tentativa de compreensão detalhada dos significados e das características situacionais apresentadas pelos entrevistados, em lugar de produção de medidas quantitativas de características ou comportamentos. Para Minayo (1996), a abordagem qualitativa aprofunda-se no mundo dos significados das ações e relações 
humanas, um lado não perceptível e não captável em equações, médias e estatísticas, permitindo ainda ampliar as relações descobertas.

Gil (2006) argumenta que a pesquisa descritiva tem como objetivo primordial à descrição das características de determinada população ou fenômeno ou então o estabelecimento de relações entre variáveis.

\subsection{PERGUNTA DE PESQUISA}

Com o intuito de alcançar os objetivos (geral e específicos) deste estudo, elaborou-se uma série de perguntas que, de maneira coerente com cada um dos objetivos, visou dar direcionamento às investigações realizadas, e com isso, conseguir obter e desvendar características e informações sobre o assunto pesquisado, que até então eram desconhecidas. Como resultado destas informações e características assim obtidas, conseguiu-se traçar as conclusões deste trabalho.

As perguntas de pesquisas foram elaboradas de forma a serem sempre coesas com os objetivos específicos determinados, conforme se pode observar abaixo:

\section{Objetivo Específico \# 1:}

Caracterizar o perfil dos consumidores entrevistados que preferem cada um dos três Shoppings Centers.

Pergunta de Pesquisa \# 1 relacionada ao objetivo específico \#1:

1. Qual o perfil dos consumidores entrevistados que preferem cada um dos três shopping centers de Ribeirão Preto?

\section{Objetivo Específico \# 2:}

Identificar os fatores motivacionais determinantes para a escolha de um dos três Shoppings Centers de Ribeirão Preto na opinião dos consumidores e gestores. 
Pergunta de Pesquisa \#2 relacionada ao objetivo específico \#2:

2. Quais os fatores motivacionais determinantes para a escolha de um dos três Shoppings Centers de Ribeirão Preto na opinião dos consumidores e gestores?

\section{Objetivo Específico \# 3:}

Verificar se há similaridades ou diferenças na classificação dos fatores motivacionais atribuídos pelos consumidores e gestores em relação a cada um dos três shoppings centers.

Pergunta de Pesquisa \# 3 relacionada ao objetivo específico \#3:

3. Há similaridades ou diferenças na classificação dos fatores motivacionais atribuídos pelos consumidores e gestores em relação a cada um dos três shoppings centers?

\section{Objetivo Específico \# 4:}

Analisar se a gestão de marcas adotada nos shoppings centers de Ribeirão Preto consegue propiciar ou contribuir para a satisfação dos fatores motivacionais de escolha considerados como determinantes pelos consumidores.

Pergunta de Pesquisa \# 4 relacionada ao objetivo específico \#4:

4. A gestão de marcas adotada pelos shoppings centers de Ribeirão Preto conseguem propiciar ou contribuir para a satisfação dos fatores motivacionais de escolha considerados como determinantes pelos consumidores?

Pergunta de Pesquisa \# 5 relacionada ao objetivo específico \#4:

5. Quais são as práticas de gestão estratégica de marcas adotadas pelos Shopping Centers de Ribeirão Preto?

Pergunta de Pesquisa \# 6 relacionada ao objetivo específico \#4:

6. Como os shoppings de Ribeirão implementam o posicionamento da sua marca?

Pergunta de Pesquisa \# 7 relacionada ao objetivo específico \#4: 
7. Qual é a estratégia de posicionamento e promoção da marca adotado pelos shoppings de Ribeirão?

Pergunta de Pesquisa \# 8 relacionada ao objetivo específico \#4:

8. Quais são considerados pelos gestores dos shoppings de Ribeirão, os pontos fortes, fracos, as oportunidades e as ameaças?

\subsection{OBJETO DE ESTUDO}

O conceito de "objeto de estudo" ampliou-se, a ponto de poder ser entendido como uma família ou qualquer outro grupo social, um pequeno grupo, uma organização, um conjunto de relações, um papel social, um processo social, uma comunidade, uma nação ou mesmo toda uma cultura (GIL, 2002).

Neste trabalho, o objeto de estudo foi constituído pelos três shoppings centers da cidade de Ribeirão Preto, sendo eles: o Novo Shopping, o Ribeirão Shopping e o Shopping Santa Úrsula.

\subsection{POPULAÇÃO E AMOSTRA}

A população desta pesquisa é formada pela população da região de Ribeirão Preto, sendo 1.162.794 pessoas, conforme dados obtidos da Fundação SEADE (2006). Segundo Lewi e Weitz (2000), esta área de influência direta pode ser expandida se for considerada um raio de cem quilômetros (região secundária e terciária de influência) - Então, conforme os autores aqui citados, pode-se considerar uma área de influencia mais ampla que a desta região, portanto, sob este novo aspecto a área de influência que passa a ser estimada é de cerca de 3.000.000 de habitantes. 
Esta pesquisa utilizou o método de amostragem não-probabilístico por conveniência, em função do procedimento escolhido para abordagem dos prováveis consumidores dos três shoppings centers de Ribeirão Preto. Neste caso, o número de respondentes não segue um percentual do número de habitantes por não se objetivar realizar uma generalização ou extrapolação dos resultados para a população.

\subsection{COLETA, ANÁLISE E INTERPRETAÇÃO DOS DADOS}

Nesta pesquisa, foram utilizados dois recursos básicos para coleta de dados, sendo:

Na primeira etapa, contemplando os objetivos específicos 1, 2 e 3, os dados foram coletados através de questionário específico com perguntas fechadas. Estes dados foram analisados por meio de uma análise do perfil dos consumidores respondentes e por meio da estatística descritiva.

Na segunda etapa, contemplando o objetivo específico 4, os dados foram coletados através da realização de entrevista com os gestores e consumidores dos três shoppings centers de Ribeirão Preto. Estes dados foram analisados utilizando-se da técnica de análise de conteúdo. Utiliza-se como técnica de coleta de dados o survey (levantamento), pois é um procedimento para coleta de dados primários a partir de indivíduos. Os dados podem variar de crenças, opiniões, atitudes e estilos de vida até informações gerais sobre a experiência do indivíduo, tais como gênero, idade, educação e renda, bem como as características de uma empresa, como lucro e número de funcionários (HAIR JUNIOR et al., 2005).

Os processos de análise e interpretação variam significativamente em função do plano de pesquisa. Nos delineamentos experimentais ou quase experimentais, assim como nos levantamentos, constitui tarefa simples identificar e ordenar os passos a serem seguidos (GIL, 2006). 
Os processos de coleta, análise e interpretação dos dados desta pesquisa foram realizados em duas etapas distintas, sendo:

A etapa I "quantitativa", contemplando o objetivo específico 2; teve sua coleta de dados por meio do método survey (levantamento) que contemplou a aplicação de um questionário para a identificação do perfil e dos fatores motivacionais dos consumidores (anexo I). Para análise e tratamento dos dados e informações coletados foram utilizadas algumas ferramentas da estatística descritiva, sendo a média, o desvio-padrão e o coeficiente de variação, os quais foram definidos no tópico de detalhamento das etapas. Segundo Hair Junior et al. (2005, p.157)

“[...] O método survey é usado quando o projeto de pesquisa envolve a coleta de informações de uma grande quantidade de amostra de indivíduos. A principal diferença entre a observação e a survey é que com esta o participante sabe claramente que estão sendo coletadas informações sobre seu comportamento elou atitudes. Desta forma, sempre existe a possibilidade de que isso influencie suas respostas e crie tendenciosidade."

A etapa II "qualitativa", contempla o objetivo específico 1, e teve sua coleta de dados por meio de entrevista com os gestores e consumidores dos shoppings centers, e a análise e interpretação por meio da técnica de análise de conteúdo. Segundo Bardin (1979 apud RICHARDSON, 1999, p. 223)

“[...] análise de conteúdo é um conjunto de técnicas de análise de comunicações visando obter, através de procedimentos sistemáticos e objetivos de descrição do conteúdo das mensagens, indicadores (quantitativos ou não) que permitam inferir conhecimentos relativos às condições de produção/recepção (variáveis inferidas) dessas mensagens.”

O tipo e a quantidade de dados a serem coletados dependem da natureza do estudo e dos objetivos da pesquisa. Se o estudo é exploratório, é provável que o pesquisador colete dados narrativos através do uso de grupos de foco, entrevistas pessoais ou observação de 
comportamentos ou eventos. Esse tipo de dado também pode ser chamado de qualitativo. As abordagens qualitativas para coleta de dados são usadas tipicamente no estado exploratório do processo de pesquisa. Seu papel é identificar e/ou refinar problemas de pesquisa que podem ajudar a formular e testar estruturas conceituais. Tais estudos normalmente envolvem o uso de amostras menores ou estudos de caso (HAIR JUNIOR et al., 2005).

A análise de dados tem como objetivo organizar e sumariar os dados de forma tal que possibilite o fornecimento de respostas ao problema proposto para investigação. Já a interpretação tem como objetivo a procura do sentido mais amplo das respostas, o que é feito mediante sua ligação a outros conhecimentos anteriormente obtidos. Conforme Gil (2006, p. 167), os processos de análise e interpretação variam significativamente em função do plano de pesquisa. Nos delineamentos experimentais ou quase experimentais, assim como nos levantamentos, constitui tarefa simples identificar e ordenar os passos a serem seguidos. Já nos estudos de caso não se pode falar num esquema rígido de análise e interpretação.

Portanto, como esta pesquisa consiste em um estudo de caso, verificou-se a necessidade de critérios claros para análise e interpretação dos dados, porém, como afirma a teoria, sem a necessidade de um esquema rígido.

\subsubsection{Tipos de dados e informações}

Os dados e informações coletados neste trabalho foram de dois tipos: dados e informações primárias e secundárias.

Dados e informações primárias são trabalhos originais de pesquisa ou dados brutos, sem interpretação ou pronunciamentos, que representam uma opinião oficial. Entre as fontes primárias estão memorandos, cartas, entrevistas ou discursos completos (em áudio, vídeo ou transcrição escrita), leis, regulamentações, decisões ou padrões judiciais e a maior parte dos 
dados governamentais, incluindo censo, dados econômicos e trabalhistas (COOPER; SCHINDLER, 2003).

Os dados e informações primárias desta pesquisa foram coletados por meio de entrevistas com gestores e da aplicação de um questionário.

Dados e informações secundárias são interpretações de dados primários. Enciclopédias, livros, manuais, artigos de revistas e jornais e a maioria das notícias são considerados fontes secundárias de informações (COOPER; SCHINDLER, 2003).

Os dados e informações secundárias desta pesquisa foram coletados através de pesquisa em livros, periódicos, artigos, dissertações e teses, além de pesquisa em relatórios específicos. Para explicitar claramente os procedimentos de coleta e tratamento de dados segue o quadro 3.4, que apresenta uma síntese dos procedimentos metodológicos. 


\begin{tabular}{|c|c|c|c|c|c|c|}
\hline Analisar a gest & o de marcas adotada pelos três Shop & $\begin{array}{r}\text { Objet } \\
\text { ings Centers de Ribeirão Preto (No } \\
\text { motivacionais aponta }\end{array}$ & $\begin{array}{l}\text { o Geral } \\
\text { Shopping, } \\
\text { s pelos cons }\end{array}$ & $\begin{array}{l}\text { irão Shopping e Sh } \\
\text { dores. }\end{array}$ & ping Santa & em relação à escolha dos fatores \\
\hline Etapas & Objetivos Específicos & Perguntas de Pesquisa & $\begin{array}{l}\text { Tipo de } \\
\text { pesquisa }\end{array}$ & $\begin{array}{l}\text { Coleta } \\
\text { De } \\
\text { Dados }\end{array}$ & $\begin{array}{l}\text { Técnicas } \\
\text { de Análise } \\
\text { dos Dados }\end{array}$ & Respondentes \\
\hline $\begin{array}{l}1^{a} \text { ETAPA } \\
\text { (Quantitativa) } \\
\text { Caracterização } \\
\text { dos fatores } \\
\text { motivacionais } \\
\text { determinantes }\end{array}$ & $\begin{array}{l}\text { 1) Caracterizar o perfil dos } \\
\text { consumidores entrevistados que } \\
\text { preferem cada um dos três } \\
\text { shoppings centers. }\end{array}$ & $\begin{array}{l}\text { P1) Qual o perfil dos consumidores } \\
\text { entrevistados que preferem cada um } \\
\text { dos três shopping centers de } \\
\text { Ribeirão Preto? }\end{array}$ & Quantitativa & $\begin{array}{l}\text { Aplicação do } \\
\text { Questionário } \\
\text { Alunos (Anexo) }\end{array}$ & $\begin{array}{l}\text { Análise de } \\
\text { dados. }\end{array}$ & $\begin{array}{l}\text { Consumidores dos três shopping centers } \\
\text { de Ribeirão Preto. }\end{array}$ \\
\hline $\begin{array}{l}\text { para a escolha de } \\
\text { um dos três } \\
\text { shoppings centers } \\
\text { de Ribeirão Preto } \\
\text { na opinião dos } \\
\text { consumidores e }\end{array}$ & $\begin{array}{l}\text { 2) Identificar os fatores } \\
\text { motivacionais determinantes para } \\
\text { a escolha de um dos três } \\
\text { shoppings centers de Ribeirão } \\
\text { Preto na opinião dos consumidores } \\
\text { e gestores. }\end{array}$ & $\begin{array}{l}\text { P2) Quais os fatores motivacionais } \\
\text { determinantes para a escolha de um } \\
\text { dos três shoppings centers de } \\
\text { Ribeirão Preto na opinião dos } \\
\text { consumidores e gestores? }\end{array}$ & Quantitativa & $\begin{array}{l}\text { Aplicação do } \\
\text { Questionário } \\
\text { Alunos e Gestores } \\
\text { (Anexo) }\end{array}$ & $\begin{array}{l}\text { Estatística } \\
\text { descritiva } \\
\text { (média, desvio } \\
\text { padrão e } \\
\text { coeficiente de } \\
\text { variação). }\end{array}$ & $\begin{array}{l}\text { Consumidores e Gestores dos três } \\
\text { shoppings centers de Ribeirão Preto. }\end{array}$ \\
\hline dos gestores. & $\begin{array}{l}\text { 3) Verificar se há similaridades ou } \\
\text { diferenças na classificação dos } \\
\text { fatores motivacionais atribuídos } \\
\text { pelos consumidores e gestores em } \\
\text { relação a cada um dos três } \\
\text { shoppings centers. }\end{array}$ & $\begin{array}{l}\text { P3) Há similaridades ou diferenças } \\
\text { na classificação dos fatores } \\
\text { motivacionais atribuídos pelos } \\
\text { consumidores e gestores em relação } \\
\text { a cada um dos três shoppings } \\
\text { centers? }\end{array}$ & Quantitativa & $\begin{array}{l}\text { A partir dos dados e } \\
\text { informações } \\
\text { gerados pelo } \\
\text { Objetivo } \\
\text { Específico \# } 2\end{array}$ & $\begin{array}{l}\text { Análise de } \\
\text { dados. }\end{array}$ & $\begin{array}{l}\text { Consumidores e Gestores dos três } \\
\text { shoppinsg centers de Ribeirão Preto. }\end{array}$ \\
\hline $\begin{array}{l}2^{\text {a ETAPA }} \\
\text { (Qualitativa) } \\
\text { Análise da Gestão } \\
\text { de Marcas dos } \\
\text { shoppings centers } \\
\text { de Ribeirão Preto } \\
\text { em função da } \\
\text { satisfação dos } \\
\text { fatores } \\
\text { motivacionais } \\
\text { considerados } \\
\text { como } \\
\text { determinantes } \\
\text { pelos } \\
\text { consumidores. }\end{array}$ & $\begin{array}{l}\text { 4) Analisar se a gestão de marcas } \\
\text { adotada nos shoppings centers de } \\
\text { Ribeirão Preto consegue propiciar } \\
\text { ou contribuir para a satisfação dos } \\
\text { fatores motivacionais de escolha } \\
\text { considerados como determinantes } \\
\text { pelos consumidores. }\end{array}$ & $\begin{array}{l}\text { P4) A gestão de marcas adotada } \\
\text { pelos shoppings centers de Ribeirão } \\
\text { Preto conseguem propiciar ou } \\
\text { contribuir para a satisfação dos } \\
\text { fatores motivacionais de escolha } \\
\text { considerados como determinantes } \\
\text { pelos consumidores? } \\
\text { P5) Quais são as práticas de gestão } \\
\text { estratégica de marcas adotadas pelos } \\
\text { shopping centers de Ribeirão Preto? } \\
\text { P6) Como os shoppings de Ribeirão } \\
\text { implementam o posicionamento da } \\
\text { sua marca? } \\
\text { P7) Qual é a estratégia de } \\
\text { posicionamento e promoção da } \\
\text { marca adotado pelos shoppings de } \\
\text { Ribeirão? } \\
\text { P8) Quais são considerados pelos } \\
\text { gestores dos shoppings de Ribeirão, } \\
\text { os pontos fortes, fracos, as } \\
\text { oportunidades e as ameaças? }\end{array}$ & Qualitativa & $\begin{array}{l}\text { Através da análise } \\
\text { dos dados obtidos } \\
\text { na } 1^{\text {a }} \text { Etapa } \\
\text { (perguntas P1, P2 e } \\
\text { P3) e realização das } \\
\text { entrevistas com os } \\
\text { gestores dos três } \\
\text { shopping centers. }\end{array}$ & $\begin{array}{l}\text { Análise de } \\
\text { conteúdo. }\end{array}$ & $\begin{array}{l}\text { Consumidores e Gestores dos três } \\
\text { shoppings centers de Ribeirão Preto. }\end{array}$ \\
\hline
\end{tabular}




\subsection{PROTOCOLO DO ESTUDO DE CASO}

No contexto de um estudo de caso, o protocolo é um instrumento orientador e regulador da condução da estratégia de pesquisa. $\mathrm{O}$ protocolo constitui-se em um forte elemento para mostrar a confiabilidade de uma pesquisa. Isto é, garantir que os achados de uma investigação possam ser assemelhados aos resultados da replicação do estudo de caso, ou mesmo de outro caso em condições equivalentes ao primeiro, orientado pelo mesmo protocolo (MARTINS, 2006).

Portanto, segundo Martins (2006, p. 74), para desenvolver a pesquisa "faz-se necessário explicitar claramente os procedimentos que nortearam o estudo de caso", ou seja, "faz-se necessário realizar uma série de etapas que juntas compõem o plano de ação", para tanto, com este propósito, segue o quadro 3.5 - Protocolo do estudo de caso orientador da etapa II qualitativa.

Ainda, de acordo com Yin (2006), o protocolo é uma das principais táticas para se aumentar a confiabilidade da pesquisa e destina-se a orientar o pesquisador no estudo.

Assim, o estudo teve como universo da pesquisa três shoppings centers na cidade de Ribeirão Preto onde foi analisado se o papel da gestão estratégica de marcas executada pela administração de cada um destes empreendimentos está resultando no sucesso ou no fracasso da adoção por parte dos consumidores.

Baseado num modelo proposto por Yin (2006), que divide basicamente em quatro partes o protocolo, foi estruturado um plano formal no qual o mesmo foi seguido para a realização da pesquisa e a coleta de dados junto aos casos a serem estudos. 


\begin{tabular}{|c|c|}
\hline Componentes do protocolo & Descrição \\
\hline a) Visão geral do estudo & $\begin{array}{l}\text { I - Objetivo do estudo: demonstrar que no setor de shoppings centers as } \\
\text { diferentes administrações podem interferir drasticamente na escolha do } \\
\text { consumidor. } \\
\text { II - Quanto às empresas a serem estudadas: as informações fornecidas foram } \\
\text { provenientes de pesquisa com os gestores e com os freqüentadores de cada um } \\
\text { dos três shoppings centers. } \\
\text { III - Quanto ao referencial teórico: foi estruturado um referencial sobre os } \\
\text { shoppings centers no Brasil, comportamento do consumidor e gestão de } \\
\text { marcas; } \\
\text { IV - Quanto aos procedimentos de campo - Coleta de Dados: foi preparada } \\
\text { uma lista de informações relevantes para as entrevistas, isto é, um roteiro de } \\
\text { entrevista. Essas entrevistas não tiveram tempo determinado e nem } \\
\text { periodicidade regular, pois foram realizadas informalmente. } \\
\text { V - Recursos: foi utilizado para a coleta e tratamento dos dados, uma folha } \\
\text { contendo um questionário, um notebook e, na tabulação dos dados, o programa } \\
\text { Microsoft EXCEL. }\end{array}$ \\
\hline b) Procedimentos de campo & $\begin{array}{l}\text { I - Coleta de dados primários obtidos nas entrevistas com os gestores e com os } \\
\text { consumidores. } \\
\text { II - Pesquisa documental interna e externa (notícias, artigo, revistas). } \\
\text { III - Observações in loco. } \\
\text { IV - Estruturação de modelos para diagnóstico se processou pela observação. }\end{array}$ \\
\hline c) Questões do estudo & $\begin{array}{l}\text { Questão central: } \\
\text { Quais os fatores motivacionais determinantes para a escolha de um shopping } \\
\text { center por parte dos consumidores de Ribeirão Preto e se existe alguma } \\
\text { influência da gestão de marcas dos shoppings centers na satisfação de tais } \\
\text { fatores. }\end{array}$ \\
\hline
\end{tabular}




\begin{tabular}{|c|c|}
\hline & $\begin{array}{l}\text { Questões específicas: } \\
\text { I - Qual o perfil dos consumidores entrevistados que preferem cada um dos três } \\
\text { shopping centers de Ribeirão Preto? } \\
\text { II - Quais os fatores motivacionais determinantes para a escolha de um dos três } \\
\text { shoppings centers de Ribeirão Preto na opinião dos consumidores e gestores? } \\
\text { III - Há similaridades ou diferenças na classificação dos fatores motivacionais } \\
\text { atribuídos pelos consumidores e gestores em relação a cada um dos três shoppings } \\
\text { centers? } \\
\text { IV - A gestão de marcas adotada pelos shoppings centers de Ribeirão Preto } \\
\text { conseguem propiciar ou contribuir para a satisfação dos fatores motivacionais de } \\
\text { escolha considerados como determinantes pelos consumidores? } \\
\text { V - Quais são as práticas de gestão estratégica de marcas adotadas pelos shopping } \\
\text { centers de Ribeirão Preto? } \\
\text { VI - Como os shoppings de Ribeirão implementam o posicionamento da sua } \\
\text { marca? }\end{array}$ \\
\hline $\begin{array}{l}\text { d) Avaliação - Análise dos } \\
\text { dados e relatório final }\end{array}$ & $\begin{array}{l}\text { I - Tabulação dos dados coletados. } \\
\text { II - Cruzamentos de informações. } \\
\text { III - Verificação de procedimentos comuns em todos os casos analisados. } \\
\text { IV - Redação do relatório final completo - revisão da literatura, metodologia e } \\
\text { análise dos casos. }\end{array}$ \\
\hline
\end{tabular}

Quadro 3.5 - Protocolo do estudo de caso da etapa II - Qualitativa 


\subsubsection{Definição de termos essenciais da pesquisa}

Os termos essenciais que nortearam a condução desta pesquisa podem ser destacados em três termos distintos: A definição destes termos segue no quadro 3.6.

\begin{tabular}{|c|c|}
\hline Termos essenciais da pesquisa & Definições \\
\hline Varejo & $\begin{array}{l}\text { O varejo inclui todas as atividades envolvidas na } \\
\text { venda de bens ou serviços diretamente aos } \\
\text { consumidores finais para uso pessoal. (KOTLER, } \\
\text { 1994) }\end{array}$ \\
\hline Shopping center & $\begin{array}{l}\text { Empreendimento comercial que oferece ao cliente as } \\
\text { facilidades de realizar compras diversas num mesmo } \\
\text { local e ao mesmo tempo; comparar produtos e seus } \\
\text { preços; desfrutar de um local confortável e } \\
\text { descontraído; estacionamento em local próximo e de } \\
\text { fácil acesso e carregamento de produtos de maneira } \\
\text { rápida e segura. (DICK apud GONÇALVES, 1990, } \\
\text { p.7) }\end{array}$ \\
\hline Marca & $\begin{array}{l}\text { "Marca é um nome, termo ou símbolo, desenho ou } \\
\text { uma combinação desses elementos que deve } \\
\text { identificar os bens ou serviços de um fornecedor ou } \\
\text { grupo de fornecedores e diferenciá-los dos da } \\
\text { concorrência". (AMA- American Marketing } \\
\text { Association). }\end{array}$ \\
\hline Gestão de marcas (branding) & $\begin{array}{l}\text { Executar a gestão estratégica de marcas (branding), é } \\
\text { proporcionar a criação de marcas fortes que cumpram } \\
\text { o que prometem, bem como a manutenção e o } \\
\text { aprimoramento da força dessas marcas ao longo do } \\
\text { tempo, é algo que se tornou- obrigatório para todos os } \\
\text { tipos de organizações. (Keller, 2006) }\end{array}$ \\
\hline
\end{tabular}




\begin{tabular}{|l|l|}
\hline Comportamento do consumidor & $\begin{array}{l}\text { O comportamento do consumidor/cliente é definido } \\
\text { como as atividades físicas e mentais realizadas por } \\
\text { consumidores/clientes de bens e serviços que resultem } \\
\text { em decisões ou ações, como as de comprar, utilizar e } \\
\text { pagar por estes bens e serviços. (Sheth, 2001). }\end{array}$ \\
\hline
\end{tabular}

Quadro 3.6 - Termos essenciais da pesquisa

\subsubsection{Atividades realizadas}

Foi realizado um levantamento bibliográfico sobre os seguintes assuntos: os shoppings centers, os shoppings centers no Brasil, comportamento do consumidor e gestão de marcas. Definição dos casos: a partir dos shoppings existentes na cidade de Ribeirão Preto, no interior do estado de São Paulo, foram escolhidos os três, sendo eles o Ribeirão Shopping, o Shopping Santa Úrsula e o Novo Shopping.

Aprimoramento da metodologia de pesquisa: detalhamento da metodologia e incorporação de instrumentos de pesquisa que viabilizaram a coleta de dados para a presente pesquisa.

Realização das entrevistas: realização de entrevistas com os gestores e com os frequientadores dos empreendimentos a serem estudados.

Análise dos casos estudados: os casos foram analisados qualitativamente e de forma comparativa a fim de se identificar a contribuição da gestão da imagem para a adoção do shopping estudado.

Elaboração de relatórios de pesquisa: redação de artigos científicos para congressos e revistas e elaboração da Dissertação de Mestrado.

Defesa da Dissertação. 


\subsection{ETAPAS DA PESQUISA}

Tratando-se de um estudo de caso com pesquisa tanto qualitativa quanto quantitativa, tornouse necessário o detalhamento dos procedimentos que foram utilizados em cada etapa da pesquisa.

\subsubsection{Etapa I: Quantitativa}

A primeira etapa consistiu de pesquisa quantitativa, contemplando o desenvolvimento de três objetivos específicos.

O primeiro objetivo específico visou caracterizar o perfil dos consumidores entrevistados de cada um dos três shoppings centers, buscando responder à seguinte pergunta: qual o perfil dos consumidores entrevistados de cada um dos três shoppings centers de Ribeirão Preto?

Para coleta de dados foi aplicado o questionário constante dos anexos.

O segundo objetivo específico visou identificar os fatores motivacionais determinantes para a escolha de um dos três shoppings centers de Ribeirão Preto na opinião dos consumidores e gestores, buscando responder à seguinte pergunta: Quais os fatores motivacionais determinantes para a escolha de um dos três shoppings centers de Ribeirão Preto na opinião dos consumidores e gestores?

Para realizar a coleta dos dados e informações que contemplam este objetivo, foi aplicado o questionário constante dos anexos.

Este questionário foi aplicado aos consumidores e gestores dos três shoppings centers de Ribeirão Preto.

Foi realizado um pré-teste com o questionário (anexo) aplicando-o a dez consumidores, com as mesmas características do público-alvo desta pesquisa, escolhidos por critério de conveniência. 
Para análise e interpretação dos dados e informações coletados foram utilizadas algumas ferramentas da estatística descritiva, sendo a média, o desvio-padrão e o coeficiente de variação.

Considerando que nesta etapa da pesquisa estava presente a análise estatística de dados, fez-se necessário definir as ferramentas estatísticas que foram utilizadas. Existem algumas abordagens básicas que puderam ser utilizadas para melhor compreender os dados e suas relações subjacentes. Essas abordagens são úteis, pois, atualmente, na maior parte das vezes, há números demais para verificar e para, a partir deles, identificar padrões que possam ser úteis. Quase todos os conjuntos de dados precisam de um resumo de suas informações, ou seja, algo que sintetize e descreva os números que eles contêm, nestes casos, a estatística descritiva tem esta função (HAIR JUNIOR et al., 2005).

Segundo Hair Junior et al. (2005), as medidas de tendência central por sua vez localizam o centro da distribuição, bem como outras informações úteis. A média e a mediana.

O terceiro objetivo específico visou Verificar se há similaridades ou diferenças na classificação dos fatores motivacionais atribuídos pelos consumidores e gestores em relação a cada um dos três shoppings centers, buscando responder à seguinte pergunta: Há similaridades ou diferenças na classificação dos fatores motivacionais atribuídos pelos consumidores e gestores em relação a cada um dos três shoppings centers? Para coleta e análise dos dados foram utilizados os dados e informações gerados a partir do alcance do segundo objetivo específico.

\subsubsection{Etapa II: Qualitativa}

A segunda etapa consistiu de pesquisa qualitativa, contemplando o desenvolvimento de um objetivo específico. 
Este objetivo específico visa Analisar se a gestão de marcas adotada nos shoppings centers de Ribeirão Preto consegue propiciar ou contribuir para a satisfação dos fatores motivacionais de escolha considerados como determinantes pelos consumidores, e buscou responder às seguintes perguntas: P4) A gestão de marcas adotada pelos shoppings centers de Ribeirão Preto conseguem propiciar ou contribuir para a satisfação dos fatores motivacionais de escolha considerados como determinantes pelos consumidores?, P5) Quais são as práticas de gestão estratégica de marcas adotadas pelos shopping centers de Ribeirão Preto?, P6) Como os shoppings de Ribeirão implementam o posicionamento da sua marca?, P7) Qual é a estratégia de posicionamento e promoção da marca adotado pelos shoppings de Ribeirão? e P8) Quais são considerados pelos gestores dos shoppings de Ribeirão, os pontos fortes, fracos, as oportunidades e as ameaças?

Considerando que nesta etapa foram realizadas entrevistas semiestruturadas com os gestores dos três shoppings centers de Ribeirão Preto. Para proceder a coleta de dados, foi elaborado um protocolo de entrevista, conforme quadro 3.5.

As análises e interpretações dos dados e informações foram conduzidas com a utilização da técnica de análise de conteúdo.

\subsubsection{Análise de Conteúdo}

De acordo com a definição de Berelson (1971), análise de conteúdo é "uma técnica de investigação que através de uma descrição objetiva, sistemática e quantitativa do conteúdo manifesto das comunicações, tem por finalidade a interpretação destas mesmas comunicações".

Bardin (1977), define análise de conteúdo como: "um conjunto de técnicas de análise das comunicações visando obter, por procedimentos sistemáticos e objetivos de descrição do conteúdo das mensagens, indicadores (quantitavos ou não) que permitam a inferência de 
conhecimentos relativos às condições de produção/recepção (variáveis inferidas) destas mensagens".

A análise de conteúdo pode ser realizada por meio de uma análise temática ou dos significantes (nesta última, analisando-se os procedimentos).

A análise temática é executada separando-se os conteúdos de um discurso agrupados em seus temas comuns, e que podem ser medidos em termos de sua incidência, sendo, neste sentido, freqüencial e quantitativa.

Dentro de um contexto de análise temática podemos utilizar a técnica da análise por categorias. Nesta, a partir de um texto objeto de análise, realizamos a classificação e recenseamento, de acordo com a presença ou não dos elementos de observação. Quando existir ambigüidade na codificação dos mesmos, devemos definir o contexto em que estes se inserem, de forma a permitir maior clareza de enquadramento em determinada categoria.

Sinteticamente podemos afirmar que a análise de conteúdo envolve três momentos básicos:

1- Pré-análise, que possui três missões- A escolha dos documentos a serem submetidos à análise, a formulação das hipóteses e dos objetivos e a elaboração de indicadores que fundamentam a interpretação final.

2- Exploração do material- Quando são aplicados os procedimentos técnicos pertinentes ao tratamento do problema.

3- Tratamento dos resultados obtidos e interpretação, neste momento "os resultados brutos são tratados de maneira a serem significativos (falantes) e válidos. Operações estatísticas simples (percentagens), ou mais complexas (análise fatorial), permitem estabelecer quadros de resultados, diagramas, figuras e modelos, os quais condensam e põem em relevo as informações fornecidas pela análise”, Bardin (1977).

A efetivação do tratamento do material para a realização da análise pressupõe que, em determinado momento, o texto seja codificado. Segundo Holsti (1969), "a codificação é o 
processo pelo qual os dados brutos são transformados sistematicamente e agregados em unidades, as quais permitem uma descrição exata das características pertinentes do conteúdo". Segundo Bardin (1977), "a organização da codificação compreende três escolhas (no caso de uma análise quantitativa e categorial):

1- O recorte: escolha das unidades;

2- A enumeração: escolha das regras de contagem;

3- A classificação e a agregação: escolha das categorias".

Finalmente, para executarmos nosso trabalho, devemos definir as unidades de registro e de contexto.

"A unidade de registro é a unidade de significação a codificar e corresponde ao segmento do conteúdo a considerar como unidade de base, visando à categorização e à contagem freqüencial. A unidade de registro pode ser de natureza e de dimensões muito variáveis", segundo Bardin (1977).

Entre as várias unidades possíveis de registro (palavra, tema, o objeto, o personagem etc.) a unidade que apresentou melhor adequação ao objetivo do estudo foi o tema.

Berelson (1971) define o tema como "uma afirmação acerca de um assunto. Quer dizer, uma frase, ou uma frase composta, habitualmente um resumo ou uma frase condensada, por influência da qual pode ser afetado um vasto conjunto de formulações singulares".

"A unidade de contexto serve de unidade de compreensão para codificar a unidade de registro e corresponde ao segmento da mensagem, cujas dimensões (superiores às da unidade de registro) são ótimas para que se possa compreender a significação exata da unidade de registro", segundo Bardin (1977).

A partir do exposto, podemos observar que na efetivação do estudo, o elemento temático é sua incidência central, sendo que a unidade de contexto aparece como elemento complementar qualificativo. 


\subsection{LIMITAÇÕES DA PESQUISA}

As limitações dessa pesquisa, primeiramente, estão relacionadas ao método de estudo de caso que foi utilizado. Essas limitações relacionam-se também ao fato de o universo amostral ser extremamente grande, o que impossibilitou a realização uma pesquisa com uma amostra que fosse, do ponto de vista estatístico, representativa. Dessa forma, os resultados provenientes dessa pesquisa não podem ser generalizados, nem extrapolados para toda a população, tendo ficado assim, restritos aos consumidores que foram alcançados pela pesquisa.

Outro ponto que necessita de ressalvas é o fato de as entrevistas realizadas com gestores dos shoppings centers apresentaram vieses por parte dos entrevistados. Isso foi percebido, mesmo com o cuidado de confrontar as visões dos entrevistados. 


\section{RESULTADOS}

\subsection{PESQUISA DE CAMPO}

A pesquisa foi realizada com alunos de graduação de cursos de Administração e Economia em centros universitários de Barretos, Bebedouro, Jaboticabal e Ribeirão Preto. De acordo com a disponibilidade de auxílio na aplicação dos questionários os mesmos foram direcionados às instituições de ensino. A aplicação dos questionários se deu em sala de aula, com uma prévia explicação sobre os objetivos da pesquisa e após a explicação os questionários foram entregues para o preenchimento.

Como o número de respondentes do curso de Economia foi somente seis, não foram apresentadas as tabulações diferenciadas por curso. A base de dados completa se encontra nos Anexos, a partir da página 111.

O período de aplicação da pesquisa foi de 10 de novembro a 10 de dezembro, procedendo-se então à tabulação e análise dos dados.

Foi também realizada uma pesquisa com os gestores dos shoppings centers. Tal pesquisa teve a utilização de dois instrumentos: uma entrevista pessoal com o gestor de cada shopping e o preenchimento de um questionário pelos integrantes da administração direta dos shoppings, inclusive o próprio gestor.

\subsection{TAMANHO DA AMOSTRA E MARGEM DE ERRO}

Após uma prévia seleção, onde foram descartados questionários incompletos, foram selecionados 672 questionários na pesquisa com os alunos, e 13 questionários na pesquisa com os gestores. A margem de erro na pesquisa com os alunos é de 3,78\% nas proporções 
apuradas, com um nível de confiança de 95\%, considerando-se o total dos questionários. A margem de erro varia na apuração dos resultados por shopping, pois o número de questionários é menor.

$\mathrm{Na}$ pesquisa com os gestores não existe estimativa de erro, pois foram entrevistados todos os gestores.

\subsection{RESULTADOS DA PESQUISA COM ALUNOS}

\subsubsection{Perfil Geral dos Respondentes}

\section{Total dos Respondentes}

\begin{tabular}{|c|c|c|c|c|}
\hline & Sexo & & Total & $\%$ \\
\hline Faixa Etária & Fem & Masc & Geral & \\
\hline 17 a 26 anos & 286 & 258 & $\overline{544}$ & $81,0 \%$ \\
\hline 27 a 36 anos & 55 & 48 & 103 & $15,3 \%$ \\
\hline 37 a 46 anos & 4 & 11 & 15 & $2,2 \%$ \\
\hline 47 a 56 anos & 1 & 5 & 6 & $0,9 \%$ \\
\hline Sem Resposta & 4 & & 4 & $0,6 \%$ \\
\hline Total & 350 & 322 & 672 & $100,0 \%$ \\
\hline$\%$ & $52,1 \%$ & $47,9 \%$ & $100,0 \%$ & \\
\hline
\end{tabular}

Tabela 4.1 - Faixa Etária vs Sexo

Como era esperado para a amostra pesquisada, a maioria dos entrevistados está na faixa de 17 a 26 anos. Além disso, em relação ao sexo, a distribuição da amostra está equilibrada, pois $52,1 \%$ é de mulheres e $47,9 \%$ é de homens. 
Total dos Respondentes

\begin{tabular}{|c|c|c|c|c|}
\hline & Sexo & & Total & $\%$ \\
\hline IES & Fem & Masc & Geral & \\
\hline FEA (RIBEIRÃO PRETO) & 66 & 91 & 157 & $23,4 \%$ \\
\hline FEB (BARRETOS) & 45 & 36 & 81 & $12,1 \%$ \\
\hline FAFIBE (BEBEDOURO) & 37 & 27 & 64 & $9,5 \%$ \\
\hline MOURA LACERDA (RIBEIRÃO PRETO) & 78 & 63 & 141 & $21,0 \%$ \\
\hline REGES (RIBEIRÃO PRETO) & 23 & 26 & 49 & $7,3 \%$ \\
\hline BARÃO DE MAUÁ (RIBEIRÃO PRETO) & 3 & 3 & 6 & $0,9 \%$ \\
\hline UNIP (RIBEIRÃO PRETO) & 59 & 54 & 113 & $16,8 \%$ \\
\hline SÃO LUIS (JABOTICABAL) & 39 & 22 & 61 & $9,1 \%$ \\
\hline Total & 350 & 322 & 672 & $100,0 \%$ \\
\hline$\%$ & $52,1 \%$ & $47,9 \%$ & $100,0 \%$ & \\
\hline
\end{tabular}

Tabela 4.2 - IES vs Sexo

A razão da coleta em diferentes Instituições de Ensino Superior (IES) da cidade e região, foi tentar capturar uma maior variedade de influencias como classe social e aspectos associados a localização que possam interferir nas respostas obtidas. A distribuição da amostra pelas Instituições de Ensino Superior (IES) se deu em razão da disponibilidade de ajuda na aplicação dos questionários. Como pode ser verificado, as IES localizadas na cidade de Ribeirão Preto representam 69,2\% do total desta amostra.

Total dos Respondentes

\begin{tabular}{|c|c|c|c|c|c|c|c|c|}
\hline \multirow[b]{2}{*}{ IES } & \multicolumn{6}{|c|}{ Faixa Salarial } & \multirow{2}{*}{$\begin{array}{l}\text { Total } \\
\text { Geral }\end{array}$} & \multirow[t]{2}{*}{$\%$} \\
\hline & 1 a 5 SM & 6 a $10 \mathrm{SM}$ & $\begin{array}{c}11 \text { a } 15 \\
\text { SM }\end{array}$ & $\begin{array}{c}16 \text { a } 20 \\
\text { SM }\end{array}$ & $\begin{array}{c}21 \text { a } 25 \\
\text { SM }\end{array}$ & $\begin{array}{c}26 \text { ou } \\
\text { mais SM }\end{array}$ & & \\
\hline FEA (RIBEIRÃO PRETO) & 17 & 37 & 26 & 16 & 7 & 54 & 157 & $23,4 \%$ \\
\hline FEB (BARRETOS) & 22 & 21 & 5 & 4 & & 29 & 81 & $12,1 \%$ \\
\hline FAFIBE (BEBEDOURO) & 25 & 11 & 3 & 1 & & 24 & 64 & $9,5 \%$ \\
\hline MOURA LACERDA (RIBEIRÃO PRETO) & 41 & 51 & 19 & 4 & 1 & 25 & 141 & $21,0 \%$ \\
\hline REGES (RIBEIRÃO PRETO) & 21 & 21 & 4 & & & 3 & 49 & $7,3 \%$ \\
\hline BARÃO DE MAUÁ (RIBEIRÃO PRETO) & 3 & 2 & & & 1 & & 6 & $0,9 \%$ \\
\hline UNIP (RIBEIRÃO PRETO) & 40 & 32 & 7 & 3 & & 31 & 113 & $16,8 \%$ \\
\hline SÃO LUIS (JABOTICABAL) & 27 & 22 & 4 & 1 & 1 & 6 & 61 & $9,1 \%$ \\
\hline Total & 196 & 197 & 68 & 29 & 10 & 172 & 672 & $100,0 \%$ \\
\hline$\%$ & $29,2 \%$ & $29,3 \%$ & $10,1 \%$ & $4,3 \%$ & $1,5 \%$ & $25,6 \%$ & $100,0 \%$ & \\
\hline
\end{tabular}

Tabela 4.3 - IES vs Faixa Salarial

Pouco mais de $25 \%$ dos respondentes fica na faixa superior de renda familiar, ou seja, acima de 26 salários mínimos, mas a grande maioria dos respondentes, 58,5\%, localiza-se nas faixas de renda familiar mais inferiores, que vão de 1 a 10 salários mínimos. 
Total dos Respondentes

\begin{tabular}{|c|c|c|c|c|c|c|c|}
\hline & \multicolumn{5}{|c|}{ NUMERO DE FILHOS MENORES QUE 18 ANOS } & \multirow{2}{*}{$\begin{array}{l}\text { Total } \\
\text { Geral }\end{array}$} & \multirow[t]{2}{*}{$\%$} \\
\hline Faixa Etária & $\mathbf{0}$ & 1 & 2 & 3 & 4 & & \\
\hline 17 a 26 anos & 513 & 20 & 9 & 1 & 1 & 544 & $81,0 \%$ \\
\hline 27 a 36 anos & 72 & 21 & 8 & 2 & & 103 & $15,3 \%$ \\
\hline 37 a 46 anos & 4 & 4 & 3 & 2 & 2 & 15 & $2,2 \%$ \\
\hline 47 a 56 anos & 4 & 2 & & & & 6 & $0,9 \%$ \\
\hline Sem Resposta & 4 & & & & & 4 & $0,6 \%$ \\
\hline Total & 597 & 47 & 20 & 5 & 3 & 672 & $100,0 \%$ \\
\hline$\%$ & $88,8 \%$ & $7,0 \%$ & $3,0 \%$ & $0,7 \%$ & $0,4 \%$ & $100,0 \%$ & \\
\hline
\end{tabular}

Tabela 4.4 - Faixa Etária vs Número de Filhos

Conforme esperado, a grande maioria dos entrevistados $(88,8 \%)$ não possui nenhum filho, pois trata-se de alunos de graduação.

\section{Total dos Respondentes}

\begin{tabular}{|c|c|c|c|c|c|}
\hline & \multicolumn{3}{|c|}{ SHOPPING PREFERIDO } & \multirow{2}{*}{$\begin{array}{l}\text { Total } \\
\text { Geral }\end{array}$} & \multirow[t]{2}{*}{$\%$} \\
\hline FREQÜÊNCIA & $\begin{array}{c}\text { Novo } \\
\text { Shopping }\end{array}$ & $\begin{array}{l}\text { Ribeirão } \\
\text { Shopping }\end{array}$ & $\begin{array}{l}\text { Santa } \\
\text { Úrsula }\end{array}$ & & \\
\hline Diariamente & 5 & 25 & & 30 & $4,5 \%$ \\
\hline Semanalmente & 47 & 199 & 14 & 260 & $38,7 \%$ \\
\hline Mensalmente & 83 & 260 & 24 & 367 & $54,6 \%$ \\
\hline SR & 3 & 11 & 1 & 15 & $2,2 \%$ \\
\hline Total & 138 & 495 & 39 & 672 & $100,0 \%$ \\
\hline$\%$ & $20,5 \%$ & $73,7 \%$ & $5,8 \%$ & $100,0 \%$ & \\
\hline
\end{tabular}

Tabela 4.5 - Freqüência vs Shopping Preferido

A maioria dos entrevistados (54\%) declara freqüentar mensalmente o shopping center. Para este público pesquisado, o Ribeirão Shopping foi considerado o preferido $(73,7 \%)$. 
Total dos Respondentes

Nos. Absolutos

\begin{tabular}{|c|c|c|c|c|c|}
\hline \multirow[b]{2}{*}{ IES } & \multicolumn{3}{|c|}{ SHOPPING PREFERIDO } & \multirow{2}{*}{$\begin{array}{l}\text { Total } \\
\text { Geral }\end{array}$} & \multirow[t]{2}{*}{$\%$} \\
\hline & $\begin{array}{c}\text { Novo } \\
\text { Shopping }\end{array}$ & $\begin{array}{l}\text { Ribeirão } \\
\text { Shopping }\end{array}$ & $\begin{array}{c}\text { Santa } \\
\text { Úrsula }\end{array}$ & & \\
\hline$\overline{\text { FEA (RIBEIRÃO PRETO) }}$ & 11 & 125 & 21 & 157 & $23,4 \%$ \\
\hline FEB (BARRETOS) & 15 & 60 & 6 & 81 & $12,1 \%$ \\
\hline FAFIBE (BEBEDOURO) & 16 & 43 & 5 & 64 & $9,5 \%$ \\
\hline MOURA LACERDA (RIBEIRÃO PRETO) & 41 & 97 & 3 & 141 & $21,0 \%$ \\
\hline REGES (RIBEIRÃO PRETO) & 22 & 26 & 1 & 49 & $7,3 \%$ \\
\hline BARÃO DE MAUÁ (RIBEIRÃ̃O PRETO) & & 6 & & 6 & $0,9 \%$ \\
\hline UNIP (RIBEIRÃO PRETO) & 21 & 90 & 2 & 113 & $16,8 \%$ \\
\hline SÃO LUIS (JABOTICABAL) & 12 & 48 & 1 & 61 & $9,1 \%$ \\
\hline Total & 138 & 495 & 39 & 672 & $100,0 \%$ \\
\hline$\%$ & $20,5 \%$ & $73,7 \%$ & $5,8 \%$ & $100,0 \%$ & \\
\hline
\end{tabular}

Tabela 4.6 - IES vs Shopping Preferido

Total dos Respondentes

Percentuais

\begin{tabular}{|c|c|c|c|c|c|}
\hline \multirow[b]{2}{*}{ IES } & \multicolumn{3}{|c|}{ SHOPPING PREFERIDO } & \multirow{2}{*}{$\begin{array}{l}\text { Total } \\
\text { Geral }\end{array}$} & \multirow[t]{2}{*}{ Base } \\
\hline & $\begin{array}{c}\text { Novo } \\
\text { Shopping }\end{array}$ & $\begin{array}{l}\text { Ribeirão } \\
\text { Shopping }\end{array}$ & $\begin{array}{l}\text { Santa } \\
\text { Úrsula }\end{array}$ & & \\
\hline FEA (RIBEIRÃO PRETO) & $7,0 \%$ & $79,6 \%$ & $13,4 \%$ & $100,0 \%$ & 157 \\
\hline FEB (BARRETOS) & $18,5 \%$ & $74,1 \%$ & $7,4 \%$ & $100,0 \%$ & 81 \\
\hline FAFIBE (BEBEDOURO) & $25,0 \%$ & $67,2 \%$ & $7,8 \%$ & $100,0 \%$ & 64 \\
\hline MOURA LACERDA (RIBEIRÃO PRETO) & $29,1 \%$ & $68,8 \%$ & $2,1 \%$ & $100,0 \%$ & 141 \\
\hline REGES (RIBEIRÃO PRETO) & $44,9 \%$ & $53,1 \%$ & $2,0 \%$ & $100,0 \%$ & 49 \\
\hline BARÃO DE MAUÁ (RIBEIRÃ́O PRETO) & & $100,0 \%$ & & $100,0 \%$ & 6 \\
\hline UNIP (RIBEIRÃO PRETO) & $18,6 \%$ & $79,6 \%$ & $1,8 \%$ & $100,0 \%$ & 113 \\
\hline SÃO LUIS (JABOTICABAL) & $19,7 \%$ & $78,7 \%$ & $1,6 \%$ & $100,0 \%$ & 61 \\
\hline Total & $20,5 \%$ & $73,7 \%$ & $5,8 \%$ & $100,0 \%$ & 672 \\
\hline Base & 138 & 495 & 39 & 672 & \\
\hline
\end{tabular}

Tabela 4.7 - IES vs Shopping Preferido (Percentuais)

A faixa salarial parece ter influência na preferência pelo shopping. Por exemplo, os respondentes da FEA são os que apresentam uma das maiores proporções dentro da faixa de 26 ou mais salários mínimos, e que possuem a maior proporção de preferência do Santa Úrsula. Os respondentes da REGES possuem a maior proporção de preferência do Novo Shopping, o que pode ser explicado pela proximidade e localização das faculdades em relação aos empreendimentos. 
Total dos Respondentes

\begin{tabular}{|c|c|c|c|c|c|}
\hline & FINALIDADE & & & Total & $\%$ \\
\hline FREQÜÊNCIA & Compras & $\begin{array}{c}\text { Recr. / } \\
\text { Entretenimento }\end{array}$ & Outros & Geral & \\
\hline Diariamente & 14 & 7 & 18 & 39 & $4,6 \%$ \\
\hline Semanalmente & 131 & 184 & 53 & 368 & $43,5 \%$ \\
\hline Mensalmente & 152 & 226 & 49 & 427 & $50,5 \%$ \\
\hline SR & 1 & 8 & 3 & 12 & $1,4 \%$ \\
\hline Total & 298 & 425 & 123 & 846 & $100,0 \%$ \\
\hline$\%$ & $35,2 \%$ & $50,2 \%$ & $14,5 \%$ & $100,0 \%$ & \\
\hline
\end{tabular}

Obs: O total é superior ao número de respondentes em razão de ser possível mais de uma resposta.

Tabela 4.8 - Frequëncia vs Finalidade

A maioria dos entrevistados declara que a finalidade de ir ao shopping é recreação e entretenimento.

Alunos de IES de Ribeirão Preto

\begin{tabular}{l|c|c}
\hline \multicolumn{1}{c|}{ FREQÜENCIA } & Total & $\%$ \\
\hline Diariamente & $\mathbf{2 2}$ & $4,7 \%$ \\
Semanalmente & $\mathbf{2 2 9}$ & $49,1 \%$ \\
Mensalmente & $\mathbf{2 1 1}$ & $45,3 \%$ \\
SR & $\mathbf{4}$ & $0,9 \%$ \\
\hline \multicolumn{1}{c|}{ Total } & $\mathbf{4 6 6}$ & $100,0 \%$ \\
\hline
\end{tabular}

Tabela 4.9 - Freqüiência (Alunos de IES de Ribeirão Preto)

Alunos de IES fora de Ribeirão Preto

\begin{tabular}{l|c|c}
\hline \multicolumn{1}{c|}{ FREQÜÉNCIA } & Total & $\%$ \\
\hline Diariamente & $\mathbf{8}$ & $3,9 \%$ \\
Semanalmente & $\mathbf{3 1}$ & $15,0 \%$ \\
Mensalmente & $\mathbf{1 5 6}$ & $75,7 \%$ \\
SR & $\mathbf{1 1}$ & $5,3 \%$ \\
\hline \multicolumn{1}{c|}{ Total } & $\mathbf{2 0 6}$ & $100,0 \%$ \\
\hline
\end{tabular}

Tabela 4.10 - Freqüência (Alunos de IES Fora de Ribeirão Preto)

Como se pode observar, a freqüência varia em função da localização da IES. A maioria dos respondentes de IES de Ribeirão Preto declara como semanalmente a freqüência de ida ao shopping, enquanto que os alunos de IES de fora de Ribeirão Preto declaram freqüência mensal. 
Total dos Respondentes

\begin{tabular}{|c|c|c|c|c|c|}
\hline \multirow[b]{2}{*}{ FINALIDADE } & \multicolumn{3}{|c|}{ SHOPPING PREFERIDO } & \multirow{2}{*}{$\begin{array}{l}\text { Total } \\
\text { Geral }\end{array}$} & \multirow[t]{2}{*}{$\%$} \\
\hline & $\begin{array}{c}\text { Novo } \\
\text { Shopping }\end{array}$ & $\begin{array}{l}\text { Ribeirão } \\
\text { Shopping }\end{array}$ & Santa Úrsula & & \\
\hline Compras & 54 & 228 & 16 & 298 & $35,2 \%$ \\
\hline Recr. / Entretenimento & 84 & 317 & 24 & 425 & $50,2 \%$ \\
\hline Outros & 22 & 94 & 7 & 123 & $14,5 \%$ \\
\hline Total & 160 & 639 & 47 & 846 & $100,0 \%$ \\
\hline$\%$ & $18,9 \%$ & $75,5 \%$ & $5,6 \%$ & $100,0 \%$ & \\
\hline
\end{tabular}

Obs: O total é superior ao número de respondentes em razão de ser possível mais de uma resposta.

Tabela 4.11 - Finalidade vs Shopping Preferido

Total dos Respondentes

Percentuais

\begin{tabular}{|c|c|c|c|c|c|}
\hline \multirow[b]{2}{*}{ FINALIDADE } & \multicolumn{3}{|c|}{ SHOPPING PREFERIDO } & \multirow{2}{*}{$\begin{array}{l}\text { Total } \\
\text { Geral }\end{array}$} & \multirow[t]{2}{*}{ Base } \\
\hline & $\begin{array}{c}\text { Novo } \\
\text { Shopping }\end{array}$ & $\begin{array}{l}\text { Ribeirão } \\
\text { Shopping }\end{array}$ & Santa Úrsula & & \\
\hline Compras & $33,8 \%$ & $35,7 \%$ & $34,0 \%$ & $35,2 \%$ & 298 \\
\hline Recr. / Entretenimento & $52,5 \%$ & $49,6 \%$ & $51,1 \%$ & $50,2 \%$ & 425 \\
\hline Outros & $13,8 \%$ & $14,7 \%$ & $14,9 \%$ & $14,5 \%$ & 123 \\
\hline Total & $100,0 \%$ & $100,0 \%$ & $100,0 \%$ & $100,0 \%$ & 846 \\
\hline Base & 160 & 639 & 47 & 846 & \\
\hline
\end{tabular}

Obs: O total é superior ao número de respondentes em razão de ser possível mais de uma resposta.

Tabela 4.12 - Finalidade vs Shopping Preferido (Percentuais)

Entre os shoppings não existe diferença de finalidade de ida, para o público pesquisado.

\subsubsection{Atributos da Pesquisa}

Os entrevistados deram notas de 1 a 10 para 18 atributos ligados a fatores de motivação para a escolha de um shopping center, de acordo com Reynolds at. all (2002)

Cada entrevistado deveria apontar também os cinco itens mais importantes, do primeiro ao quinto em ordem de importância. Desta forma foi construído um índice que fosse capaz de levar em conta a ordem de importância atribuída pelo entrevistado, e que gerasse um número 
comparável entre os diferentes grupos. Para os atributos apontados como o primeiro mais importante foi atribuído peso 5, para o segundo mais importante peso 4 e assim sucessivamente, até que o $5^{\circ}$ atributo mais importante tenha peso 1 . Foi então somado o total de pesos de cada um dos atributos, e utilizado este índice como indicativo da importância do atributo. Mas como temos tamanhos de amostras diferentes para cada um dos shoppings ocorre uma variação de escala, o que dificulta a comparação dos gráficos. Para corrigir tal característica foi aplicada uma transformação ao índice, através da seguinte fórmula:

$$
\text { Índice Transformado }=\frac{\text { Índice }- \text { Média Índices }}{\text { Desvio Padrão dos Índices }}
$$

Ou seja, temos o índice de importância agora como número de Desvios-Padrão que o índice está distante da importância média geral. Tal transformação permite utilizar uma escala de valores de -3,0 até 3,0 para todos dos gráficos com baixa probabilidade de um dos índices estar fora da mesma.

Na tabela, as colunas Nota média e Importância são formatadas de acordo com o seguinte critério: itens que estão acima do $3^{\circ}$ Quartil são formatados com a cor azul; itens abaixo do primeiro quartil com a cor vermelha e itens intermediários com a cor preta. Esta formatação tem por objetivo chamar a atenção para os valores extremos e gerar as comparações.

Os gráficos apresentam de forma resumida os dados das tabelas de atributos e importância, mas que gera uma análise extremamente útil e poderosa. A divisão dos quadrantes no gráfico é feita pela mediana de cada uma das variáveis; assim pode-se observar que acima da linha horizontal temos metade dos pontos, e conseqüentemente abaixo a outra metade. Da mesma forma, à direita da linha vertical temos a metade dos pontos e à esquerda a outra metade. A maior atenção deve ser dada aos atributos situados no lado esquerdo superior do gráfico, pois são atributos considerados importantes, mas que receberam baixa nota média.

Todos os gráficos foram construídos com as mesmas escalas vertical e horizontal, de forma a poderem ser facilmente comparados. 
ATRIBUTOS POR SHOPPING: Novo Shopping

Freqüência das Notas

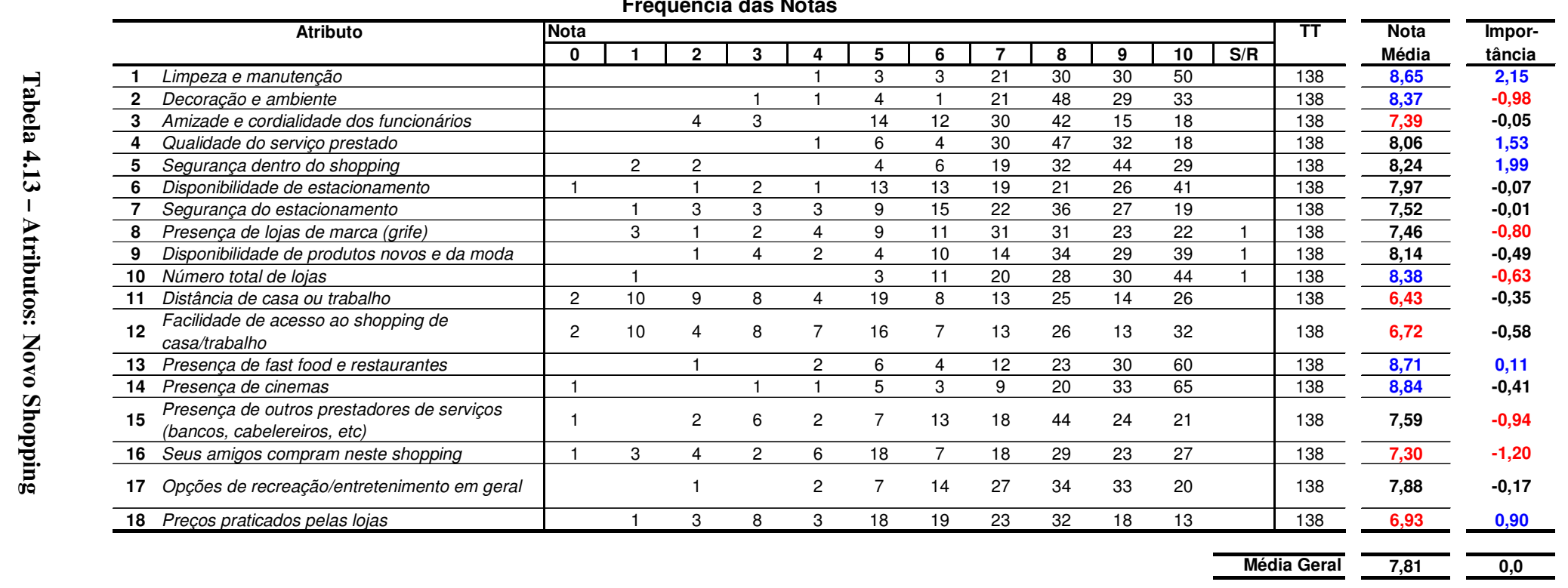




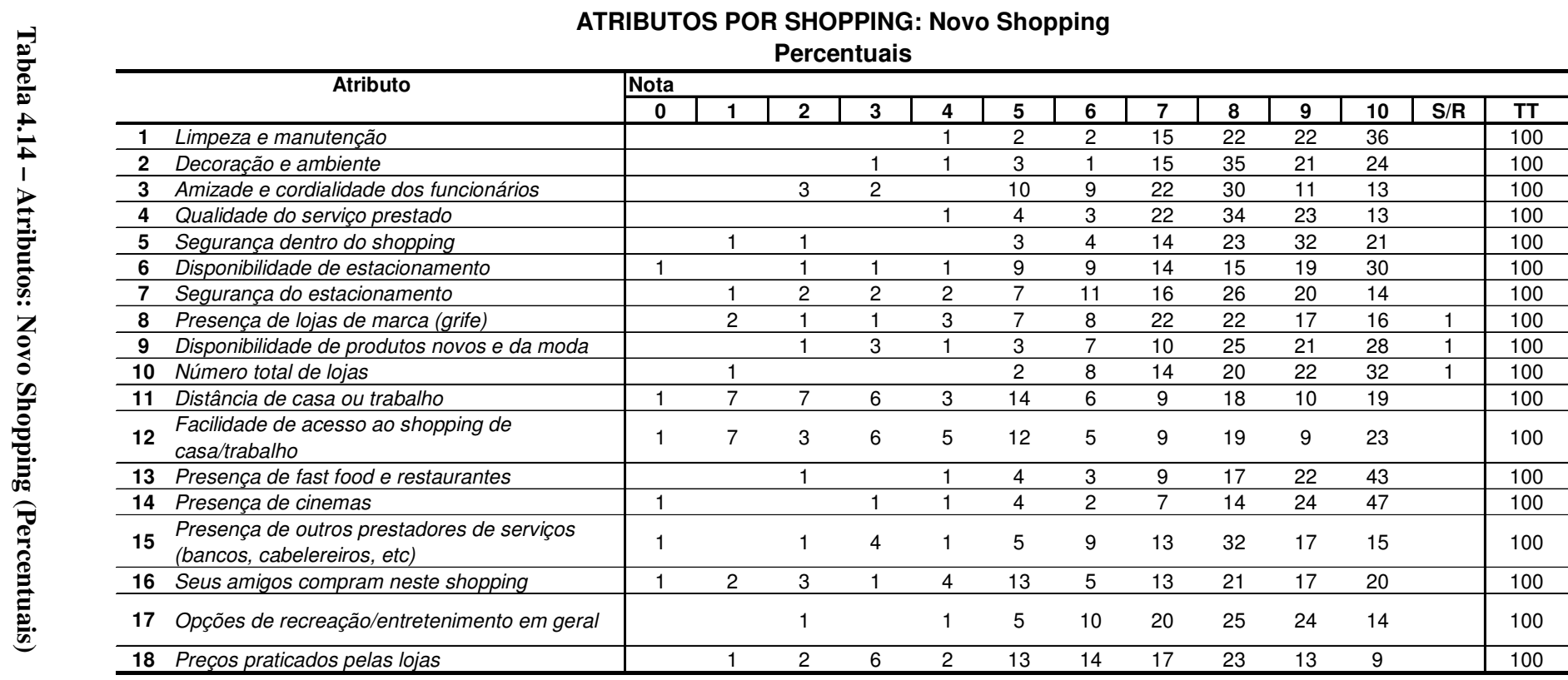


Novo Shopping - Alunos

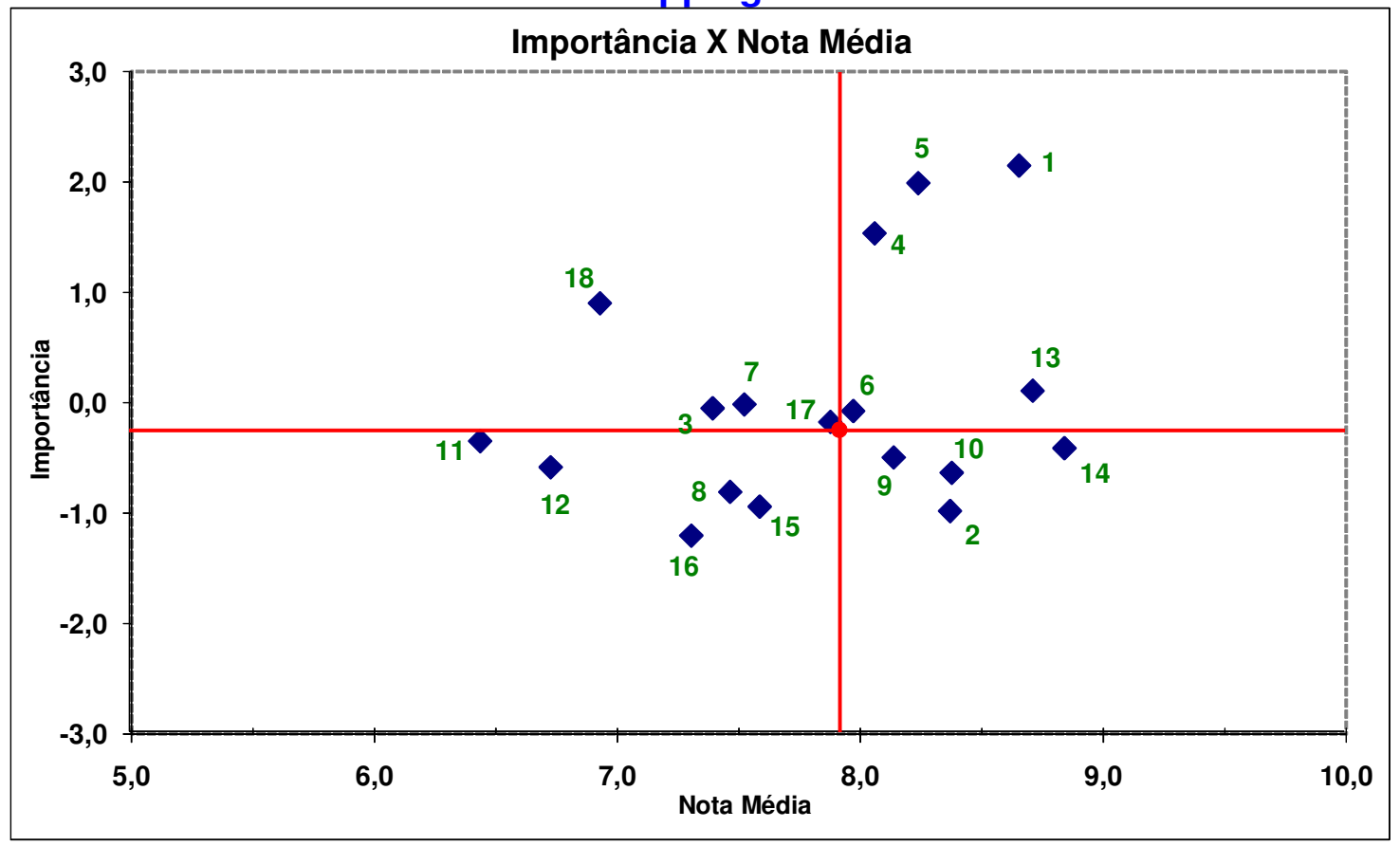

Gráfico 4.1 - Importância vs Nota Média (Novo Shopping)

Conforme se observa no gráfico (4.1) e nas tabelas (4.1.3) e (4.1.4) acima, os atributos que receberam a maior nota média e a maior importância, por parte dos alunos que escolheram (preferiram) o Novo Shopping foram, respectivamente:

1. Limpeza e manutenção (Atributo \# 1)

2. Segurança dentro do shopping (Atributo \# 5)

3. Qualidade do serviço prestado (Atributo \# 4)

4. Presença de fast food e restaurantes (Atributo \# 13) 
ATRIBUTOS POR SHOPPING: Ribeirão Shopping

Freqüência das Notas

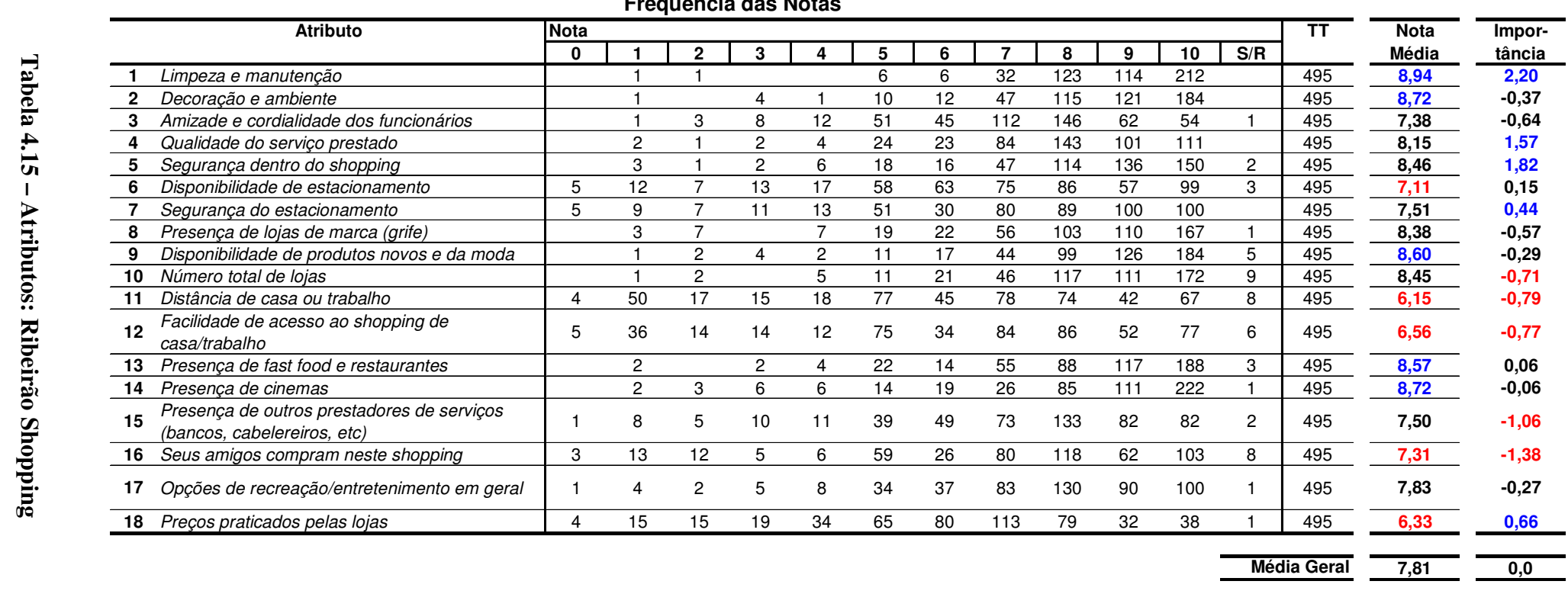


ATRIBUTOS POR SHOPPING: Ribeirão Shopping

Percentuais

\begin{tabular}{|c|c|c|c|c|c|c|c|c|c|c|c|c|c|}
\hline \multirow[t]{2}{*}{ Atributo } & \multicolumn{13}{|l|}{ Nota } \\
\hline & 0 & 1 & 2 & 3 & 4 & 5 & 6 & 7 & 8 & 9 & 10 & $\mathbf{S} / \mathbf{R}$ & TT \\
\hline 1 Limpeza e manutenção & & 0 & 0 & & & 1 & 1 & 6 & 25 & 23 & 43 & & 100 \\
\hline 2 Decoração e ambiente & & 0 & & 1 & 0 & 2 & 2 & 9 & 23 & 24 & 37 & & 100 \\
\hline 3 Amizade e cordialidade dos funcionários & & 0 & 1 & 2 & 2 & 10 & 9 & 23 & 29 & 13 & 11 & 0 & 100 \\
\hline $4 \quad$ Qualidade do serviço prestado & & 0 & 0 & 0 & 1 & 5 & 5 & 17 & 29 & 20 & 22 & & 100 \\
\hline $\begin{array}{ll}5 & \text { Segurança dentro do shopping }\end{array}$ & & 1 & 0 & 0 & 1 & 4 & 3 & 9 & 23 & 27 & 30 & 0 & 100 \\
\hline 6 Disponibilidade de estacionamento & 1 & 2 & 1 & 3 & 3 & 12 & 13 & 15 & 17 & 12 & 20 & 1 & 100 \\
\hline 7 Segurança do estacionamento & 1 & 2 & 1 & 2 & 3 & 10 & 6 & 16 & 18 & 20 & 20 & & 100 \\
\hline 8 Presença de lojas de marca (grife) & & 1 & 1 & & 1 & 4 & 4 & 11 & 21 & 22 & 34 & 0 & 100 \\
\hline 9 Disponibilidade de produtos novos e da moda & & 0 & 0 & 1 & 0 & 2 & 3 & 9 & 20 & 25 & 37 & 1 & 100 \\
\hline 10 Número total de lojas & & 0 & 0 & & 1 & 2 & 4 & 9 & 24 & 22 & 35 & 2 & 100 \\
\hline 11 Distância de casa ou trabalho & 1 & 10 & 3 & 3 & 4 & 16 & 9 & 16 & 15 & 8 & 14 & 2 & 100 \\
\hline $\begin{array}{l}12 \text { Facilidade de acesso ao shopping de } \\
\text { casa/trabalho }\end{array}$ & 1 & 7 & 3 & 3 & 2 & 15 & 7 & 17 & 17 & 11 & 16 & 1 & 100 \\
\hline 13 Presença de fast food e restaurantes & & 0 & & 0 & 1 & 4 & 3 & 11 & 18 & 24 & 38 & 1 & 100 \\
\hline 14 Presença de cinemas & & 0 & 1 & 1 & 1 & 3 & 4 & 5 & 17 & 22 & 45 & 0 & 100 \\
\hline $\begin{array}{l}15 \text { Presença de outros prestadores de serviços } \\
\text { (bancos, cabelereiros, etc) }\end{array}$ & 0 & 2 & 1 & 2 & 2 & 8 & 10 & 15 & 27 & 17 & 17 & 0 & 100 \\
\hline 16 Seus amigos compram neste shopping & 1 & 3 & 2 & 1 & 1 & 12 & 5 & 16 & 24 & 13 & 21 & 2 & 100 \\
\hline 17 Opções de recreação/entretenimento em geral & 0 & 1 & 0 & 1 & 2 & 7 & 7 & 17 & 26 & 18 & 20 & 0 & 100 \\
\hline 18 Preços praticados pelas lojas & 1 & 3 & 3 & 4 & 7 & 13 & 16 & 23 & 16 & 6 & 8 & 0 & 100 \\
\hline
\end{tabular}


Ribeirão Shopping - Alunos

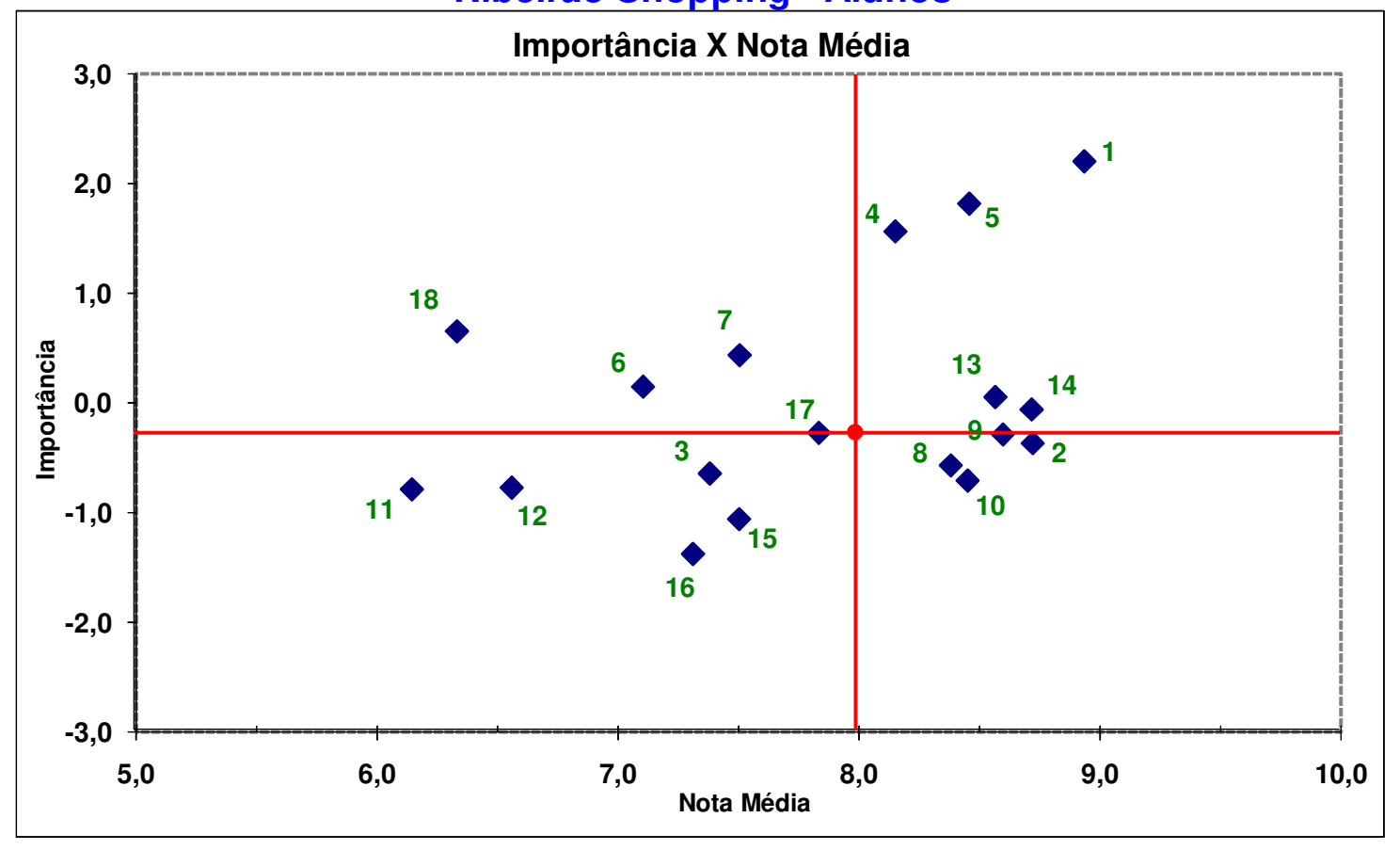

Gráfico 4.2 - Importância vs Nota Média (Ribeirão Shopping)

Conforme se observa no gráfico (4.2) e nas tabelas (4.1.5) e (4.1.6) acima, os atributos que receberam a maior nota média e a maior importância, por parte dos alunos que escolheram (preferiram) o Ribeirão Shopping foram, respectivamente:

1. Limpeza e manutenção (Atributo \# 1)

2. Segurança dentro do shopping (Atributo \# 5)

3. Qualidade do serviço prestado (Atributo \# 4)

4. Presença de fast food e restaurantes (Atributo \# 13) 
ATRIBUTOS POR SHOPPING: Santa Úrsula Freqüência das Notas

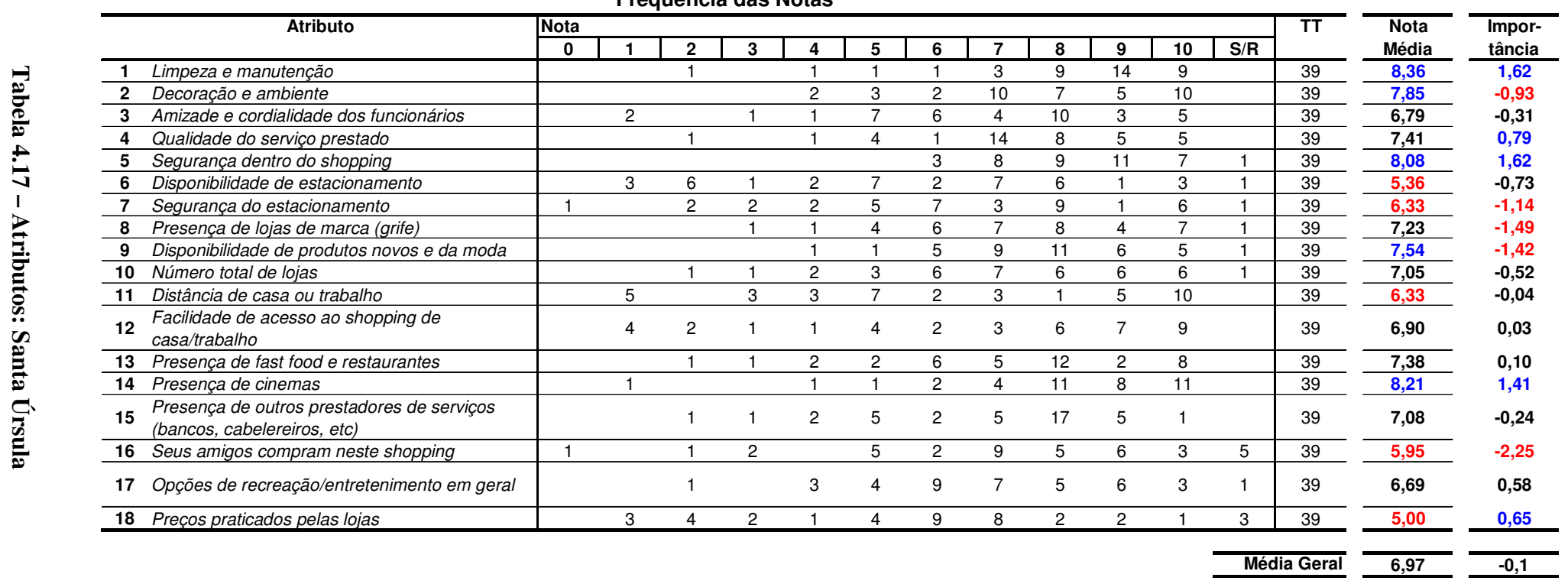


ATRIBUTOS POR SHOPPING: Santa Úrsula

Percentuais

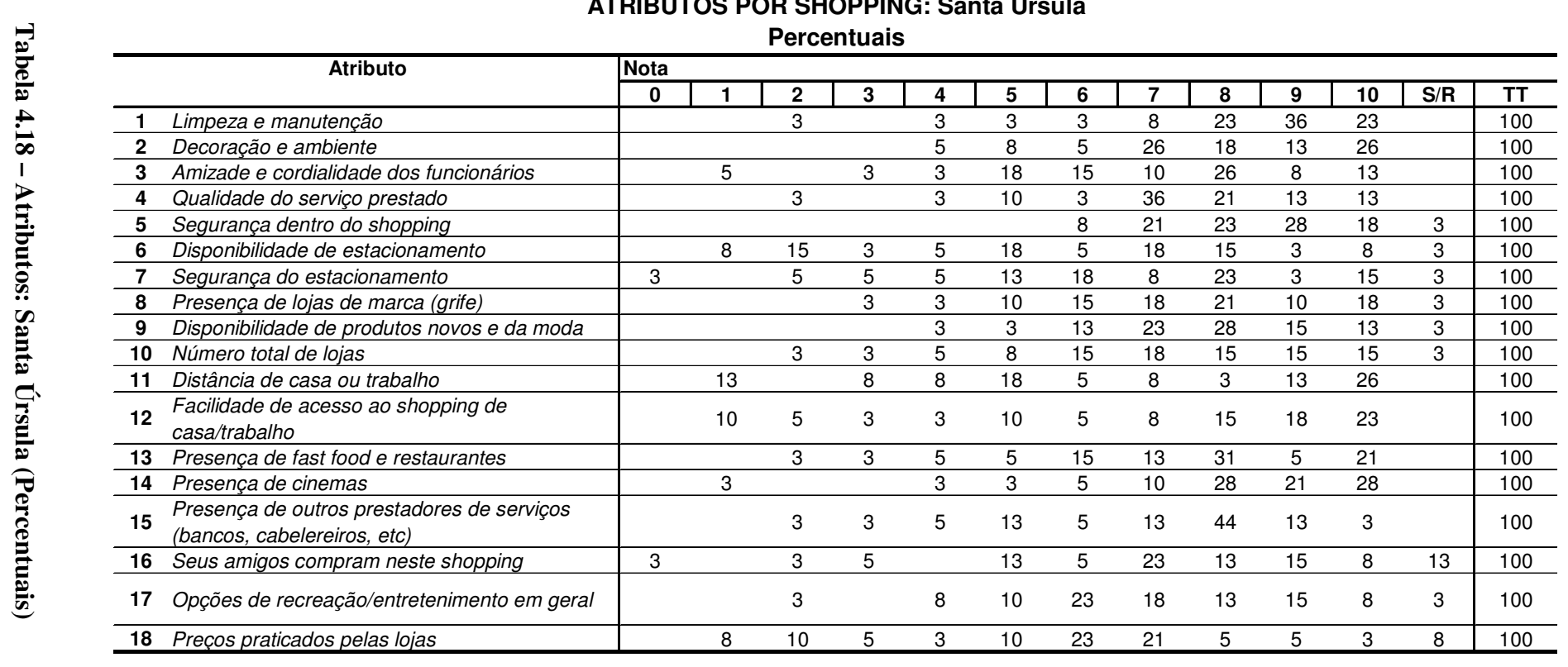




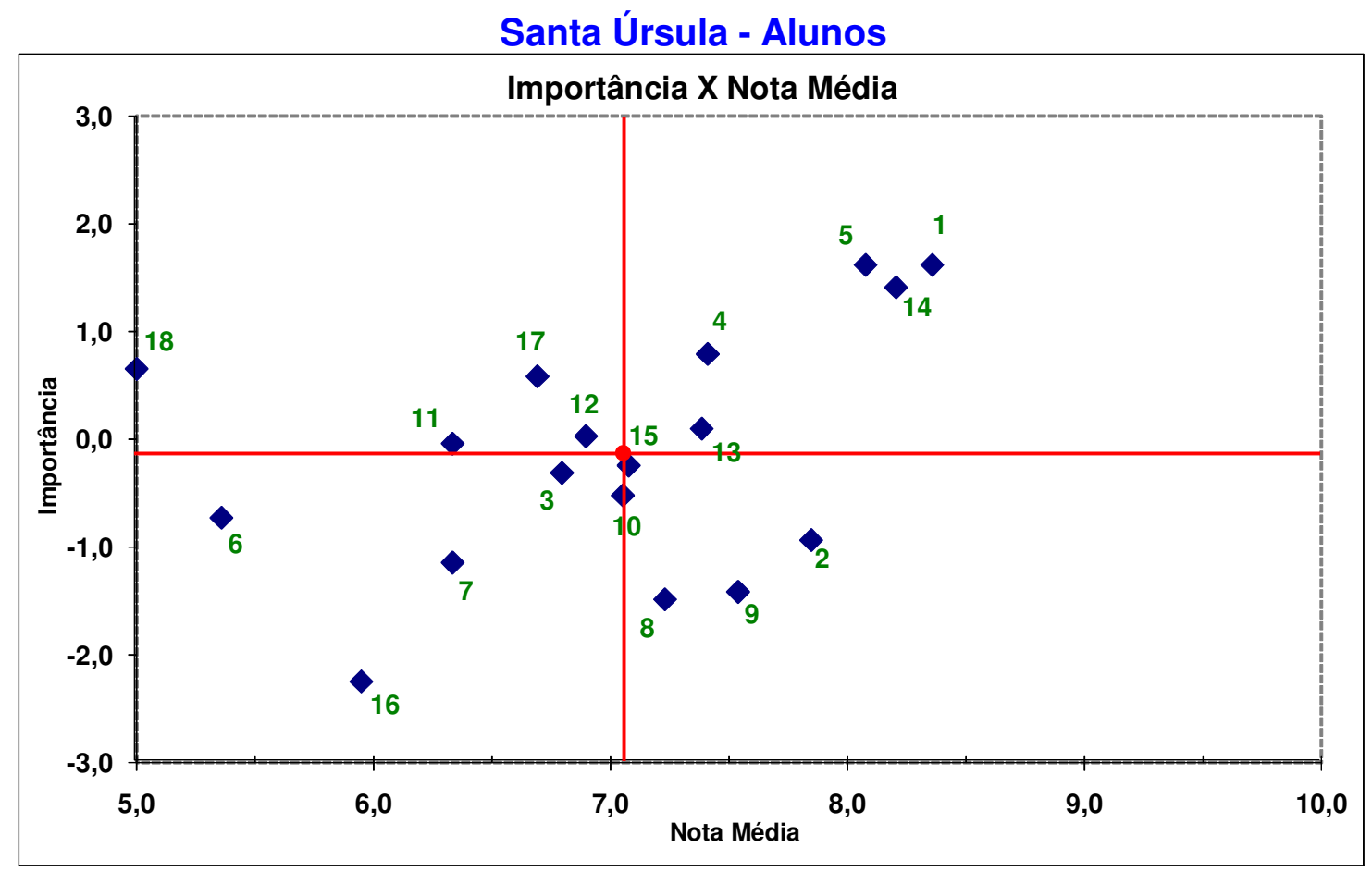

Gráfico 4.3 - Importância vs Nota Média (Santa Úrsula)

Conforme se observa no gráfico (4.3) e nas tabelas (4.1.7) e (4.1.8) acima, os atributos que receberam a maior nota média e a maior importância, por parte dos alunos que escolheram (preferiram) o Santa Úrsula foram, respectivamente:

1. Limpeza e manutenção (Atributo \# 1)

2. Segurança dentro do shopping (Atributo \# 5)

3. Presença de cinemas (Atributo \# 14)

4. Qualidade do serviço prestado (Atributo \# 4) 
ATRIBUTOS POR SHOPPING: Respostas dos Gestores - Novo Shopping

Freqüência das Notas

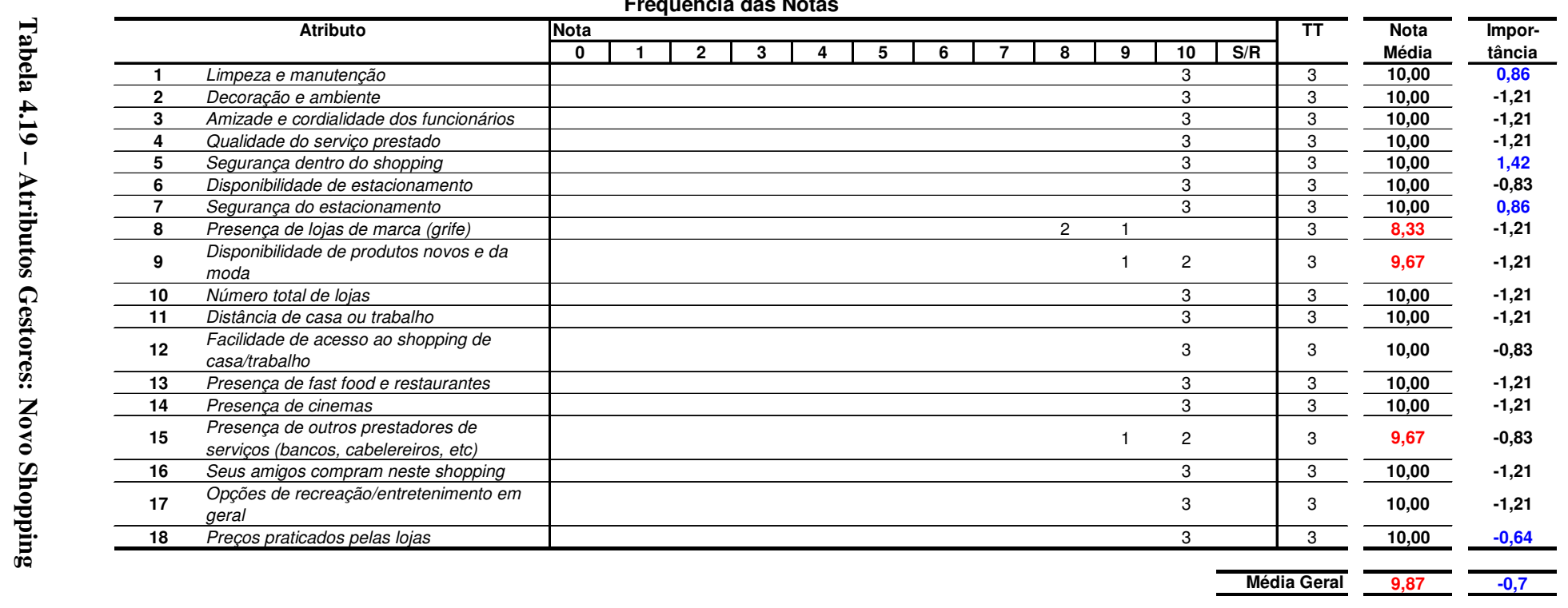


ATRIBUTOS POR SHOPPING: Respostas dos Gestores - Novo Shopping Percentuais

\begin{tabular}{|c|c|c|c|c|c|c|c|c|c|c|c|c|c|}
\hline \multirow{2}{*}{\multicolumn{2}{|c|}{ Atributo }} & \multicolumn{12}{|l|}{ Nota } \\
\hline & & 0 & 1 & 2 & 3 & 4 & 5 & 6 & 7 & 8 & 9 & $\mathbf{S} / \mathbf{R}$ & TT \\
\hline 1 & Limpeza e manutenção & & & & & & & & & & & 100 & 100 \\
\hline 2 & Decoração e ambiente & & & & & & & & & & & 100 & 100 \\
\hline 3 & Amizade e cordialidade dos funcionários & & & & & & & & & & & 100 & 100 \\
\hline 4 & Qualidade do serviço prestado & & & & & & & & & & & 100 & 100 \\
\hline 5 & Segurança dentro do shopping & & & & & & & & & & & 100 & 100 \\
\hline 6 & Disponibilidade de estacionamento & & & & & & & & & & & 100 & 100 \\
\hline 7 & Segurança do estacionamento & & & & & & & & & & & 100 & 100 \\
\hline 8 & Presença de lojas de marca (grife) & & & & & & & & & 67 & 33 & & 100 \\
\hline 9 & $\begin{array}{l}\text { Disponibilidade de produtos novos e da } \\
\text { moda }\end{array}$ & & & & & & & & & & 33 & 67 & 100 \\
\hline 10 & Número total de lojas & & & & & & & & & & & 100 & 100 \\
\hline 11 & Distância de casa ou trabalho & & & & & & & & & & & 100 & 100 \\
\hline 12 & $\begin{array}{l}\text { Facilidade de acesso ao shopping de } \\
\text { casa/trabalho }\end{array}$ & & & & & & & & & & & 100 & 100 \\
\hline 13 & Presença de fast food e restaurantes & & & & & & & & & & & 100 & 100 \\
\hline 14 & Presença de cinemas & & & & & & & & & & & 100 & 100 \\
\hline 15 & $\begin{array}{l}\text { Presença de outros prestadores de } \\
\text { serviços (bancos, cabelereiros, etc) }\end{array}$ & & & & & & & & & & 33 & 67 & 100 \\
\hline 16 & Seus amigos compram neste shopping & & & & & & & & & & & 100 & 100 \\
\hline 17 & $\begin{array}{l}\text { Opções de recreação/entretenimento em } \\
\text { geral }\end{array}$ & & & & & & & & & & & 100 & 100 \\
\hline 18 & Preços praticados pelas lojas & & & & & & & & & & & 100 & 100 \\
\hline
\end{tabular}


Novo Shopping - Gestores

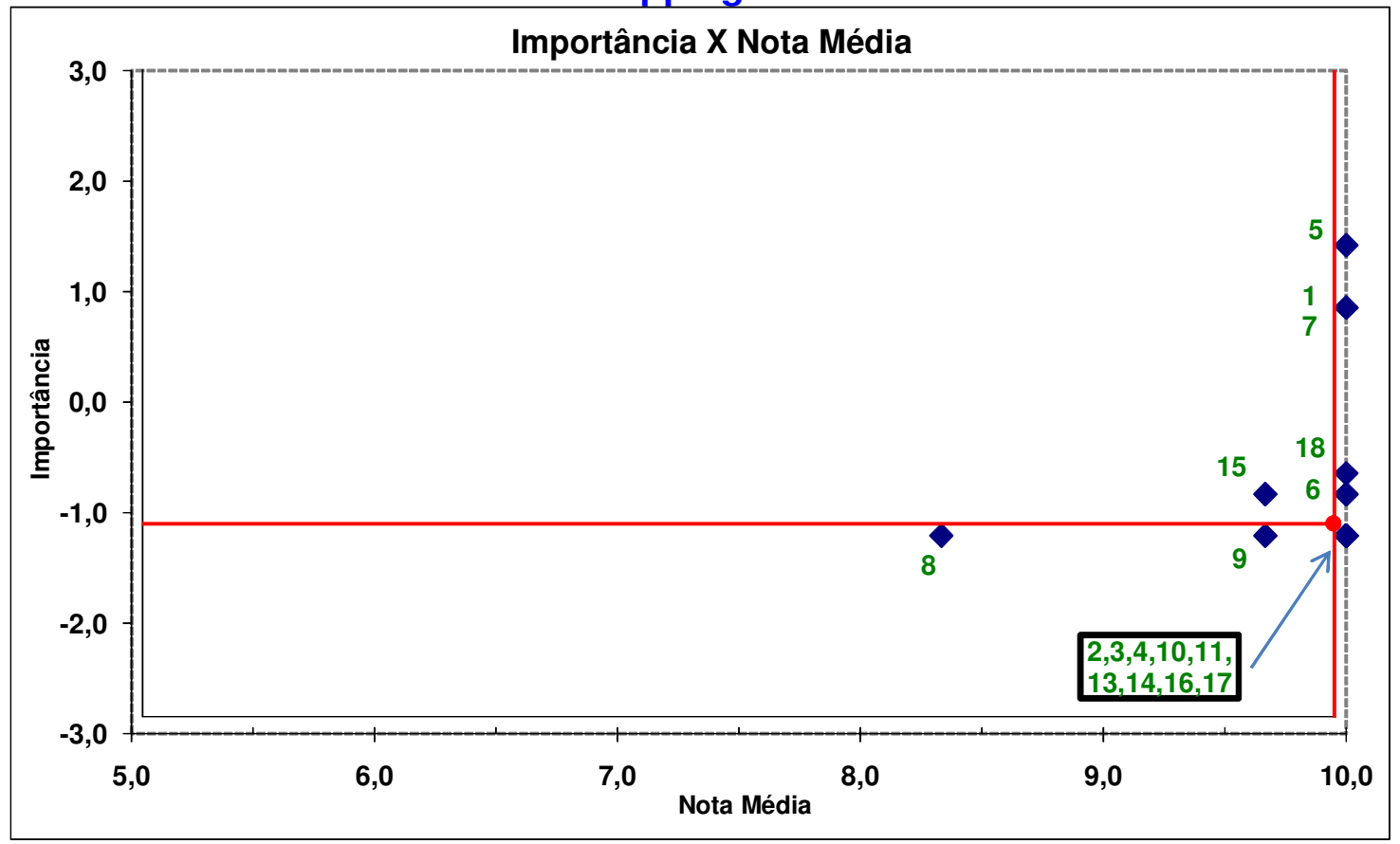

Gráfico 4.4 - Importância vs Nota Média (Gestores Novo Shopping)

Conforme se observa no gráfico (4.4) e nas tabelas (4.19) e (4.20) acima, os atributos que receberam a maior nota média e a maior importância, por parte dos gestores do Novo Shopping foram, respectivamente:

1. Segurança dentro do shopping (Atributo \# 5)

2. Limpeza e manutenção (Atributo \# 1) e Segurança do estacionamento (Atributo \#7)

3. Preços praticados pelas lojas (Atributo \# 18)

4. Disponibilidade de estacionamento (Atributo \# 6) 
ATRIBUTOS POR SHOPPING: Respostas dos Gestores - Ribeirão Shopping

Freqüência das Notas

\begin{tabular}{|c|c|c|c|c|c|c|c|c|c|c|c|c|c|c|c|c|}
\hline \multicolumn{15}{|c|}{ Freqüência das Notas } & \multirow{3}{*}{$\begin{array}{c}\text { Nota } \\
\text { Média }\end{array}$} & \multirow{3}{*}{$\begin{array}{l}\text { Impor- } \\
\text { tância }\end{array}$} \\
\hline \multirow{2}{*}{\multicolumn{2}{|c|}{ Atributo }} & Nota & & & & & & & & & & & & TT & & \\
\hline & & 0 & 1 & 2 & 3 & 4 & 5 & 6 & 7 & 8 & 9 & 10 & $\mathbf{S} / \mathbf{R}$ & & & \\
\hline 1 & Limpeza e manutenção & & & & & & & & & 1 & & 3 & & 4 & 9,50 & $-0,31$ \\
\hline 2 & Decoração e ambiente & & & & & & & & 1 & & & 3 & & 4 & 9,25 & $-1,17$ \\
\hline 3 & Amizade e cordialidade dos funcionários & & & & & & & & 1 & & 1 & 2 & & 4 & 9,00 & $-0,96$ \\
\hline 4 & Qualidade do serviço prestado & & & & & & & & & 1 & & 3 & & 4 & 9,50 & 1,41 \\
\hline 5 & Segurança dentro do shopping & & & & & & & & & & 1 & 3 & & 4 & 9,75 & 2,27 \\
\hline 6 & Disponibilidade de estacionamento & & & & & & & & & & 2 & 2 & & 4 & 9,50 & $-0,31$ \\
\hline 7 & Segurança do estacionamento & & & & & & & & & & 2 & 2 & & 4 & 9,50 & $-0,31$ \\
\hline 8 & Presença de lojas de marca (grife) & & & & & & & & & & 3 & 1 & & 4 & 9,25 & 0,33 \\
\hline 9 & $\begin{array}{l}\text { Disponibilidade de produtos novos e da } \\
\text { moda }\end{array}$ & & & & & & & & 1 & & & 3 & & 4 & 9,25 & $-0,74$ \\
\hline 10 & Número total de lojas & & & & & & & 1 & 1 & 2 & & & & 4 & 7,25 & $-0,96$ \\
\hline 11 & Distância de casa ou trabalho & & & & & & & 2 & & 1 & & 1 & & 4 & 7,50 & $-0,10$ \\
\hline 12 & $\begin{array}{l}\text { Facilidade de acesso ao shopping de } \\
\text { casa/trabalho }\end{array}$ & & & & & & & & 2 & 1 & & 1 & & 4 & 8,00 & $-0,31$ \\
\hline 13 & Presença de fast food e restaurantes & & & & & & 1 & & & 1 & 1 & 1 & & 4 & 8,00 & $-1,17$ \\
\hline 14 & Presença de cinemas & & & & & 1 & & & & 1 & & 2 & & 4 & 8,00 & $-1,17$ \\
\hline 15 & $\begin{array}{l}\text { Presença de outros prestadores de } \\
\text { serviços (bancos, cabelereiros, etc) }\end{array}$ & & & & & 1 & & & 1 & 2 & & & & 4 & 6,75 & $-1,17$ \\
\hline 16 & Seus amigos compram neste shopping & & & 1 & & & & & & 1 & & 2 & & 4 & 7,50 & $-1,17$ \\
\hline 17 & $\begin{array}{l}\text { Opções de recreação/entretenimento em } \\
\text { geral }\end{array}$ & & & & 1 & & & & & & 1 & 2 & & 4 & 8,00 & $-1,17$ \\
\hline 18 & Preços praticados pelas lojas & & & & & & & 2 & & 2 & & & & 4 & 7,00 & $-1,17$ \\
\hline & & & & & & & & & & & & & & Geral & 8,47 & $-0,5$ \\
\hline
\end{tabular}


ATRIBUTOS POR SHOPPING: Respostas dos Gestores - Ribeirão Shopping Percentuais

\begin{tabular}{|c|c|c|c|c|c|c|c|c|c|c|c|c|c|c|}
\hline \multirow{2}{*}{\multicolumn{2}{|c|}{ Atributo }} & \multicolumn{13}{|l|}{ Nota } \\
\hline & & 0 & 1 & 2 & 3 & 4 & 5 & 6 & 7 & 8 & 9 & 10 & $\mathbf{S} / \mathbf{R}$ & TT \\
\hline 1 & Limpeza e manutenção & & & & & & & & & 25 & & 75 & & 100 \\
\hline 2 & Decoração e ambiente & & & & & & & & 25 & & & 75 & & 100 \\
\hline 3 & Amizade e cordialidade dos funcionários & & & & & & & & 25 & & 25 & 50 & & 100 \\
\hline 4 & Qualidade do serviço prestado & & & & & & & & & 25 & & 75 & & 100 \\
\hline 5 & Segurança dentro do shopping & & & & & & & & & & 25 & 75 & & 100 \\
\hline 6 & Disponibilidade de estacionamento & & & & & & & & & & 50 & 50 & & 100 \\
\hline 7 & Segurança do estacionamento & & & & & & & & & & 50 & 50 & & 100 \\
\hline 8 & Presença de lojas de marca (grife) & & & & & & & & & & 75 & 25 & & 100 \\
\hline 9 & $\begin{array}{l}\text { Disponibilidade de produtos novos e da } \\
\text { moda }\end{array}$ & & & & & & & & 25 & & & 75 & & 100 \\
\hline 10 & Número total de lojas & & & & & & & 25 & 25 & 50 & & & & 100 \\
\hline 11 & Distância de casa ou trabalho & & & & & & & 50 & & 25 & & 25 & & 100 \\
\hline 12 & $\begin{array}{l}\text { Facilidade de acesso ao shopping de } \\
\text { casa/trabalho }\end{array}$ & & & & & & & & 50 & 25 & & 25 & & 100 \\
\hline 13 & Presença de fast food e restaurantes & & & & & & 25 & & & 25 & 25 & 25 & & 100 \\
\hline 14 & Presença de cinemas & & & & & 25 & & & & 25 & & 50 & & 100 \\
\hline 15 & $\begin{array}{l}\text { Presença de outros prestadores de } \\
\text { serviços (bancos, cabelereiros, etc) }\end{array}$ & & & & & 25 & & & 25 & 50 & & & & 100 \\
\hline 16 & Seus amigos compram neste shopping & & & 25 & & & & & & 25 & & 50 & & 100 \\
\hline 17 & $\begin{array}{l}\text { Opções de recreação/entretenimento em } \\
\text { geral }\end{array}$ & & & & 25 & & & & & & 25 & 50 & & 100 \\
\hline 18 & Preços praticados pelas lojas & & & & & & & 50 & & 50 & & & & 100 \\
\hline
\end{tabular}


Ribeirão Shopping - Gestores

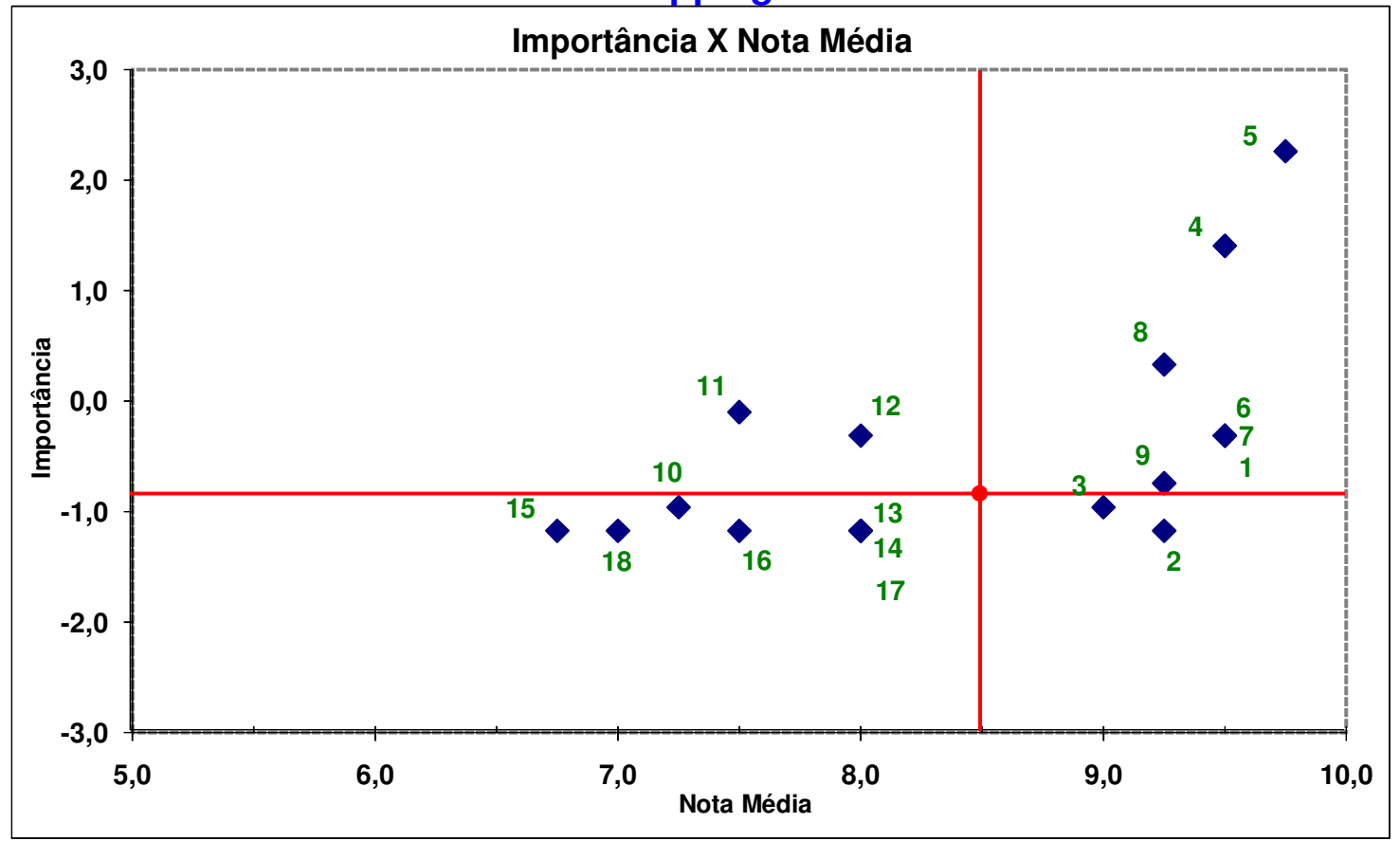

Gráfico 4.5 - Importância vs Nota Média (Gestores Ribeirão Shopping)

Conforme se observa no gráfico (4.5) e nas tabelas (4.21) e (4.22) acima, os atributos que receberam a maior nota média e a maior importância, por parte dos gestores do Ribeirão Shopping foram, respectivamente:

1. Segurança dentro do shopping (Atributo \# 5)

2. Qualidade do serviço prestado (Atributo \# 4)

3. Presença de lojas de marca (grife) (Atributo \# 8)

4. Disponibilidade de estacionamento (Atributo \# 6) e Segurança do estacionamento (Atributo \#7) 
ATRIBUTOS POR SHOPPING: Respostas dos Gestores - Santa Úrsula

Freqüência das Notas

\begin{tabular}{|c|c|c|c|c|c|c|c|c|c|c|c|c|c|c|c|c|}
\hline \multirow{2}{*}{\multicolumn{2}{|c|}{ Atributo }} & \multicolumn{12}{|l|}{ Nota } & \multirow[t]{2}{*}{ TT } & \multirow{2}{*}{$\begin{array}{l}\text { Nota } \\
\text { Média }\end{array}$} & \multirow{2}{*}{$\begin{array}{l}\text { Impor- } \\
\text { tância }\end{array}$} \\
\hline & & 0 & 1 & 2 & 3 & 4 & 5 & 6 & 7 & 8 & 9 & 10 & $\mathbf{S} / \mathbf{R}$ & & & \\
\hline 1 & Limpeza e manutenção & & & & & & & $\frac{5}{2}$ & & 2 & $\frac{5}{1}$ & $\frac{1}{1}$ & & 6 & 7,83 & 0,80 \\
\hline 2 & Decoração e ambiente & & & & & & & 1 & 2 & & 2 & 1 & & 6 & 8,00 & $-0,95$ \\
\hline 3 & Amizade e cordialidade dos funcionários & & & & 1 & & & & 1 & 1 & 1 & 2 & & 6 & 7,83 & $-1,12$ \\
\hline 4 & Qualidade do serviço prestado & & & & & & & 1 & 1 & 1 & 1 & 2 & & 6 & 8,33 & 1,67 \\
\hline 5 & Segurança dentro do shopping & & & & & & & & 1 & 2 & 1 & 2 & & 6 & 8,67 & 1,85 \\
\hline 6 & Disponibilidade de estacionamento & & & & & & & & 2 & 1 & 1 & 2 & & 6 & 8,50 & $-0,60$ \\
\hline $\begin{array}{ll}7 & \\
\end{array}$ & Segurança do estacionamento & & & & & & & & 1 & 2 & & 3 & & 6 & 8,83 & $-0,77$ \\
\hline 8 & Presença de lojas de marca (grife) & & & & & & & & 1 & 2 & 2 & 1 & & 6 & 8,50 & 1,50 \\
\hline 9 & $\begin{array}{l}\text { Disponibilidade de produtos novos e da } \\
\text { moda }\end{array}$ & & & & & & & & 1 & 1 & 2 & 2 & & 6 & 8,83 & $-0,25$ \\
\hline 10 & Número total de lojas & & & & & & & 1 & 2 & & 3 & & & 6 & 7,83 & $-0,42$ \\
\hline 11 & Distância de casa ou trabalho & & & & & & 1 & & & & 2 & 3 & & 6 & 8,83 & $-1,12$ \\
\hline 12 & $\begin{array}{l}\text { Facilidade de acesso ao shopping de } \\
\text { casa/trabalho }\end{array}$ & & & & & & & & 1 & 1 & 1 & 3 & & 6 & 9,00 & $-0,25$ \\
\hline 13 & Presença de fast food e restaurantes & & & & & & & 1 & 2 & 2 & & 1 & & 6 & 7,67 & $-0,60$ \\
\hline 14 & Presença de cinemas & & & & & & & & & 2 & 1 & 3 & & 6 & 9,17 & $-1,12$ \\
\hline 15 & $\begin{array}{l}\text { Presença de outros prestadores de } \\
\text { servicos (bancos, cabelereiros, etc) }\end{array}$ & & & & & & & & 1 & 1 & & 4 & & 6 & 9,17 & $-0,77$ \\
\hline 16 & Seus amigos compram neste shopping & & & & & 1 & & & 1 & 2 & 1 & 1 & & 6 & 7,67 & $-1,12$ \\
\hline 17 & $\begin{array}{l}\text { Opções de recreação/entretenimento em } \\
\text { geral }\end{array}$ & & & & & & 1 & & 2 & & 1 & 2 & & 6 & 8,00 & $-0,42$ \\
\hline 18 & Preços praticados pelas lojas & & & & & 1 & & & & 3 & 1 & 1 & & 6 & 7,83 & $-0,77$ \\
\hline & & & & & & & & & & & & & & Gera & 8,36 & $-0,2$ \\
\hline
\end{tabular}


ATRIBUTOS POR SHOPPING: Respostas dos Gestores - Santa Úrsula

Percentuais

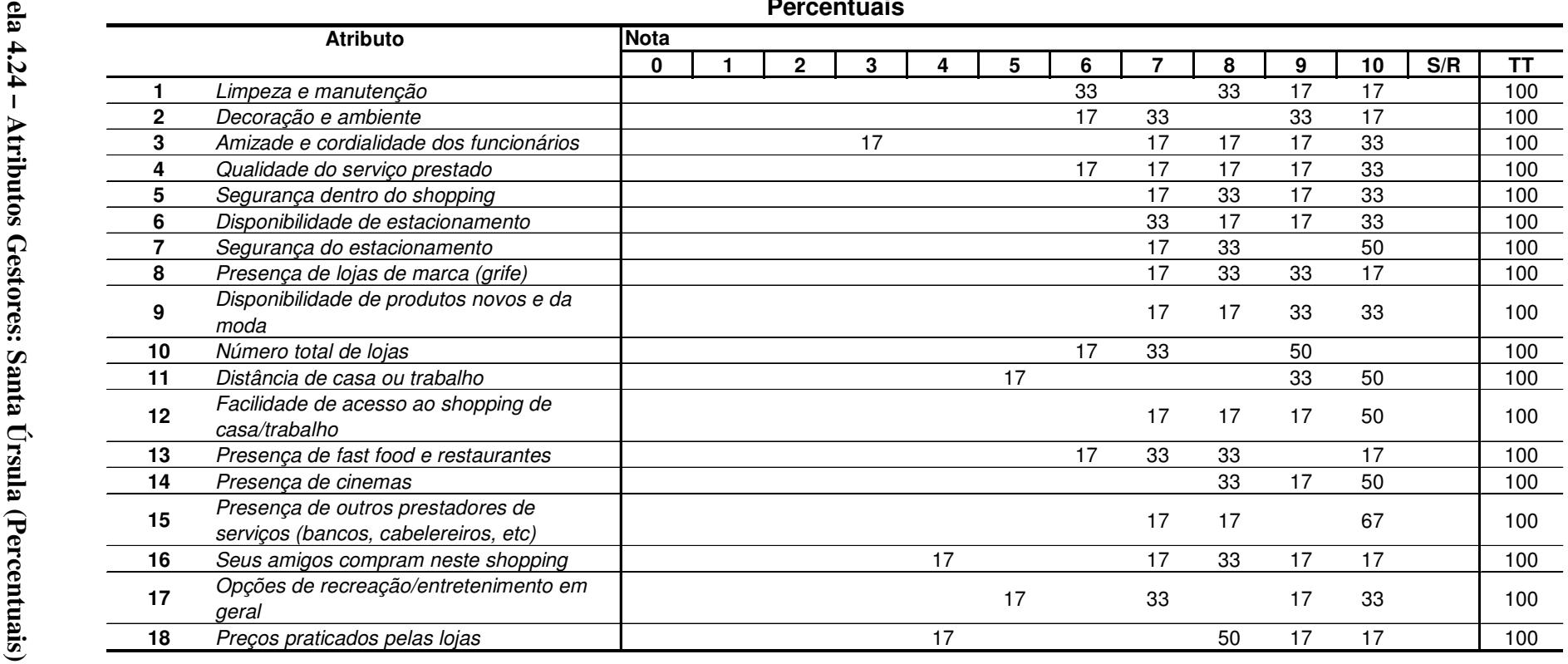


Santa Úrsula - Gestores

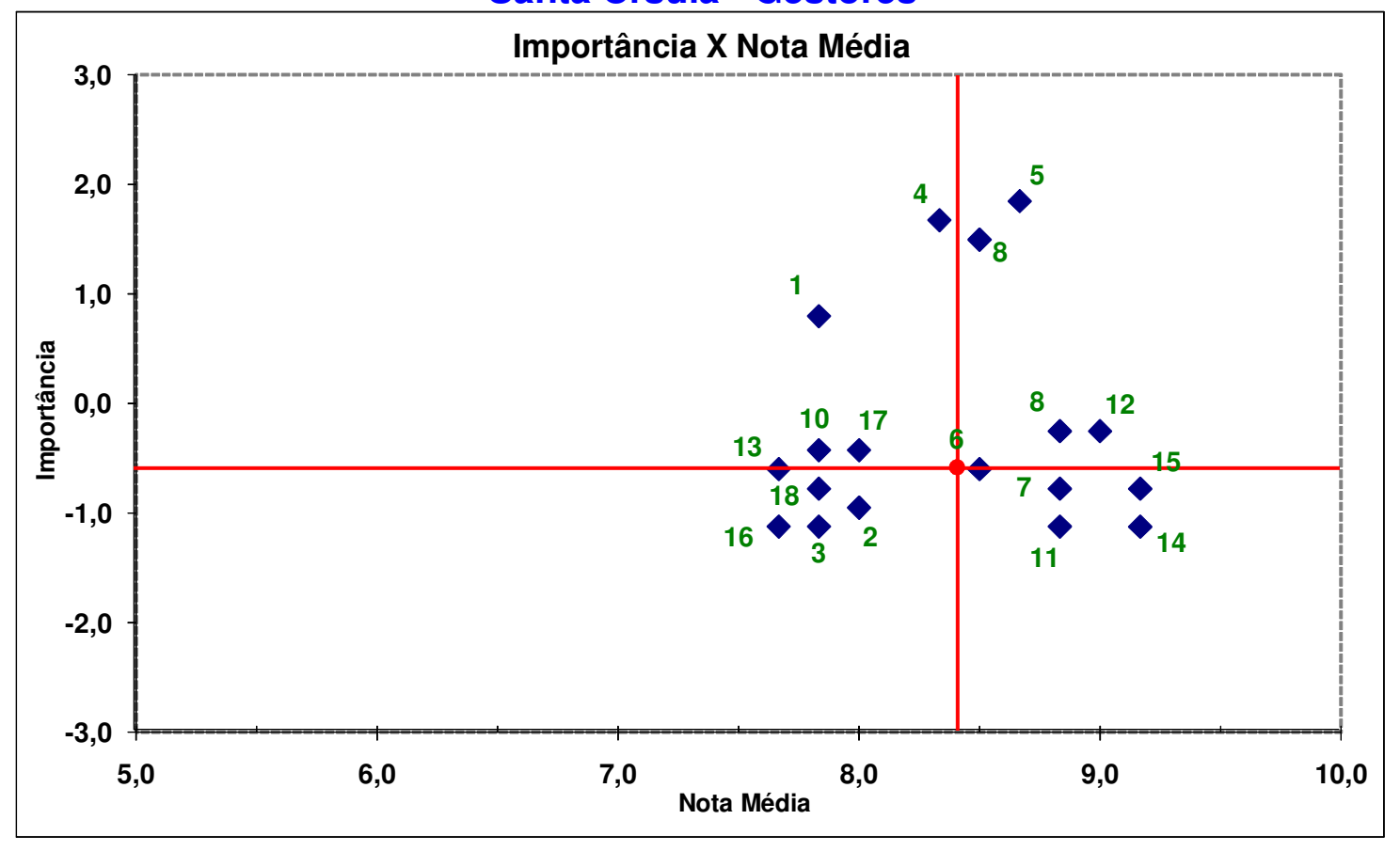

Gráfico 4.6 - Importância vs Nota Média (Gestores Santa Úrsula)

Conforme se observa no gráfico (4.6) e nas tabelas (4.23) e (4.24) acima, os atributos que receberam a maior nota média e a maior importância, por parte dos gestores do Shopping Santa Úrsula foram, respectivamente:

1. Segurança dentro do shopping (Atributo \# 5)

2. Qualidade do serviço prestado (Atributo \# 4)

3. Presença de lojas de marca (grife) (Atributo \# 8)

4. Limpeza e manutenção (Atributo \# 1) 
4.4.4 TABULAÇÃO DAS PERGUNTAS DAS ENTREVISTAS COM OS GESTORES

\begin{tabular}{|c|c|c|c|c|c|}
\hline & & Perguntas & $\begin{array}{l}\text { Novo } \\
\text { Shopping }\end{array}$ & $\begin{array}{l}\text { Ribeirão } \\
\text { Shopping }\end{array}$ & Santa Úrsula \\
\hline \multirow{3}{*}{ 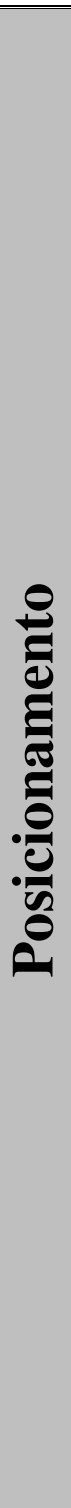 } & 1 & $\begin{array}{l}\text { Este shopp. } \\
\text { pertence a algum } \\
\text { grupo? }\end{array}$ & Grupo Savoy & Grupo MultiPlan & $\begin{array}{l}\text { Grupo Almeida } \\
\mathrm{Jr}\end{array}$ \\
\hline & 2 & $\begin{array}{l}\text { Qual é a liberdade } \\
\text { que o gestor tem } \\
\text { para tomar } \\
\text { decisões? }\end{array}$ & $\begin{array}{l}\text { Relativa } \\
\text { liberdade. }\end{array}$ & $\begin{array}{l}\text { Relativa autonomia, } \\
\text { com liberdade de } \\
\text { fazer ações dentro de } \\
\text { um orçamento pré - } \\
\text { estabelecido. }\end{array}$ & $\begin{array}{l}\text { Relativa, pois as } \\
\text { decisões são } \\
\text { centralizadas na } \\
\text { administradora, } \\
\text { porém com } \\
\text { participação dos } \\
\text { gestores. }\end{array}$ \\
\hline & 3 & $\begin{array}{l}\text { Qual é o } \\
\text { posicionamento } \\
\text { declarado deste } \\
\text { shopp.? Qual é o } \\
\text { posicionamento que } \\
\text { estão trabalhando } \\
\text { hoje? }\end{array}$ & $\begin{array}{l}\text { Atender todas as } \\
\text { necessidades dos } \\
\text { cliente. }\end{array}$ & $\begin{array}{l}\text { Um shopping para a } \\
\text { Família, sem } \\
\text { distinção de classes } \\
\text { sociais e idade. }\end{array}$ & $\begin{array}{l}\text { O mais elegante, } \\
\text { charmoso e } \\
\text { moderno, no } \\
\text { coração da cidade. }\end{array}$ \\
\hline
\end{tabular}




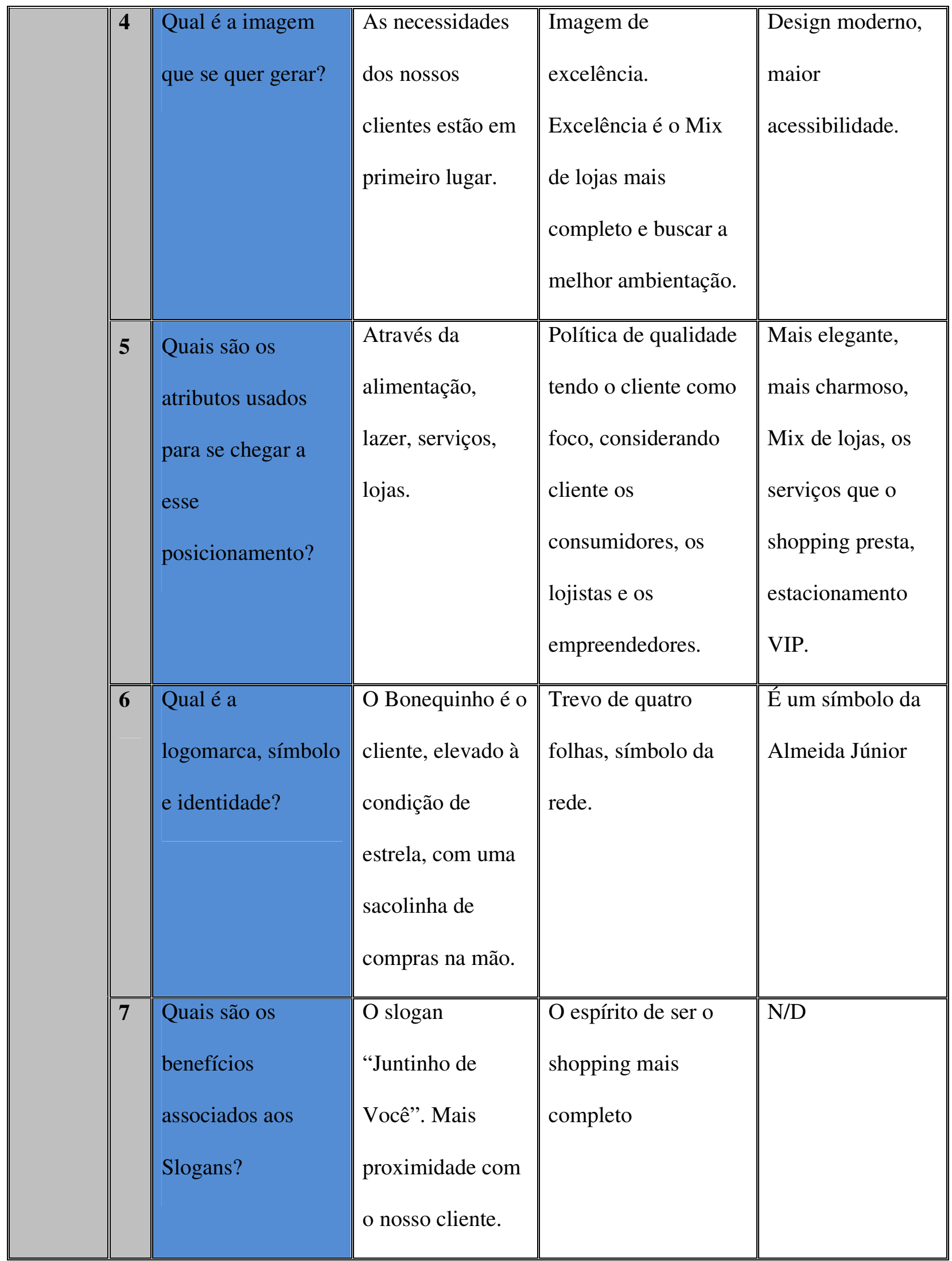




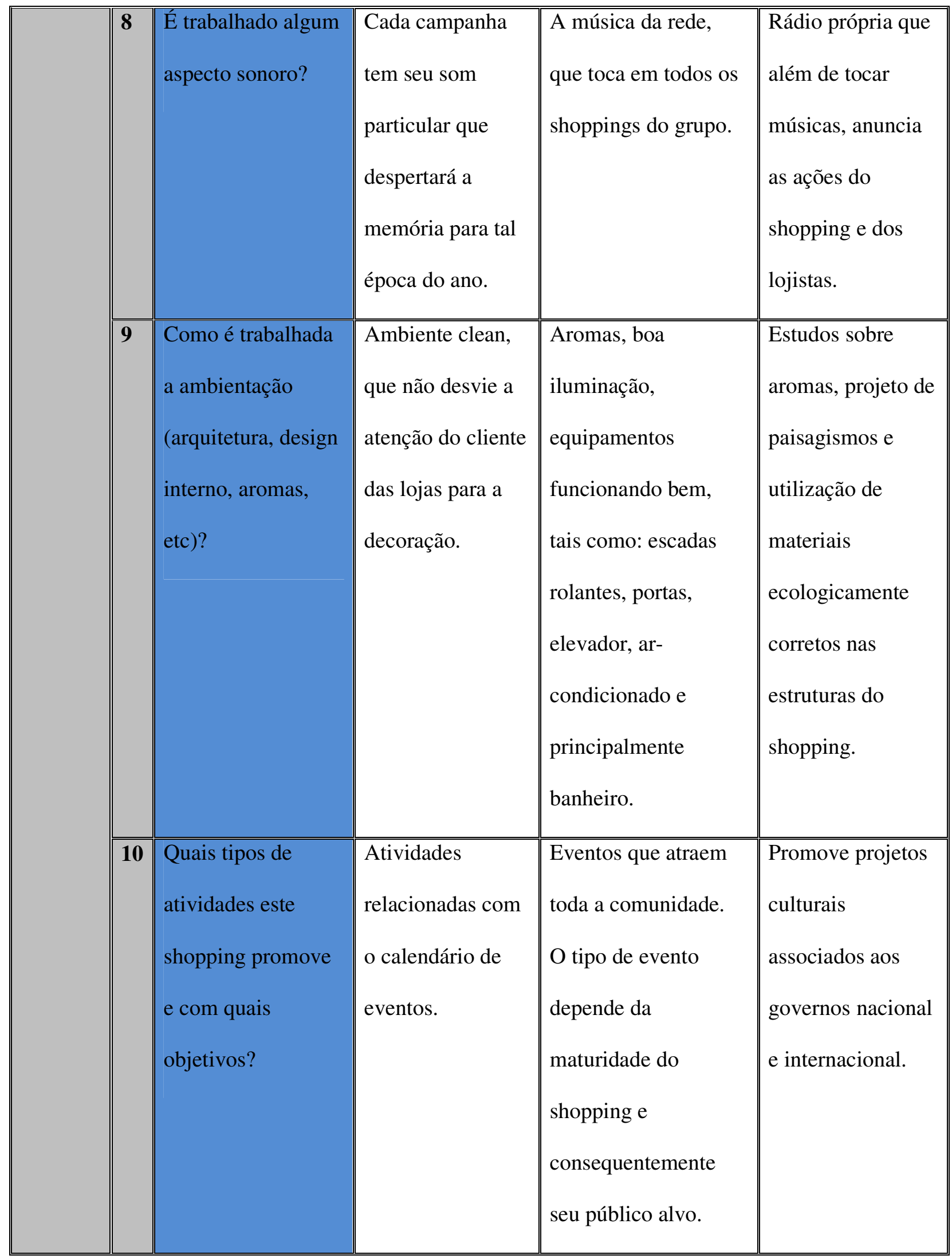




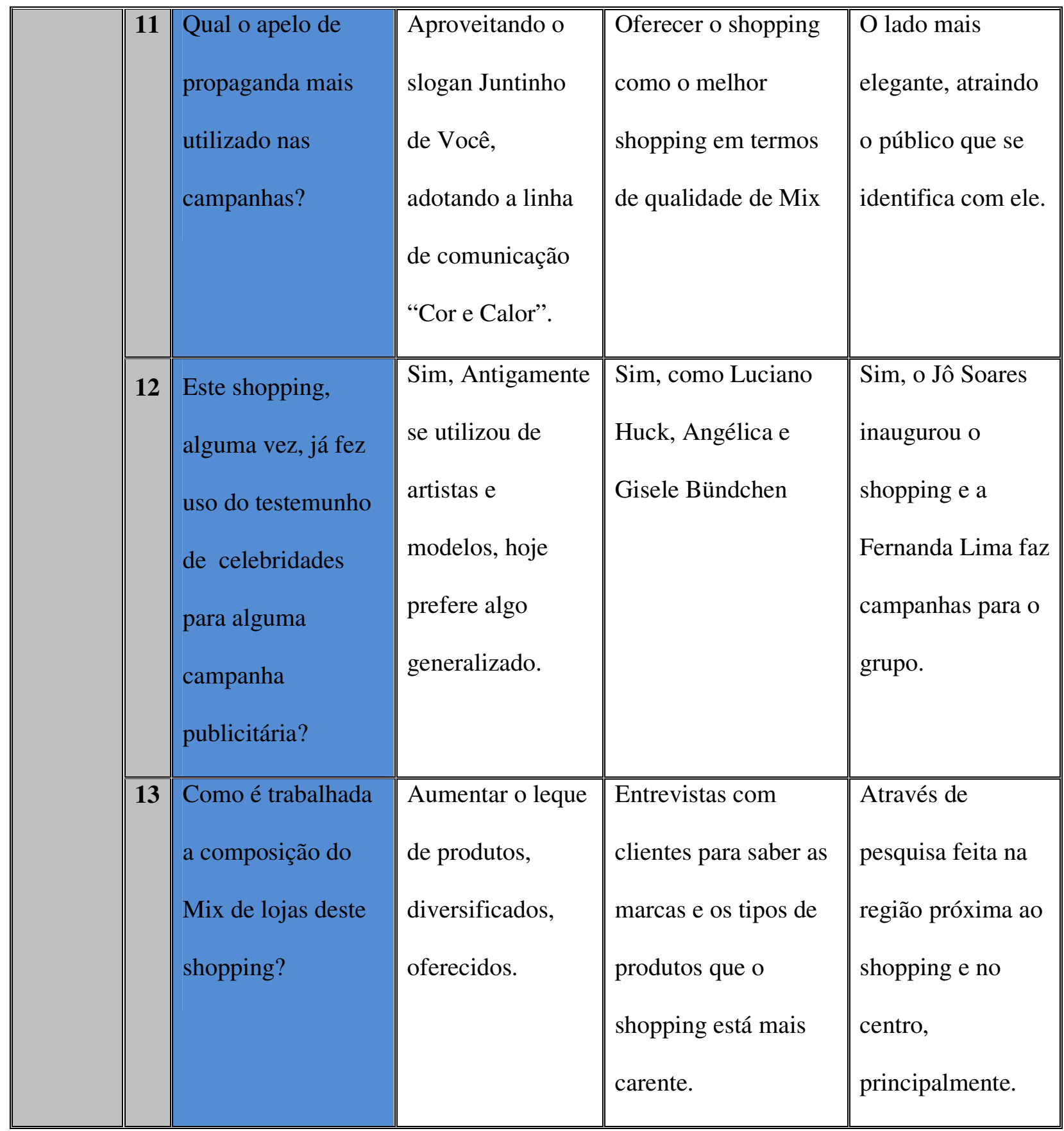




\begin{tabular}{|c|c|c|c|c|c|}
\hline & 14 & $\begin{array}{l}\text { Qual o papel das } \\
\text { lojas-âncora e das } \\
\text { demais lojas dentro } \\
\text { deste shopping? } \\
\text { Como foram } \\
\text { escolhidas? }\end{array}$ & $\begin{array}{l}\text { São atrativas de } \\
\text { publico. Foram } \\
\text { escolhidas de } \\
\text { forma que } \\
\text { atendam todas as } \\
\text { necessidades dos } \\
\text { consumidores. }\end{array}$ & $\begin{array}{l}\text { Apresentam } \\
\text { características } \\
\text { similares aos } \\
\text { interesses do } \\
\text { shopping. }\end{array}$ & $\begin{array}{l}\text { Atrair o público } \\
\text { para o local onde } \\
\text { ela se encontram. }\end{array}$ \\
\hline & 15 & $\begin{array}{l}\text { Qual o papel } \\
\text { estratégico a ser } \\
\text { cumprido por elas? }\end{array}$ & Atrair o público. & $\begin{array}{l}\text { Atrair o público para } \\
\text { o shopping }\end{array}$ & $\begin{array}{l}\text { Composição do } \\
\text { Mix }\end{array}$ \\
\hline & 16 & $\begin{array}{l}\text { Quais esforços de } \\
\text { comunicação são } \\
\text { utilizados? }\end{array}$ & $\begin{array}{l}\text { Rádio, televisão, } \\
\text { out-door, mídia } \\
\text { impressa e } \\
\text { internet. }\end{array}$ & $\begin{array}{l}\text { Rádio, outdoor, TV, } \\
\text { usa jornal, revista, } \\
\text { assessoria de } \\
\text { imprensa, banco de } \\
\text { dados se e marketing } \\
\text { direto. }\end{array}$ & $\begin{array}{l}\text { Radio, Tv e } \\
\text { Internet. }\end{array}$ \\
\hline हृ & 17 & $\begin{array}{l}\text { Quais os } \\
\text { procedimentos para } \\
\text { atribuir nomes às } \\
\text { promoções do } \\
\text { shopping? Existe } \\
\text { relação com o } \\
\text { posicionamento? }\end{array}$ & $\begin{array}{l}\text { A agência de } \\
\text { publicidade que } \\
\text { propõe os } \\
\text { projetos, sempre } \\
\text { respeitando o } \\
\text { slogan Juntinho } \\
\text { de Você. }\end{array}$ & $\begin{array}{l}\text { Depende de cada } \\
\text { caso, mas está } \\
\text { relacionada com o } \\
\text { posicionamento. }\end{array}$ & $\begin{array}{l}\text { Uma agencia que } \\
\text { promove as } \\
\text { campanhas de } \\
\text { acordo com o } \\
\text { posicionamento } \\
\text { do shopping. }\end{array}$ \\
\hline
\end{tabular}




\begin{tabular}{|c|c|c|c|c|}
\hline 18 & $\begin{array}{l}\text { Como se escolhem } \\
\text { os nomes das } \\
\text { promoções? }\end{array}$ & $\begin{array}{l}\text { Um comitê no } \\
\text { departamento de } \\
\text { marketing que } \\
\text { aprova ou } \\
\text { desaprova às } \\
\text { campanhas. }\end{array}$ & $\begin{array}{l}\text { Depende de cada } \\
\text { caso. A idéia é } \\
\text { sempre causar o } \\
\text { maior impacto. }\end{array}$ & $\begin{array}{l}\text { A agência elabora } \\
\text { três linhas de } \\
\text { promoção, para } \\
\text { que seja escolhida } \\
\text { uma. }\end{array}$ \\
\hline 19 & $\begin{array}{l}\text { Quais são os fatores } \\
\text { de decisão adotados } \\
\text { para a escolha? O } \\
\text { por que } \\
\text { dessa escolha? }\end{array}$ & $\begin{array}{l}\text { Respeitando o } \\
\text { conceito do } \\
\text { Juntinho de você. }\end{array}$ & $\begin{array}{l}\text { Cria-se em função do } \\
\text { próprio apelo que a } \\
\text { promoção tem. }\end{array}$ & $\begin{array}{l}\text { Será aquela que } \\
\text { estiver mais } \\
\text { próxima do } \\
\text { posicionamento e } \\
\text { conceito do } \\
\text { shopping. }\end{array}$ \\
\hline 20 & $\begin{array}{l}\text { Quais as estratégias } \\
\text { ou quais métodos } \\
\text { são utilizados para } \\
\text { promover } \\
\text { a extração de } \\
\text { significados para a } \\
\text { marca? }\end{array}$ & $\begin{array}{l}\text { Através das } \\
\text { campanhas } \\
\text { promocionais. }\end{array}$ & $\begin{array}{l}\text { É um trabalho de } \\
\text { manutenção. Os } \\
\text { atributos das marcas } \\
\text { já existem e foram } \\
\text { construídos ao longo. }\end{array}$ & $\begin{array}{l}\text { A utilização da } \\
\text { estrutura do } \\
\text { shopping como } \\
\text { plano de fundo } \\
\text { para promoção de } \\
\text { atividades } \\
\text { culturais e sociais. }\end{array}$ \\
\hline
\end{tabular}




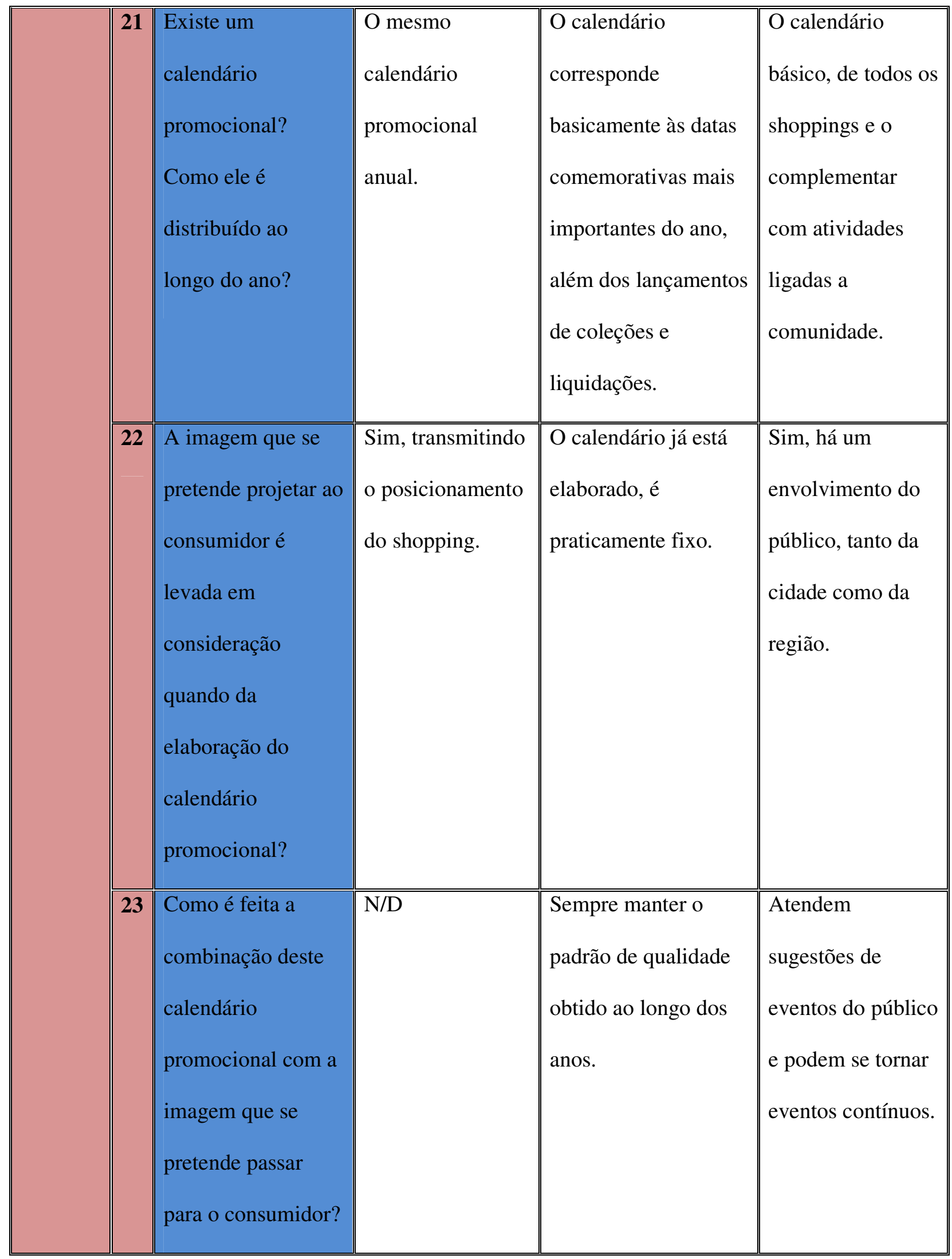


Os dados da tabulação acima compilam o resultado das entrevistas feitas com os gestores dos três shoppings centers de Ribeirão Preto (Novo Shopping, Ribeirão Shopping e Shopping Santa Úrsula).

Pode-se observar na tabela acima que todos seguem um mesmo estilo de gestão, havendo pouca variação quanto à estratégia de promoção e posicionamento que é adotado por cada um dos gestores. Todos os gestores têm autonomia relativa, ou seja, todos eles trabalham com orçamentos pré-definidos pelos seus grupos proprietários (Grupos Almeida Junior, Savoy e Multiplan), todos seguem o calendário padrão e tem pouca flexibilidade para encaixar outras promoções fora deste calendário. Todos os gestores atestam ter seu foco principal no cliente, o que não é plenamente verificável, principalmente se for considerado os resultados obtidos neste trabalho, pois neles há a demonstração de uma pequena diferença de valoração entre os atributos eleitos pelos consumidores e os atributos escolhidos pelos gestores como sendo os mais importantes. 


\section{CONCLUSÕES}

Este trabalho teve por objetivo fazer uma contribuição com os estudos sobre as analises dos fatores motivacionais determinantes para a escolha de um shopping por parte dos consumidores. Foram analisados, portanto, a influência da gestão dos shoppings centers sobre a satisfação e o comportamento dos consumidores.

Dentre as descobertas deste estudo estão as revelações de quais atributos motivadores são os mais valorizados no processo de escolha feito pelos consumidores pesquisados. Os fatores limpeza, manutenção, segurança dentro do shopping e qualidade do serviço prestado receberam altas notas médias e alto grau de importância, atribuídos tanto pelos consumidores, quanto pelos gestores, identificando assim, nestes fatores, um aspecto de grande relevância para ambos os pesquisados.

Adicionalmente, foi realizada uma entrevista em profundidade com os gestores dos três shoppings centers da cidade de Ribeirão Preto. Com essas entrevistas, pôde-se traçar um panorama da atuação dos 3 shoppings centers em termos de gestão estratégica.

O que se observa neste trabalho é a ausência de uma gestão de marcas que possa ser plenamente adotada como sendo resposta às demandas dos seus consumidores, pois apesar de indicarem que valorizam a opinião destes, ainda assim falta efetuar um ajuste fino, afim de garantir que as ações e planos traçados estejam em consonância com o que realmente satisfará o consumidor de shoppings centers.

O quadro abaixo, faz uma tabulação das respostas dadas pelos alunos e gestores com relação aos atributos mais valorados, o que facilita, sobremaneira, a interpretação dos dados. 


\begin{tabular}{|c|c|c|c|c|c|c|}
\hline & $\begin{array}{l}\text { NS } \\
\text { Alunos }\end{array}$ & $\begin{array}{l}\text { NS } \\
\text { Gestor }\end{array}$ & $\begin{array}{l}\text { RS } \\
\text { Alunos }\end{array}$ & $\begin{array}{l}\text { RS } \\
\text { Gestor }\end{array}$ & $\begin{array}{l}\text { SU } \\
\text { Alunos }\end{array}$ & $\begin{array}{l}\text { SU } \\
\text { Gestor }\end{array}$ \\
\hline $\begin{array}{l}1 \text { Atributo mais } \\
\text { valorado }\end{array}$ & $\begin{array}{c}\text { Atributo } \\
\text { \# } 1\end{array}$ & $\begin{array}{c}\text { Atributo } \\
\text { \# } 5\end{array}$ & $\begin{array}{c}\text { Atributo } \\
\text { \# } 1\end{array}$ & $\begin{array}{c}\text { Atributo } \\
\text { \# } 5\end{array}$ & $\begin{array}{l}\text { Atributo } \\
\text { \# } 1\end{array}$ & $\begin{array}{c}\text { Atributo } \\
\text { \# } 5\end{array}$ \\
\hline $\begin{array}{l}2 \text { Atributo mais } \\
\text { valorado }\end{array}$ & $\begin{array}{c}\text { Atributo } \\
\text { \# } 5\end{array}$ & $\begin{array}{c}\text { Atributo } \\
\text { \# } 1\end{array}$ & $\begin{array}{c}\text { Atributo } \\
\text { \# } 5\end{array}$ & $\begin{array}{c}\text { Atributo } \\
\text { \# } 4\end{array}$ & $\begin{array}{c}\text { Atributo } \\
\text { \# } 5\end{array}$ & $\begin{array}{c}\text { Atributo } \\
\text { \# } 4\end{array}$ \\
\hline $\begin{array}{l}3 \text { Atributo mais } \\
\text { valorado }\end{array}$ & $\begin{array}{c}\text { Atributo } \\
\text { \# } 4\end{array}$ & $\begin{array}{c}\text { Atributo } \\
\text { \# } 18\end{array}$ & $\begin{array}{c}\text { Atributo } \\
\text { \# } 4\end{array}$ & $\begin{array}{c}\text { Atributo } \\
\text { \# } 8\end{array}$ & $\begin{array}{c}\text { Atributo } \\
\text { \# } 14\end{array}$ & $\begin{array}{c}\text { Atributo } \\
\text { \# } 8\end{array}$ \\
\hline
\end{tabular}

Tabela 5.1 - Atributos mais valorados Alunos VS Gestores

Legenda:

NS $=>$ Novo Shopping,

RS $=>$ Ribeirão Shopping

$\mathrm{SU}=>$ Shopping Santa Úrsula

Atributo \# 1 => Limpeza e manutenção

Atributo \# 4 => Qualidade do serviço prestado

Atributo \# 5 => Segurança dentro do shopping

Atributo \# $8 \Rightarrow$ Presença de lojas de marca (grife)

Atributo \# 14 => Presença de cinemas

Atributo \# 18 => Preços praticados pelas lojas

Após a análise da tabela (5.1) acima, verifica-se que os alunos elegeram o atributo "limpeza e manutenção" como sendo o primeiro atributo mais valorado, já os gestores, por sua vez elegeram o atributo "segurança dentro do shopping" como sendo o primeiro atributo mais valorado por eles.

Como o segundo atributo mais valorado os alunos elegeram o atributo "segurança dentro do shopping", já os gestores elegeram na sua maioria o atributo "qualidade do serviço prestado".

Esta informação demonstra que os gestores estão focando seus esforços em atributos que não são o primeiro, nem o mais importante a ser valorado pelos seus consumidores. 
Com essas análises, este trabalho pretende contribuir com a compreensão da importância dos fatores valorados pelos consumidores de shoppings centers e assim sendo, fornecer material para a melhoria da gestão deste importante tipo empreendimento. 


\section{REFERÊNCIAS BIBLIOGRÁFICAS}

ABRASCE. Disponível em:< http://www.abrasce.com.br.> Acesso em: janeiro de 2008.

ALENCAR, E. O estudo de caso é uma categoria válida em pesquisa social? Lavras: ESAL, 1988. 5 p.

ALLEGRETTI, R. D. Diagnóstico empresarial. SEBRAE Nacional, 2004.

BULGACOV, S. (Org.). Vários autores. Manual de gestão empresarial. 1.ed. São Paulo: Atlas, 1999.

CHAUVEL, Maria Agnes. A Satisfação do Consumidor no Pensamento de Marketing: revisão de literatura. In: CONGRESSO ANPAD, 22, 1999, Foz do Iguaçu. Anais ANPAD/ENANPAD. São Paulo, 1999, 1CD.

COOPER, D. R.; SCHINDLER, P. S. Métodos de pesquisa em administração. $7^{\mathrm{a}}$ ed. Tradução Luciana de Oliveira da Rocha. Porto Alegre: Bookman, 2003.

CZINKOTA, M. R. et al. Marketing: as melhores práticas. Porto Alegre: Bookman, 2001.

DAFT, R. L. Organizações: teorias e projetos. Tradução Knipel Moreira. São Paulo: Pioneira Thomson Learning, 2002.

DRUCKER, Peter F. Management: tasks, responsibilities, practices. New York: Harper \& Row, 1973.

FERREIRA, Aurélio B. de H. Novo Aurélio Século XXI: o dicionário da língua portuguesa. 3. ed. Rio de Janeiro: Nova Fronteira, 1999.

FITZSIMMONS, J. A. Administração de serviços. Porto Alegre: Bookman, 2005.

FREITAS, H.; JANISSEK, R. Análise léxica e análise de conteúdo: técnicas complementares, seqüenciais e recorrentes para exploração de dados qualitativos. Porto Alegre: Sagra Luzzatto, 2000.

FUNDAÇÃO SISTEMA ESTADUAL DE ANÁLISE DE DADOS (SEADE). Sistema de informações dos municípios paulistas. São Paulo, 2006. Disponível em: $<$ http://www.seade.gov.br/produtos/imp/index.php?page=consulta\&action=ano_save $>$. Acesso em: 11 de junho de 2007.

GIL, A. C. Métodos e técnicas de pesquisa social. 5. ed. São Paulo: Atlas, 1999. 206 p.

HAIR JUNIOR, J. F.; BABIN, B.; MONEY, A. H. et al. Fundamentos de métodos de pesquisa em administração. Tradução Lene Belon Ribeiro. Porto Alegre: Bookman, 2005.

KAPFERER, J. N. As marcas, capital da empresa. Tradução Arnaldo Ryngelblum. Porto Alegre: Bookman, 2004. 
K.E. Reynolds et al. Traditional malls vs. factory outlets: comparing shopper typologies and implications for retail strategy. Journal of Business Research 55 (2002) 687-696

KELLER, K. L.; MACHADO M. Gestão estratégica de marcas. Tradução Arlete Simille Marques. São Paulo: Pearson, 2006.

KOTLER, P. Administração de marketing: análise, planejamento, implementação e controle. 10. ed. São Paulo: Atlas, 2000.

KOTLER, P. Administração de marketing. São Paulo: Editora Prentice Hall, 2000.

KOTlER, P.; ARMSTRONG, G. Princípios de marketing. 9. ed. São Paulo: Prentice Hall, 2003.

MARTINS, G. A. Estudo de caso: uma estratégia de pesquisa. São Paulo: Atlas, 2006.

MAXIMIANO, A. C. A. Introdução à administração. 6. ed. São Paulo: Atlas, 2004.

McGOLDRICK, P. J. Retail marketing. Londres, McGraw-Hill, 2002.

MERLO, E. M. Contrato de gestão: análise da experiência paulista em empresas públicas do setor energético. 1995. Dissertação (Mestrado). Faculdade de Economia, Administração e Contabilidade,Universidade de São Paulo, São Paulo, 1995.

MERLO, E. M.; MAUAD, T. M.; NAGANO, M. S. Um modelo simplificado da prática de gerenciamento por categorias no varejo de médio porte. Revista de administração, São Paulo, v. 39, n.1, p. 30-41, jan./fev./mar. 2004.

MONTANA, P. J.; CHARNOV, B. H. Administração. São Paulo: Saraiva, 2000.

NEVES, J. L. Pesquisa qualitativa - características, usos e possibilidades. Caderno de Pesquisa em Administração, São Paulo, v. 1, n. 3, 1-5 p, 1996.

NEVES, R. de C. Imagem empresarial: como as organizações (e as pessoas) podem proteger e tirar partido do seu maior patrimônio. Rio de Janeiro: Mauad, 1998.

PARENTE, J. Varejo no Brasil: gestão e estratégia. São Paulo: Atlas, 2000.

PORTER, M. E. Estratégia competitiva. Rio de Janeiro: Campos, 1986.

SHETH J. N.; MITTAL, B.; NEWMAN, B. Comportamento do cliente. São Paulo: Atlas, 2001.

SLACK, N.; CHAMBERS, S.; HARLAND, C. et al. Administração da produção. São Paulo: Atlas, 1997.

STEVENSON, J. W. Estatística aplicada à administração. São Paulo: Harbra, 1981.

VERGARA, S. C. Projetos e relatórios de pesquisa em administração. São Paulo: Atlas, 2004.

YIN, R. K. Estudo de caso: planejamento e métodos. 3. ed. Porto Alegre: Bookman, 2003. 


\section{ANEXOS}

\section{QUESTIONÁRIO ALUNOS}

Questionário de avaliação dos fatores motivacionais determinantes para a escolha de um shopping center na opinião dos consumidores de Ribeirão Preto - SP

\section{Avaliação dos fatores determinantes para a escolha de um Shopping Center}

1) Perfil do Consumidor

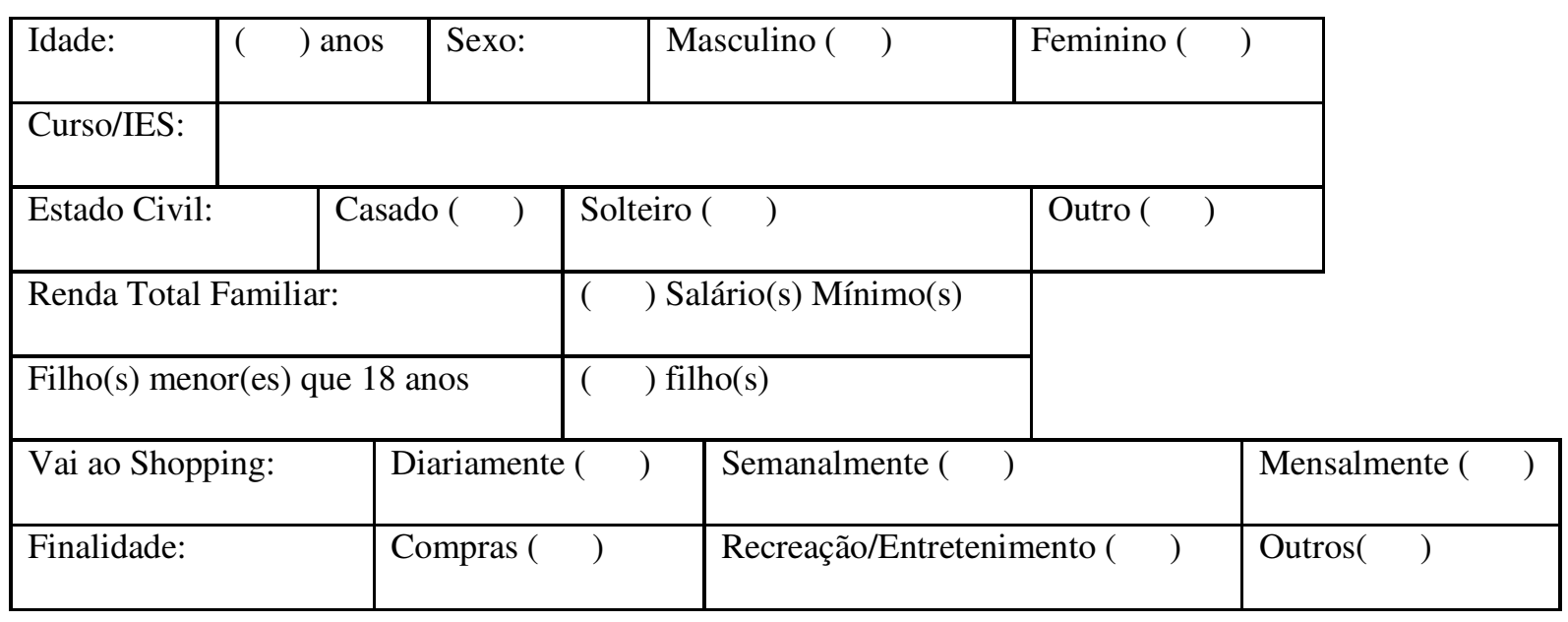

2) Dentre os três Shopping Centers de Ribeirão Preto, qual o de sua preferência:
( ) Novo Shopping
( ) Ribeirão Shopping
( ) Santa Ursula 
3) Indique notas de 1 a 10 em cada um dos atributos abaixo (10 a maior nota e 1 a menor nota):

\begin{tabular}{|c|l|c|}
\hline Item & \multicolumn{1}{|c|}{ Atributos } & Nota \\
\hline 1 & Limpeza e manutenção & $(\quad)$ \\
\hline 2 & Decoração e ambiente & $(\quad)$ \\
\hline 3 & Amizade e cordialidade dos funcionários & $(\quad)$ \\
\hline 4 & Qualidade do serviço prestado & $(\quad)$ \\
\hline 5 & Segurança dentro do shopping & $(\quad)$ \\
\hline 6 & Disponibilidade de estacionamento & $(\quad)$ \\
\hline 7 & Segurança do estacionamento & $(\quad)$ \\
\hline 8 & Presença de lojas de marca (grife) & $(\quad)$ \\
\hline 9 & Disponibilidade de produtos novos e da moda & $(\quad)$ \\
\hline 10 & Número total de lojas & $(\quad)$ \\
\hline 11 & Distância de casa ou trabalho & $(\quad)$ \\
\hline 12 & Facilidade de acesso ao shopping de casa/trabalho & $(\quad)$ \\
\hline 13 & Presença de fast food e restaurantes & $(\quad)$ \\
\hline 14 & Presença de cinemas & $(\quad)$ \\
\hline 15 & Presença de outros prestadores de serviços (bancos, cabelereiros, etc) & $(\quad)$ \\
\hline 16 & Seus amigos compram neste shopping & $(\quad)$ \\
\hline 17 & Opções de recreação/entretenimento em geral & $(\quad)$ \\
\hline 18 & Preços praticados pelas lojas & $(\quad)$ \\
\hline
\end{tabular}

4) Na sua opinião, quais dos atributos acima são os cinco mais importantes:

\begin{tabular}{|c|c|c|c|}
\hline $1^{\circ}$ atributo mais importante ( & ) & $4^{\circ}$ atributo mais importante ( & ) \\
\hline $2^{\circ}$ atributo mais importante ( & ) & $5^{\circ}$ atributo mais importante ( & ) \\
\hline $3^{\circ}$ atributo mais importante ( & ) & & \\
\hline
\end{tabular}




\section{QUESTIONÁRIO GESTORES}

Questionário de avaliação dos fatores motivacionais determinantes para a escolha de um shopping center na opinião dos consumidores de Ribeirão Preto - SP

\section{Avaliação dos fatores determinantes para a escolha de um Shopping Center}

Indique notas de 1 a 10 em cada um dos atributos abaixo (10 a maior nota e 1 a menor nota):

\begin{tabular}{|c|l|c|}
\hline Item Atributos & \multicolumn{1}{|c|}{ Nota } \\
\hline 1 & Limpeza e manutenção & $(\quad)$ \\
\hline 2 & Decoração e ambiente & $(\quad)$ \\
\hline 3 & Amizade e cordialidade dos funcionários & $(\quad)$ \\
\hline 4 & Qualidade do serviço prestado & $(\quad)$ \\
\hline 5 & Segurança dentro do shopping & $(\quad)$ \\
\hline 6 & Disponibilidade de estacionamento & $(\quad)$ \\
\hline 7 & Segurança do estacionamento & $(\quad)$ \\
\hline 8 & Presença de lojas de marca (grife) & $(\quad)$ \\
\hline 9 & Disponibilidade de produtos novos e da moda & $(\quad)$ \\
\hline 10 & Número total de lojas & $(\quad)$ \\
\hline 11 & Distância de casa ou trabalho & $(\quad)$ \\
\hline 12 & Facilidade de acesso ao shopping de casa/trabalho & $(\quad)$ \\
\hline 13 & Presença de fast food e restaurantes & $(\quad)$ \\
\hline 14 & Presença de cinemas & $(\quad)$ \\
\hline 15 & Presença de outros prestadores de serviços (bancos, cabelereiros, etc) & $(\quad)$ \\
\hline 16 & Seus amigos compram neste shopping & $(\quad)$ \\
\hline 17 & Opções de recreação/entretenimento em geral & $(\quad)$ \\
\hline 18 & Preços praticados pelas lojas & $(\quad)$ \\
\hline
\end{tabular}

Na sua opinião, quais dos atributos acima são os cinco mais importantes:

\begin{tabular}{|l|l|}
\hline $1^{\circ}$ atributo mais importante $(\quad)$ & $4^{\circ}$ atributo mais importante ( ) \\
\hline $2^{\circ}$ atributo mais importante ( ) & $5^{\circ}$ atributo mais importante ( ) \\
\cline { 1 - 2 } $3^{\circ}$ atributo mais importante ( ) & \multicolumn{2}{|l}{} \\
\hline
\end{tabular}




\section{ROTEIRO DE ENTREVISTA COM OS GESTORES}

\author{
Data: \\ início: \\ Nome do Shopping: \\ Identificação do entrevistado \\ Nome: \\ Cargo: \\ Data de admissão:
}

duração:

\section{Quanto tempo está no grupo:}

\section{ROTEIRO}

\section{Posicionamento}

1.1. Este shopping pertence a algum grupo? (Grupo ...., etc.)

1.1. Qual é a liberdade que ele (gestor) tem para tomar decisões? (ex.: pouca, pois o poder é centralizado, tem liberdade vigiada, limitada, etc).

1.2. Qual é o posicionamento declarado deste shopping? ) Qual é o posicionamento que estão trabalhando hoje? (ex.: o shoping mais perto...)

1.3. Qual é a imagem que se quer gerar?

1.4. Quais são os atributos usados para se chegar a esse posicionamento?

1.5. Qual é a logomarca, símbolo e identidade?

1.6. Quais são os benefícios associados aos Slogans?

1.7. É trabalhado algum aspecto sonoro? (ex.: jingle)

1.8. Como é trabalhada a ambientação (arquitetura, design interno, aromas, etc)?

1.9. Quais tipos de atividades este shopping promove e com quais objetivos? (ex.: eventos, atrações, experiências, atividades esportivas, etc)

1.10.Qual o apelo de propaganda mais utilizado nas campanhas?

1.11.Este shopping, alguma vez, já fez uso do testemunho de celebridades para alguma campanha publicitária?

1.12. Como é trabalhada a composição do Mix de lojas deste shopping (variedade / quantidade / qualidade)?

1.13. Qual o papel das lojas-âncora e das demais lojas dentro deste shopping? (Diretrizes de setorização). Como foram escolhidas?

1.14.Qual o papel estratégico a ser cumprido por elas?

1.15. Quais esforços de comunicação são utilizados? (ex.: Relações Públicas, cartão de fidelidade, etc). 


\section{Promoções}

2.1. Quais os procedimentos para atribuir nomes às promoções do shopping? Existe relação com o posicionamento?

2.2. Como se escolhem os nomes das promoções?

2.3. Quais são os fatores de decisão adotados para a escolha? O por quê dessa escolha?

2.4. Quais as estratégias ou quais métodos são utilizados para promover a extração de significados para a marca (ex.: Promoção lápis vermelho, etc).

2.5. Existe um calendário promocional? Como ele é distribuído ao longo do ano?

2.6. A imagem que se pretende projetar ao consumidor é levada em consideração quando da elaboração do calendário promocional?

2.7. Como é feita a combinação deste calendário promocional com a imagem que se pretende passar para o consumidor? 
TABULAÇÃO DOS DADOS - PESQUISA ALUNOS

\begin{tabular}{|c|c|c|c|c|c|c|c|c|c|}
\hline S ID & IDADE & F & 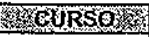 & 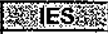 & W ESTCHML & 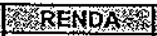 & 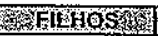 & SERQ 2 SHPP & K \\
\hline 50001120 & 19 & Fem & 1 & 1 & 2 & 21 & $\begin{array}{c}0 \\
\end{array}$ & Mensalmente & 1 \\
\hline 0 & 19 & Masc & 1 & 1 & 2 & 25 & 0 & Semanalmente & 12 \\
\hline 40003 & 20 & Fem & 1 & 1 & 2 & 10 & 0 & Semanalmente & 2 \\
\hline 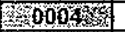 & 19 & Fen & 1 & 1 & 2 & 15 & 0 & Semanalmente & 12 \\
\hline 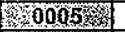 & 19 & Masc & 1 & $i$ & 2 & SR & 0 & Mensalmente & 12 \\
\hline $60006 \%$ & 21 & Fem & 1 & 1 & 2 & 30 & 0 & Mensalmente & $i$ \\
\hline W0007 & 20 & Masc & 1 & 1 & 2 & 20 & $\overline{0}$ & Mensalmente & 2 \\
\hline 0008 - & 20 & Fem & 1 & 1 & 2 & SR & 0 & Semanalmente & 1 \\
\hline 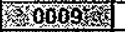 & 19 & Fem & 1 & 1 & 2 & 10 & 0 & Dianiamente & 3 \\
\hline (20010 & 22 & Fem & 1 & 1 & 2 & 7 & 1 & Semanalmente & 23 \\
\hline 0 & 19 & Fem & 1 & 1 & 2 & 20 & 0 & Semanalmente & 12 \\
\hline 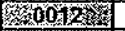 & 23 & Fem & 1 & 1 & 2 & 20 & 0 & Semanalmente & 1 \\
\hline 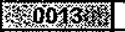 & 21 & Fem & 1 & 1 & 2 & $\mathrm{SR}$ & 2 & Semanalmente & 12 \\
\hline S 0094 & 20 & Fem & 1 & 1 & 2 & SR & 0 & Mensalmente & 2 \\
\hline 50015 & 19 & Masc & 1 & 1 & 2 & 22 & 0 & Semanalmente & 12 \\
\hline 60010 & 19 & Fem & 1 & 1 & 2 & 32 & 2 & Semanalmente & 3 \\
\hline 䈘得 & 19 & Fem & 1 & 1 & 2 & 9 & 0 & Semanalmente & 13 \\
\hline 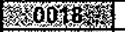 & 20 & Fem & 1 & 1 & 2 & 20 & 0 & Mensalmente & 1 \\
\hline 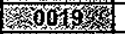 & 22 & Masc & 1 & 1 & 2 & 10 & 0 & Mensalmente & 2 \\
\hline 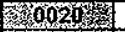 & 20 & Fem & 1 & 1 & 2 & $\mathrm{SR}$ & 0 & Mensalmente & 2 \\
\hline 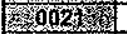 & 20 & Fem & 1 & 1 & 2 & 25 & 0 & Semanaimente & 2 \\
\hline 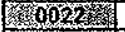 & 20 & Fem & $\frac{1}{1}$ & 1 & 2 & 10 & 0 & Semanalmente & 23 \\
\hline 翏起0023 & 19 & Fem & 1 & 1 & 2 & 30 & 0 & Semanaimente & 12 \\
\hline $602{ }^{2}$ & 20 & Fem & 1 & 1 & 2 & 4 & 0 & Semanaimente & 2 \\
\hline 0025 & 20 & Fem & 1 & 1 & 2 & SR & 0 & Semanalmente & 12 \\
\hline 6026 & 21 & Fem & 1 & 1 & 2 & 14 & 0 & Semanaimente & 23 \\
\hline Y & 19 & Fem & 1 & 1 & 2 & 38 & 0 & Sernanalmente & 23 \\
\hline 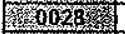 & 20 & Fem & 1 & 1 & 2 & 50 & 0 & Mensalmente & 1 \\
\hline 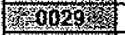 & 26 & Fem & 1 & 2 & 2 & 9 & 0 & Mensalmente & 2 \\
\hline 3500306 & 27 & Fem & 1 & 2 & 2 & 35 & 0 & $S R$ & 2 \\
\hline 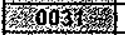 & 29 & Fem & 1 & 2 & 2 & $\mathrm{SR}$ & 0 & SR & 2 \\
\hline 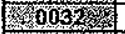 & 29 & Fem & 1 & 2 & 3 & $\overrightarrow{\mathrm{SR}}$ & 1 & Mensaimente & 3 \\
\hline 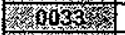 & 32 & Fem & 1 & 2 & 1 & SR & 1 & Mensalmente & 2 \\
\hline (30034) & 40 & Fem & 1 & 2 & 1 & SR & 0 & Mensalmente & 12 \\
\hline xis 0035 & 24 & Fem & 1 & 2 & 1 & SR & 1 & Mensalmente & 2 \\
\hline 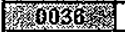 & 23 & Fem & 1 & 2 & 2 & SR & 0 & Mensalmente & 1 \\
\hline$\sigma_{5}$ & 23 & Fem & 1 & 2 & 2 & SR & 0 & Mensalmente & 2 \\
\hline 业 20030 & 28 & Fem & 1 & 2 & 2 & SR & 0 & Mensalmente & 2 \\
\hline 3. & 32 & Fem & 1 & 2 & 2 & 15 & 0 & Mensalmente & 1 \\
\hline 傢 0040 & 21 & Masc & 1 & 2 & 2 & 10 & 0 & Mensalmente & 2 \\
\hline 80041 济 & 19 & Masc & 1 & 2 & 2 & 9 & 2 & Mensalmente & 12 \\
\hline 00425 & 21 & Masc & 1 & 2 & 2 & 60 & 0 & Mensalmente & 12 \\
\hline 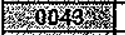 & 19 & Masc & 1 & 2 & 2 & $\mathrm{SR}$ & 0 & Mensalmente & 12 \\
\hline 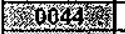 & 26 & Masc & 1 & 2 & 2 & 3 & 0 & Mensalmente & 3 \\
\hline mo045 & 25 & Masc & 1 & 2 & 2 & 7 & 0 & Mensalmente & 12 \\
\hline 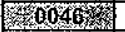 & 20 & Masc & 1 & 2 & 2 & 20 & 1 & Mensalmente & 2 \\
\hline 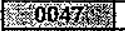 & 20 & Masc & 1 & 2 & 2 & 10 & 0 & Mensalmente & 1 \\
\hline 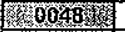 & 19 & Masc & 1 & 2 & 2 & 6 & 0 & Mensalmente & 2 \\
\hline (50\% & 24 & Fem & 1 & 2 & 2 & SR & 0 & Mensalmente & 1 \\
\hline 䇣 & 19 & Fem & 1 & 2 & 2 & SR & 0 & Mensalmente & 1 \\
\hline 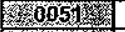 & 26 & Masc & 1 & 2 & 2 & 4 & 0 & Mensaimente & 1 \\
\hline 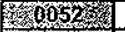 & 37 & Fem & 1 & 2 & 1 & 4 & 1 & Mensalmente & 2 \\
\hline 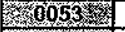 & 20 & Fem & 1 & 2 & 2 & 5 & 0 & Mensalmente & 2 \\
\hline 0054 - & 24 & Masc & 1 & 2 & 2 & SR & 0 & Mensalmente & 1 \\
\hline 1005 & 18 & Fem & 1 & 2 & 2 & 3 & 0 & Semanalmente & 2 \\
\hline 50056 & 25 & Fem & 1 & 2 & 2 & 10 & 1 & Mensalmente & 12 \\
\hline S & 21 & Fem & 1 & 2 & 2 & 10 & 0 & Mensalmente & 12 \\
\hline 80058 & 19 & Masc & 1 & 2 & 2 & SR & 0 & Semanalmente & 2 \\
\hline 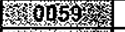 & 19 & Masc & 1 & 2 & 2 & 2 & 0 & Mensalmente & 2 \\
\hline 40069 & 22 & Masc & 1 & 2 & 2 & 15 & 0 & Mensalmente & 2 \\
\hline 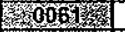 & 43 & Masc & 1 & 2 & 1 & 20 & 0 & Mensalmente & 12 \\
\hline 0062 & 19 & Fem & 1 & 2 & 1 & 5 & 0 & Mensalmente & 12 \\
\hline 180063 & 19 & Fem & 1 & 2 & 2 & 8 & 0 & Mensalmente & 12 \\
\hline 20064 & 19 & Fem & 1 & 2 & 2 & 9 & 0 & Mensalmente & 3 \\
\hline 0065 & 22 & Fem & 1 & 2 & 2 & 40 & 0 & Mensalmente & 12 \\
\hline 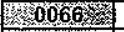 & 19 & Fem & $t$ & 2 & 2 & 26 & 0 & Mensalmente & 12 \\
\hline Kan & 17 & Fem & 1 & 2 & 2 & SR & 0 & Mensalmente & 2 \\
\hline 6068 & 40 & Masc & 1 & 2 & 1 & 10 & 2 & Mensalmente & 2 \\
\hline 50069 & 22 & Fem & 1 & 2 & 2 & 20 & 0 & Mensalmente & 2 \\
\hline $60030 \%$ & 29 & Fem & 1 & 2 & 3 & 7 & 0 & Mensalmente & 3 \\
\hline 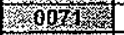 & 23 & Masc: & 1 & 2 & 2 & SR & 0 & Mensalmente & 1 \\
\hline 0072 & 21 & Fem & 1 & 2 & 2 & 7 & 0 & Mensalmente & 2 \\
\hline $06075<$ & 22 & Masc & 1 & 2 & 2 & 10 & 0 & Diariamente & 1 \\
\hline 20074 & 24 & Fem & 1 & 2 & 2 & 20 & 0 & Mensaimente & 1 \\
\hline 0075 & 22 & Masc & 1 & 2 & 2 & 7 & 0 & Mensalmente & 2 \\
\hline 00765 & 32 & Fem & 1 & 2 & 1 & $\overline{S R}$ & 0 & Mensalmente & 1 \\
\hline 0077 & 32 & Masc & 1 & 2 & 2 & $\overline{S R}$ & 0 & Mensalmente & 2 \\
\hline 5008 . & 27 & Masc & 1 & 2 & 2 & SR & 0 & Mensalmente & 2 \\
\hline 0079 & 23 & Masc & 1 & 4 & 2 & 8 & 0 & Semanalmente & 2 \\
\hline 20080 - & 22 & Fem & 1 & 4 & 2 & 5 & 0 & Semanalmente & 2 \\
\hline 0081 徨 & 22 & Fem & 1 & 4 & 1 & 2 & 0 & Semanaimente & 2 \\
\hline 0082 & $\overline{18}$ & Fem & 1 & 4 & 2 & 15 & 0 & Semanalmente & 2 \\
\hline 0083 & 18 & Fem & 1 & 4 & 2 & 1 & 0 & Mensalmente & 2 \\
\hline 0084 & $\mathrm{SR}$ & Fem & $i$ & 4 & 2 & 6 & 0 & Mensalmente & 12 \\
\hline
\end{tabular}




\begin{tabular}{|c|c|c|c|c|c|c|c|c|c|}
\hline K & 聯 & SWEXOS & 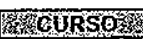 & X & W & 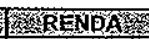 & 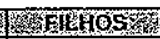 & SRERE & 3) \\
\hline 0085 & 20 & Fem & 1 & 4 & 2 & 6 & 0 & $S R$ & 2 \\
\hline 00862 & 29 & Fem & 1 & 4 & 2 & 30 & 0 & Mensaimente & 2 \\
\hline 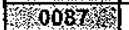 & 24 & Fem & 1 & 4 & 2 & 5 & 0 & Semanalmente & 2 \\
\hline 0088 & 21 & Fem & 1 & 4 & 2 & 5 & 0 & Mensalmente & 2 \\
\hline 0089 & 23 & Fem & 1 & 4 & 2 & 4 & 0 & Semanalmente & 2 \\
\hline 00090 & 18 & Fem & 1 & 4 & 2 & SR & 0 & Sernanalmente & 1 \\
\hline woogin & 23 & Fem & 1 & 4 & 2 & 6 & 0 & Mensalmente & 1 \\
\hline 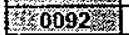 & 18 & Fem & 1 & 4 & 2 & 7 & 0 & Mensaimente & 2 \\
\hline 00938 & 21 & Fem & 1 & 4 & 2 & 10 & 0 & Semanalmente & 12 \\
\hline K & 18 & Fem & 1 & 4 & 2 & 12 & 0 & Semanalmeste & 1 \\
\hline 130095 & 21 & Fem & 1 & 4 & 2 & 30 & 0 & Semanalmente & 2 \\
\hline 3 & 24 & Masc & 1 & 4 & 2 & 7 & 0 & Semanalmente & 2 \\
\hline Whoog & 19 & Fem & 1 & 4 & 2 & 7 & 0 & Semanalmente & 2 \\
\hline 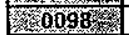 & 20 & Fem & 1 & 4 & 2 & 6 & 0 & Semanalmente & 123 \\
\hline 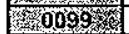 & 30 & Fem & 1 & 4 & 2 & 3 & 0 & Semanalmente & 2 \\
\hline S 0100 os & 25 & Fem & 1 & 4 & 2 & 10 & 0 & Semanalmente & 12 \\
\hline 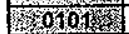 & 21 & Fem & 1 & 4 & 2 & 8 & 0 & Semanalmente & 12 \\
\hline 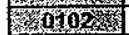 & 21 & Masc & 1 & 4 & 2 & 2 & 0 & Mensalmente & 3 \\
\hline Kin & 18 & Fem & 1 & 4 & 2 & 5 & 0 & Mensalmente & 3 \\
\hline 35 & 20 & Masc & 1 & 4 & 2 & 3 & 1 & Mensalmente & 2 \\
\hline T.8. & 20 & Masc & 1 & 4 & 2 & SR & 0 & Semanalmente & 12 \\
\hline 10006 & 18 & Fem & 1 & 4 & 2 & 7 & 0 & Semanalmente & 3 \\
\hline 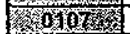 & 19 & Fem & 1 & 4 & 2 & 13 & 0 & Mensalmente & 1 \\
\hline 经 0108 & 18 & Masc & 1 & 4 & 2 & 20 & 0 & Semanalmente & 2 \\
\hline 3. & 24 & Fem & 1 & 4 & 1 & 5 & 0 & Diariamente & 3 \\
\hline 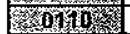 & 18 & Fem & 1 & 4 & 2 & 20 & 0 & Semanalmente & 2 \\
\hline 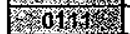 & 20 & Masc & 1 & 4 & 2 & 5 & 0 & Mensalmente & $i$ \\
\hline W & 18 & Masc & 1 & 4 & 2 & 10 & 0 & Mensajmente & 12 \\
\hline 15. & 19 & Masc & 1 & 4 & 2 & 12 & 0 & Mensalmente & 1 \\
\hline S & 24 & Masc & 1 & 4 & 1 & 4 & 0 & Mensalmente & 3 \\
\hline 6 & 25 & Masc & 1 & 4 & 2 & 4 & 0 & Semanalmente & 2 \\
\hline 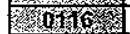 & 33 & Masc & 1 & 4 & 2 & 5 & 0 & Mersalmente & 3 \\
\hline 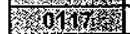 & 30 & Fem & 1 & 4 & 1 & 13 & 0 & Diariamente & 3 \\
\hline X & 20 & Fem & 1 & 4 & 2 & 12 & 0 & Semanalmente & 12 \\
\hline 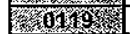 & 25 & Masc & 1 & 4 & 1 & 5 & 0 & Mensalmente & 12 \\
\hline F & 23 & Fem & 1 & 4 & 2 & 8 & 0 & Semanalmente & 12 \\
\hline 5. & 29 & Masc & 1 & 4 & 1 & 10 & 2 & Mensalmente & 2 \\
\hline 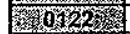 & 22 & Fem & 1 & 4 & 2 & 5 & 0 & Semanalmente & 1 \\
\hline 160123 & 25 & Masc & 1 & 4 & 2 & 3 & 0 & Mensalmente & 3 \\
\hline 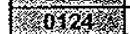 & 22 & Masc & 1 & 4 & 1 & 5 & 1 & Semanalmente & 2 \\
\hline 6. & 27 & Masc & 1 & 4 & $t$ & 10 & 2 & Semanalmente & 12 \\
\hline 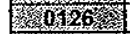 & 18 & Masc & 1 & 4 & 2 & 3 & 0 & Semanalmente & 123 \\
\hline 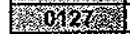 & 19 & Masc & 1 & 4 & 2 & SR & 0 & Mensalmente & 2 \\
\hline 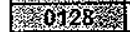 & 23 & Masc & 1 & 4 & 2 & 10 & 0 & Mensalmente & 1 \\
\hline 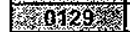 & 19 & Masc & 1 & 4 & 2 & 10 & 0 & Diariamente & 3 \\
\hline 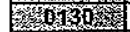 & 19 & Masc & 1 & 4 & 2 & 10 & 0 & Semanalmente & 2 \\
\hline - 013 X & 21 & Masc & 1 & 4 & 2 & 30 & 0 & Mensalmente & 123 \\
\hline 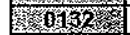 & 19 & Fem & 1 & 4 & 2 & 7 & 0 & Semanalmente & 1 \\
\hline 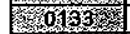 & 23 & Fem & 1 & 4 & 2 & 7 & 0 & $S R$ & $\mathrm{SR}$ \\
\hline O134 & 33 & Masc & 1 & 4 & 1 & 15 & 0 & Semanalmente & 3 \\
\hline 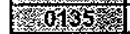 & 22 & Fem & 1 & 4 & 2 & 10 & 0 & Mernsalmente & 2 \\
\hline 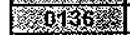 & 23 & Fem & 1 & 4 & 2 & to & 0 & Semanalmente & 12 \\
\hline 0137 綿落 & SR & Fem & 1 & 4 & 1 & 6 & 0 & Mensalmente & 2 \\
\hline 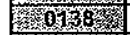 & 22 & Masc & 1 & 4 & 2 & 4 & 0 & Semanalmente & 2 \\
\hline W159 & 22 & Fem & 1 & 4 & 2 & 12 & 0 & Diariamente & 1 \\
\hline 0100 & 19 & Masc & 1 & 4 & 2 & 10 & 0 & Mensalmente & 2 \\
\hline 0144 & 24 & Fem & 1 & 4 & 3 & 4 & 0 & Mensalmente & 2 \\
\hline 0 & 27 & Masc & $T$ & 4 & 2 & 7 & 0 & Semanalmente & 2 \\
\hline 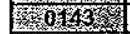 & 20 & Fem & 1 & 4 & 2 & 25 & 0 & Semana!mente & 2 \\
\hline 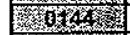 & 20 & Masc & 1 & 4 & 2 & 15 & 0 & Mensalmente & 2 \\
\hline 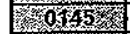 & 22 & Masc & 1 & 4 & 2 & 10 & 0 & Semanalmente & 2 \\
\hline ext & 22 & Fem & 1 & 4 & 2 & 6 & 0 & Semanalmente & 3 \\
\hline 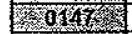 & 48 & Masc & 1 & 4 & 1 & 15 & 1 & Semanalmente & 1 \\
\hline 15 & 19 & Fem & 1 & 4 & 2 & 5 & 0 & Mensaimente & 1 \\
\hline 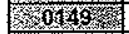 & 22 & Fem & 1 & 4 & 2 & 4 & 0 & Diariamente & 12 \\
\hline $40750 \%$ & 19 & Fem & 1 & 4 & 2 & 3 & 0 & Mensalmente & 1 \\
\hline 00251 & 24 & Fem & 1 & 4 & 2 & 2 & 0 & Mensalmente & 3 \\
\hline 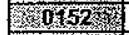 & 29 & Fem & 1 & 4 & 1 & 15 & 1 & Mensalmente & 2 \\
\hline 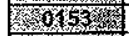 & 23 & Masc & 1 & 4 & 2 & 5 & 0 & Semanalmente & 12 \\
\hline$\delta_{2}$ & 22 & Masc & 1 & 4 & 2 & SR & 0 & Semanalmente & 3 \\
\hline - 0155 & 27 & Masc & 1 & 4 & 2 & 15 & 0 & Mensalmente & 2 \\
\hline $0156^{\circ}$ 次 & 28 & Masc & 1 & 4 & 2 & 6 & 0 & Mensalmente & 1 \\
\hline \% $035 \%$ & 26 & Fem & 1 & 4 & 1 & SR & 0 & Semanalmente & 12 \\
\hline 2.0158 & 22 & Fem & 1 & 4 & 2 & 5 & 0 & Semanalmente & 2 \\
\hline 0359 & 25 & Fem & 1 & 4 & 2 & 10 & 0 & Mensalmente & 2 \\
\hline 1. 0160 & 21 & Fem & 1 & 4 & 2 & 6 & 0 & Mensalmente & 2 \\
\hline 0161 漓 & 30 & Fern & 1 & 4 & 2 & SR & 0 & Mensalmente & 2 \\
\hline 0162 & 33 & Masc & 1 & 4 & 1 & 8 & 0 & Semanaimente & 2 \\
\hline 0163 & 27 & Masc & 1 & 4 & 1 & 5 & 1 & Diariamente & 3 \\
\hline (5164\% & 28 & Masc & 1 & 4 & 2 & 8 & 0 & Semanalmente & 12 \\
\hline 2. 0165 \% & 26 & Masc & 1 & 4 & 2 & 3 & 0 & Mensalmente & 3 \\
\hline 6166 & 23 & Masc & 1 & 4 & 1 & 4 & 1 & Mensalmente & 3 \\
\hline 0167 & 25 & Fem & 1 & 4 & 2 & 12 & 0 & Mensalmente & 2 \\
\hline K6168\% & 24 & Fem & $t$ & 4 & 2 & 6 & 0 & Semanalmente & 12 \\
\hline
\end{tabular}




\begin{tabular}{|c|c|c|c|c|c|c|c|c|c|}
\hline 㛭 ID & 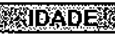 & 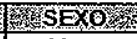 & 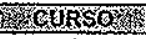 & 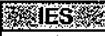 & H & RENDA & 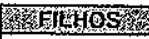 & F & 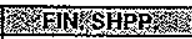 \\
\hline 0169 & 21 & Masc & 1 & 4 & 2 & 2 & 0 & Mensalmente & 2 \\
\hline $01 \mathrm{Ka}$ & 25 & Masc & 1 & 4 & 2 & 5 & 0 & Mensalmente & 12 \\
\hline 0171 & 24 & Fem & 1 & 4 & 2 & $\mathrm{SR}$ & 0 & Mensaimente & 2 \\
\hline 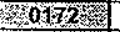 & 23 & Masc & 1 & 4 & 2 & 6 & 0 & Mensalmente & 2 \\
\hline 垔 0173 . & 43 & Masc & 1 & 4 & 1 & 26 & 4 & Mensalmente & 12 \\
\hline Q174 & 24 & Masc & 1 & 4 & 2 & 8 & 0 & Mensalmente & 2 \\
\hline 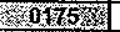 & 23 & Fem & 1 & 4 & 2 & 6 & 0 & Mensalmente & 1 \\
\hline 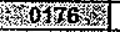 & 21 & Fem & 1 & 4 & 2 & 20 & 0 & Semanalmente & 3 \\
\hline 40182 & 26 & Fem & 1 & 4 & 2 & 5 & 0 & Diariamente & 12 \\
\hline 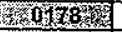 & 24 & Fern & 1 & 4 & 1 & SR & 0 & Sernanalmente & 2 \\
\hline $0179^{6}$ & 50 & Masc & 1 & 4 & 1 & 15 & 0 & Mensalmente & 1 \\
\hline 301800 & 25 & Fem & 1 & 4 & 2 & 6 & 0 & Mensalmente & 2 \\
\hline 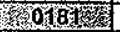 & 31 & Fem & 1 & 4 & 1 & 8 & 1 & Mensalmente & 1 \\
\hline S 01818 & 20 & Fem & 1 & 4 & 2 & 5 & 0 & Semanalmente & 3 \\
\hline 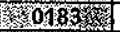 & 28 & Fem & 1 & 4 & 1 & 6 & 1 & Semanalmente & 3 \\
\hline 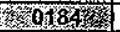 & 26 & Fem & 1 & 4 & 1 & 7 & 1 & Mensalmente & 3 \\
\hline 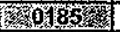 & 19 & Fem & 1 & 4 & 2 & 7 & 0 & Mensalmente & 12 \\
\hline 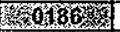 & 19 & Fem & 1 & 4 & 2 & 3 & 0 & Mensalmente & 2 \\
\hline 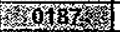 & 27 & Masc & 1 & 4 & 2 & SR & 0 & Mensalmente & 3 \\
\hline 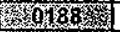 & 19 & Fem & 1 & 4 & 2 & 7 & 0 & Mensalmente & 1 \\
\hline M 0189 & 20 & Masc & 1 & 4 & 2 & 6 & 0 & Semanaimente & 2 \\
\hline 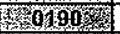 & 18 & Masc & 1 & 4 & 2 & 8 & 0 & Semanalmente & 2 \\
\hline 5 & 18 & Fem & 1 & 4 & 2 & SR & 0 & Mensalmente & 1 \\
\hline 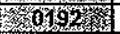 & 21 & Masc & 1 & 4 & 2 & SR & 0 & Mensalmente & 1 \\
\hline 淩 6093 & 18 & Fem & 1 & 4 & 2 & 4 & 0 & Semanalmente & 3 \\
\hline 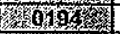 & 18 & Masc & 1 & 4 & 2 & 35 & 0 & Semanalmente & 12 \\
\hline 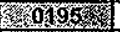 & 22 & Masc & 1 & 4 & 2 & 18 & 0 & Semanalmente & 2 \\
\hline 01962 & 19 & Masc & 1 & 4 & 2 & 30 & 0 & Semanalmente & 2 \\
\hline $019 \%$ & 19 & Masc & 1 & 4 & 2 & 12 & 1 & Mensalmente & 2 \\
\hline 1490 & 23 & Fem & 1 & 4 & 2 & 10 & 0 & Mensalmente & 2 \\
\hline Y01995 & 19 & Fem & 1 & 4 & 2 & 12 & 1 & Semanalmente & 12 \\
\hline S & 25 & Masc & 1 & 4 & 2 & 15 & 0 & Semanalmente & 12 \\
\hline 3. & 21 & Fern & 1 & 4 & 2 & 6 & 0 & Mensalmente & 2 \\
\hline 0203 & 18 & Fem & 1 & 4 & 2 & SR & 0 & Semanalmente & 1 \\
\hline 20204 & 21 & Fem & 1 & 4 & 2 & 8 & 0 & Semanalmente & 1 \\
\hline 0205 & 19 & Fem & 1 & 4 & 2 & 4 & 0 & Semanalmente & 2 \\
\hline - 0206 & 21 & Fem & 1 & 4 & 2 & SR & 0 & Semanalmente & 123 \\
\hline 0207 & 25 & Masc & 1 & 4 & 2 & 8 & 0 & Mensalmente & 2 \\
\hline 0208 & 47 & Fem & 1 & 4 & 3 & 7 & 0 & Mensalmente & 1 \\
\hline 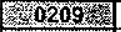 & 27 & Fem & 1 & 4 & 2 & 10 & 0 & Semanalmente & 1 \\
\hline 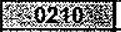 & 26 & Masc & 1 & 4 & 2 & 2 & 0 & Semanalmente & 2 \\
\hline 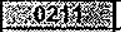 & 25 & Masc & 1 & 4 & 2 & $S R$ & 0 & Mensalmente & 1 \\
\hline 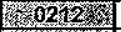 & 32 & Masc & 1 & 4 & 3 & 3 & 0 & Semanalmente & 123 \\
\hline 6213 & 20 & Masc & 1 & 4 & 2 & SR & 0 & Mensalmente & 2 \\
\hline 0219 & 19 & Masc & 1 & 4 & 2 & SR & 0 & Semanalmente & 12 \\
\hline 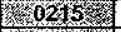 & 19 & Masc & 1 & 4 & 2 & 13 & 0 & Mensalmente & 2 \\
\hline 02160 & 18 & Masc & 1 & 4 & 2 & SR & 0 & Mensalmente & SR \\
\hline 58217 & 18 & Fem & 1 & 4 & 2 & 5 & 0 & Mensalmente & 12 \\
\hline 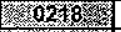 & 18 & Fem & 1 & 4 & 2 & SR & 1 & Mensalmente & 1 \\
\hline 0240 & 18 & Fem & 1 & 4 & 2 & SR & 0 & Mensalmente & 2 \\
\hline 0220 & 18 & Masc & 1 & 4 & 2 & 15 & 0 & Mensalmente & 12 \\
\hline 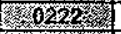 & 24 & Fem & 1 & 5 & 2 & 3 & 0 & Mensalmente & 1 \\
\hline r 02 2 & 20 & Fem & 1 & 5 & 2 & 5 & 0 & Mensalmente & 2 \\
\hline 02245 & 35 & Masc & 1 & 5 & 2 & 8 & 0 & Mensalmente & 2 \\
\hline 0225 & 21 & Masc & 1 & 5 & 2 & 5 & 0 & Mensalmente & 2 \\
\hline S 02260 . & 21 & Fem & 1 & 5 & 2 & 4 & 0 & Mensalmente & $\overline{S R}$ \\
\hline Y 027 & 51 & Masc & 1 & 5 & 1 & 15 & 0 & Mensalmente & 12 \\
\hline (5) & 38 & Masc & 1 & 5 & 1 & 10 & 2 & Semanaimente & 12 \\
\hline 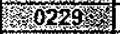 & 30 & Masc & 1 & 5 & 1 & 10 & 1 & Semanalmente & 12 \\
\hline 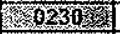 & 21 & Fem & 1 & 5 & 2 & 5 & 0 & Semanalmente & 123 \\
\hline 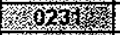 & 27 & Fem & 1 & 5 & 1 & 4 & 0 & Semanamente & 1 \\
\hline W $033^{2}=$ & 25 & Fern & 1 & 5 & 2 & 15 & 0 & Semanalmente & 123 \\
\hline 1533 02 & 26 & Fem & 1 & 5 & 2 & 4 & 0 & Semanalmente & 2 \\
\hline 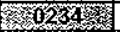 & 23 & Masc & 1 & 5 & 2 & 4 & 0 & Semanalmente & 123 \\
\hline 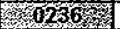 & 39 & Masc & 1 & 5 & 1 & 7 & 4 & Mensalmente & 1 \\
\hline 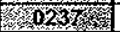 & 25 & Fem & 1 & 5 & 2 & 2 & 0 & Mensalmente & 2 \\
\hline 20\%38 & 23 & Masc & 1 & 5 & 2 & 5 & 0 & Mensalmente & 1 \\
\hline 䉟致 02399 & 21 & Masc & 1 & 5 & 2 & 3 & 0 & Mensalmente & 1 \\
\hline 20\% & 23 & Masc & 1 & 5 & 1 & 3 & 1 & Mensalmente & 3 \\
\hline 20242 & 23 & Fem & 1 & 5 & 2 & 10 & 0 & Mensalmente & 1 \\
\hline r 0043, & 24 & Masc & 1 & 5 & 2 & 3 & 2 & Mensalmente & 1 \\
\hline 620244 & 24 & Masc & 1 & 5 & 2 & 6 & 0 & Mensalmente & 2 \\
\hline 02455 & 27 & Masc & 1 & 5 & 2 & 4 & 0 & Semanalmente & 2 \\
\hline 50246 & 26 & Masc & 1 & 5 & 2 & 10 & 0 & Mensalmente & 12 \\
\hline 0247 & 27 & Masc & 1 & 5 & SR & 3 & 0 & Semanalmente & 3 \\
\hline E248 & 28 & Fem & 1 & 5 & 2 & 3 & 0 & Mensalmente & 2 \\
\hline 嬨 0249 & 28 & Fem & 1 & 5 & 2 & 6 & 0 & Semanalmente & 3 \\
\hline 20250 & 27 & Fem & 1 & 5 & 2 & 3 & 1 & Semanalmente & 2 \\
\hline 0251 敉 & 23 & Fem & 1 & 5 & 2 & 10 & 0 & Mensalmente & 1 \\
\hline 5025 & 30 & Fem & 1 & 5 & 2 & $\mathrm{SR}$ & 0 & Mensalmente & 1 \\
\hline 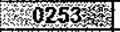 & 26 & Fem & 1 & 5 & 2 & 10 & 0 & Mensalmente & 12 \\
\hline 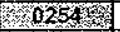 & 23 & Fem & 1 & 5 & 2 & $\mathrm{SR}$ & 0 & Semanalmente & 2 \\
\hline 50255 & 26 & Fem & 1 & 5 & 1 & 6 & 0 & Semanalmente & 12 \\
\hline 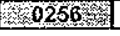 & 30 & Masc & 1 & 5 & 2 & 10 & 0 & Semanalmente & 2 \\
\hline
\end{tabular}




\begin{tabular}{|c|c|c|c|c|c|c|c|c|c|}
\hline 4. & 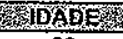 & 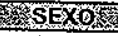 & 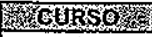 & 20 & 证 & S3 & ming & W & 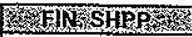 \\
\hline $025 \%$ & 23 & Masc & 1 & 5 & 2 & $\frac{7}{7}$ & 0 & Mensalmente & $\frac{2}{2}$ \\
\hline 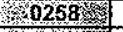 & 27 & Masc & 1 & 5 & 2 & 3 & 0 & Semanalmente & 2 \\
\hline 0259 & 24 & Fem & 1 & 5 & 2 & 8 & 0 & Semanalmente & 2 \\
\hline 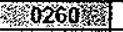 & 25 & Fem & 1 & 5 & 2 & 8 & 0 & Semanalmente & 123 \\
\hline 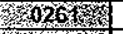 & 31 & Masc & 1 & 5 & 1 & 3 & 1 & Mensalmente & 3 \\
\hline 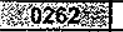 & 24 & Masc & 1 & 5 & 2 & 12 & 0 & Semanalmente & 1 \\
\hline 02633 & 27 & Fern & 1 & 5 & 1 & 6 & 0 & Semanalmente & 1 \\
\hline 0264 & 30 & Masc & 1 & 5 & 2 & 8 & 0 & Mensaimente & 1 \\
\hline 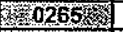 & 25 & Masc & 1 & 5 & 2 & SR & 0 & Semanalmente & 3 \\
\hline 0267 & 34 & Masc & 1 & 5 & 1 & 10 & 3 & Semanalmente & 3 \\
\hline 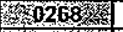 & 22 & Masc & 1 & 5 & 2 & 2 & 0 & Semanalmente & 2 \\
\hline 0250.0 & 27 & Fern & 1 & 5 & 1 & 6 & 1 & Semanalmente & 1 \\
\hline 篓 0270 & 23 & Fem & 1 & 5 & 2 & 13 & 0 & Semanalmente & 12 \\
\hline 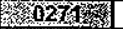 & 22 & Masc & 1 & 5 & 2 & 10 & 0 & Semanalmente & 2 \\
\hline 蘩 0222 & 23 & Fem & 1 & 5 & 2 & 10 & 0 & Semanalmente & SR \\
\hline 0223 & 24 & Masc & 1 & 5 & 2 & 5 & 0 & Mensalmente & 1 \\
\hline r & 23 & Masc & 1 & 1 & 2 & 16 & 0 & Semanalmente & 12 \\
\hline 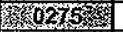 & 20 & Masc & 1 & 1 & 2 & 10 & 0 & Mensalmente & 4 \\
\hline 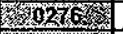 & 23 & Masc & 1 & 1 & 2 & SR & 0 & Mensaimente & 2 \\
\hline 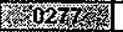 & 22 & Masc & 1 & 1 & 2 & 4 & 0 & Mensalmente & 2 \\
\hline S 0278 S & 19 & Masc & 2 & 1 & 2 & 6 & 0 & Mensalmente & 2 \\
\hline K3 & 19 & Masc & 2 & 1 & 2 & 5 & 0 & Semanalmente & 1 \\
\hline 36000 & 19 & Fem & 2 & 1 & 2 & 12 & 0 & Semanaimente & 123 \\
\hline 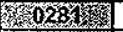 & 19 & Masc & 2 & 1 & 2 & $\mathrm{SR}$ & 0 & Mensalmente & 1 \\
\hline 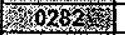 & 20 & Masc & 2 & 1 & 2 & SR & 0 & Semanalmente & 12 \\
\hline r & 24 & Masc & 1 & 3 & 2 & 2 & 0 & Mensaimente & 2 \\
\hline 6285 & 21 & Fem & 1 & 3 & 2 & 10 & 0 & Mensalmente & 1 \\
\hline $0286 x^{2}$ & 29 & Masc & 1 & 3 & 1 & 6 & 0 & SR & 2 \\
\hline 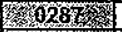 & 22 & Fem & 1 & 3 & 2 & 2 & 0 & Mensalmente & 2 \\
\hline 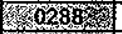 & 21 & Fem & 1 & 3 & 2 & 15 & 0 & Mensalmente & 2 \\
\hline 纂 0289 & 33 & Masc & 1 & 3 & 1 & 10 & 1 & Mensalmente & 1 \\
\hline 02809 & 24 & Fem & 1 & 3 & 2 & SR & 0 & Mensalmente & 3 \\
\hline 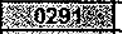 & 29 & Masc & 1 & 3 & 2 & 1 & 0 & Mensalmente & SR \\
\hline 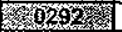 & 22 & Masc & 1 & 3 & 1 & 3 & 3 & $\mathrm{SR}$ & 2 \\
\hline 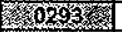 & 23 & Fem & 1 & 3 & 2 & SR & 0 & Mensalmente & SR \\
\hline (50\% & 50 & Masc & 1 & 3 & 1 & 7 & 0 & Mensalmente & 12 \\
\hline 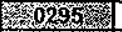 & 23 & Fem & 1 & 3 & 2 & $\mathrm{SR}$ & 0 & Semanalmente & 12 \\
\hline 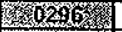 & 25 & Fem & 1 & 3 & 2 & SR & 0 & Diariamente & 3 \\
\hline 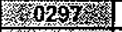 & 20 & Fern & 1 & 3 & 2 & 5 & 0 & Mensalmente & 2 \\
\hline 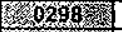 & 24 & Fem & 1 & 3 & 2 & 6 & 0 & Mensalmente & 2 \\
\hline 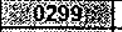 & 18 & Masc & 1 & 1 & 2 & $\mathrm{SR}$ & 0 & Semanalmente & 123 \\
\hline 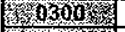 & 20 & Fem & 1 & 1 & 2 & 12 & 0 & Mensalmente & 1 \\
\hline 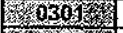 & 18 & Masc & 1 & 1 & 2 & SR & 0 & Semanalmente & 3 \\
\hline 03025 & 18 & Fem & 1 & 1 & 2 & SR & 0 & Semanalmente & 2 \\
\hline 䔝 & 19 & Fem & 1 & 1 & 2 & $\mathrm{SR}$ & 0 & Diariamente & 3 \\
\hline S & 19 & Fem & 1 & 1 & 2 & $\mathrm{SR}$ & 0 & Semanalmente & 1 \\
\hline 0305 & 19 & Masc & 1 & 1 & 2 & 15 & 0 & Semanalmente & 12 \\
\hline 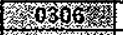 & 19 & Masc & 1 & 1 & 2 & SR & 0 & Mensaimente & 2 \\
\hline $4030 \%$ & 18 & Masc & 1 & 1 & 2 & $\mathrm{SR}$ & 0 & Semanalmente & 12 \\
\hline 00308 & 20 & Masc & 1 & 1 & 2 & 30 & 0 & Diariamente & 3 \\
\hline 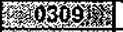 & 19 & Fem & 1 & 1 & 2 & 30 & 1 & Semanalmente & 12 \\
\hline 13030 & 20 & Masc & 1 & 1 & 2 & SR & 0 & Semanalmente & 12 \\
\hline 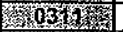 & 20 & Masc & 1 & 1 & 2 & 15 & 0 & Semanalmente & 2 \\
\hline 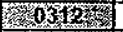 & 18 & Fem & 1 & 1 & SR & 15 & 1 & Mensalmente & 12 \\
\hline 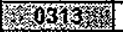 & 21 & Masc & 1 & 1 & 2 & 8 & 0 & Mensalmente & 2 \\
\hline (x) & 19 & Fern & 1 & 1 & 2 & 15 & 0 & Semanalmente & 2 \\
\hline 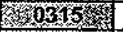 & 18 & Masc & 1 & 1 & 2 & 10 & 0 & Semanalmente & 2 \\
\hline $50366 \%$ & 19 & Fem & 1 & 1 & 2 & 52 & 0 & Semanalmente & 123 \\
\hline 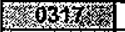 & 22 & Fem & $t$ & 1 & 2 & SR & 0 & Semanalmente & 1 \\
\hline 8 \% & 18 & $\mathrm{Fem}$ & $t$ & 1 & 2 & 52 & 1 & Semanalmente & 12 \\
\hline 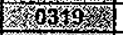 & 20 & Masc & 1 & 1 & 2 & 15 & 1 & Mensalmente & 2 \\
\hline 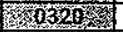 & 19 & Fem & 1 & 1 & 2 & 12 & 0 & Semanalmente & 23 \\
\hline $0334 \mathrm{~K}$ & 21 & Fem & 1 & 1 & 2 & SR & 0 & Semanalmente & 3 \\
\hline 1032 & 19 & Fem & 1 & 1 & 2 & 15 & 0 & Semanamente & 12 \\
\hline 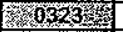 & 19 & Fem & 1 & 1 & 2 & $\mathrm{SR}$ & 0 & Sernanalmente & 12 \\
\hline 230324 & 20 & Fem & 1 & 1 & 2 & 9 & 0 & Mensalmente & 2 \\
\hline 0325 & 45 & Masc & 1 & 1 & 1 & 25 & 3 & Semanalmente & 12 \\
\hline 6 & 23 & Masc & 1 & 1 & 2 & 4 & 0 & Semanalmente & 2 \\
\hline $0_{0} 03 \%$ & 23 & Masc & 1 & 1 & 2 & 50 & 0 & Semanalmente & 2 \\
\hline 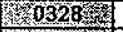 & 26 & Masc & 1 & 1 & 2 & 10 & 0 & Semanalmente & 3 \\
\hline 0329 & 23 & Masc & 1 & 1 & 2 & 26 & 0 & Semanalmente & 2 \\
\hline 0330 & 21 & Fem & 1 & 1 & 2 & 12 & 0 & Semanalmente & 13 \\
\hline 2033j & 23 & Fem & 1 & 1 & 2 & 10 & 0 & Mensalmente & 12 \\
\hline $0332 \times$ & 21 & Masc & 1 & 1 & 2 & 22 & 0 & Mensalmente & $\mathrm{SR}$ \\
\hline 0333 & 22 & Fem & 1 & 1 & 2 & 15 & 0 & Semanalmente & 3 \\
\hline 0334 & 25 & Masc & 1 & 1 & 2 & SR & 0 & Mensalmente & 3 \\
\hline 6335 & 21 & Masc & 1 & 1 & 2 & SR & 0 & Mensalmente & 2 \\
\hline 14 00336 & 23 & Masc & 1 & 1 & 2 & 11 & 0 & Mensalmente & 12 \\
\hline 0337 & 21 & Masc & 1 & 1 & 2 & 2 & 0 & Semanalmente & 1 \\
\hline 0338 & 23 & Masc & 1 & 1 & 2 & 15 & 0 & Semanalmente & 3 \\
\hline 00395 & 26 & Masc & 1 & 1 & 2 & 10 & 0 & Semanalmente & 2 \\
\hline X & 23 & Fem & 1 & 1 & 2 & $\mathrm{SR}$ & 0 & Semanaimente & 1 \\
\hline 20345 & 20 & Masc & 1 & 1 & 2 & 15 & 0 & Mensalmente & 2 \\
\hline 0342 . & 21 & Masc & 1 & 1 & 2 & SR & 0 & Semanalmente & 2 \\
\hline
\end{tabular}




\begin{tabular}{|c|c|c|c|c|c|c|c|c|c|}
\hline SW & 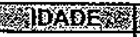 & 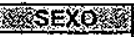 & S & 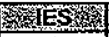 & 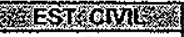 & S & Ever & 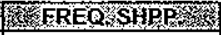 & 6 \\
\hline 0343 & 19 & Masc & 1 & 1 & 2 & 15 & 0 & Semanaimente & 2 \\
\hline 30344 & 20 & Masc & $i$ & 1 & 2 & 4 & 0 & Semanalmente & 13 \\
\hline 0345 & 29 & Masc & 1 & 1 & 2 & 20 & 0 & Semanalmente & 12 \\
\hline 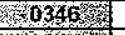 & 20 & Fem & 1 & 1 & 2 & 10 & 0 & Mensalmente & 12 \\
\hline 20347 & 22 & Fem & 1 & 1 & 2 & 10 & 0 & Semanalmente & 1 \\
\hline 發o34 B & 19 & Masc & 1 & 1 & 2 & 20 & 0 & Semanalmente & 2 \\
\hline $30349 \mathrm{~g}$ & 21 & Fem & 1 & 1 & 2 & 25 & 0 & Sernanalmente & 1 \\
\hline 303500 & 20 & Fem & 1 & 1 & 2 & 20 & 0 & Semanalmente & 12 \\
\hline 03513 & 19 & Fem & 1 & 1 & 2 & 13 & 0 & Mensalmente & 2 \\
\hline 0352 & 20 & Masc & 1 & 1 & 2 & 10 & 0 & Mensalmente & 2 \\
\hline$y_{3}=0353$ & 19 & Masc & 1 & 1 & 2 & 7 & 0 & Semanalmente & 1 \\
\hline-30354 & 21. & Masc & 1 & 1 & 2 & 6 & 0 & Semanalmente & 2 \\
\hline 13035 & 20 & Masc & 1 & 1 & 2 & SR & 0 & Semanalmente & 12 \\
\hline Mes56 & 21 & Fem & 1 & 1 & 2 & 28 & 0 & Mensalmente & 1 \\
\hline 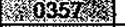 & 19 & Masc & 1 & 1 & 2 & 15 & 0 & Semanalmente & 12 \\
\hline 0358 & 18 & Masc & 1 & 1 & 2. & 20 & 0 & Mensalmente & 12 \\
\hline 侄 & 20 & Fem & 1 & 1 & 2 & 4 & 0 & Mensalmente & 2 \\
\hline 6 & 22 & Masc & 1 & 1 & 2 & 10 & 0 & Semanaimente & 2 \\
\hline 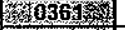 & 20 & Masc & 1 & 1 & 2 & 10 & 0 & Semanalmente & 12 \\
\hline S- & 26 & Fem & 1 & 6 & 2 & 6 & 0 & Mensalmente & 2 \\
\hline 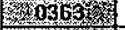 & 23 & Masc & 1 & 6 & 3 & 5 & 0 & Semanalmente & 3 \\
\hline 036 & 19 & Masc & 1 & 6 & 2 & 5 & 0 & Mensalmente & 2 \\
\hline 363653 & 20 & Fem & 1 & 6 & 2 & 4 & 0 & Mensalmente & 12 \\
\hline 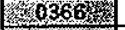 & 21 & Fem & 1 & 6 & 2 & 6 & 0 & Diariamente & 1 \\
\hline 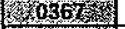 & 31 & Masc & 1 & 6 & 2 & 25 & 1 & Diariamente & 123 \\
\hline 0368 & 18 & Fem & 1 & 7 & 2 & SR & 0 & Diariamente & 12 \\
\hline 30369 r & 25 & Masc & 1 & 7 & 2 & SR & 0 & Mensalmente & 2 \\
\hline 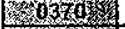 & 26 & Masc & 1 & 7 & 2 & 2 & 0 & Mensalmente & 3 \\
\hline 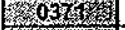 & 21 & Masc & 1 & 7 & 2 & 12 & 0 & Mensalmente & 3 \\
\hline - & 19 & Masc & 1 & 7 & 2 & 7 & 0 & Semanalmente & 1 \\
\hline 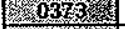 & 27 & Masc & 1 & 7 & 1 & 2 & 2 & Mensalmente & 3 \\
\hline 0374 & 27 & Fem & 1 & 7 & 2 & 6 & 0 & Diariamente. & 3 \\
\hline 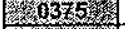 & 29 & Fem & $t$ & 7 & 1 & SR & 2 & Semanalmente & 12 \\
\hline 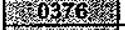 & 43 & Masc & 1 & 7 & 1 & 20 & 3 & Semanalmente & 12 \\
\hline 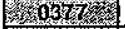 & 18 & Fem & 1 & 7 & 2 & 9 & 0 & Semanalmente & SR \\
\hline 0 & 20 & Masc & 1 & 7 & 2 & $S R$ & 0 & Semanalmente & 2 \\
\hline ( & 31 & Masc & 1 & 7 & 1 & 3 & 1 & Semanalmente & 1 \\
\hline 0680 & 35 & Fem & 1 & 7 & 1 & SR & 0 & Semanalmente & 2 \\
\hline 1 035 & 18 & Fem & 1 & 7 & 2. & 4 & 2 & Mensalmente & 2 \\
\hline Ser $098 \%$ & 20 & Masc & 1 & 7 & 2 & SR & 0 & Semanalmente & 1 \\
\hline 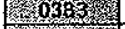 & 19 & Masc & 1 & 7 & 2 & SR & 0 & Semanaimente & 12 \\
\hline 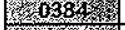 & 24 & Masc & 1 & 7 & 2 & 6 & 0 & Mensalmente & 2 \\
\hline 3. 0385 & 24 & Masc & 1 & 7 & 2 & 3 & 0 & Mensalmente & 2 \\
\hline 03865 & 37 & Fem & 1 & 7 & 1 & 20 & 1 & Semanalmente & $\dagger$ \\
\hline - 0387 , & 22 & Fem & 1 & 7 & 2 & 12 & 0 & Semanalmente & 12 \\
\hline resos & 21 & Masc & 1 & 7 & 2 & 5 & 0 & Diariamente & 3 \\
\hline 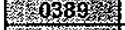 & 19 & Fem & 1 & 7 & 2 & 7 & 0 & Diariamente & 13 \\
\hline 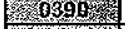 & 23 & Fem & 1 & 7 & 2 & 5 & 0 & Semanalmente & 2 \\
\hline rem & 27 & Fem & 1 & 7 & 2 & SR & 0 & Mensalmente & 12 \\
\hline - & 21 & Fem & 1. & 7 & 2 & 9 & 0 & Mensalmente & 1 \\
\hline 3.0393. & 19 & Fem & 1 & 7 & 2 & 10 & 0 & Mensalmente & 13 \\
\hline 0304 & 25 & Fem & 1 & 7 & 2 & 6 & 0 & Mensalmente & 3 \\
\hline 㥞 & 20 & Masc & 1 & 7 & 2 & 3 & 0 & Diariamente & 3 \\
\hline 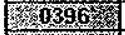 & 18. & Fem & 1 & 7 & 2 & SR & 0 & Semanalmente & 12 \\
\hline $039{ }^{2}$ & 32 & Fem & 1 & 7 & 1 & 10 & 2 & Semanalmente & 12 \\
\hline 0398 & 20 & Fem & 1 & 7 & 2 & 8 & 0 & Semanalmente & 12 \\
\hline 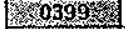 & 18 & Fem & 1 & 7 & 2 & 5 & 0 & Semanalmente & 2 \\
\hline 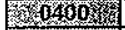 & 22 & Masc & 1 & 7 & 2 & 7 & 0 & Semanalmente & 3 \\
\hline 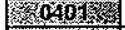 & 25 & Masc & 1 & 7 & 2 & $\mathrm{SR}$ & 0 & Semanalmente & 2 \\
\hline 6 0402 & 26 & Fem & 1 & 7 & 1 & 10 & 2 & Semanalmente & 12 \\
\hline 0403 & 22 & Fem & 1 & 7 & 2 & 5 & 0 & Semanalmente & 2 \\
\hline $0404 y^{2}$ & 20 & Ferm & 1 & 7 & 2 & 3 & 0 & Mensalmente & 1 \\
\hline 0405 & 25 & Fem & 1 & 7 & 2 & 2 & 0 & Mensalmente & 2 \\
\hline $30406=$ & 20 & Masc & 1 & 7 & 2. & SR & 0 & Mensalmente & 2 \\
\hline 0407 & 26 & Masc & 1 & 7 & 2 & 6 & 0 & Mensaimente & 1 \\
\hline r. & 19 & Fem & 1 & 7 & 2 & 8 & 0 & Semanalmente & 3 \\
\hline 304095 & 18 & Masc & $t$ & 7 & 2 & 3 & 0 & Semanalmente & 12 \\
\hline Fono: & 19 & Fem & 1 & 7 & 2 & $\mathrm{SR}$ & 0 & Mensalmente & 1 \\
\hline Wris & 18 & Masc & 1 & 7 & 2 & 12 & 0 & Sernanalmente & 2 \\
\hline 0412 & 25 & Fem & $t$ & 7 & 2 & 3 & 0 & Mensalmente & 12 \\
\hline 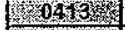 & 29 & Fern & 1 & 7 & 1 & 3 & 1 & Semanalmente & 3 \\
\hline 0414 & 20 & Fem & 1 & 7 & 2 & SR & 0 & Mensalmente & 1 \\
\hline 0035 & 38 & Masc & 1 & 7 & 2 & 4 & 0 & Semanalmente & 2 \\
\hline$y_{0} 04160$ & 19 & Masc & 1 & 7 & 2 & 5 & 1 & Mensalmente & 2 \\
\hline 0412 & 19 & Masc & 1 & 7 & 2 & SR & 0 & Semanalmente & 1 \\
\hline 0418 & 20 & Fem & 1 & 7 & 2 & 6 & 0 & Mensalmente & 3 \\
\hline S 0419 & 26 & Masc & 1 & 7 & 3 & 5 & 0 & Mensalmente & 2 \\
\hline 0.20 & 22 & Masc & 1 & 7 & 2 & 10 & 0 & Semanalmente & 1 \\
\hline 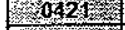 & 19 & Masc & 1 & 7 & 2 & SR & 0 & Semanalmente & 12 \\
\hline 0.222. & 28 & Masc & 1 & 7 & 2 & SR & 0 & Semanalmente & 2 \\
\hline 0423 & 23 & Fem & 1 & 7 & 2 & 3 & 0 & Mensalmente & 2 \\
\hline 0424 & 24 & Fem & 1 & 7 & 2 & 4 & 0 & Semanalmenke & 2 \\
\hline 0425 & 28 & Fem & 1 & 7 & 1 & 3 & 0 & Sernanalmente & 3 \\
\hline 3. 0426 ? & 19 & Fem & $t$ & 7 & 2 & 10 & 2 & Semanalmente & 2 \\
\hline
\end{tabular}




\begin{tabular}{|c|c|c|c|c|c|c|c|c|c|}
\hline W" & 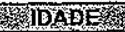 & KSEXO & 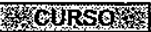 & VIXS & 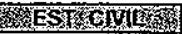 & Y & 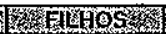 & W & 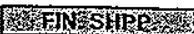 \\
\hline 0427 & 22 & Fem & 1 & 7 & 2 & 2 & 0 & Mensalmente & 123 \\
\hline 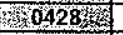 & 22 & Masc & 1 & 7 & 2 & 14 & 0 & Semanalmente & 123 \\
\hline 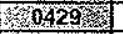 & 35 & Masc & 1 & 7 & 1 & 10 & 0 & Semanalmente & 123 \\
\hline 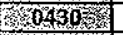 & 26 & Masc & 1 & 7 & 2 & 15 & 0 & Mensalmente & 3 \\
\hline 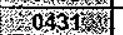 & 19 & Fem & 1 & 7 & 2 & 3 & 0 & Mensalmente & 2 \\
\hline 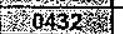 & 23 & Masc & 1 & 7 & 2 & 5 & 0 & Mensalmente & 2 \\
\hline 30433 & 19 & Fern & 1 & 7 & 2 & 4 & 0 & Semanalmente & 2 \\
\hline 0 & 21 & Fem & 1 & 7 & 2 & 3 & 0 & Mensalmente & 2 \\
\hline Y & 21 & Fem & 1 & 7 & 2 & 4 & 0 & Mensalmente & 2 \\
\hline 荟 04364 & 28 & Masc & 1 & 7 & 2 & 105 & 0 & Mensalmente & 2 \\
\hline 0435 & 21 & Masc & 1 & 7 & 2 & 42 & 2 & Semanalmente & 2 \\
\hline 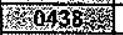 & 28 & Masc & 1 & 7 & 3 & 16 & 0 & Mensalmente & 12 \\
\hline 0439 \% & 25 & Fem & 1 & 7 & 2 & 4 & 0 & Diariamente & 3 \\
\hline 26 & 20 & Masc & $i$ & 7 & 2 & 8 & 0 & Mensajmente & 12 \\
\hline 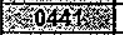 & 21 & Masc & 1 & 7 & 2 & 6 & 0 & Semanalmente & 1 \\
\hline 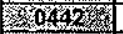 & 23 & Fem & 1 & 7 & 2 & 5 & 0 & Mensalmente & 1 \\
\hline 40,433 & 22 & Fem & 1 & 7 & 2 & 4 & 0 & Sernanalmente & 12 \\
\hline 3045\% & 20 & Fem & 1 & 7 & 2 & SR & 0 & Mensalmente & 1 \\
\hline 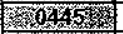 & 20 & Fem & 1 & 7 & 2 & 2 & 0 & Mensalmente & 2 \\
\hline 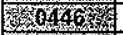 & 22 & Masc & 1 & 7 & 3 & 1 & 0 & Mensalmente & 123 \\
\hline S 04986 & 19 & Fem & 1 & 7 & 2 & SR & 0 & Semanalmente & 12 \\
\hline 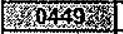 & 19 & Fem & 1 & 7 & 2 & SR & 4 & Mensaimente & SR \\
\hline 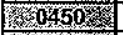 & 19 & Fem & 1 & 7 & 2 & 9 & 0 & Mensalmente & 2 \\
\hline 6045 & 20 & Fem & 1 & 7 & 2 & 8 & 0 & Semanalmente & 1 \\
\hline $0453^{3}$ & 21 & Fem & 1 & 7 & 2 & 3 & 0 & Sernanalmente & 123 \\
\hline 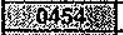 & 32 & Fem & 1 & 7 & 3 & 6 & 1 & Mensalmente & 2 \\
\hline S0455 & 29 & Fem & 1 & 7 & 1 & 7 & 1 & Mensalmente & 12 \\
\hline 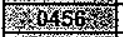 & 19 & Fem & 1 & 7 & 2 & 5 & 0 & Mensalmente & 1 \\
\hline 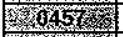 & 22 & Masc & 1 & 7 & 2 & 10 & 0 & Semanalmente & 2 \\
\hline 6 658 J & 21 & Fem & 1 & 7 & 2 & $\mathrm{SR}$ & 0 & Mensalmente & 2 \\
\hline 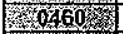 & 18 & Masc & 1 & 7 & 2 & SR & 0 & Mensalmente & 2 \\
\hline 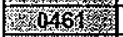 & 23 & Masc & 1 & 7 & 1 & 15 & 0 & Semanalmente & 1 \\
\hline F & 20 & Masc & 1 & 7 & 2 & SR & 0 & Mensalmente & 1 \\
\hline 6063 & 20 & Masc & 1 & 7 & 2 & SR & 0 & Mensalmente & 1 \\
\hline 00462 & 20 & Fem & $i$ & 7 & 2 & SR & 0 & Mensalmente & 2 \\
\hline 0465 & 25 & Masc & 1 & 7 & 2 & 10 & 0 & Mensaimente & 2 \\
\hline $30466 x_{3}$ & 26 & Masc & 1 & 7 & 2 & 4 & 0 & Mensaimente & 13 \\
\hline $30467 \mathrm{~m}$ & 21 & Masc & 1 & 7 & 2 & 6 & 0 & Semanalmente & 1 \\
\hline 00468 & 18 & Masc & 1 & 7 & 2 & 4 & 0 & Mensalmente & 3 \\
\hline 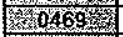 & 21 & Fem & 1 & 7 & 2 & $\mathrm{SR}$ & 0 & Diariamente & 2 \\
\hline 60470 & 30 & Masc & 1 & 7 & 1 & 1 & 0 & Mensalmente & 3 \\
\hline 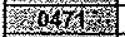 & 19 & Masc & 1 & 7 & 2 & 10 & 0 & Semanalmente & 2 \\
\hline 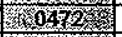 & 20 & Masc & 1 & 7 & 2 & 13 & 0 & Semanalmente & 12 \\
\hline 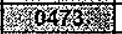 & 19 & Fem & 1 & 7 & 2 & 10 & 0 & SR & 3 \\
\hline 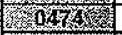 & 19 & Masc & 1 & 7 & 2 & 10 & 0 & Mensalmente & 2 \\
\hline 364750 & 25 & Fem & 1 & 7 & 2 & 6 & 0 & Mensalmente & 2 \\
\hline W 69476 & 18 & Masc & 1 & 7 & 2 & 3 & 0 & Mensalmente & 2 \\
\hline Kon & 18 & Fem & 1 & 7 & 2 & SR & 0 & Mensalmente & 1 \\
\hline 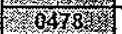 & 20 & Fem & 1 & 7 & 2 & 3 & 0 & Mensalmente & 2 \\
\hline 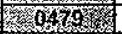 & 20 & Fem & 1 & 7 & 2 & 3 & 0 & Mensalmente & 3 \\
\hline 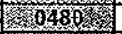 & 23 & Masc & 1 & 7 & 2 & SR & 0 & Diariarsente & 3 \\
\hline 30181 & 20 & Masc & 1 & 7 & SR & 10 & 0 & Mensalmente & 3 \\
\hline y & 21 & Masc & 1 & 7 & 2 & SR & 0 & Semanalmente & 2 \\
\hline 26 0483 & 22 & Fem & 1 & 7 & 2 & SR & 0 & Semanalmente & 2 \\
\hline 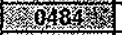 & 27 & Masc & 1 & 2 & 2 & 2 & 0 & Mensalmente & 2 \\
\hline X & 18 & Fem & 1 & 2 & 2 & $i$ & 0 & Mensalmente & 123 \\
\hline 3 096 & 21 & Masc & 1 & 2 & 2 & 3 & 0 & Mensalmente & 2 \\
\hline 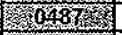 & 19 & Masc & 1 & 2 & 2 & 5 & 0 & Mensalmente & 2 \\
\hline 0488 . & 33 & Fem & 1 & 2 & $\overline{2}$ & 5 & 0 & Mensalmente & 1 \\
\hline 40489 & 19 & Masc & 1 & 2 & 2 & 2 & 0 & SR & SR \\
\hline 02090 & 18 & Masc & 1 & 2 & 2 & SR & 0 & Mensalmente & 3 \\
\hline 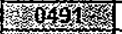 & 18 & Masc & 1 & 2 & 2 & SR & 0 & Mensalmente & 1 \\
\hline 0492 济 & 23 & Masc & 1 & 2 & 2 & 105 & 0 & Semanalmente & 12 \\
\hline 36 & 18 & Fem & 1 & 2 & 2 & SR & 0 & Mensalmente & 1 \\
\hline 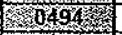 & 20 & Fem & 1 & 2 & 2 & 3 & 0 & Mensalmente & 3 \\
\hline K 0495 & 21 & Fem & 1 & 2 & 2 & SR & 0 & Mensalmente & 3 \\
\hline 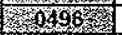 & 18 & Fem & 1 & 2 & 2 & 10 & 0 & Mensalmente & 1 \\
\hline 0497 . & 29 & Masc & 1 & 2 & 2 & 4 & 0 & Mensalmente & 2 \\
\hline S 0498 & 18 & Masc & 1 & 2 & 2 & 13 & 0 & Mensalmente & 1 \\
\hline 10799 & 24 & Masc: & 1 & 2 & 2 & SR & 0 & Sernanaimente & 1 \\
\hline $0500 \%$ & 18 & Masc & 1 & 2 & 2 & 13 & 0 & Diariamente & 1 \\
\hline 0501 & 18 & Fem & 1 & 2 & 3 & SR & 0 & Mensalmente & 12 \\
\hline 05025 & 18 & Masc: & 1 & 2 & 2 & 5 & 0 & Mensaimente & 1 \\
\hline W. 0503 & 30 & Fem & 1 & 2 & 2 & 10 & 0 & Mensalmente & 3 \\
\hline S0504 & 21 & Fem & 1 & 2 & 2 & 5 & 0 & Mensalmente & 1 \\
\hline S 0505 & 28 & Fem & $t$ & 2 & 2 & 4 & 0 & Mensalmente & 3 \\
\hline 0506 , & 22 & Fem & 1 & 2 & 2 & 5 & 0 & Mensalmente & 1 \\
\hline 0507 & 22 & Masc & 1 & 2 & 2 & 10 & 0 & Mensaimente & 1 \\
\hline 0508 & 21 & Fem & 1 & 2 & 2 & 3 & 0 & Mensalmente & 1 \\
\hline 50509 . & 21 & Masc & $i$ & 2 & 2 & 7 & 0 & Mensaimente & 2 \\
\hline 0510 , & 23 & Fem & 1 & 2 & 2 & 15 & 0 & Mensalmente & 2 \\
\hline 05416 & 21 & Fen & 1 & 2 & 2 & 6 & 0 & Mensalmente & 3 \\
\hline 05122 & 23 & Fem & 1 & 2 & 2 & 5 & 0 & Mensalmente & 1 \\
\hline 0513 xख & 28 & Masc & 1 & 2 & 2 & 2 & 0 & Mensalmente & 23 \\
\hline
\end{tabular}




\begin{tabular}{|c|c|c|c|c|c|c|c|c|c|}
\hline 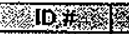 & 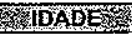 & K & 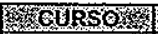 & Whys & SWX & 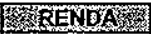 & W & 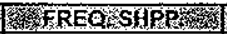 & 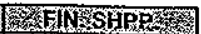 \\
\hline 蕬 0514 & 35 & Fem & 1 & 2 & 1 & 6 & 2 & Mensalmente & 12 \\
\hline 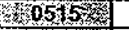 & 18 & Fem & 1 & 3 & 2 & 4 & 0 & Mensalmente & 2 \\
\hline 056 \% & 20 & Masc & 1 & 3 & 2 & SR & 0 & Diariamente & 3 \\
\hline 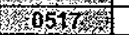 & 19 & Masc & 1 & 3 & 2 & 7 & 0 & Mensalmente & 1 \\
\hline 305/8 & 25 & Masc & 1 & 3 & 1 & 12 & 1 & SR & 2 \\
\hline W0519 & 19 & Fem & 1 & 3 & 2 & 6 & 0 & Mensalmente & 1 \\
\hline 60520 & 18 & Fern & 1 & 3 & 2 & 4 & 0 & Mensaimente & 2 \\
\hline 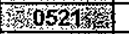 & 18 & Masc & 1 & 3 & 2 & $\overline{\mathrm{SR}}$ & 0 & Semanalmente & 1 \\
\hline 4052215 & 20 & Masc & 1 & 3 & 2 & 4 & 0 & Mensalmente & 3 \\
\hline $0523 x$ & 18 & Fem & 1 & 3 & 2 & SR & 0 & Diariamente & 1 \\
\hline 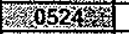 & 20 & Fem & 1 & 3 & 2 & SR & 0 & Mensalmente & 2 \\
\hline 05258 & 20 & Fern & 1 & 3 & 2 & SR & 0 & Mensaimente & 2 \\
\hline 45526 & 18 & Fem & 1 & 3 & 2 & 2 & 0 & Mensalmente & 1 \\
\hline r & 20 & Fem & 1 & 3 & 2 & 3 & 0 & Mensalmente & 2 \\
\hline 635 & 18 & Fem & 1 & 3 & 2 & 3 & 0 & Mensalmente & 2 \\
\hline 30529 & 18 & Fem & 1 & 3 & 2 & SR & 0 & SR & 3 \\
\hline mo5396 & 19 & Fem & 1 & 3 & 2 & SR & 0 & Mensalmente & 1 \\
\hline 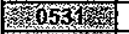 & 20 & Masc & 1 & 3 & 2 & 3 & 0 & Mensalmente & 2 \\
\hline 6532 & 30 & Masc & 1 & 3 & 1 & $\mathrm{SR}$ & 0 & SR & $\mathrm{SR}$ \\
\hline 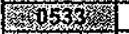 & 22 & Masc & 1 & 3 & 2 & SR & 0 & Mensalmente & 1 \\
\hline 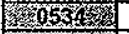 & 32 & Masc & 1 & 3 & 3 & 3 & 1 & Mensalmente & 1 \\
\hline 20.535 & 18 & Masc & 1 & 3 & 2 & 2 & 0 & Semanalmente & 2 \\
\hline 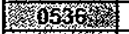 & 19 & Fem & 1 & 3 & 2 & 3 & 0 & Mensalmente & 2 \\
\hline $053{ }^{2}$ & 35 & Fem & 1 & 3 & 2 & 7 & 0 & Mensalmente & 1 \\
\hline 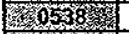 & 18 & Fem & 1 & 3 & 2 & 3 & 0 & Semanalmente & 2 \\
\hline 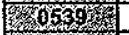 & 28 & Masc & 1 & 3 & 2 & 10 & 0 & Mensalmente & 2 \\
\hline kns & 18 & Masc & 1 & 3 & 2 & SR & 0 & Mensalmente & 1 \\
\hline 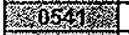 & 40 & Masc & 1 & 3 & 1 & 4 & 0 & Mensalmente & SR \\
\hline - 0542 & 18 & Masc & 1 & 3 & 2 & 18 & 0 & Mensalmente & 12 \\
\hline 6 $0543 \mathrm{~s}$ & 21 & Fem & 1 & 3 & 2 & SR & 0 & Mensalmente & 1 \\
\hline 傢 & 19 & Masc & 1 & 3 & 2 & 1 & 0 & Mensalmente & 12 \\
\hline 02055 & 20 & Fem & 1 & 3 & 2 & SR & 0 & Mensalmente & 12 \\
\hline 0546 列 & 21 & Fem & 1 & 3 & 2 & SR & 0 & Mensalmente & 2 \\
\hline \% & 26 & Masc & 1 & 3 & 2 & SR & 0 & Mensalmente & 1 \\
\hline 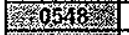 & 21 & Fem & 1 & 3 & 2 & 5 & 0 & Mensalmente & 12 \\
\hline 60500 & 20 & Masc & 1 & 3 & 2 & 10 & 0 & Semanalmente & 1 \\
\hline 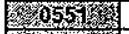 & 21 & Masc & 1 & 3 & 2 & 5 & 0 & Mensalmente & 12 \\
\hline 0350 - & 18 & Fem & 1 & 3 & 2 & SR & 0 & Diariamente & 1 \\
\hline 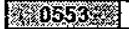 & 18 & Masc & 1 & 3 & 2 & 8 & 0 & Semanalmente & 2 \\
\hline 0554 & 34 & Fem & 1 & 3 & 1 & $\mathrm{SR}$ & 2 & Mensalmente & 2 \\
\hline 嬨 0555 & SR & Fem & 1 & 3 & 2 & SR & 0 & Mensalmente & $\overline{S R}$ \\
\hline 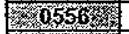 & 22 & Fem & 1 & 3 & 2 & 12 & 0 & Mensalmente & 12 \\
\hline $30657 \times$ & 32 & Fem & 1 & 3 & 3 & 4 & 0 & Mensalmente & 12 \\
\hline 臸0558 & 28 & Masc & 1 & 3 & 2 & $\mathrm{SR}$ & 0 & Semanaimente & 1 \\
\hline 0560 . & 22 & Fem & 1 & 3 & 2 & SR & 0 & Mensalmente & 2 \\
\hline 30 & 24 & Fem & 1 & 1 & 2 & 20 & 0 & Mensalmente & 12 \\
\hline 0562 \% & 25 & Masc & 1 & 1 & 2 & 10 & 0 & Semanalmente & 13 \\
\hline 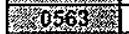 & 21 & Masc & 1 & 1 & 2 & 6 & 0 & Semanaimente & 2 \\
\hline $3^{2}-565$ & 19 & Masc & 1 & 1 & 2 & 40 & 0 & Semanalmente & 12 \\
\hline 8565 . & 23 & Masc & 1 & 1 & 2 & 3 & 0 & Diariamente & 123 \\
\hline 0566 & 19 & Masc & 1 & 1 & 2 & $\mathrm{SR}$ & 0 & Semanalmente & 2 \\
\hline 0567 聯 & 19 & Fem & 1 & 1 & 2 & 20 & 0 & Semanalmente & 1 \\
\hline 0568 & 24 & Fem & 1 & 1 & 2 & 3 & 0 & Mensalmente & 2 \\
\hline 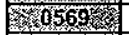 & 22 & Fem & 1 & 1 & 3 & 18 & 0 & Semanalmente & 12 \\
\hline Kun 0 & 19 & Fem & 1 & 1 & 2 & SR & 0 & Semanalmente & 1 \\
\hline 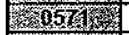 & 22 & Fem & 1 & 1 & 2 & 10 & 0 & Mensalmente & 1 \\
\hline 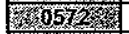 & 31 & Masc & 1 & 1 & 2 & 20 & 0 & Semanalmente & 12 \\
\hline 6ris & 18 & Masc & 1 & 1 & 2 & 10 & 0 & Mensaimente & 2 \\
\hline 057 & 18 & Masc & 1 & 1 & 2 & 10 & 0 & Semanalmente & 2 \\
\hline 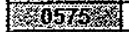 & 18 & Masc & 1 & 1 & 2 & 10 & 0 & Mensalmente & 2 \\
\hline 6576 & 26 & Masc & 1 & 1 & 2 & 30 & 0 & Semanalmente & 12 \\
\hline 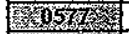 & 17 & Masc & 2 & 1 & 2 & 5 & 0 & Semanalmente & 123 \\
\hline 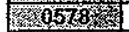 & 18 & Masc & 1 & 1 & 2 & 30 & 0 & Semanalmente & 12 \\
\hline 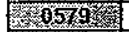 & 25 & Fem & 1 & 1 & 2 & 20 & 0 & Semanalmente & 12 \\
\hline reso58 & 27 & Fem & 1 & 1 & 2 & SR & 0 & SR & $i$ \\
\hline 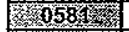 & 20 & Fem & 1 & $i$ & 2 & 10 & 0 & Semanalmente & 2 \\
\hline S6582 & 24 & Masc & 1 & 1 & 2 & 15 & 0 & Mensalmente & 2 \\
\hline Fing & 26 & Fem & 1 & 1 & 2 & SR & 0 & Mensalmente & 2 \\
\hline 20584 6 & 19 & Masc & 1 & 1 & 2 & SR & 0 & Semanalmente & $\overline{\mathrm{SR}}$ \\
\hline 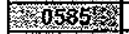 & 30 & Fem & 1 & 8 & 2 & 7 & 1 & Mensalmente & 2 \\
\hline 20586 & 22 & Fem & 1 & 8 & 2 & 7 & 0 & Semanalmente & 3 \\
\hline 0597 & 30 & Fem & 1 & 8 & 1 & 11 & 0 & Mensalmente & 12 \\
\hline 0588 & 22 & Masc & 1 & 8 & 2 & SR & 0 & Mensalmente & 2 \\
\hline 05896 & 22 & Fem & 1 & 8 & 2 & SR & 0 & Mensalmente & 12 \\
\hline 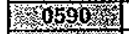 & 37 & Fem & 1 & 8 & 1 & $\widehat{\mathrm{SR}}$ & 2 & Semanalmente & 12 \\
\hline S $0599 \mathrm{~S}$ & 28 & Fem & 1 & 8 & 1 & 10 & 0 & Semanalmente & 1 \\
\hline 0592 & 27 & Fem & 1 & 8 & 2 & 5 & 0 & Mensalmente & 2 \\
\hline 65931 & 24 & Fem & 1 & 8 & 2 & 4 & 0 & Mensalmente & 12 \\
\hline 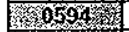 & 26 & Masc & 1 & 8 & 2 & 4 & 0 & $\dot{S R}$ & 3 \\
\hline 0596 & 23 & Fem & 1 & 8 & 2 & 4 & 0 & Mensalmente & 2 \\
\hline 6596 & 28 & Fern & 1 & 8 & 1 & 4 & 0 & Mensalmente & 12 \\
\hline 6597 & 26 & Fem & 1 & 8 & 2 & 6 & 0 & Mensalmente & 2 \\
\hline y 0598 & 22 & Masc & 1 & 8 & 2 & 5 & 0 & Mensalmente & 2 \\
\hline 0599 & 22 & Fem & 1 & 8 & 2 & 5 & 0 & Mensalmente & 2 \\
\hline
\end{tabular}




\begin{tabular}{|c|c|c|c|c|c|c|c|c|c|}
\hline - & NOHA & S SEXO & KEIRSO & 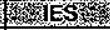 & 豚登 & 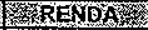 & 冈 & S筑 & 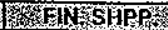 \\
\hline $60600 \mathrm{Ym}$ & 23 & Masc & 1 & 8 & 2 & 6 & 0 & Mensalmente & 1 \\
\hline 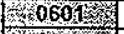 & 21 & Masc & 1 & 8 & 2 & $\mathrm{SR}$ & 0 & Mensalmente & 12 \\
\hline-0602 & 22 & Masc & 1 & 8 & 2 & 7 & 0 & Mensalmente & 3 \\
\hline - 0603 & 26 & Fem & 1 & 8 & 2 & 3 & 0 & Semanalmente & 12 \\
\hline 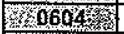 & 24 & Masc & 1 & 8 & 2 & 6 & 0 & Mensalmente & 2 \\
\hline 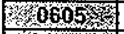 & 22 & Fem & 1 & 8 & 2 & 4 & 0 & Mensalmente & 1 \\
\hline 06004 & 21 & Fem & 1 & 8 & 2 & 3 & 0 & Mensalmente & 2 \\
\hline 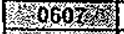 & 23 & Fem & $t$ & 8 & 2 & 10 & 0 & SR & 2 \\
\hline 尉 & 32 & Fem & 1 & 8 & 1 & 4 & 2 & Mensalmente & 2 \\
\hline 0609 & 37 & Masc & 1 & 8 & 1 & 3 & 1 & Mensalmente & 2 \\
\hline 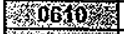 & SR & Fem & 1 & 8 & 2 & SR & 0 & Semanalmente & 2 \\
\hline $2600 \mathrm{~g}$ & 21 & Fem & 1 & 8 & 1 & 3 & 0 & Mensalmente & 2 \\
\hline 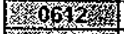 & 26 & Fem & 1 & 8 & 2 & 2 & 0 & Mensalmente & 2 \\
\hline 0.5135 & 28 & Fem & 1 & 8 & 2 & 5 & 0 & Mensalmente & 12 \\
\hline 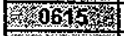 & 21 & Masc & 1 & 8 & 2 & 2 & 0 & Mensalmente & SR \\
\hline 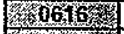 & 28 & Fem & $t$ & 8 & 2 & 13 & 0 & Semanalmente & 1 \\
\hline 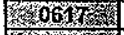 & 21 & Masc & 1 & 8 & 2 & 7 & 0 & Semanalmente & 3 \\
\hline 0014 & 30 & Fem & 1 & 8 & 2 & $\overline{S R}$ & 0 & Mensalmente & 2 \\
\hline 5 062020 & 21 & Fem & 1 & 8 & 2 & 4 & 0 & Semanalmente & 3 \\
\hline 1506\% & 28 & Fem & 1 & 8 & 2 & 6 & 1 & Semanalmente & 2 \\
\hline-0627 & 31 & Fem & 1 & 8 & 2 & 6 & 0 & Mensalmente & 2 \\
\hline 60624 & 22 & Fern & 1 & 8 & 1 & 4 & 0 & Mensalmente & 2 \\
\hline 0625 & 21 & Masc & 1 & 8 & 2 & 3 & 0 & Semanalmente & 2 \\
\hline 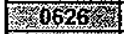 & 52 & Masc & 1 & 8 & 1 & 25 & 1 & Semanalmente & 13 \\
\hline 30627 & 21 & Fem & 1 & 8 & 2 & 8 & 0 & Mensalmente & 2 \\
\hline - 0528 & 27 & Masc & 1 & 8 & 2 & 5 & 0 & Mensalmente & SR \\
\hline - 0630 & 28 & Masc & 1 & 8 & 1 & 10 & 1 & Mensalmente & 2 \\
\hline 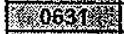 & 21 & Fem & 1 & 8 & 2 & 7 & 0 & Semanalmente & 12 \\
\hline 006325 & 22 & Fem & 1 & 8 & 2 & 20 & 0 & Diariamente & 1 \\
\hline 筇 & 25 & Masc & 1 & 8 & 2 & 4 & 1 & Mensalmente & 3 \\
\hline 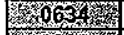 & 30 & Fem & $i$ & 8 & 2 & 4 & 0 & Mensalmente & 3 \\
\hline 0635 & 27 & Fem & 1 & 8 & 2 & 15 & 0 & Diariamente & 13 \\
\hline $3 x=636$ & 38 & Masc & 1 & 8 & 2 & 10 & 1 & Semanalmente & 2 \\
\hline reso & 35 & Fem & 1 & 8 & 2 & 8 & 0 & Semanalmente & 12 \\
\hline 0.038 & 29 & Masc & 1 & 8 & 2 & 5 & 0 & SR & 2 \\
\hline 0639, & 29 & Fem & 1 & 8 & 3 & 5 & 3 & Semanalmente & 12 \\
\hline 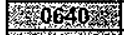 & 23 & Fem & 1 & 8 & 2 & 8 & 0 & Mensalmente & 12 \\
\hline 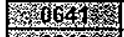 & 23 & Fem & 1 & 8 & 2 & 4 & 0 & Mensalmente & 2 \\
\hline 0642 & 23 & Fem & 1 & 8 & 2 & 10 & 0 & Semanalmente & 2 \\
\hline 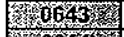 & 26 & Fem & 1 & 8 & 2 & 10 & 0 & Mensalmente & 2 \\
\hline 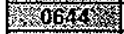 & 21 & Masc & 1 & 8 & 2 & 5 & 0 & Mensalmente & 12 \\
\hline 4 . & 24 & Masc & 1 & 8 & 2 & 10 & 0 & Semanalmente & 12 \\
\hline 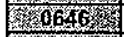 & 24 & Masc & 1 & 8 & 2 & 8 & 0 & Semanalmente & 2 \\
\hline 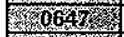 & 22 & Masc & 1 & 8 & 2 & 12 & 0 & Mensalmente & 12 \\
\hline 0648 & 21 & Fem & 1 & 8 & 2 & 2 & 0 & Semanalmente & 2 \\
\hline 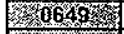 & 27 & Masc & 1 & 8 & 1 & 6 & 0 & Mensalmente & 2 \\
\hline OS50 & 19 & Fem & 1 & 1 & 2 & 12 & 0 & Mensalmente & 12 \\
\hline 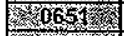 & 18 & Fem & $i$ & 1 & 2 & SR & 0 & Mensalmente & 13 \\
\hline 0652 - & 20 & Masc & 1 & 1 & 2 & 10 & 0 & Semanalmente & 3 \\
\hline 0653 & 23 & Masc & 1 & 1 & 2 & 15 & 0 & Diariamente & 2 \\
\hline 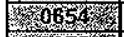 & 22 & Masc & $t$ & 1 & 2 & 10 & 0 & Mensalmente & 3 \\
\hline 0655 & 20 & Fem & 1 & 1 & 2 & 15 & 0 & Mensalmente & 1 \\
\hline 00656 & 20 & Fem & 1 & 1 & 2 & 30 & 1 & Semanalmente & 12 \\
\hline 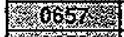 & 19 & Masc & $t$ & 1 & 2 & 2 & 2 & Mensalmente & 2 \\
\hline 0 & 19 & Masc & 1 & 1 & 2 & 30 & 0 & Mensalmente & $i$ \\
\hline 0659 & 19 & Masc & 1 & 1 & 2 & 7 & 0 & Mensalmente & 2 \\
\hline 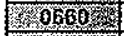 & 19 & Masc & 1 & 1 & 2 & 9 & 0 & Mensalmente & 2 \\
\hline 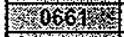 & 18 & Masc & 1 & 1 & 2 & 20 & 0 & Semanalmente & 2 \\
\hline 06832 & 19 & Masc & 1 & 1 & 2 & 5 & 0 & Mensalmente & 2 \\
\hline 6- 1668 & 19 & Masc & 1 & 1 & 2 & 12 & 0 & Mensalmente & 12 \\
\hline 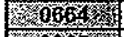 & 19 & Masc & 1 & 1 & 2 & SR & 0 & Mensalmente & 2 \\
\hline 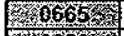 & 18 & Masc & 1 & 1 & 2 & 8 & 0 & Mensalmente & 2 \\
\hline 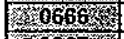 & 23 & Masc & 1 & 1 & 2 & 10 & 0 & Mensalmente & 2 \\
\hline $606 \mathrm{~J}$ & 20 & Masc & 1 & 1 & 2 & 5 & 0 & Semanalmente & 2 \\
\hline seres & 20 & Masc & 1 & $i$ & 2 & 8,5 & 0 & Semanalmente & 2 \\
\hline 0669 & 18 & Masc & 1 & 1 & 2 & 30 & 0 & Semanalmente & 12 \\
\hline 06700 , & 18 & Masc & 1 & 1 & 2 & 15 & 0 & Mensalmente & 12 \\
\hline 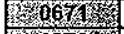 & 18 & Masc & 1 & 1 & 2 & 8 & 0 & Semanalmente & 3 \\
\hline 0672 & 20 & Masc & 1 & 1 & 2 & 5 & 0 & Mensalmente & 2 \\
\hline 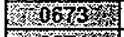 & 19 & Fem & 1 & 1 & 2 & 2 & 0 & Mensalmente & 2 \\
\hline 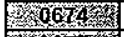 & 19 & Fem & 1 & 1 & 2 & SR & 0 & Mensalmente & 2 \\
\hline 40675 & 18 & Masc & 1 & 1 & 2 & 10 & 0 & Mensalmente & 3 \\
\hline $1066^{\circ}$ & 20 & Masc & 1 & 1 & 2 & 5 & 0 & Mensalmente & 2 \\
\hline HOGT & 21 & Masc & 1 & 1 & 2 & 40 & 0 & Semanatmente & 2 \\
\hline 3. $06 \%$ & 20 & Masc & 1 & 1 & 2 & 40 & 0 & Semanalmente & 2 \\
\hline - 0629 & 21 & Masc & 1 & 1 & 2 & 1 & 0 & Mensalmente & 2 \\
\hline O0681 & 18 & Masc & 1 & 1 & 2 & 13 & 0 & Mensalmente & 1 \\
\hline 0682 & 19 & Masc & 1 & 1 & 2 & 30 & 0 & Mensalmente & 2 \\
\hline 0683 & 33 & Masc & 1 & 1 & 1 & 18 & 1 & Semanalmente & 2 \\
\hline 盗 068 & 20 & Fem & 1 & 3 & 2 & 5 & 0 & Mensalmente & 2 \\
\hline 00685 & 20 & Fem & 1 & 3 & 2 & 1 & 0 & Mensalmente & 1 \\
\hline 1206865 & 19 & Masc & 1 & 3 & 2 & 4 & 0 & Mensalmente & 3 \\
\hline 0687 T得 & 18 & Fem & 1 & 3 & 2 & SR & 0 & Semanalmente & 2 \\
\hline 60685 & 21 & Fem & 1 & 3 & 2 & 5 & 0 & Mensalmente & 1 \\
\hline
\end{tabular}




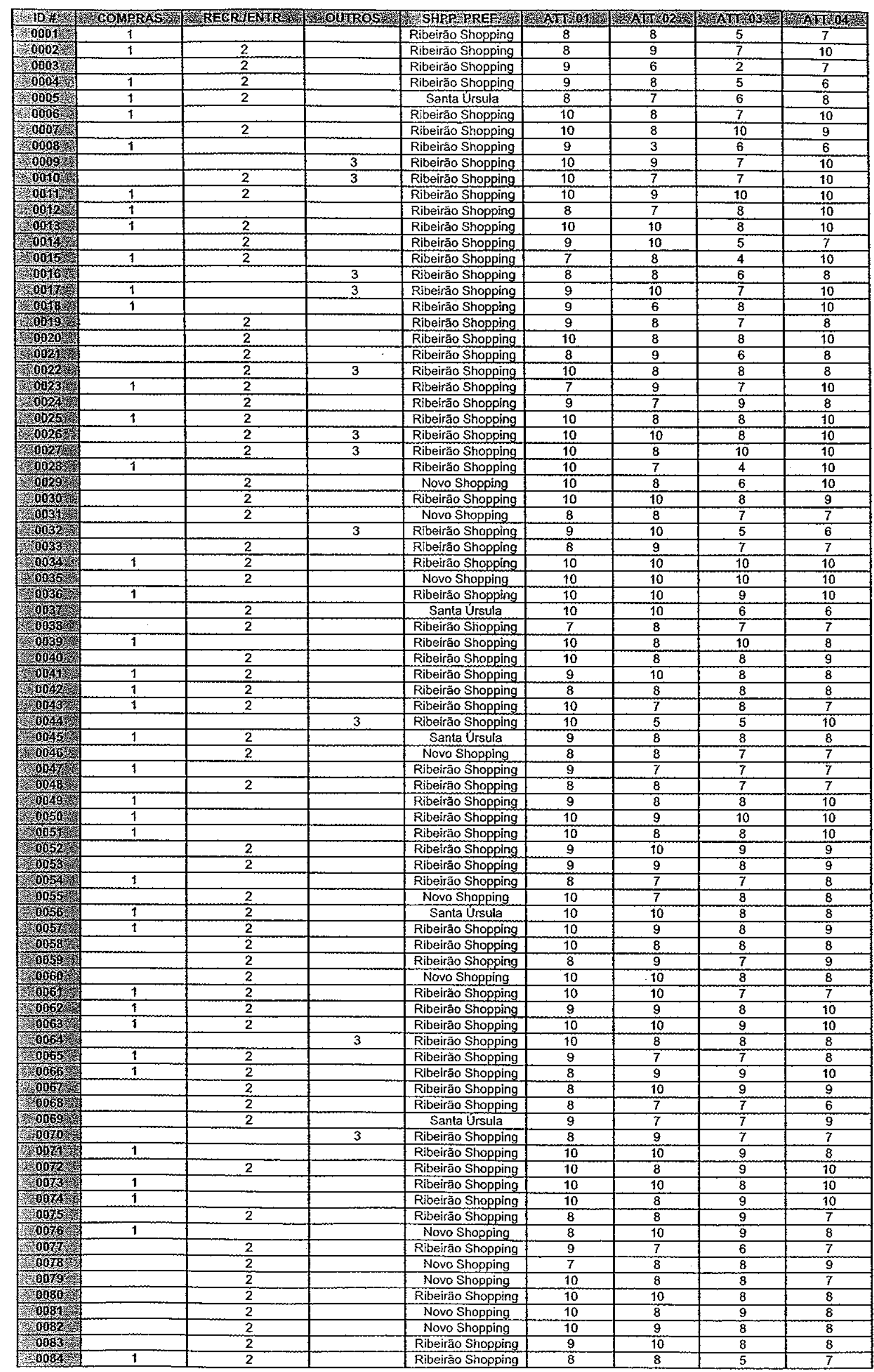




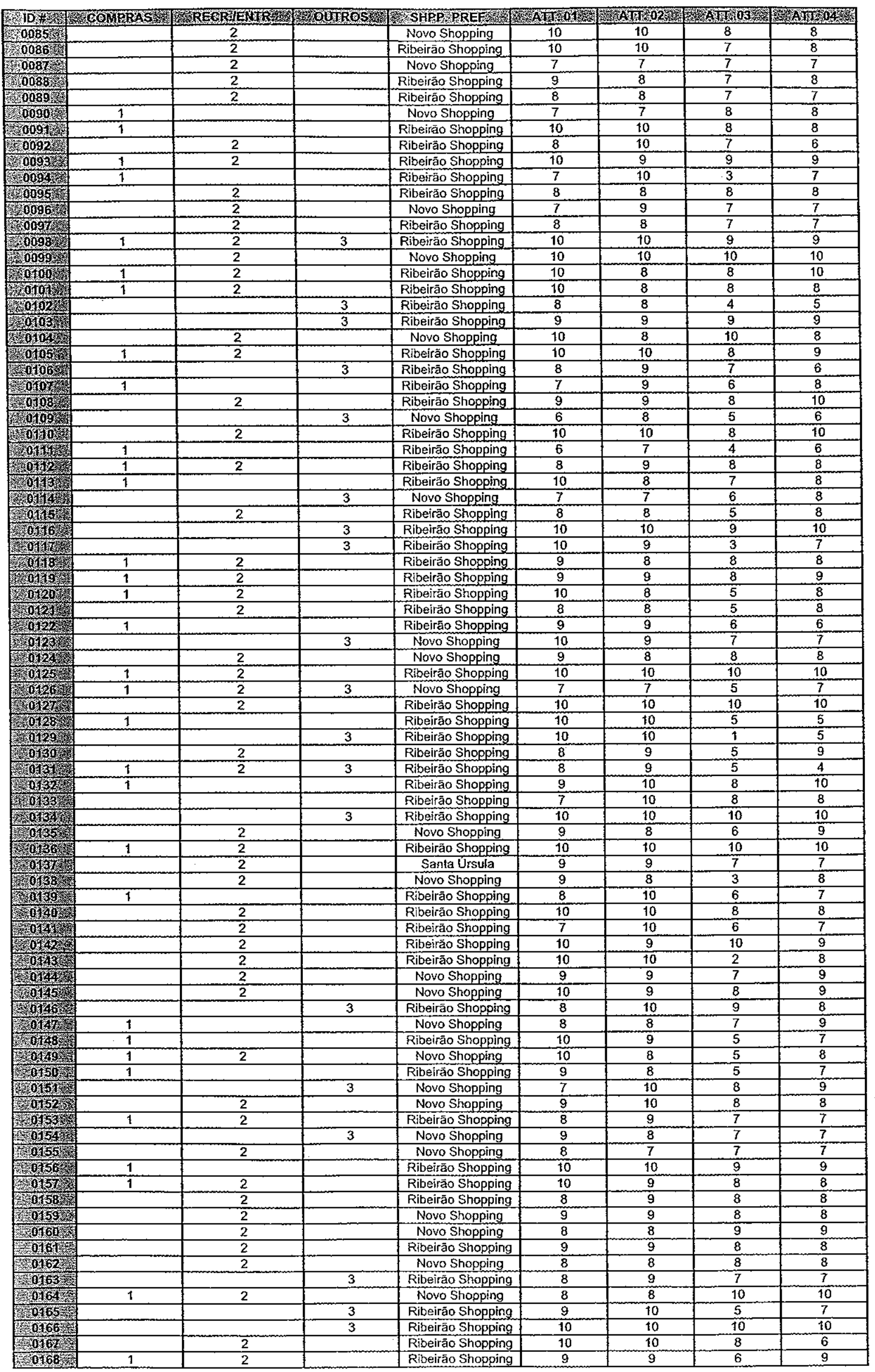




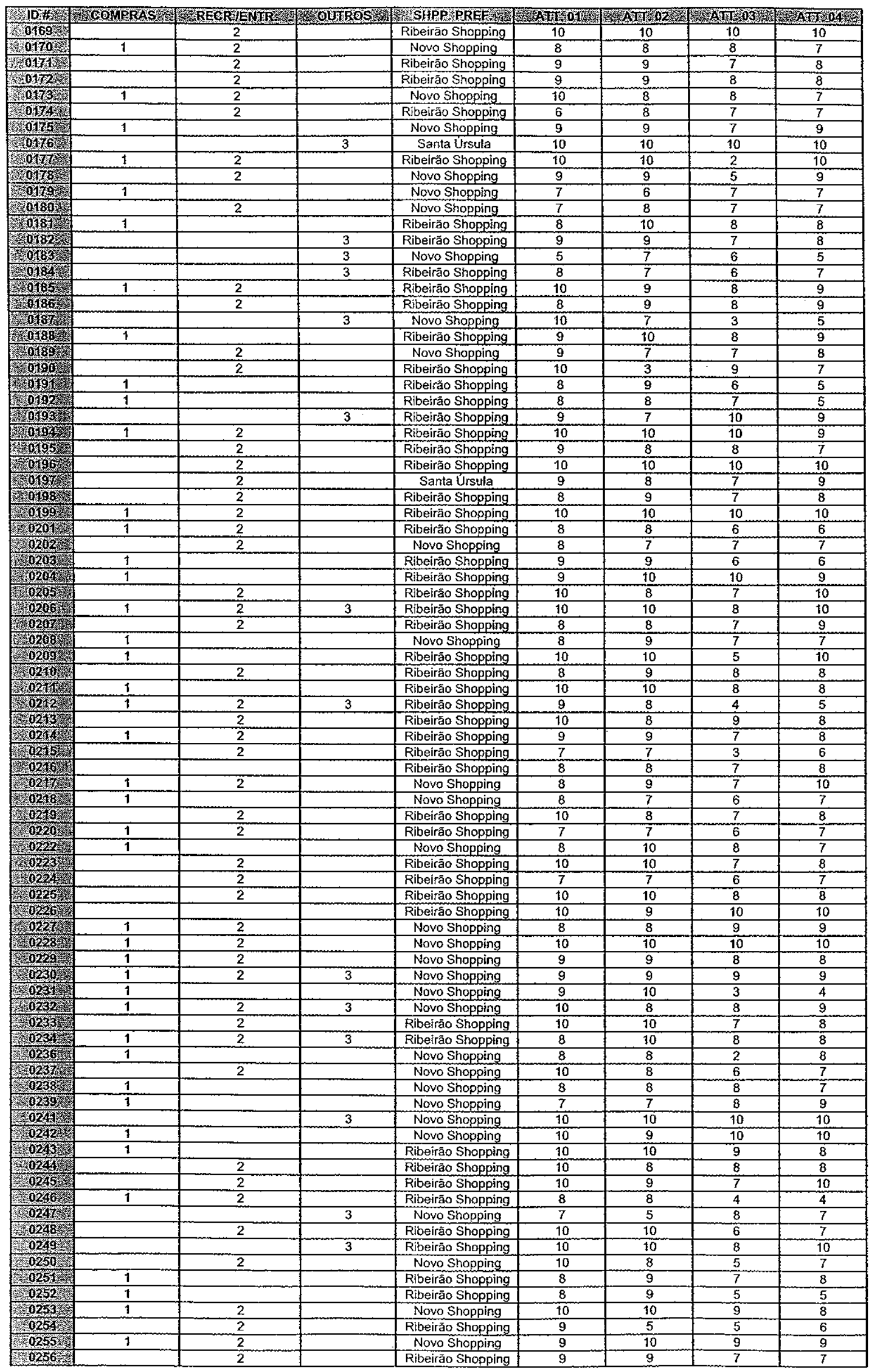




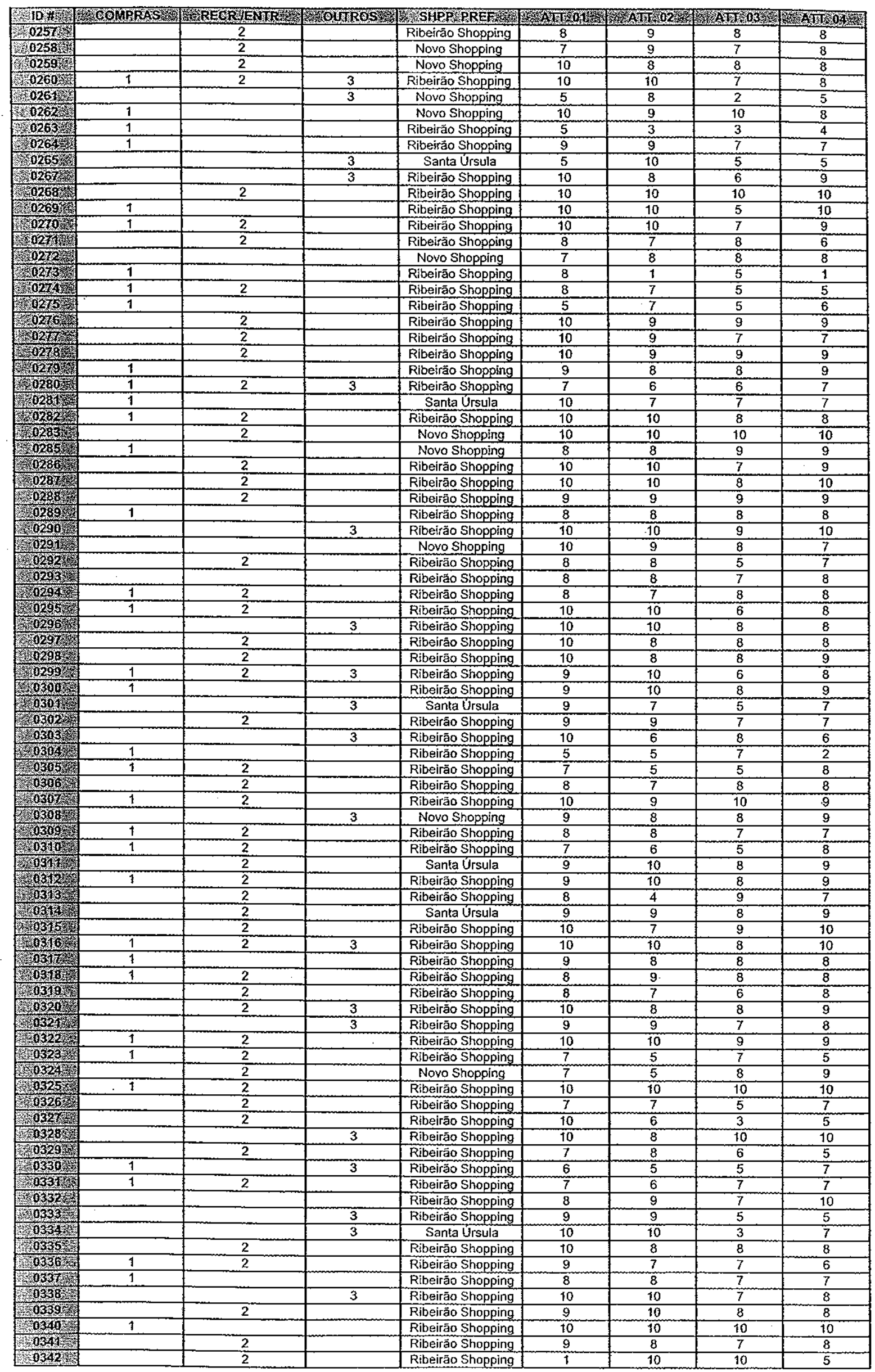




\begin{tabular}{|c|c|c|c|c|c|c|c|c|}
\hline 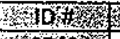 & COMRRASZ & 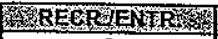 & moUROS & 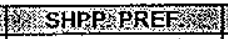 & 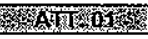 & X & 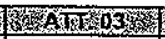 & 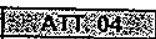 \\
\hline Astos 0343 & & 2 & & Ribeirão Shopping & 10 & 10 & 8 & 10 \\
\hline 0345 S & 1 & 2 & & Ribeirāo Shopping & 8 & 8 & 5 & 7 \\
\hline 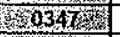 & 1 & & & Ribeirāo Shopping & 10 & 8 & 7 & 8 \\
\hline 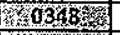 & & 2 & & Ribeirāo Shopping & 8 & 8 & 5 & 6 \\
\hline 0349 & 1 & & & Ribeirăo Shopping & 8 & 8 & 7 & 9 \\
\hline 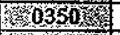 & 1 & 2 & & Ribeirāo Shopping & 8 & 7 & 8 & 8 \\
\hline 40350 & & 2 & & Novo Shopping & 10 & 8 & 7 & 9 \\
\hline 0352 & & 2 & & Novo Shopping & 8 & 5 & 2 & 6 \\
\hline 30353 & 1 & & & Novo Shopping & 10 & 7 & 7 & 8 \\
\hline $5035 \%$ X & & 2 & & Ribeirão Shopping & 10 & 9 & 9 & 10 \\
\hline 0355 & $t$ & 2 & & Santa Úrsula & 8 & 8 & 9 & 8 \\
\hline 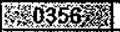 & 1 & & & Ribeirão Shopping & 8 & 8 & 7 & 8 \\
\hline 0357 & 1 & 2 & & Ribeiräo Shopping & 10 & 10 & 10 & 10 \\
\hline 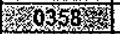 & 1 & 2 & & Ribeirăo Shopping & 10 & 8 & 7 & 10 \\
\hline 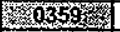 & & 2 & & Ribeirāo Shopping & 8 & 8 & 7 & .7 \\
\hline 30360 & & 2 & & Ribeirāo Shopping & 8 & 8 & 7 & 8 \\
\hline - & 1 & 2 & & Ribeirāo Shopping & 8 & 8 & 7 & 5 \\
\hline 3036\% & & 2 & & Ribeirảo Shopping & 10 & 10 & 7 & 8 \\
\hline 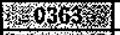 & & & 3 & Ribeirăo Shopping & 7 & 8 & 6 & 9 \\
\hline 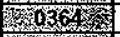 & & 2 & & Ribeiräo Shopping & 9 & 9 & 10 & 8 \\
\hline 365 & 1 & 2 & & Ribeirāo Shopping & 8 & 9 & 8 & 8 \\
\hline 0366 & 1 & & & Ribeirão Shopping & 10 & 10 & 6 & 9 \\
\hline - & 1 & 2 & 3 & Ribeirāo Shopping & 9 & 9 & 7 & 6 \\
\hline 50366 & 1 & 2 & & Ribeirão Shopping & 10 & 10 & 5 & 10 \\
\hline S & & 2 & & Santa Ursula & 7 & 9 & 6 & 10 \\
\hline 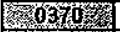 & & & 3 & Ribeirăo Shopping & 10 & 10 & 5 & 5 \\
\hline 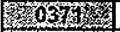 & & & 3 & Ribeirāo Shopping & 6 & 8 & 5 & 6 \\
\hline 森 & 1 & & & Ribeirāo Shopping & 9 & 9 & 8 & 9 \\
\hline 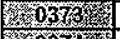 & & & 3 & Ribeirão Shopping & 10 & 10 & 7 & 10 \\
\hline 5 & & & 3 & Ribeiråa Shopping & 8 & 10 & 8 & 8 \\
\hline 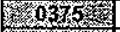 & 1 & 2 & & Novo Shopping & 10 & 8 & 7 & 8 \\
\hline (5) 03765 & 1 & 2 & & Ribeirāo Shopping & 9 & 10 & 7 & 8 \\
\hline 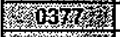 & & & & Ribeirāo Shopping & 7 & 5 & 6 & 7 \\
\hline 60378 & & 2 & & Ribeirão Shopping & 10 & 9 & 8 & 8 \\
\hline OS78 & 1 & & & Novo Shopping & 8 & 9 & 7 & 8 \\
\hline 36038003 & & 2 & & Ribeirāo Shopping & 8 & 8 & 9 & 7 \\
\hline X $038 \mathrm{~B}$ & & 2 & & Ribeirão Shopping & 10 & 8 & 10 & 10 \\
\hline 15. 0382 & 1 & & & Ribeirāo Shopping & 8 & 6 & 7 & 8 \\
\hline 0363 & 1 & 2 & & Ribeirāo Shopping & 9 & 8 & 3 & 10 \\
\hline 03944 & & 2 & & Ribeirão Shopping & 10 & 7 & 7 & 7 \\
\hline 0385 & & 2 & & Ribeirāo Shopping & 7 & 9 & 6 & 8 \\
\hline 60306 & 1 & & & Ribeirão Shopping & 8 & 9 & 7 & 8 \\
\hline 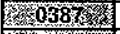 & 1 & 2 & & Novo Shopping & 10 & 10 & 8 & 8 \\
\hline 3. & & & 3 & Ribeirāo Shopping & 10 & 10 & 8 & 9 \\
\hline 30039 & 1 & & 3 & Ribeirão Shopping & 9 & 9 & 8 & 9 \\
\hline$\gamma_{30390}$ & & 2 & & Ribeirāo Shopping & 10 & 10 & 9 & 9 \\
\hline 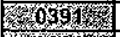 & 1 & 2 & & Ribeirāo Shopping & 9 & 9 & 8 & 9 \\
\hline 0392 & 1 & & & Novo Shopping & 8 & 9 & 5 & 6 \\
\hline 263923 & 1 & & 3 & Ribeirāo Shopping & 8 & 10 & 5 & 7 \\
\hline K & & & 3 & Ribeirão Shopping & 8 & 10 & 8 & 8 \\
\hline 0395 & & & 3 & Ribeirăo Shopping & 10 & 10 & 8 & 8 \\
\hline 0396 & 1 & 2 & & Novo Shopping & 8 & 7 & 7 & 8 \\
\hline 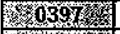 & 1 & 2 & & Ribeirāo Shopping & 9 & 10 & 10 & 10 \\
\hline 0398 . & 1 & 2 & & Ribeiräo Shopping & 8 & 8 & 6 & 7 \\
\hline 6 0399 & & 2 & & Novo Shopping & 10 & 8 & 10 & 9 \\
\hline 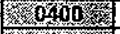 & & & 3 & Ribeiräo Shopping & 10 & 6 & 5 & 7 \\
\hline \% & & 2 & & Rịbeirāo Shopping & 10 & 10 & 6 & 7 \\
\hline 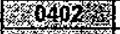 & 1 & 2 & & Ribeirão Shopping & 8 & 10 & 5 & 8 \\
\hline 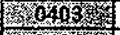 & & 2 & & Santa Úrsula & $\overline{9}$ & 10 & 5 & 7 \\
\hline 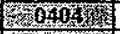 & 1 & & & Novo Shopping & $\dot{9}$ & 10 & 10 & 9 \\
\hline$x_{x}=0405$ & & 2 & & Novo Shopping & 10 & 10 & 10 & 10 \\
\hline$=04065 \%$ & & 2 & & Ribeirão Shopping & 9 & 9 & 9 & 10 \\
\hline - $0400_{0}$ & 1 & & & Novo Shopping & 7 & 8 & 7 & 8 \\
\hline$=0408$ & & & 3 & Ribeiräo Shopping & 10 & 9 & 5 & 5 \\
\hline $2000 \%$ & 1 & 2 & & Ribeirão Shopping & 10 & 5 & 5 & 8 \\
\hline r. 0400 & 1 & & & Ribeirão Shopping & 9 & 8 & 9 & 9 \\
\hline 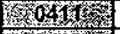 & & 2 & & Ribeiräo Shopping & 7 & 6 & 5 & 7 \\
\hline 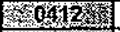 & 1 & 2 & & Ribeirão Shopping & 8 & 8 & 6 & 5 \\
\hline 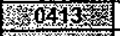 & & & 3 & Ribeirão Shopping & 10 & 10 & 10 & 10 \\
\hline 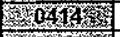 & 1 & & & Ribeiräo Shopping & $\dot{8}$ & 9 & 8 & 9 \\
\hline 045 & & 2 & & Ribeirāo Shopping & 10 & 10 & 8 & 10 \\
\hline 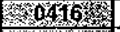 & & 2 & & Ribeirão Shopping & 9 & 7 & 7 & 7 \\
\hline 30417 纹 & 1 & & & Ribeirāo Shopping & 10 & 9 & 5 & 7 \\
\hline $041 \mathrm{~B}^{2}$ & & & 3 & Ribeirāo Shopping & 9 & 9 & 9 & 8 \\
\hline 0049 & & 2 & & Novo Shopping & 8 & 7 & 6 & 9 \\
\hline 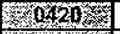 & 1 & & & Ribeirāo Shopping & 9 & 9 & 7 & 9 \\
\hline 0421 \% & 1 & 2 & & Ribeirâo Shopping & 9 & 9 & 7 & 8 \\
\hline $10422 \leq 1$ & & 2 & & Ribeirão Shopping & 10 & $\overline{9}$ & 7 & 9 \\
\hline 0483 & & 2 & & Ribeirāo Shopping & 9 & 10 & 8 & 8 \\
\hline 02240 & & 2 & & Ribeirāo Shopping & 9 & 10 & 8 & 8 \\
\hline 0425 政 & & & 3 & Novo Shopping & 9 & 10 & 8 & 8 \\
\hline 0426 & & 2 & & Ribeirão Shopping & 9 & 10 & 8 & 9 \\
\hline
\end{tabular}




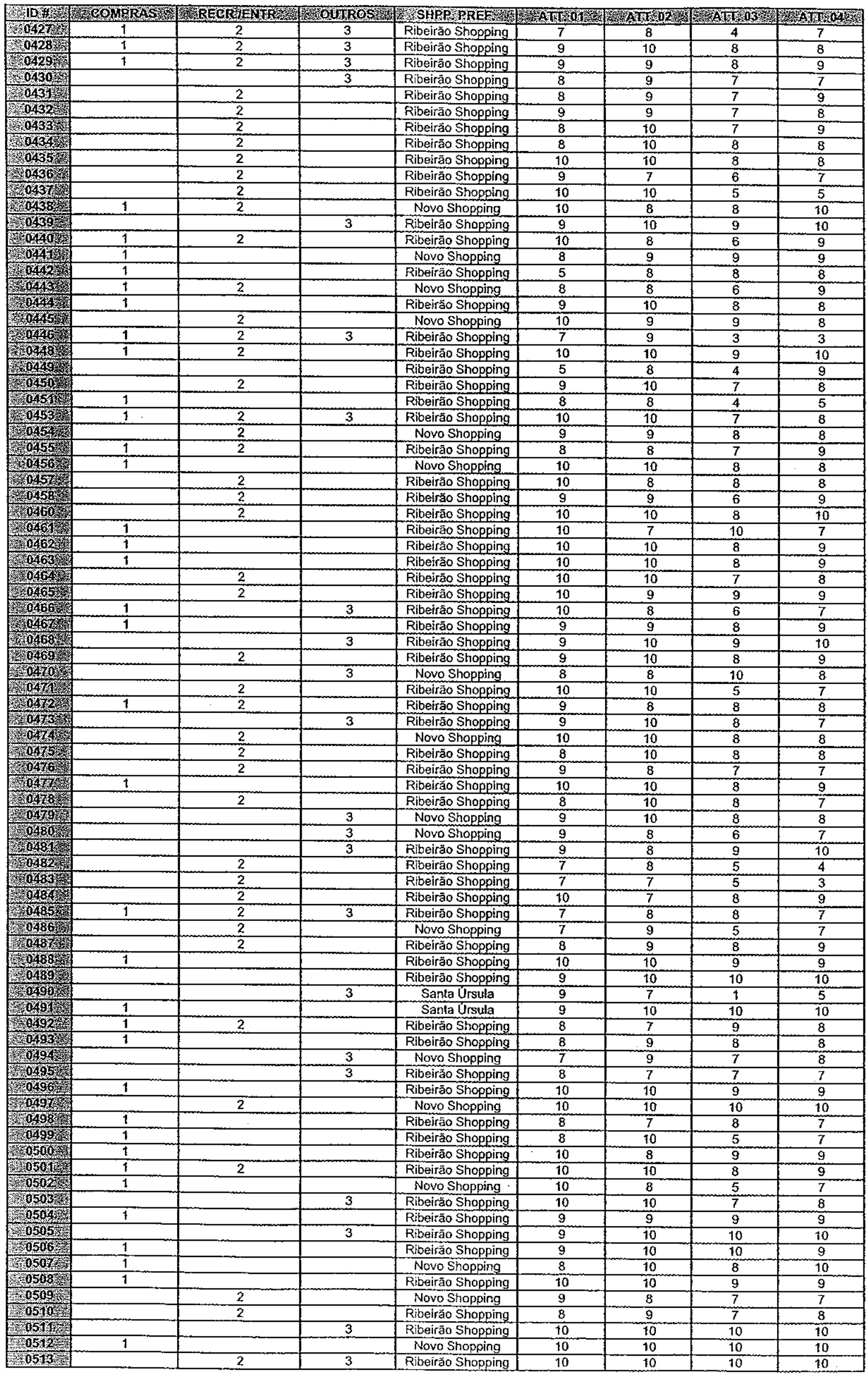




\begin{tabular}{|c|c|c|c|c|c|c|c|c|}
\hline 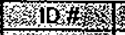 & 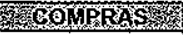 & 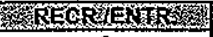 & 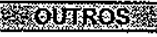 & W & 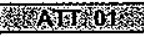 & 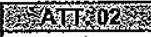 & 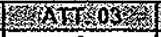 & 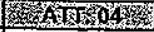 \\
\hline 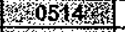 & 1 & 2 & & Ribeirăo Shopping & 10 & 10 & 8 & 7 \\
\hline 20516 & & & 3 & Ribeirão Shopping & 9 & 10 & 9 & 10 \\
\hline yost & 1 & & & Novo Shopping & 10 & 7 & 10 & 10 \\
\hline - & & 2 & & Ribeirāo Shopping & 8 & 10 & 8 & 9 \\
\hline 0,519 & 1 & & & Santa Ursula & 10 & 10 & 10 & 7 \\
\hline 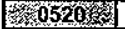 & & 2 & & Ribeirão Shopping & 8 & 9 & 7 & 8 \\
\hline 0521 & 1 & & & Novo Shopping & 6 & 7 & 2 & 9 \\
\hline 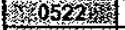 & & & 3 & Novo Shopping & 8 & 8 & 7 & 8 \\
\hline 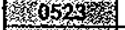 & 1 & & & Novo Shopping & 6 & 7 & 8 & 5 \\
\hline 0524 & & 2 & & Ribeirāo Shopping & 10 & 10 & 9 & 5 \\
\hline ( 0525 & & 2 & & Ribeirão Shopping & 9 & 9 & 7 & 8 \\
\hline 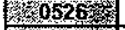 & 1 & & & Ribeirāo Shopping & 10 & 9 & 10 & 10 \\
\hline 節 & & 2 & & Novo Shopping & 7 & 5 & 6 & 7 \\
\hline r & & 2 & & Novo Shopping & 10 & 9 & 9 & 8 \\
\hline 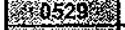 & & & 3 & Ribeirāo Shopping & 9 & 10 & 8 & 10 \\
\hline 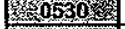 & 1 & & & Novo Shopping & 5 & 7 & 7 & 10 \\
\hline 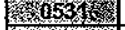 & & 2 & & Novo Shopping & 8 & 8 & 7 & 9 \\
\hline 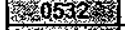 & & & & Ribeirâo Shopping & 10 & 7 & 8 & 10 \\
\hline 答 & 1 & & & Santa Úrsula & 8 & 5 & 4 & 5 \\
\hline 20534 & 1 & & & Novo Shopping & 10 & 10 & 10 & 9 \\
\hline 1. 15353 & & 2 & & Ribeirão Shopping & 10 & 10 & 10 & 9 \\
\hline - & & 2 & & Novo Shopping & 10 & 10 & 6 & 8 \\
\hline 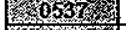 & 1 & & & Ribeirāo Shopping & 10 & 5 & 8 & 8 \\
\hline 0 & & 2 & & Ribeirāo Shopping & 8 & 9 & 8 & 8 \\
\hline 0539 & & 2 & & Ribeirāo Shopping & 10 & 10 & 8 & 8 \\
\hline 13ros & 1 & & & Novo Shopping & 10 & 10 & 8 & 8 \\
\hline 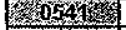 & & & & Ribeirăo Shopping & 6 & 8 & 8 & 5 \\
\hline 䇣 & 1 & 2 & & Rjbeirāo Shopping & 9 & 7 & 6 & 7 \\
\hline 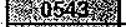 & 1 & & & Ribeirão Shopping & 2 & 3 & 4 & 1. \\
\hline Fisys & 1 & 2 & & Ribeiråo Shopping & 9 & 9 & 9 & 9 \\
\hline - & 1 & 2 & & Ribeirão Shopping & 10 & 10 & 8 & 9 \\
\hline 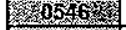 & & 2 & & Ribeirão Shopping & 10 & 9 & 6 & 8 \\
\hline 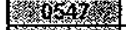 & 1 & & & Santa Ursula & 8 & 6 & 8 & 7 \\
\hline 20 & 1 & 2 & & Santa Ursula & 10 & 9 & 8 & 8 \\
\hline Co50 & 1 & & & Ribeirăo Shopping & 10 & 9 & 5 & 9 \\
\hline 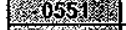 & 1 & 2 & & Ribeirāo Shopping & 8 & 9 & 7 & 8 \\
\hline 205020 & 1 & & & Ribeirảo Shopping & 10 & 10 & 9 & 10 \\
\hline 0553 & & 2 & & Ribeirăo Shopping & 10 & 9 & 8 & 8 \\
\hline 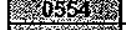 & & 2 & & Ribeirāo Shopping & 9 & 8 & 7 & 8 \\
\hline 棇 & & & & Ribeirão Shopping & 10 & 10 & 8 & 8 \\
\hline S & 1 & 2 & & Ribeirão Shopping & 10 & 10 & 7 & 8 \\
\hline 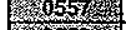 & 1 & 2 & & Novo Shopping & 9 & 9 & 7 & 8 \\
\hline 10558 & 1 & & & Santa Ursula & 10 & 7 & 8 & 8 \\
\hline 等 & & 2 & & Novo Shopping & 10 & 10 & 9 & 9 \\
\hline 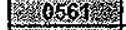 & 1 & 2 & & Ribeirāo Shopping & 10 & 10 & 8 & 9 \\
\hline 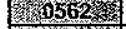 & 1 & & 3 & Ribeirão Shopping & 9 & 8 & 7 & 9 \\
\hline 0563 & & 2 & & Ribeiräo Shopping & 8 & 8 & 7 & 8 \\
\hline 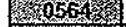 & 1 & 2 & & Ribeiräo Shopping & 9 & 10 & 10 & 10 \\
\hline 0565 & 1 & 2 & 3 & Ribeirāo Shopping & 8 & 8 & 9 & 7 \\
\hline 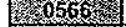 & & 2 & & Santa Ưrsula & 7 & 7 & 9 & 9 \\
\hline 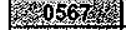 & 1 & & & Ribeirāo Shopping & 7 & 7 & 7 & 8 \\
\hline 0558 & & 2 & & Santa Úrsula & 8 & 8 & 8 & 8 \\
\hline 3 & 1 & 2 & & Santa Úrsula & 2 & 4 & 5 & 4 \\
\hline 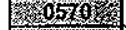 & 1 & & & Ribeirão Shopping & 8 & 9 & 7 & 8 \\
\hline ris & 1 & & & Ribeiråo Shopping & 10 & 10 & 10 & 10 \\
\hline 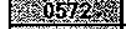 & 1 & 2 & & Santa Ursula & 8 & 8 & 8 & 7 \\
\hline 0583 & & 2 & & Santa Úrsula & 7 & 5 & 5 & 5 \\
\hline 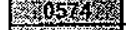 & & 2 & & Santa Ursula & 9 & 7 & 5 & 7 \\
\hline 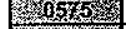 & & 2 & & Ribeirão Shopping & 10 & 9 & 9 & 10 \\
\hline 50566 & 1 & 2 & & Ribeirâo Shopping & 10 & 10 & 9 & 8 \\
\hline 057 & 1 & 2 & 3 & Ribeirâo Shopping & 8 & 7 & 9 & 7 \\
\hline 20578 & 1 & 2 & & Ribeirāo Shopping & 9 & 10 & 7 & 7 \\
\hline 659 & 1 & 2 & & Ribeirāo Shopping & 9 & 10 & 8 & 8 \\
\hline 0580 & 1 & & & Santa Úrsula & 8 & 8 & 8 & 8 \\
\hline 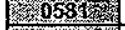 & & 2 & & Ribeirão Shopping & 10 & 10 & 10 & 9 \\
\hline gros & & 2 & & Ribeirāo Shopping & 8 & 9 & 7 & 7 \\
\hline - & & 2 & & Ribeirāo Shopping & 9 & 9 & 10 & 10 \\
\hline - 0588 & & & & Ribeirāo Shopping & 10 & 10 & & 10 \\
\hline 10585\% & & 2 & & Novo Shopping & 9 & 8 & 5 & 7 \\
\hline 0586 & & & 3 & Ribeirāo Shopping & 8 & 7 & 7 & 8 \\
\hline 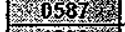 & 1 & 2 & & Ribeirâo Shopping & 8 & 10 & 8 & 10 \\
\hline . & & 2 & & Novo Shopping & 7 & 7 & 5 & 7 \\
\hline res89. & 1 & 2 & & Ribeirāo Shopping & 10 & 10 & 8 & 9 \\
\hline 30590 & 1 & 2 & & Ribeirão Shopping & 9 & 9 & 8 & 10 \\
\hline 0591 & 1 & & & Ribeirāo Shopping & 10 & 10 & 9 & 9 \\
\hline$=0592$ & & 2 & & Ribeirão Shopping & 8 & 10 & 8 & 8 \\
\hline 0593 & 1 & 2 & & Ribeirao Shopping & 8 & 9 & 3 & 9 \\
\hline 0594 & & & 3 & Novo Shopping & 8 & 10 & 5 & 7 \\
\hline $2=0595$ & & 2 & & Ribeiräo Shopping & 8 & 9 & 10 & 7 \\
\hline res96 & 1 & 2 & & Ribeirāo Shopping & 10 & 9 & 8 & 9 \\
\hline 0597 & & 2 & & Ribeirão Shopping & 9 & 10 & 9 & 9 \\
\hline 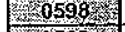 & & 2 & & Ribeirão Shopping & 8 & 7 & 7 & 6 \\
\hline 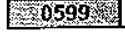 & & 2 & & Ribeirão Shopping & 10 & 9 & 10 & 10 \\
\hline
\end{tabular}




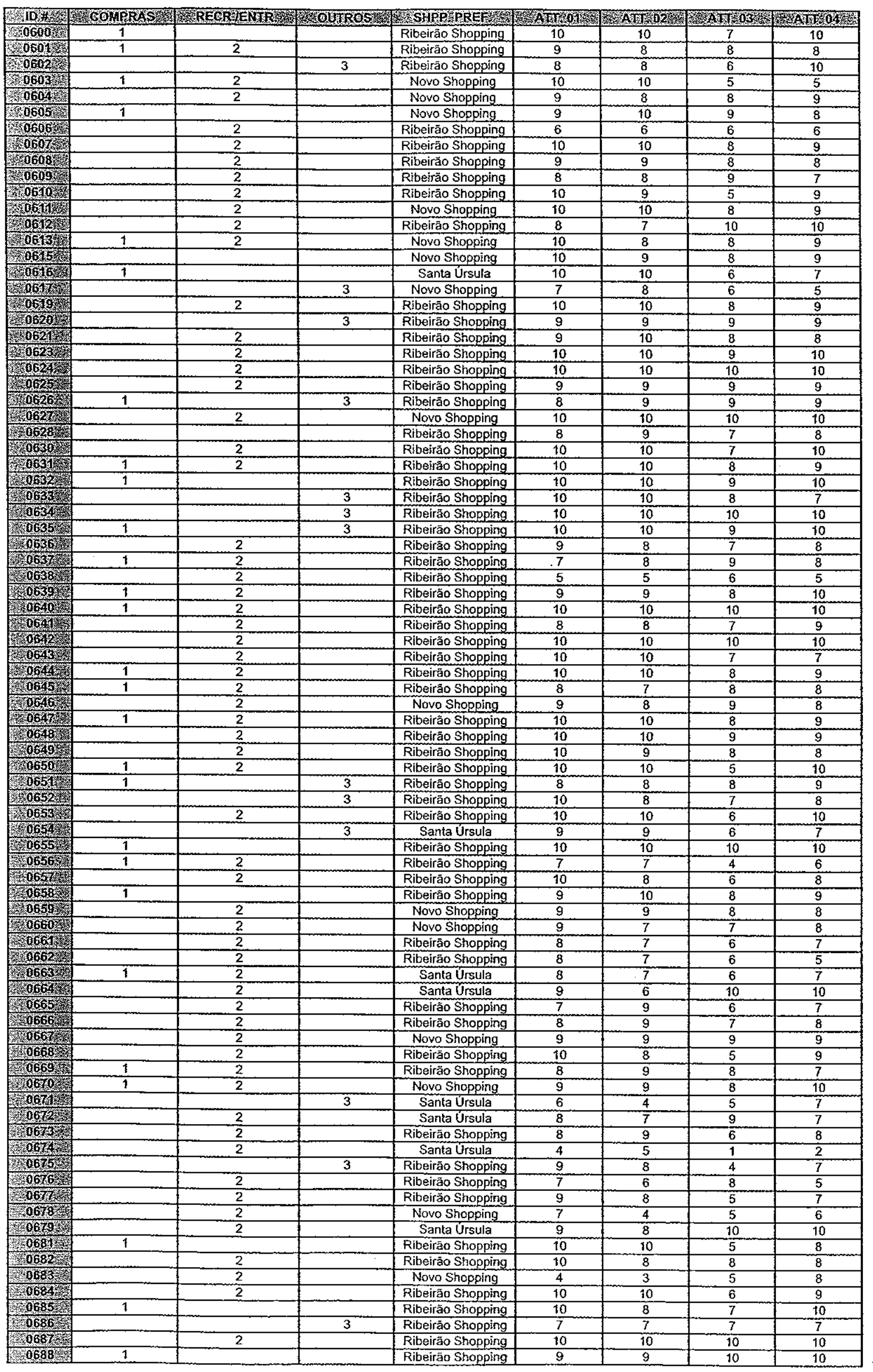




\begin{tabular}{|c|c|c|c|c|c|c|c|c|c|}
\hline 筑 10 & 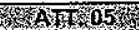 & 96 & 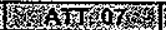 & 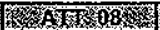 & 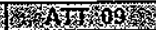 & 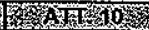 & 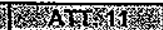 & r & 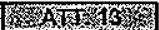 \\
\hline 00012 & 6 & 0 & 8 & 6 & 6 & 2 & 9 & 10 & 8 \\
\hline W 0003 & 5 & 8 & 9 & 4 & 3 & 7 & 7 & 7 & 9 \\
\hline 0005 & 7 & 7 & 6 & 5 & 7 & 4 & 10 & 9 & 6 \\
\hline S & 10 & 10 & 10 & 4 & 5 & 10 & 10 & 10 & 5 \\
\hline S & 7 & 8 & 10 & 6 & 7 & 6 & 1 & 5 & 7 \\
\hline 150008 & 9 & 7 & 9 & 10 & 2 & 4 & 7 & 1 & 9 \\
\hline 13001 & 10 & 9 & 9 & 8 & 9 & 8 & 9 & 9 & 10 \\
\hline 落 0012 & 8 & 7 & 7 & 7 & 8 & 6 & 7 & 9 & 9 \\
\hline 0013 & 10 & 10 & 10 & 9 & 10 & 5 & 5 & 7 & 7 \\
\hline Y $00 \mathrm{TS}$ & 9 & 9 & 9 & 9 & 9 & 8 & 2 & 4 & 5 \\
\hline 6 0015 & 6 & 10 & 8 & 10 & 10 & 5 & 8 & 8 & 8 \\
\hline 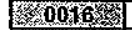 & 9 & 9 & 9 & 7 & 9 & 9 & 6 & 7 & 9 \\
\hline 5002 & 9 & 9 & 8 & 10 & 9 & 9 & 3 & 3 & 9 \\
\hline 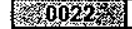 & 9 & 10 & 8 & 5 & 6 & 8 & 10 & 8 & 10 \\
\hline $0023 \%$ & 9 & 10 & 9 & 9 & 9 & 8 & 5 & 6 & 9 \\
\hline Fin & 10 & 7 & 10 & 4 & 6 & 6 & 9 & 9 & 6 \\
\hline 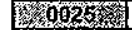 & 10 & 10 & 10 & 7 & 8 & 9 & 9 & 7 & 8 \\
\hline 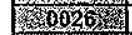 & 10 & 6 & 10 & 8 & 10 & 6 & 8 & 10 & 8 \\
\hline S $002 \%$ \% & 8 & 9 & 7 & 7 & 8 & 6 & 5 & 5 & 10 \\
\hline 20028 & 10 & 10 & 10 & 7 & 7 & 10 & 7 & 5 & 10 \\
\hline ris 00026 & 10 & 10 & 9 & 9 & 10 & 8 & 10 & 10 & 7 \\
\hline \% 6030 & 9 & 10 & 9 & 9 & 9 & 9 & 1 & 1 & 9 \\
\hline 00315 & 7 & 9 & 7 & 6 & 7 & 9 & 1 & 1 & 8 \\
\hline 00032 & 9 & 8 & 8 & 7 & 8 & 10 & 5 & 8 & 8 \\
\hline 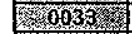 & 7 & 6 & 5 & 8 & 9 & 9 & 1 & 9 & 9 \\
\hline 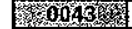 & 5 & 6 & 8 & 9 & 9 & 9 & 5 & 5 & 9 \\
\hline 6004 & 4 & 2 & 3 & 6 & 8 & 10 & 1 & 1 & 8 \\
\hline - 0045 & 9 & 7 & 8 & 9 & 9 & 9 & 5 & 5 & 8 \\
\hline$\xi_{20046}$ & 6 & 8 & 7 & 7 & 6 & 6 & 8 & 6 & 7 \\
\hline ( & 9 & 10 & 10 & 10 & 9 & 10 & 10 & 10 & 10 \\
\hline 0048 & 7 & 6 & 6 & 8 & 7 & 8 & 2 & 2 & 6 \\
\hline 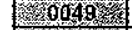 & 9 & -8 & 8 & 10 & 10 & 9 & 7 & 7 & 9 \\
\hline 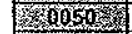 & 10 & 9 & 10 & 9 & 10 & 9 & 6 & 7 & 9 \\
\hline 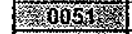 & 10 & 8 & 9 & 10 & 10 & 8 & 7 & 10 & 10 \\
\hline S & 9 & 10 & 9 & 8 & 9 & 8 & 8 & 10 & 10 \\
\hline 6 & 7 & 9 & 8 & 10 & 9 & 8 & 7 & 8 & 9 \\
\hline - 005, & 7 & 6 & 5 & 7 & 9 & 6 & 10 & 10 & 10 \\
\hline S & 7 & 10 & 5 & 10 & 8 & 8 & 5 & 3 & 9 \\
\hline W05 & 8 & 7 & 8 & 10 & 10 & 10 & 1 & 1 & 10 \\
\hline 3. 005 & 10 & 7 & 5 & 10 & 9 & 10 & 1 & 1 & 10 \\
\hline 3 & 10 & 10 & 10 & 10 & 10 & 10 & 0 & 0 & 10 \\
\hline $0059 \mathrm{x}$ & 9 & 10 & 9 & 10 & 9 & 9 & 7 & 7 & 9 \\
\hline K & 9 & 8 & 8 & 7 & 8 & 8 & 7 & 7 & 8 \\
\hline 3006 T & 7 & 3 & 3 & 8 & 7 & 8 & 5 & 8 & 7 \\
\hline 1.002 & 10 & 7 & 10 & 10 & 10 & 9 & 0 & 0 & 10 \\
\hline ro003 & 9 & 8 & 10 & 10 & 9 & 10 & 1 & 1 & 10 \\
\hline S 0060 \% & 8 & 8 & 9 & 9 & 10 & & 6 & 9 & 10 \\
\hline 2. 0065 & 8 & 1 & 1 & 9 & 10 & 9 & 1 & 1 & 9 \\
\hline 0066 & 10 & 5 & 10 & 8 & 10 & 10 & 5 & 8 & 10 \\
\hline COD & 10 & 5 & 7 & 8 & 10 & 10 & 7 & 8 & 10 \\
\hline $0068 \mathrm{~g}$ & 8 & 5 & 5 & 8 & 8 & 7 & 5 & 7 & 7 \\
\hline
\end{tabular}




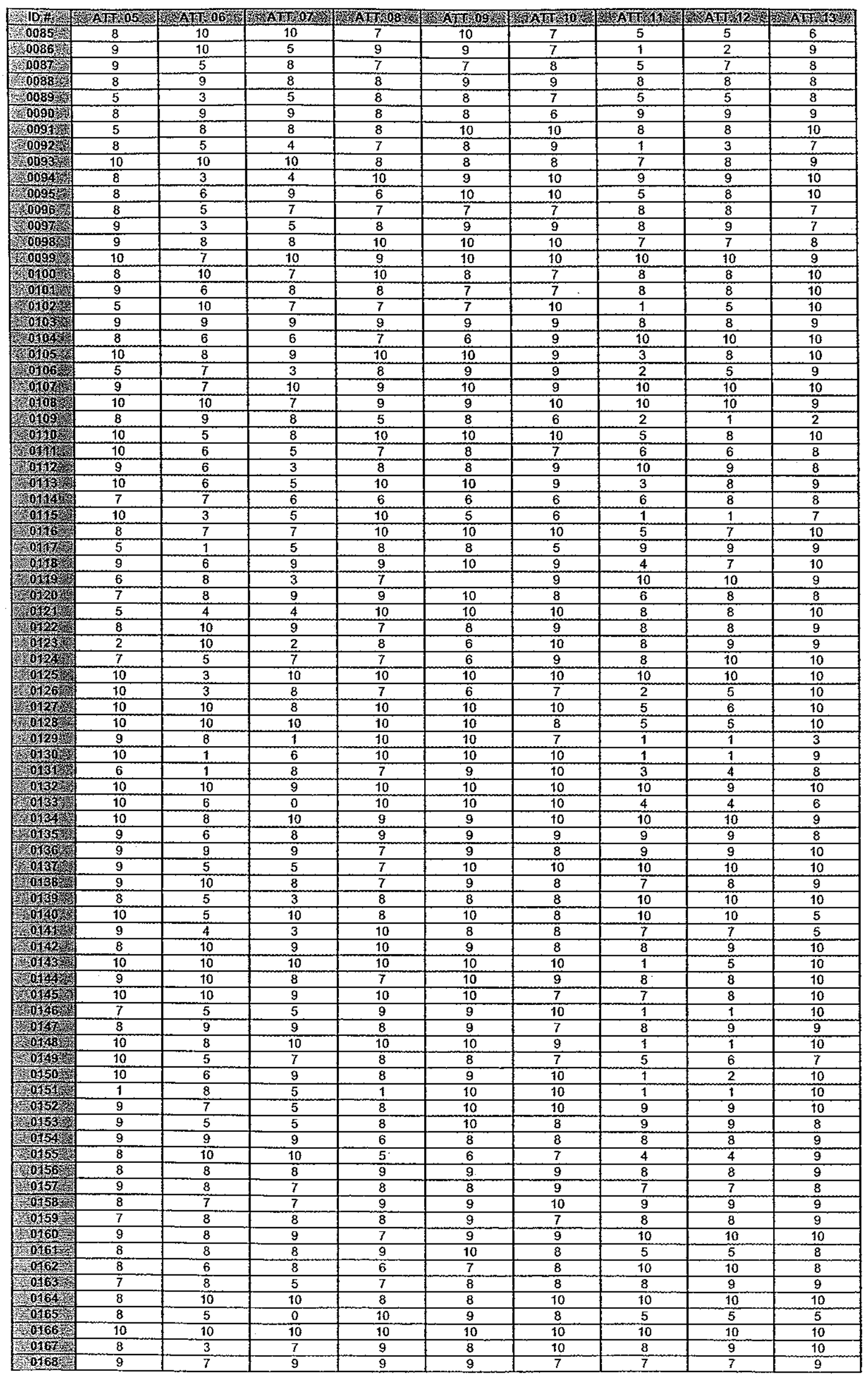




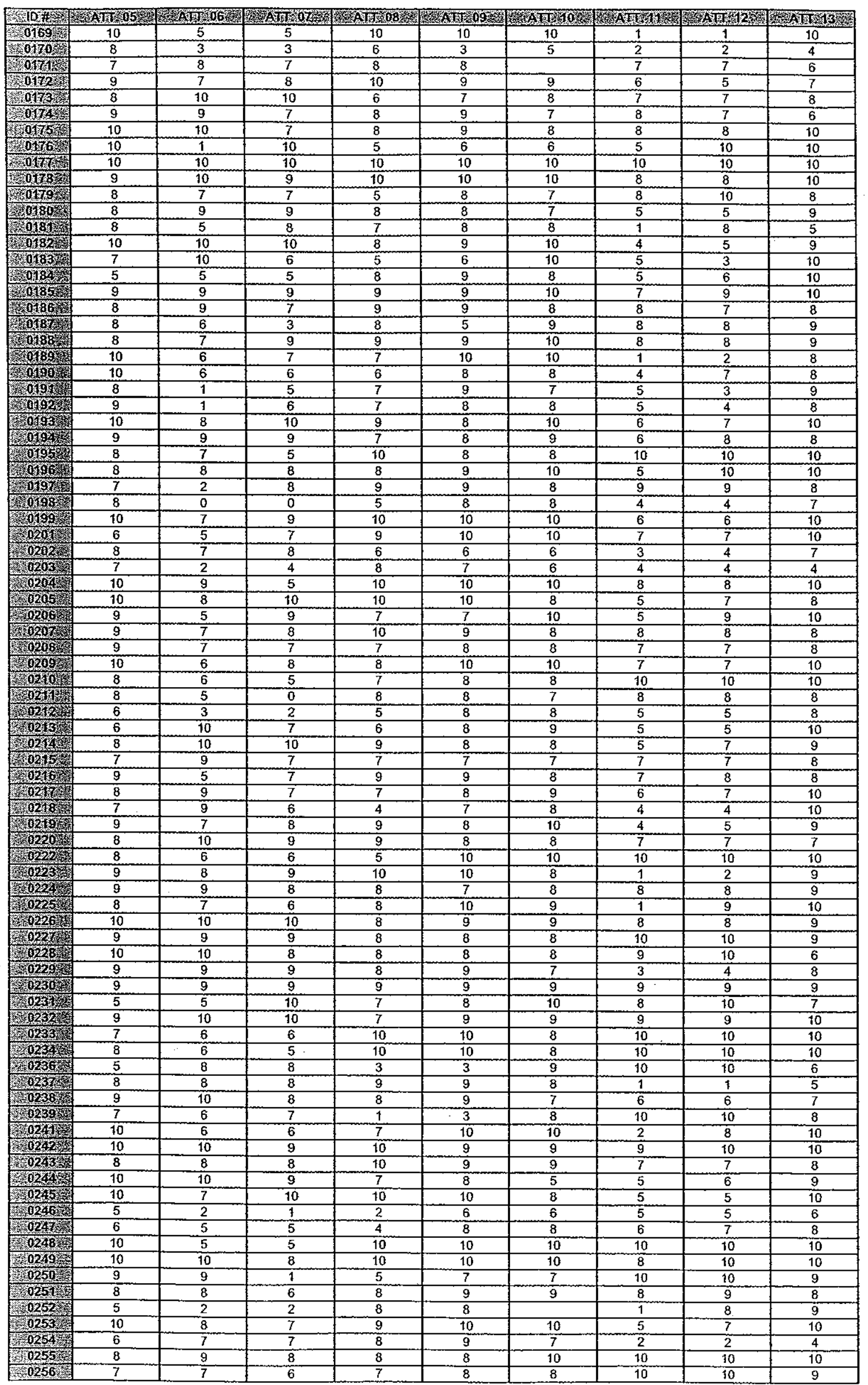




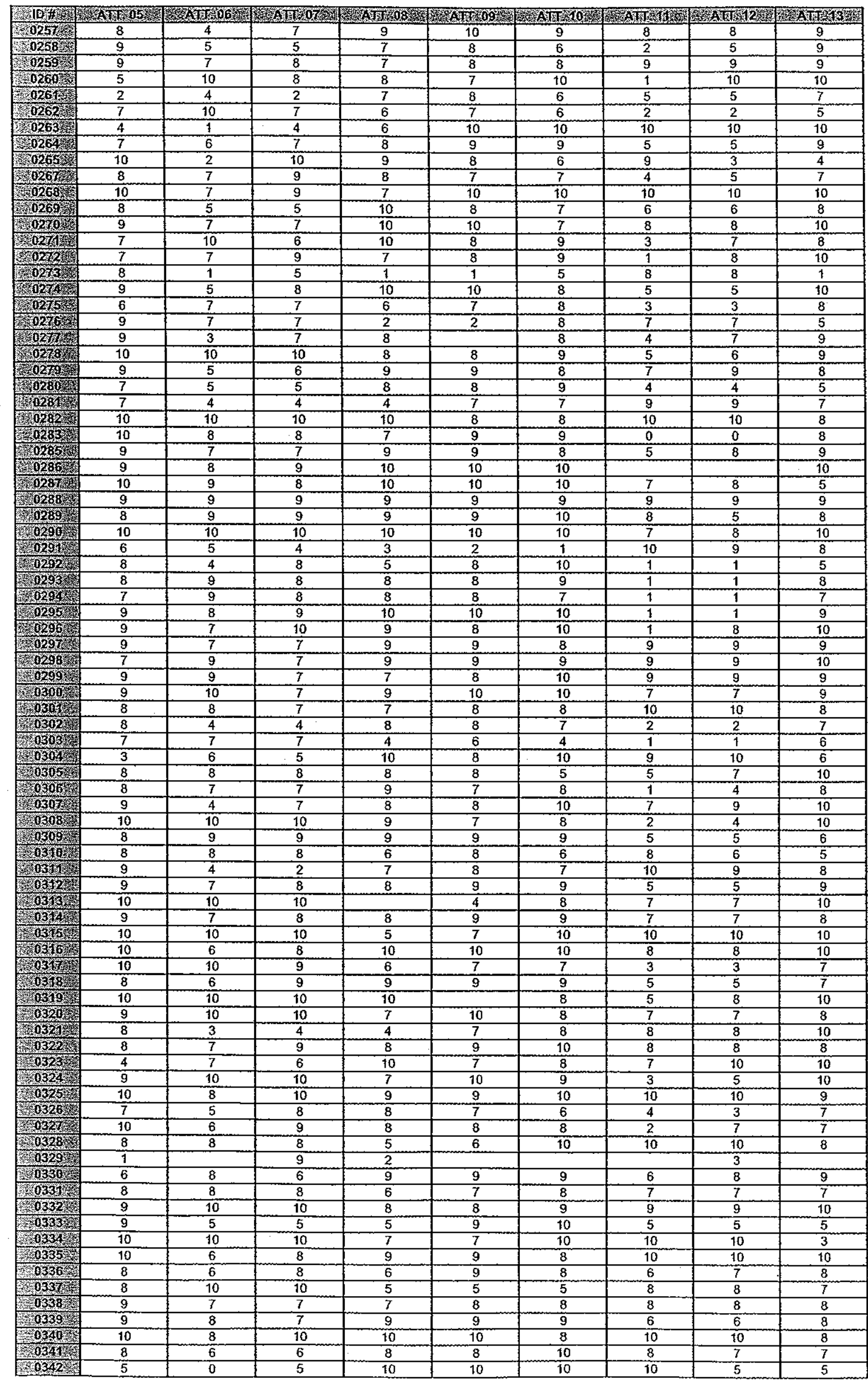




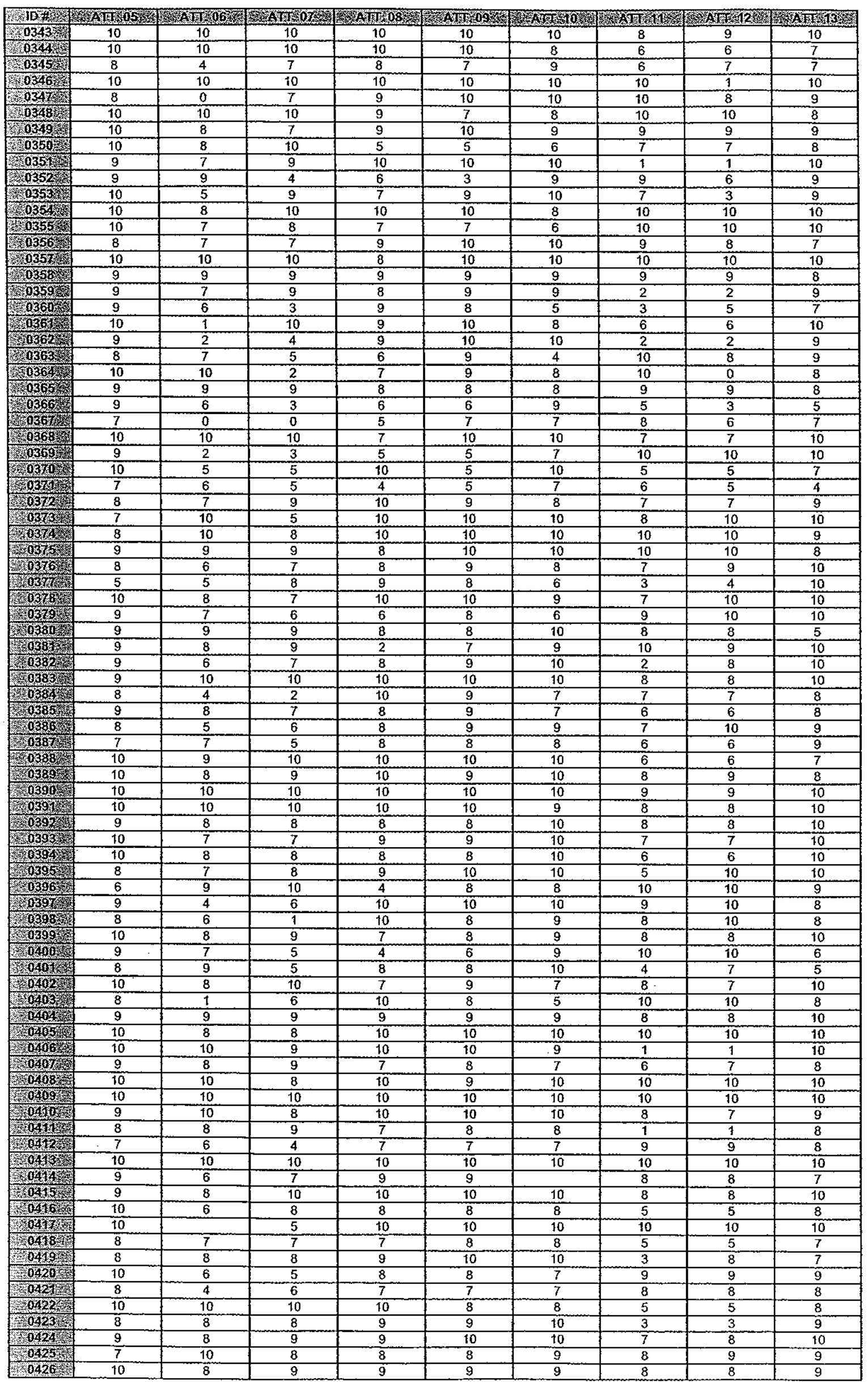




\begin{tabular}{|c|c|c|c|c|c|c|c|c|c|}
\hline 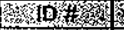 & 型 & 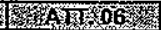 & 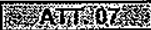 & 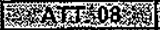 & 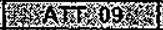 & 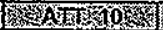 & W & 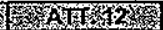 & 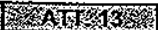 \\
\hline 04276 & 7 & 6 & 2 & 9 & 10 & 9 & 7 & 7 & 7 \\
\hline 0.429 & 9 & 7 & 6 & 7 & 8 & 8 & 5 & 5 & 5 \\
\hline 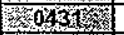 & 8 & 9 & 7 & 8 & 9 & 9 & 10 & 9 & 9 \\
\hline 30432 & 9 & 8 & 7 & 9 & 9 & 9 & 9 & 9 & 8 \\
\hline 04338 & 8 & 8 & 8 & 10 & 10 & 10 & 7 & 7 & 10 \\
\hline (10434 & 9 & 5 & 6 & 8 & 8 & 8 & 6 & 6 & 9 \\
\hline 3\% & 10 & 10 & 10 & 5 & 5 & 10 & 5 & 10 & 10 \\
\hline $50438 ;$ & 10 & 10 & 10 & 10 & 10 & 8 & 10 & 10 & 10 \\
\hline 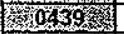 & 9 & 5 & 7 & 9 & 9 & 9 & 9 & 9 & 7 \\
\hline O 06010 & 1 & 3 & 8 & 6 & 3 & 4 & 9 & 6 & 5 \\
\hline - 0440 & 9 & 10 & 8 & 10 & 9 & 10 & 10 & 9 & 10 \\
\hline 至 & 7 & 4 & 4 & 8 & 8 & 8 & 10 & 8 & 8 \\
\hline 5 K & 10 & 5 & 9 & 10 & 10 & 10 & 10 & 10 & 10 \\
\hline 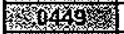 & 4 & 5 & 9 & 10 & 10 & 10 & 8 & 7 & 10 \\
\hline S & 10 & 6 & 6 & 9 & 8 & 8 & 8 & 10 & 9 \\
\hline 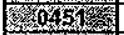 & 8 & 4 & 4 & 9 & 10 & 8 & 10 & 10 & 7 \\
\hline 6 & 9 & 10 & 10 & 10 & 10 & 10 & 6 & 5 & 10 \\
\hline S & 9 & 8 & 9 & 9 & 10 & 9 & 10 & 10 & 10 \\
\hline 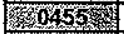 & 8 & 5 & 7 & 8 & 8 & 9 & 10 & 8 & 8 \\
\hline 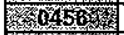 & 9 & 9 & 9 & 9 & 10 & 9 & 9 & 10 & 10 \\
\hline K & 8 & 8 & 8 & 10 & 9 & 10 & 8 & 10 & 10 \\
\hline 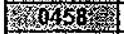 & 6 & 6 & 5 & 9 & 9 & 9 & 7 & 8 & 9 \\
\hline 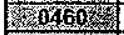 & 10 & 8 & 10 & 10 & 10 & 10 & 8 & 10 & 10 \\
\hline 3 & 7 & 4 & 8 & 8 & 8 & 6 & 6 & 6 & 7 \\
\hline 04625 & 8 & 7 & 7 & 10 & 10 & 9 & 8 & 6 & 8 \\
\hline - 042 & 9 & 6 & 6 & 10 & 10 & 9 & 7 & 5 & 9 \\
\hline $04 \mathrm{z}$ & 10 & 8 & 9 & 10 & 10 & 8 & 5 & 5 & 10 \\
\hline - 04784 & 9 & 5 & 7 & 9 & 9 & 10 & 5 & 8 & 10 \\
\hline 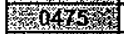 & 9 & 5 & 8 & 7 & 9 & 10 & 5 & 5 & 8 \\
\hline 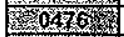 & 8 & 3 & 5 & 7 & 8 & 6 & 9 & 8 & 10 \\
\hline $0,9 \mathrm{~g}$ & 9 & 8 & 7 & 10 & 10 & 10 & 10 & 10 & 10 \\
\hline 00428 . & 10 & 10 & 10 & 10 & 10 & 10 & 5 & 5 & 10 \\
\hline 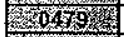 & 10 & 9 & 9 & 8 & 8 & 9 & 3 & 3 & 10 \\
\hline 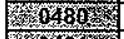 & 8 & 10 & 6 & 7 & 5 & 9 & 7 & 3 & 5 \\
\hline S6 & 8 & 7 & 10 & 6 & 7 & 7 & 6 & 6 & 8 \\
\hline S & 3 & 5 & 1 & 10 & 9 & 8 & 10 & 10 & 9 \\
\hline 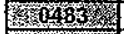 & & 7 & 7 & 7 & 7 & 5 & 5 & 5 & 7 \\
\hline 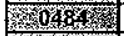 & 9 & 10 & 9 & 10 & 9 & 8 & 7 & 7 & 10 \\
\hline 680465 & 7 & 9 & 7 & 9 & 10 & 10 & 3 & 1 & 10 \\
\hline 15. 0485 & 7 & 5 & 5 & 8 & 8 & 7 & 1 & 1 & 7 \\
\hline 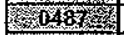 & 7 & 5 & 7 & 9 & 10 & 10 & 5 & 6 & 9 \\
\hline 6 & 10 & 9 & 9 & 9 & 10 & 10 & 9 & 9 & 9 \\
\hline 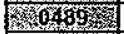 & 10 & 10 & 10 & 10 & 10 & 10 & 5 & 5 & 10 \\
\hline K & 8 & 5 & 0 & 3 & 8 & 6 & 3 & 9 & 6 \\
\hline 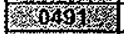 & 9 & 7 & 7 & 10 & 9 & 8 & 1 & 1 & 8 \\
\hline K & 7 & 9 & 8 & 10 & 9 & 6 & 5 & 3 & 9 \\
\hline Ka & 9 & 4 & 8 & 8 & 7 & 6 & 1 & 1 & 8 \\
\hline 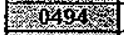 & 8 & 9 & 8 & 9 & 9 & 10 & 8 & 8 & 9 \\
\hline 沗 & 6 & 6 & 6 & 8 & 10 & 10 & 5 & 5 & 7 \\
\hline 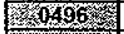 & 10 & 9 & 10 & 10 & 10 & 10 & 5 & 9 & 10 \\
\hline 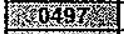 & 10 & 10 & 10 & 10 & 10 & 10 & 8 & 8 & 10 \\
\hline
\end{tabular}




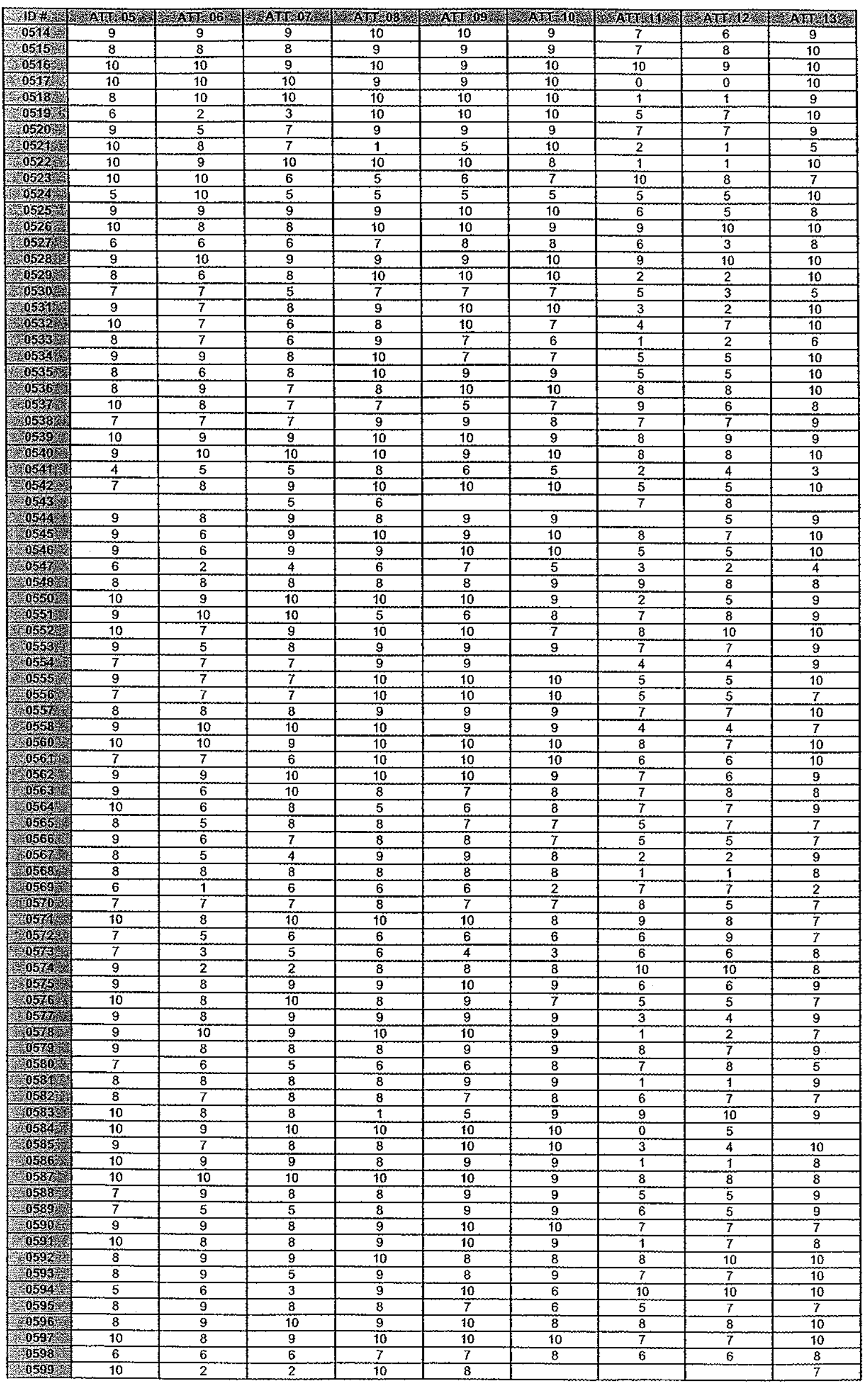




\begin{tabular}{|c|c|c|c|c|c|c|c|c|c|}
\hline - & 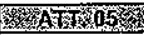 & F & 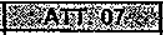 & 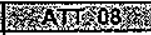 & M & 徨 & 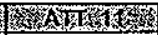 & 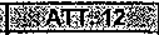 & 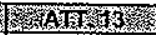 \\
\hline $0600 \mathrm{k}$ & 10 & 1 & 1 & 7 & 8 & 10 & & & 8 \\
\hline 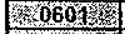 & 10 & 8 & 8 & 10 & 10 & 10 & & & 9 \\
\hline 0602 . & 10 & 10 & 10 & 6 & 6 & 7 & 9 & 8 & 9 \\
\hline 3. 0603 & 5 & 10 & 2 & 5 & 10 & 5 & 5 & 5 & 10 \\
\hline 0604 & 9 & 9 & 10 & 10 & 9 & 10 & 8 & 7 & 9 \\
\hline 20605 & 8 & 6 & 8 & 10 & 10 & 10 & 9 & 9 & 10 \\
\hline 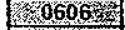 & 6 & 6 & 6 & 6 & 6 & 6 & 6 & 6 & 6 \\
\hline 20607 & 9 & 9 & 8 & 9 & 9 & 10 & 7 & 7 & 10 \\
\hline 经 & 8 & 7 & 8 & 8 & 10 & 10 & 5 & 5 & 10 \\
\hline 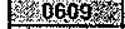 & 7 & 6 & 6 & 8 & 9 & 9 & 7 & 7 & 9 \\
\hline 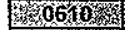 & 10 & 8 & 8 & 9 & 10 & 9 & 2 & 5 & 4 \\
\hline - & 8 & 7 & 6 & 8 & 9 & 10 & 7 & 7 & 10 \\
\hline 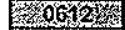 & 10 & 10 & 10 & 5 & 8 & 10 & 5 & 5 & 10 \\
\hline 20 & 9 & 10 & 8 & 6 & 7 & 8 & 4 & 5 & 10 \\
\hline 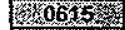 & 9 & 6 & 10 & 10 & 10 & 10 & 5 & 5 & 5 \\
\hline 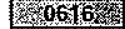 & 9 & 8 & 9 & 10 & 10 & 10 & 1 & 1 & 6 \\
\hline 筑 & 1 & 2 & 7 & 10 & 10 & 9 & 8 & 5 & 4 \\
\hline 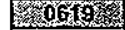 & 9 & 8 & 8 & 9 & 9 & 9 & 9 & 9 & 9 \\
\hline 206903 & 8 & 8 & 10 & 10 & 10 & 10 & 6 & 7 & 10 \\
\hline 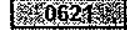 & 8 & 7 & 9 & 9 & 10 & 8 & 5 & 5 & 8 \\
\hline 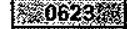 & 9 & 7 & 8 & 10 & 10 & 8 & 5 & 5 & 10 \\
\hline 0624 & 9 & 9 & 9 & 9 & 10 & 9 & 8 & 8 & 9 \\
\hline 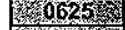 & 8 & 8 & 7 & 10 & 10 & 10 & 9 & 10 & 10 \\
\hline 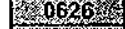 & 9 & 9 & 9 & 8 & 8 & 9 & 10 & 10 & 10 \\
\hline 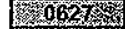 & 8 & 8 & 8 & 10 & 10 & 10 & 5 & 5 & 10 \\
\hline 管 & 7 & 6 & 7 & 9 & 8 & 9 & 6 & 9 & 9 \\
\hline 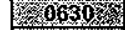 & 10 & 6 & 10 & 5 & 8 & 8 & 10 & 10 & 6 \\
\hline re651 & 10 & 7 & 8 & 10 & 10 & 10 & 8 & 8 & 10 \\
\hline 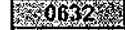 & 9 & 10 & 10 & 10 & 10 & 10 & 10 & 10 & 10 \\
\hline 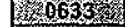 & 7 & 6 & 7 & 10 & 10 & 10 & 6 & 1 & 8 \\
\hline 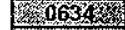 & 10 & 10 & 10 & 10 & 10 & 10 & 10 & 10 & 10 \\
\hline 0635 & 9 & 7 & 7 & 10 & 10 & 10 & 7 & 7 & 10 \\
\hline 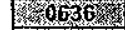 & 9 & 9 & 7 & 9 & 9 & 10 & 1 & 1 & 5 \\
\hline 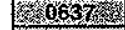 & 8 & 3 & 3 & 7 & 7 & 8 & 6 & 6 & 6 \\
\hline K & 5 & 5 & 6 & 10 & 6 & 6 & 6 & 8 & 6 \\
\hline 20393 & 9 & 5 & 3 & 5 & 9 & 10 & 6 & 5 & 9 \\
\hline 40640 & 8 & 7 & 9 & 8 & 10 & 10 & 5 & 5 & 7 \\
\hline 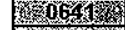 & 10 & 9 & 9 & 7 & 10 & 10 & 2 & 2 & 8 \\
\hline F & 10 & 5 & 5 & 10 & 10 & 10 & 10 & 5 & 10 \\
\hline 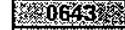 & 10 & 8 & 5 & 10 & 10 & 8 & 5 & 5 & 8 \\
\hline 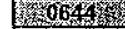 & 10 & 5 & 5 & 10 & 10 & 10 & 10 & 10 & 9 \\
\hline 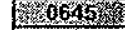 & 8 & 7 & 7 & 7 & 7 & 7 & 7 & 7 & 9 \\
\hline 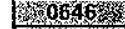 & 10 & 8 & 8 & 8 & 10 & 10 & 7 & 7 & 10 \\
\hline 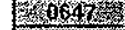 & 10 & 9 & 10 & 10 & 10 & 10 & 8 & 1 & 10 \\
\hline 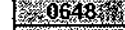 & 9 & 5 & 7 & 10 & 9 & to & 5 & 5 & 8 \\
\hline 筮 & 8 & 5 & 7 & 9 & 9 & 10 & 7 & 7 & 10 \\
\hline - & 7 & 7 & 8 & 6 & 10 & 8 & 10 & 10 & 8 \\
\hline 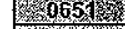 & 7 & 10 & 9 & 7 & 10 & 10 & 1 & 1 & 10 \\
\hline U & 8 & 6 & 8 & 8 & 7 & 8 & 3 & 6 & 5 \\
\hline . 0653 & 9 & 10 & 10 & 10 & 10 & 8 & 7 & 10 & 10 \\
\hline 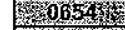 & 10 & 8 & 8 & 8 & 7 & 7 & 10 & 10 & 9 \\
\hline 20655 & 9 & 8 & 9 & 7 & 10 & 8 & 0 & 0 & 10 \\
\hline ris 0656 & 2 & 5 & 7 & 10 & 7 & 2 & 1 & 2 & 8 \\
\hline 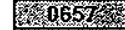 & 10 & 5 & 5 & 2 & 3 & 7 & 9 & 9 & 8 \\
\hline 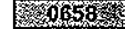 & 9 & 4 & 8 & 10 & 10 & 10 & 6 & 10 & 10 \\
\hline 4 & 8 & 10 & 9 & 8 & 8 & 8 & 2 & 6 & 9 \\
\hline 0 & 10 & 9 & 8 & 8 & 9 & 9 & 1 & 1 & 9 \\
\hline 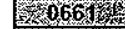 & 7 & 5 & 5 & 8 & 8 & 7 & 7 & 8 & 9 \\
\hline 0662 & 8 & 6 & 10 & 5 & 5 & 8 & 10 & 0 & 9 \\
\hline $666 \%$ & 7 & 5 & 5 & 8 & 8 & 4 & 5 & 8 & 6 \\
\hline 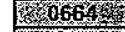 & 10 & 5 & 5 & 5 & 8 & 9 & 8 & 8 & 10 \\
\hline 8665 & 6 & 7 & 9 & 7 & 7 & 8 & 9 & 7 & 9 \\
\hline F 0656 & 9 & 8 & 8 & 9 & 9 & 10 & 6 & 5 & 9 \\
\hline r 60663 & 9 & 7 & 6 & 9 & 8 & 7 & 4 & 4 & 7 \\
\hline 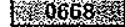 & 9 & 5 & 5 & 7 & 10 & 10 & 8 & 8 & 7 \\
\hline$F^{1}=66.9$ & 8 & 9 & 10 & 8 & 8 & 8 & 10 & 10 & 9 \\
\hline 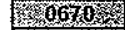 & 7 & 10 & 9 & & & & 3 & 3 & 8 \\
\hline 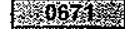 & 8 & 5 & 6 & 6 & 7 & 7 & 4 & 5 & 5 \\
\hline$x_{5} 6067$ & 7 & 5 & 6 & 7 & 7 & 5 & 4 & 6 & 8 \\
\hline 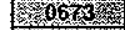 & 8 & 5 & 9 & 8 & 9 & 8 & 1 & 5 & 8 \\
\hline 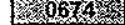 & & & & & & & 3 & 8 & 6 \\
\hline 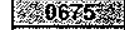 & 8 & 7 & 8 & 9 & 6 & 8 & 4 & 6 & 8 \\
\hline 6 & 9 & 10 & 10 & 1 & 8 & 4 & 5 & 3 & 1 \\
\hline 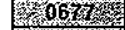 & 9 & 6 & 8 & 10 & 10 & 8 & 3 & 3 & 7 \\
\hline $8-0678$ & 8 & 8 & 8 & 4 & 4 & 5 & 10 & 10 & 8 \\
\hline 50679 & 10 & 10 & 10 & 7 & 9 & 7 & 5 & 8 & 7 \\
\hline 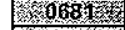 & 10 & 5 & 7 & 10 & 10 & 10 & 2 & 2 & 10 \\
\hline 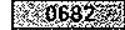 & 10 & 8 & 10 & 9 & 9 & 7 & 6 & 7 & 10 \\
\hline S & 6 & 7 & 6 & 2 & 4 & 7 & 10 & 10 & 9 \\
\hline 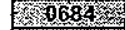 & 9 & 8 & 9 & 10 & 10 & 9 & 4 & 1 & 10 \\
\hline 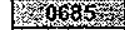 & 5 & 8 & 10 & 10 & 7 & 9 & 1 & 5 & 5 \\
\hline 5066 & 9 & 5 & 9 & 8 & 8 & 10 & 8 & 8 & 8 \\
\hline-0687 & 10 & 10 & 5 & 10 & 10 & 10 & 10 & 10 & 10 \\
\hline S5688 & 8 & 10 & 9 & 7 & 6 & 8 & 5 & 5 & 10 \\
\hline
\end{tabular}




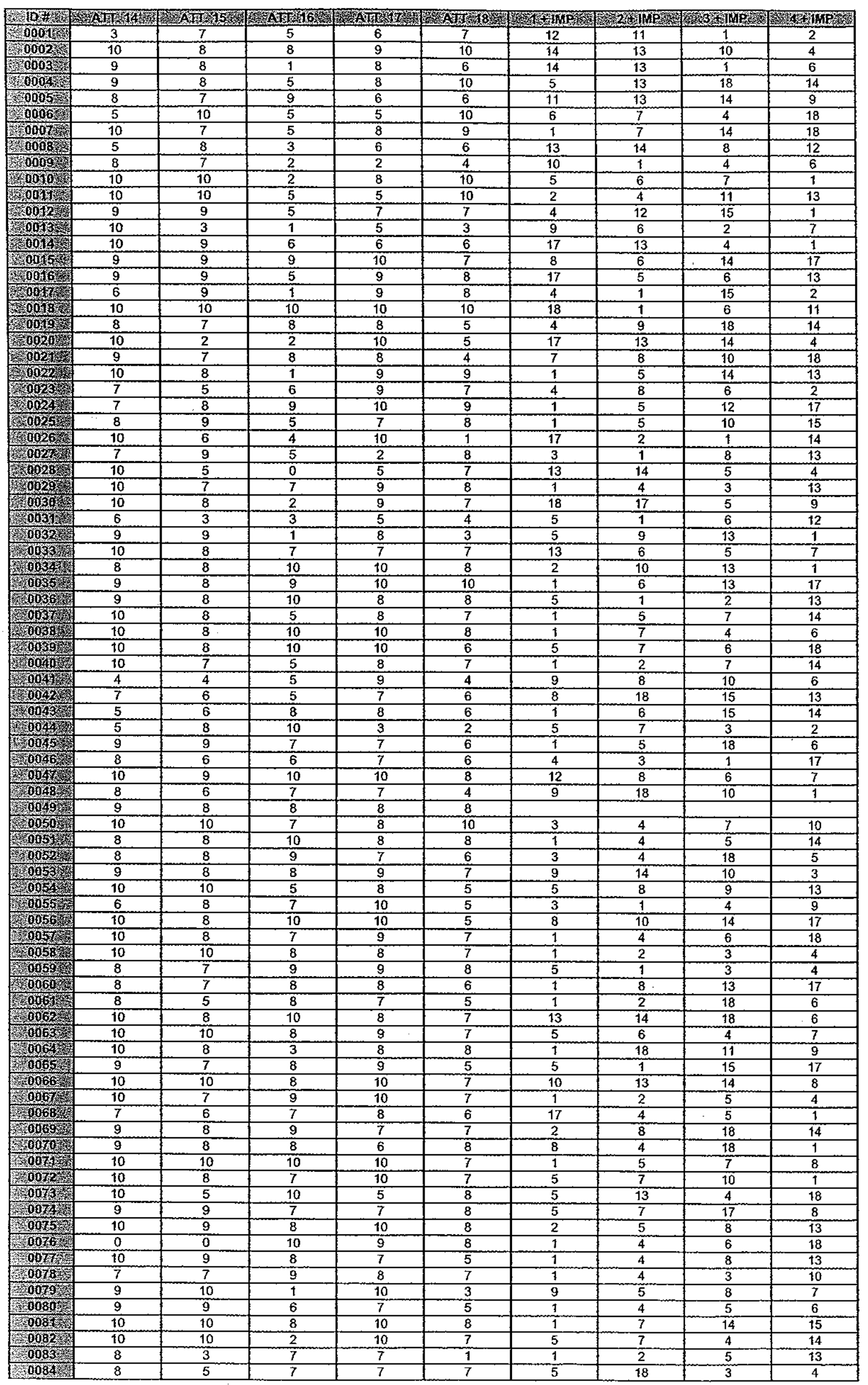




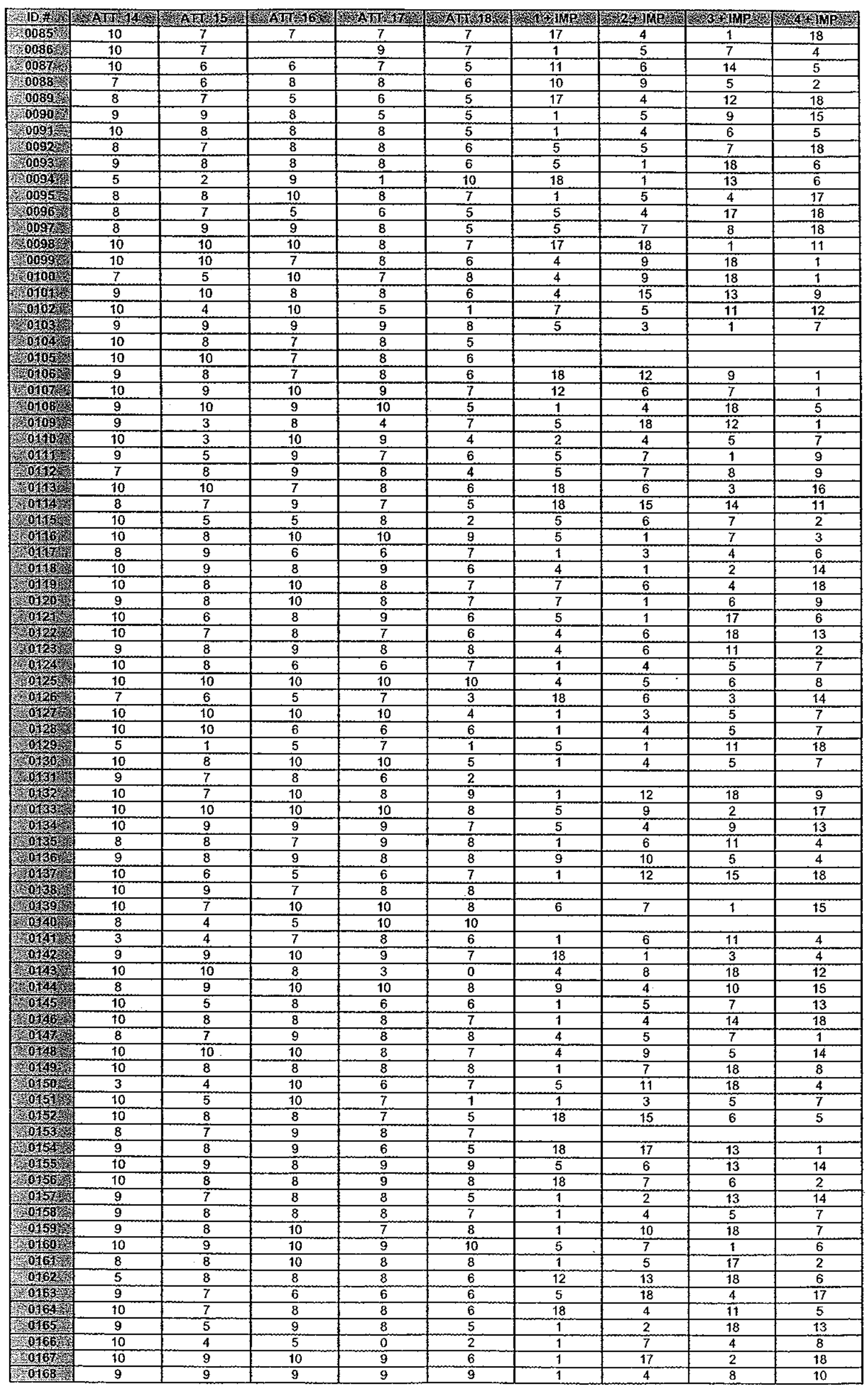




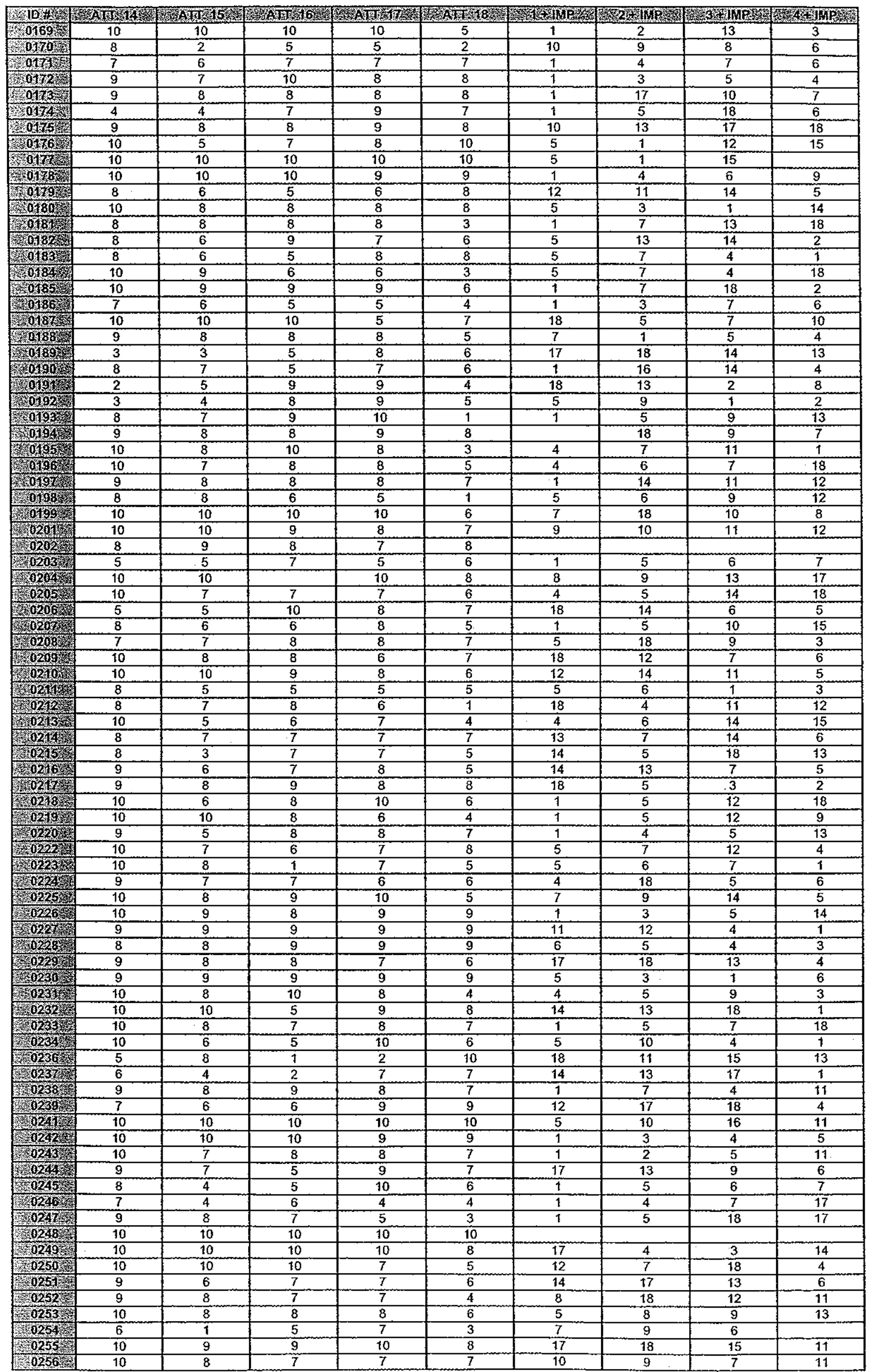




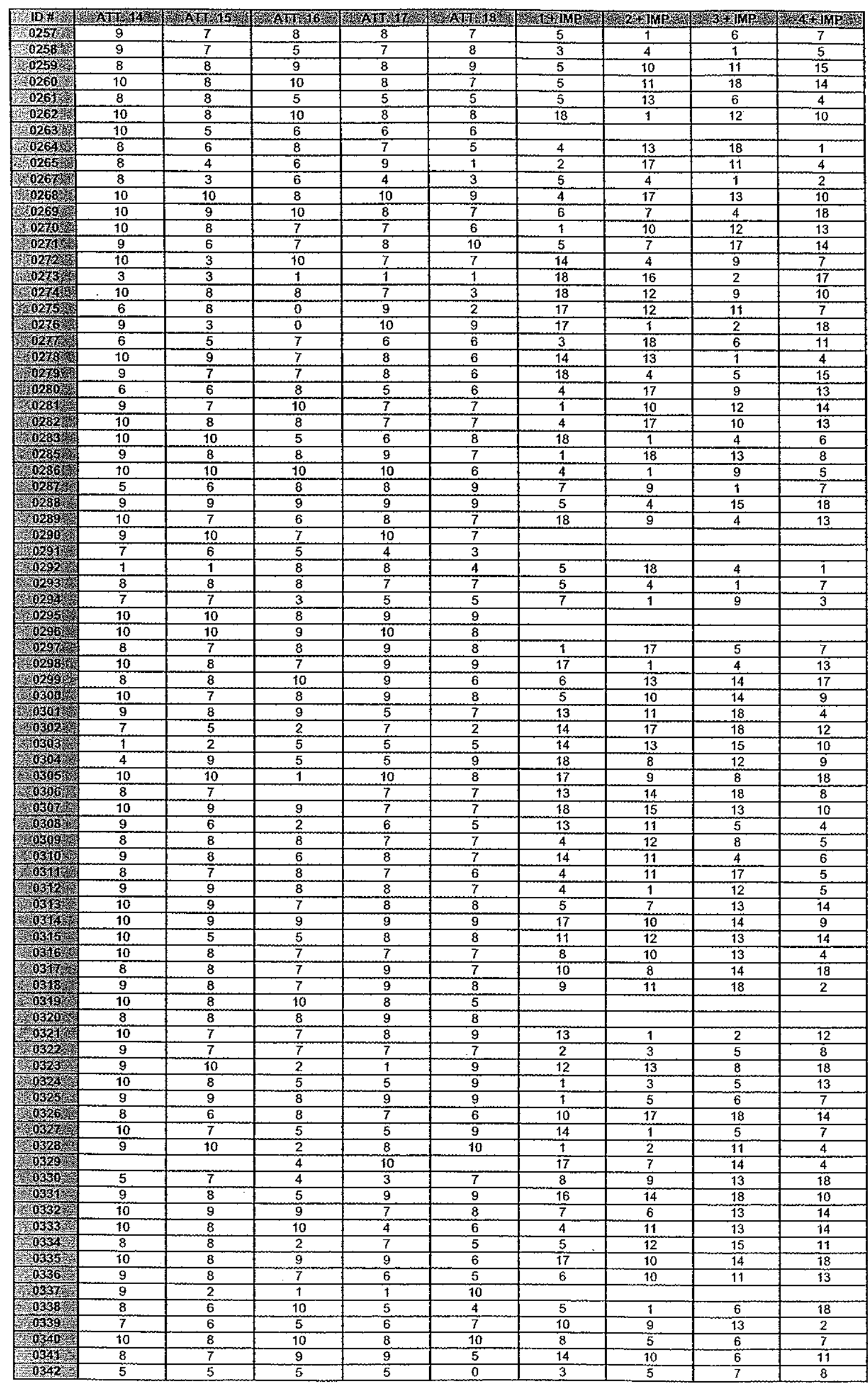




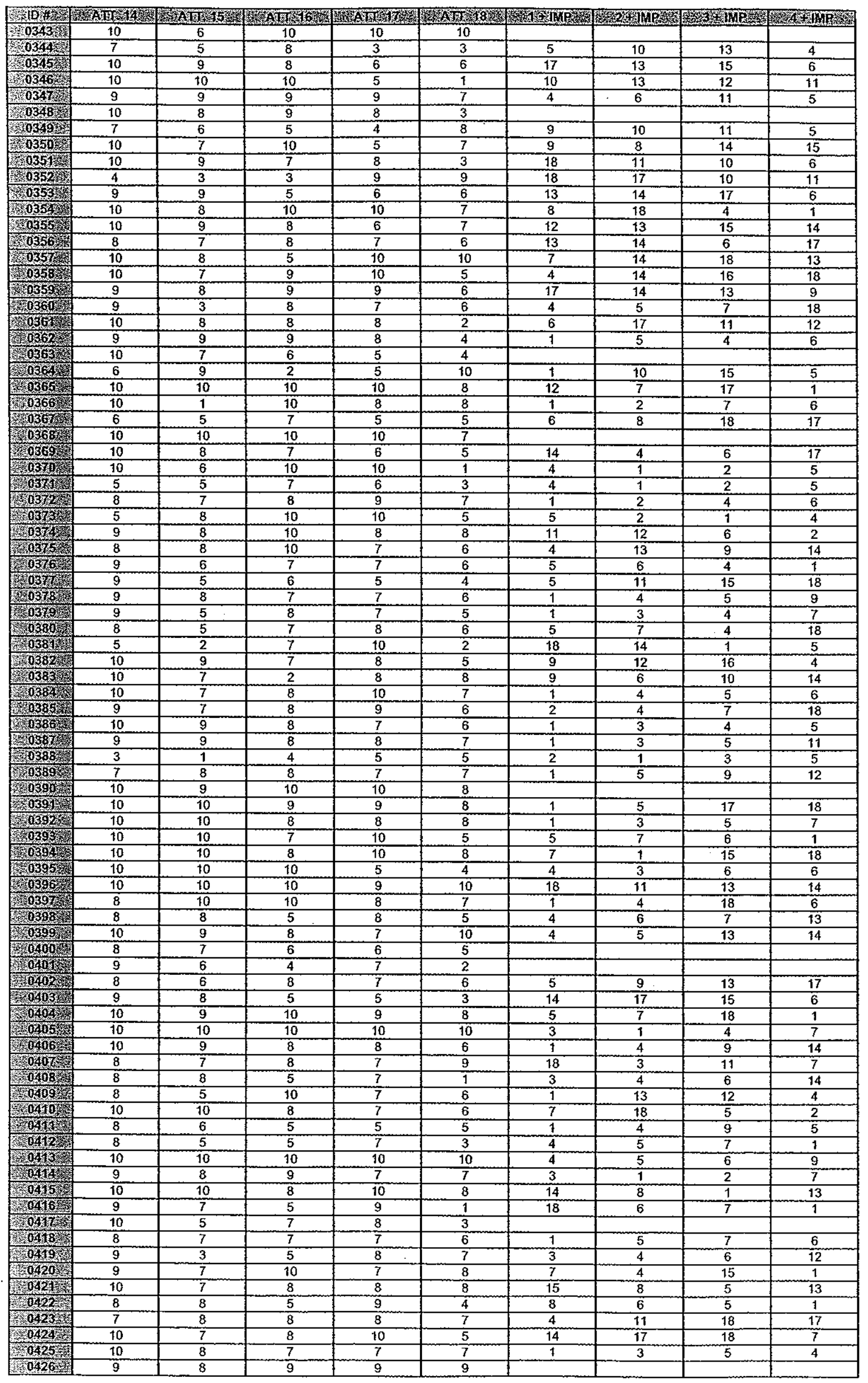




\begin{tabular}{|c|c|c|c|c|c|c|c|c|c|}
\hline Y & 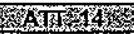 & 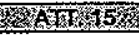 & - & 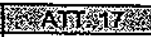 & S & W & 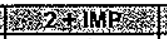 & 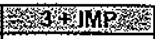 & 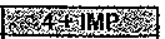 \\
\hline 0,427 \% & 7 & 7 & 8 & 7 & 5 & 13 & 18 & 3 & 9 \\
\hline 320428 & 9 & 9 & 9 & 8 & 7 & 6 & 3 & 1 & 5 \\
\hline 5429 & 9 & 7 & 7 & 8 & 7 & 5 & 7 & 4 & 10 \\
\hline $0430<$ & 9 & 8 & 7 & 6 & 5 & 1 & 6 & 7 & 5 \\
\hline 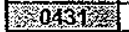 & 8 & 7 & 7 & 10 & 7 & 4 & 11 & 17 & 2 \\
\hline $0 \% 32$ S & 6 & 6 & 8 & 7 & 6 & 1 & 6 & 5 & 2 \\
\hline 04333 & 10 & 10 & 9 & 7 & 7 & 9 & 4 & 2 & 5 \\
\hline 8640 & 9 & 8 & 9 & 8 & 7 & 1 & 4 & 5 & 6 \\
\hline \% 035,36 & 8 & 8 & 8 & 10 & 8 & 1 & 4 & 5 & 13 \\
\hline 0336 & 4 & 0 & 2 & 4 & 8 & 18 & 15 & 12 & 8 \\
\hline 16437 & 10 & 10 & 5 & 10 & 10 & 5 & 6 & 12 & 17 \\
\hline 0438 & 10 & 10 & 10 & 10 & 10 & 18 & 17 & 15 & 14 \\
\hline 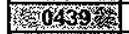 & 8 & 9 & 8 & 10 & 8 & 4 & 6 & 7 & 10 \\
\hline 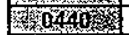 & 7 & 6 & 8 & 4 & 3 & & & & \\
\hline 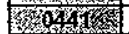 & 9 & 9 & 9 & 9 & 10 & 5 & 7 & 11 & 6 \\
\hline 040 & 6 & 6 & 9 & 8 & 8 & 4 & 6 & 18 & 7 \\
\hline 3. 04434 & 9 & 7 & 8 & 9 & 9 & 1 & 4 & 5 & 7 \\
\hline 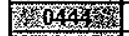 & 4 & 1 & 8 & 7 & 7 & 6 & 7 & 18 & 9 \\
\hline 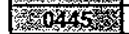 & 8 & 7 & 10 & 10 & 8 & 1 & 4 & 2 & 5 \\
\hline 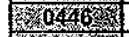 & 6 & 8 & 5 & 5 & 1 & 2 & 6 & 7 & 13 \\
\hline s & 10 & 10 & 5 & 10 & 10 & 6 & 14 & 18 & 5 \\
\hline 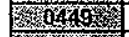 & 10 & 10 & 10 & 10 & 4 & & & & \\
\hline 13. & 10 & 8 & 10 & 9 & 6 & 17 & 5 & 18 & 3 \\
\hline 50454 & 6 & 5 & 8 & 6 & 5 & 5 & 6 & 7 & 18 \\
\hline$y^{2} z_{5} 045$ & 10 & 9 & 10 & 10 & 8 & 3 & 5 & 12 & 2 \\
\hline 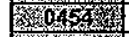 & 10 & 8 & 10 & 10 & 7 & 13 & 6 & 5 & 3 \\
\hline 3 & 10 & 8 & 10 & 5 & 5 & 5 & 7 & 6 & $t$ \\
\hline 0456 & 10 & 8 & 9 & 9 & 9 & 4 & 5 & 1 & 6 \\
\hline 4045 & 10 & 9 & 8 & 7 & 7 & & & & \\
\hline 0458 & 8 & 7 & 8 & 9 & 6 & 5 & 7 & 14 & 18 \\
\hline 304603 & 10 & 10 & 8 & 10 & 7 & 1 & 2 & 4 & 12 \\
\hline 304640 & 9 & 7 & 1 & 7 & 2 & 1 & 4 & 3 & 9 \\
\hline 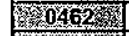 & 10 & 10 & 7 & 8 & 6 & 1 & 4 & 9 & 13 \\
\hline $40 \% 63$ & 10 & 10 & 10 & 10 & 8 & 1 & 8 & 2 & 5 \\
\hline K & 9 & 8 & 10 & 10 & 2 & 18 & 5 & 7 & 15 \\
\hline 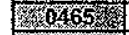 & 9 & 8 & 9 & 9 & 8 & 4 & 5 & 3 & 1 \\
\hline 5066 & 10 & 8 & 7 & 3 & 4 & 18 & 1 & 2 & 5 \\
\hline (6) & 10 & 8 & 9 & 8 & 5 & 6 & 3 & 10 & 17 \\
\hline 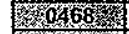 & 10 & 9 & 10 & 10 & 9 & 1 & 11 & 12 & 18 \\
\hline s. & 10 & 9 & 8 & 8 & 8 & 4 & 9 & 12 & 5 \\
\hline 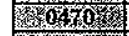 & 10 & 10 & 10 & 8 & 10 & 2 & 1 & 5 & 11 \\
\hline Scr. & 10 & 5 & 8 & 10 & 7 & 1 & 4 & 5 & 6 \\
\hline$x^{2}=0 \%$ & 9 & 7 & 9 & 9 & 8 & 1 & 3 & 4 & 5 \\
\hline (20493 & 9 & 5 & 7 & 7 & 6 & 1 & 5 & 7 & 13 \\
\hline 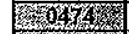 & 10 & 9 & 8 & 9 & 6 & 1 & 3 & 4 & 5 \\
\hline 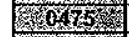 & 9 & 10 & 8 & 10 & 8 & 4 & 18 & 17 & 9 \\
\hline 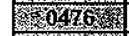 & 9 & 8 & 5 & 8 & 2 & 13 & 1 & 18 & 14 \\
\hline 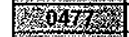 & 6 & 10 & 10 & 8 & 2 & 1 & 18 & 12 & 6 \\
\hline s $6478 y^{2}$ & 10 & 10 & 7 & 9 & 4 & 1 & 2 & 14 & 13 \\
\hline 0 & 10 & 8 & 7 & 8 & 8 & 5 & 9 & 5 & 2 \\
\hline S 2040 & 9 & 8 & 9 & 6 & 5 & 1 & 5 & 12 & 15 \\
\hline r & 7 & 7 & 8 & 7 & 10 & 1 & 18 & 7 & 4 \\
\hline 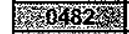 & 10 & 1 & 10 & 10 & 2 & & & & \\
\hline 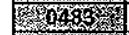 & 8 & 6 & 5 & 6 & 7 & 4 & 5 & 1 & 7 \\
\hline S & 10 & 7 & 8 & 9 & 7 & 4 & 5 & 1 & 3 \\
\hline 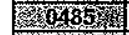 & 10 & 9 & 5 & 10 & 6 & 1 & 3 & 2 & 9 \\
\hline Y & 7 & 5 & 5 & 7 & 6 & 4 & 1 & 5 & 6 \\
\hline K 8499 & 9 & 8 & 7 & 9 & 5 & 18 & 7 & 6 & 3 \\
\hline S 058 o & 10 & 9 & 9 & 9 & 8 & 9 & 4 & 5 & 18 \\
\hline (6/909 & 10 & 10 & 10 & 10 & 10 & 7 & 4. & 5 & 8 \\
\hline 30490 , & 4 & 3 & & 5 & 1 & 4 & 5 & 6 & \\
\hline 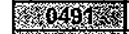 & 9 & 8 & 7 & 10 & 6 & 5 & 3 & 18 & 4 \\
\hline 3 & 8 & 7 & 1 & 8 & 7 & 7 & 6 & 13 & 14 \\
\hline 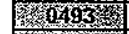 & 6 & 5 & 5 & 8 & 7 & 1 & 3 & 7 & 6 \\
\hline 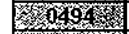 & 9 & 9 & 8 & 9 & 7 & 4 & 17 & 1 & 13 \\
\hline 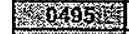 & 7 & 8 & 9 & 9 & 5 & 4 & 5 & 1 & 15 \\
\hline $049 \sigma \sigma^{\prime \prime}$ & 10 & 6 & 10 & 10 & 10 & 1 & 2 & 5 & 18 \\
\hline 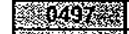 & to & 10 & 7 & 10 & 8 & 4 & 17 & 5 & 13 \\
\hline SOX98 & 10 & 6 & 7 & 8 & 7 & 3 & 1 & 5 & 9 \\
\hline 8499 & 10 & 8 & 8 & 7 & 6 & 8 & 5 & 7 & 1 \\
\hline WOSHO & 9 & 8 & 9 & 8 & 7 & 4 & 3 & 10 & 18 \\
\hline 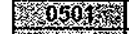 & 10 & 9 & 8 & 10 & 9 & 1 & 2 & 4 & 5 \\
\hline 5002 & 7 & 6 & 7 & 7 & 7 & 4 & 3 & 5 & 1 \\
\hline K & 10 & 10 & & 10 & 7 & 18 & 10 & 5 & 3 \\
\hline 30564 & 9 & 9 & 9 & 9 & 9 & 5 & 4 & 18 & 6 \\
\hline 60505 & 10 & 8 & 10 & 9 & 9 & 4 & 5 & 3 & 1 \\
\hline 0506 & 9 & 10 & 10 & 8 & 8 & 4 & 12 & 3 & 7 \\
\hline 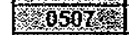 & 10 & 5 & 7 & 6 & 3 & 1 & 4 & 5 & 8 \\
\hline 2508 哬 & 10 & 9 & 9 & 10 & 9 & 1 & 2 & 4 & 3 \\
\hline \%50g & 7 & 6 & 7 & 7 & 7 & 18 & 10 & 5 & 1 \\
\hline 020510 , 得 & 10 & 10 & 8 & 9 & 8 & 1 & 5 & 4 & 6 \\
\hline 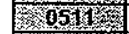 & 10 & 3 & 5 & 10 & 6 & 4 & 5 & 14 & 9 \\
\hline 6512 & 10 & 10 & 10 & 10 & 10 & 1 & 5 & 7 & 4 \\
\hline 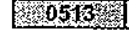 & 10 & 9 & 8 & 9 & 9 & 1 & 3 & 4 & 5 \\
\hline
\end{tabular}




\begin{tabular}{|c|c|c|c|c|c|c|c|c|c|}
\hline N & 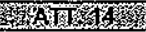 & 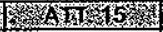 & 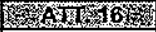 & W & 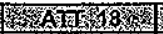 & 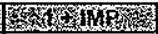 & (6) & 3 & 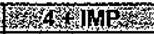 \\
\hline 0514 & 10 & 9 & 9 & 10 & 7 & 2 & $t$ & 4 & 5 \\
\hline 0516 & 10 & 8 & 8 & 8 & 10 & 10 & 2 & 4 & 18 \\
\hline 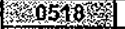 & 8 & 1 & 10 & 9 & 6 & 5 & 7 & 18 & 9 \\
\hline 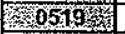 & 10 & 8 & & & & & & & \\
\hline 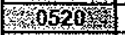 & 10 & 9 & 8 & 9 & 7 & 4 & 12 & 17 & 18 \\
\hline 30521 & 5 & 5 & 10 & 8 & 8 & & & & \\
\hline 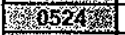 & 8 & 5 & 7 & 6 & 7 & 2 & 1 & 5 & 9 \\
\hline 0525 S & 8 & 8 & 9 & 9 & 8 & 1 & 3 & 5 & 7 \\
\hline 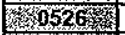 & 9 & 8 & 7 & 10 & 10 & 4 & 5 & 3 & 18 \\
\hline 30526 & 8 & 7 & 4 & 8 & 3 & 5 & 6 & 7 & 9 \\
\hline $05 \% 8$ & 9 & 9 & 9 & 9 & 9 & 18 & 4 & 5 & 17 \\
\hline 0529 洷 & 10 & 8 & 10 & 10 & 8 & 1 & 4 & 7 & 9 \\
\hline 305346 & 7 & 10 & 7 & 7 & 6 & 5 & 1 & 3 & 4 \\
\hline 00335 & 10 & 8 & 7 & 10 & 8 & 1 & 11 & 6 & 3 \\
\hline 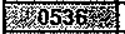 & 10 & 8 & 9 & 9 & 8 & 1 & 2 & 5 & 7 \\
\hline S & 8 & $\overline{9}$ & 5 & 5 & 10 & 4 & 18 & 5 & 15 \\
\hline 3058 & 9 & 9 & 7 & 7 & 7 & 1 & 2 & 5 & 9 \\
\hline$x_{2} \times 1530$ & 10 & 7 & 8 & 9 & 5 & 4 & 5 & 7 & 2 \\
\hline 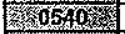 & 10 & 8 & 5 & 9 & 7 & 5 & 13 & 14 & 6 \\
\hline (O54 & 2 & 8 & 6 & 5 & 4 & 5 & 3 & 2 & 1 \\
\hline 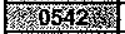 & 10 & 8 & 9 & 9 & 9 & 9 & 7 & 10 & 4 \\
\hline 64 & 9 & & & & 10 & & & & \\
\hline (20) & 9 & 8 & 7 & 8 & 5 & 18 & 17 & 13 & 8 \\
\hline Sys & 9 & 9 & 10 & 10 & 8 & 9 & 4 & 17 & 13 \\
\hline Y & 9 & 7 & 7 & 9 & 5 & & & & \\
\hline Kin & 9 & 8 & 9 & 9 & 9 & 9 & 18 & 4 & 13 \\
\hline 56558 得 & 10 & 8 & 5 & 8 & 6 & 5 & 4 & 7 & 9 \\
\hline 0550 & 8 & 8 & 10 & 9 & 7 & 8 & 2 & 9 & 10 \\
\hline 留 & 10 & 6 & & 7 & 5 & 5 & 7 & 6 & 10 \\
\hline 3. 0552 & 8 & 9 & 10 & 9 & 7 & 4 & 6 & 13 & 14 \\
\hline 05633 & 9 & 10 & 8 & 7 & 5 & 7 & 1 & 10 & 15 \\
\hline 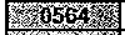 & 10 & 5 & 7 & 8 & 9 & 14 & 13 & 17 & 10 \\
\hline 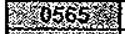 & 8 & 6 & 7 & 7 & 3 & 3 & 7 & 13 & 16 \\
\hline 0566 & 8 & 7 & 9 & 7 & 8 & 5 & 3 & 17 & 4 \\
\hline 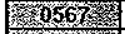 & 9 & 6 & 10 & 6 & 6 & 17 & 16 & 9 & 2 \\
\hline 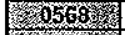 & 8 & 8 & 0 & 4 & 2 & 3 & 4 & 6 & 13 \\
\hline 0559 & 1 & 5 & 9 & 4 & 6 & 11 & 14 & 18 & 13 \\
\hline 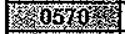 & 9 & 5 & 5 & 6 & 7 & 2 & 14 & 1 & 8 \\
\hline 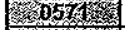 & 10 & 8 & 10 & 8 & 7 & 14 & 13 & 11 & 10 \\
\hline 3 & 6 & 6 & 7 & 8 & 7 & 7 & 15 & 17 & 10 \\
\hline 2 & 7 & 4 & 3 & 2 & 2 & 14 & 13 & 9 & 8 \\
\hline 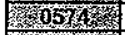 & 8 & 8 & 10 & 9 & 6 & 17 & 3 & 1 & 5 \\
\hline 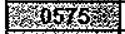 & 10 & 9 & 10 & 10 & 5 & 5 & 18 & 14 & 3 \\
\hline 505 65 & 10 & to & 7 & 8 & 6 & 12 & 14 & 18 & 13 \\
\hline 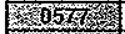 & 10 & 9 & 7 & 10 & 7 & 17 & 13 & 14 & 11 \\
\hline 0578 & 8 & 8 & 7 & 7 & 7 & 11 & 14 & 18 & 17 \\
\hline 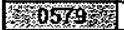 & 10 & 9 & 6 & 8 & 7 & 5 & 4 & 18 & 17 \\
\hline 60580 , & $\overline{7}$ & 5 & & 5 & 6 & 1 & 5 & 18 & 10 \\
\hline $058 \mathrm{~T}$ & 9 & 8 & 8 & 9 & 7 & 1 & 5 & 4 & 9 \\
\hline 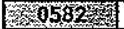 & 6 & 6 & 7 & 6 & 5 & 8 & 4 & 5 & 15 \\
\hline T. $058 \%$ & 8 & 9 & 5 & 9 & 10 & 5 & 4 & 18 & 11 \\
\hline
\end{tabular}




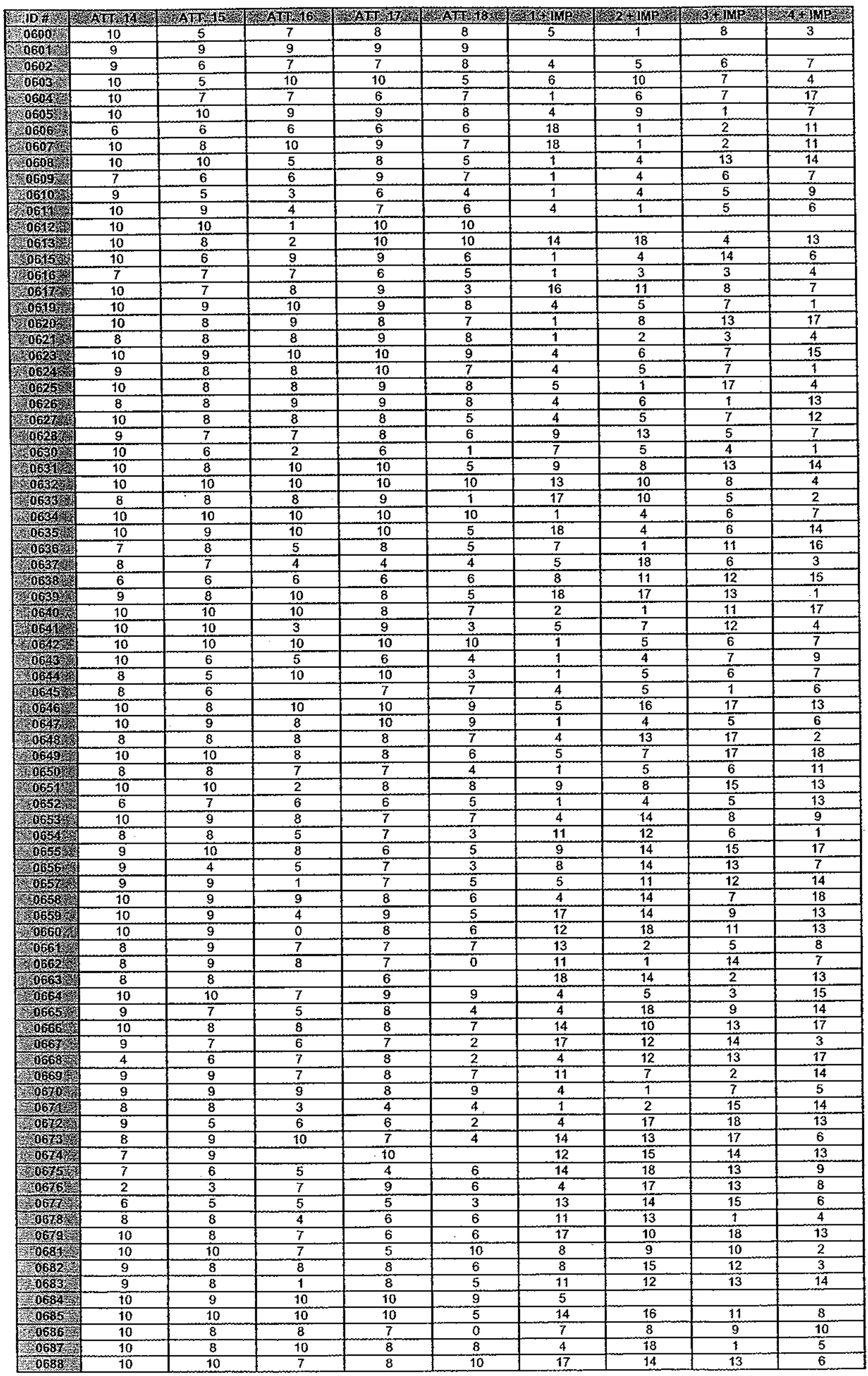




\begin{tabular}{|c|c|c|c|c|c|c|c|c|}
\hline 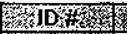 & 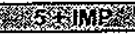 & 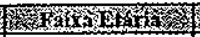 & Sth & 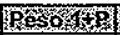 & Pesso/2 & 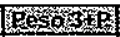 & (possomp & Pros os \\
\hline 0001 & 14 & 17 a 26 anos & $21 \mathrm{a} 25 \mathrm{SM}$ & 5 & 4 & 3 & 2 & 1 \\
\hline 0002 称 & 5 & 17 a 26 anos & 21 a $25 \mathrm{SM}$ & 5 & 4 & 3 & 2 & 1 \\
\hline 20009 & 7 & 17 a 26 anos & 6 a $10 \mathrm{SM}$ & 5 & 4 & 3 & 2 & 1 \\
\hline 0004 & 6 & 17 a 26 anos & 11 a $15 \mathrm{SM}$ & 5 & 4 & 3 & 2 & 1 \\
\hline 烈 & 18 & 17 a 26 anos & 26 ou mais SM & 5 & 4 & 3 & 2 & 1 \\
\hline 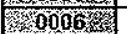 & 5 & 17 a 26 anos & 26 ou mais SM & 5 & 4 & 3 & 2 & 1 \\
\hline 6 $600 \mathrm{x}$ & 17 & 17 a 26 anos & 16 a $20 \mathrm{SM}$ & 5 & 4 & 3 & 2 & 1 \\
\hline 6008 & 6 & 17 a 26 anos & 26 ou mais SM & 5 & 4 & 3 & 2 & 1 \\
\hline 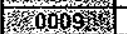 & 8 & 17 a 26 anos & 6 a $10 \mathrm{SM}$ & 5 & 4 & 3 & 2 & 1 \\
\hline K & 18 & 17 a 26 anos & 6 a $10 \mathrm{SM}$ & 5 & 4 & 3 & 2 & 1 \\
\hline 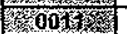 & 14 & 17 a 26 anos & 16 a $20 \mathrm{SM}$ & 5 & 4 & 3 & 2 & 1 \\
\hline W & 13 & 17 a 26 anos & 16 a $20 \mathrm{SM}$ & 5 & 4 & 3 & 2 & 1 \\
\hline 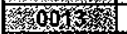 & 4 & 17 a 26 anos & 26 ou mais SM & 5 & 4 & 3 & 2 & 1 \\
\hline 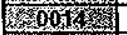 & 11 & 17 a 26 anos & 26 ou mais SM & 5 & 4 & 3 & 2 & 1 \\
\hline 10015 & 4 & 17 a 26 anos & 21 a $25 \mathrm{SM}$ & 5 & 4 & 3 & 2 & 1 \\
\hline 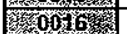 & 14 & 17 a 26 anos & 26 ou mais SM & 5 & 4 & 3 & 2 & 1 \\
\hline K & 5 & 17 a 26 anos & $6 \mathrm{a} 10 \mathrm{SM}$ & 5 & 4 & 3 & 2 & 1 \\
\hline 3001B & 14 & 17 a 26 anos & 16 a $20 \mathrm{SM}$ & 5 & 4 & 3 & 2 & 1 \\
\hline 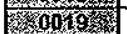 & 10 & 17 a 26 anos & 6 a $10 \mathrm{SM}$ & 5 & 4 & 3 & 2 & 1 \\
\hline $00 \%$ & 1 & 17 a 26 anos & 26 ou mais SM & 5 & 4 & 3 & 2 & 1 \\
\hline (5: & 6 & 17 a 26 anos & 21 a $25 \mathrm{SM}$ & 5 & 4 & 3 & 2 & 1 \\
\hline W025 & 15 & 17 a 26 anos & 6 a $10 \mathrm{SM}$ & 5 & 4 & 3 & 2 & 1 \\
\hline 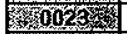 & 9 & 17 a 26 anos & 26 ou mais $\mathrm{SM}$ & 5 & 4 & 3 & 2 & 1 \\
\hline W602 & 11 & 17 a 26 anos & 1 a $5 \mathrm{SM}$ & 5 & 4 & 3 & 2 & 1 \\
\hline 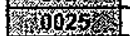 & 12 & 17 a 26 anos & 26 ou mais SM & 5 & 4 & 3 & 2 & 1 \\
\hline 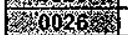 & 12 & 17 a 26 anos & 11 a $15 \mathrm{SM}$ & 5 & 4 & 3 & 2 & 1 \\
\hline W02 & 14 & 17 a 26 anos & 26 ou mais SM & 5 & 4 & 3 & 2 & 1 \\
\hline 0028 & 6 & 17 a 26 anos & 26 ou mais SM & 5 & 4 & 3 & 2 & 1 \\
\hline 0029 & 17 & 17 a 26 anos & 6 a $10 \mathrm{SM}$ & 5 & 4 & 3 & 2 & 1 \\
\hline K & 1 & 27 a 36 anos & 26 ou mais $S M$ & 5 & 4 & 3 & 2 & 1 \\
\hline 㕄经 & 18 & 27 a 36 anos & 26 ou mais SM & 5 & 4 & 3 & 2 & 1 \\
\hline 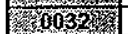 & 17 & 27 a 36 anos & 26 ou mais $S M$ & 5 & 4 & 3 & 2 & 1 \\
\hline E. & 1 & 27 a 36 anos & 26 ou mais $S M$ & 5 & 4 & 3 & 2 & 1 \\
\hline 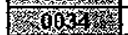 & 17 & 37 a 46 anos & 26 ou mais $S M$ & 5 & 4 & 3 & 2 & 1 \\
\hline 㣞 & 18 & 17 a 26 anos & 26 ou mais SM & 5 & 4 & 3 & 2 & 1 \\
\hline 20036 & 6 & 17 a 26 anos & 26 ou mais SM & 5 & 4 & 3 & 2 & 1 \\
\hline 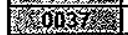 & 18 & 17 a 26 anos & 26 ou mais SM & 5 & 4 & 3 & 2 & 1 \\
\hline 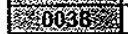 & 5 & 27 a 36 anos & 26 ou mais SM & 5 & 4 & 3 & 2 & 1 \\
\hline 0030 & 1. & 27 a 36 anos & 11 a $15 \mathrm{SM}$ & 5 & 4 & 3 & 2 & $t$ \\
\hline 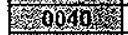 & 13 & 17 a 26 anos & 6 a $10 \mathrm{SM}$ & 5 & 4 & 3 & 2 & 1 \\
\hline 50040 & 2 & 17 a 26 anos & $6 \mathrm{a} 10 \mathrm{SM}$ & 5 & 4 & 3 & 2 & 1 \\
\hline 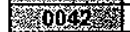 & 7 & 17 a 26 anos & 26 ou mais $\mathrm{SM}$ & 5 & 4 & 3 & 2 & 1 \\
\hline 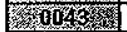 & 18 & 17 a 26 anos & 26 ou mais SM & 5 & 4 & 3 & 2 & 1 \\
\hline 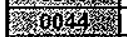 & 13 & 17 a 26 anos & ta $5 \mathrm{SM}$ & 5 & 4 & 3 & 2 & 1 \\
\hline K. & 7 & 17 a 26 anos & 6 a $10 \mathrm{SM}$ & 5 & $\frac{1}{4}$ & 3 & 2 & 1 \\
\hline 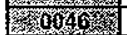 & 18 & 17 a 26 anos & 16 a $20 \mathrm{SM}$ & 5 & 4 & 3 & $\frac{2}{2}$ & $\frac{1}{1}$ \\
\hline 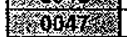 & 13 & 17 a 26 anos & 6 a $10 \mathrm{SM}$ & 5 & 4 & 3 & 2 & 1 \\
\hline 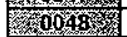 & 14 & 17 a 26 anos & 6 a $10 \mathrm{SM}$ & 5 & 4 & 3 & 2 & 1 \\
\hline K & & 17 a 26 anos & 26 ou mais SM & 5 & 4 & 3 & 2 & 1 \\
\hline 0.050 & 18 & 17 a 26 anos & 26 ou mais $S M$ & 5 & 4 & 3 & 2 & 1 \\
\hline 1505 & 18 & 17 a 26 anos & 1 a $5 \mathrm{SM}$ & 5 & 4 & 3 & 2 & 1 \\
\hline 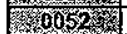 & 9 & 37 a 46 anos & 1 a 5 SM & 5 & 4 & 3 & 2 & 1 \\
\hline 16 & 2 & 17 a 26 anos & 1 a $5 \mathrm{SM}$ & 5 & 4 & 3 & 2 & 1 \\
\hline 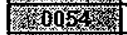 & 18 & 17 a 26 anos & 26 ou mais SM & 5 & 4 & 3 & 2 & $i$ \\
\hline $005^{5} 5$ & 18 & 17 a 26 anos & 1 a $5 \mathrm{SM}$ & 5 & 4 & 3 & 2 & 1 \\
\hline 6 20056 6 & 13 & 17 a 26 anos & $6 \mathrm{a} 10 \mathrm{SM}$ & 5 & 4 & 3 & 2 & 1 \\
\hline 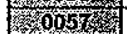 & 13 & 17 a 26 anos & 6 a $10 \mathrm{SM}$ & 5 & 4 & 3 & 2 & 1 \\
\hline - & 5 & 17 a 26 anos & 26 ou mais SM & 5 & 4 & 3 & 2 & 1 \\
\hline T6059 & 8 & 17 a 26 anos & 1 a $5 \mathrm{SM}$ & 5 & 4 & 3 & 2 & 1 \\
\hline 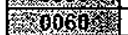 & 4 & 17 a 26 anos & 11 a $15 \mathrm{SM}$ & 5 & 4 & 3 & 2 & 1 \\
\hline 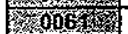 & 8 & 37 a 46 anos & 16 a $20 \mathrm{SM}$ & 5 & 4 & 3 & 2 & 1 \\
\hline 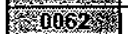 & 4 & 17 a 26 anos & 1 a $5 \mathrm{SM}$ & 5 & 4 & 3 & 2 & 1 \\
\hline Yuck & 18 & 17 a 26 anos & 6 a $10 \mathrm{SM}$ & 5 & 4 & 3 & 2 & 1 \\
\hline (500\% & 13 & 17 a 26 anos & 6 a $10 \mathrm{SM}$ & 5 & 4 & 3 & 2 & 1 \\
\hline 0065 涹 & 4 & 17 a 26 anos & 26 ou mais SM & 5 & 4 & 3 & 2 & 1 \\
\hline 60066 & 7 & 17 a 26 anos & 26 ou mais $S M$ & 5 & 4 & 3 & 2 & 1 \\
\hline 0067 & 9 & 17 a 26 anos & 26 ou mais $S M$ & 5 & 4 & 3 & 2 & 1 \\
\hline 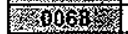 & 18 & 37 a 46 anos & 6 a $10 \mathrm{SM}$ & 5 & 4 & 3 & 2 & 1 \\
\hline 6069 & 10 & 17 a 26 anos & 16 a $20 \mathrm{SM}$ & 5 & 4 & 3 & 2 & 1 \\
\hline 26070 & 6 & 27 a 36 anos & 6 a $10 \mathrm{SM}$ & 5 & 4 & 3 & 2 & 1 \\
\hline 2007 1 z & 10 & 17 a 26 anos & 26 ou mais $S M$ & 5 & 4 & 5 & 2 & 1 \\
\hline Kooz & 2 & 17 a 26 anos & 6 a $10 \mathrm{SM}$ & 5 & 4 & 3 & 2 & 1 \\
\hline Won & 8 & 17 a 26 anos & 6 a $10 \mathrm{SM}$ & 5 & 4 & 3 & 2 & 1 \\
\hline 0074 & 15 & 17 a 26 anos & 16 a $20 \mathrm{SM}$ & 5 & 4 & 3 & 2 & 1 \\
\hline 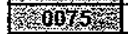 & 18 & 17 a 26 anos & 6 a $10 \mathrm{SM}$ & 5 & 4 & 3 & 2 & 1 \\
\hline W & 13 & 27 a 36 anos & 26 ou mais SM & 5 & 4 & 3 & 2 & 1 \\
\hline $007 x^{2}$ & 18 & 27 a 36 anos & 26 ou mais SM & 5 & 4 & 3 & 2 & 1 \\
\hline 0078 & 13 & 27 a 36 anos & 26 ou mais SM & 5 & 4 & 3 & 2 & 1 \\
\hline 0079 & $i$ & 17 a 26 anos & 6 a $10 \mathrm{SM}$ & 5 & 4 & 3 & 2 & 1 \\
\hline 0080 . & 18 & 17 a 26 anos & 1 a 5 SM & 5 & 4 & 3 & 2 & 1 \\
\hline 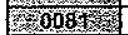 & 5 & 17 a 26 anos & 1 a 5 SM & 5 & 4 & 3 & 2 & 1 \\
\hline 6082 & 17 & 17 a 26 anos & $11 \mathrm{a} 15 \mathrm{SM}$ & 5 & 4 & 3 & 2 & 1 \\
\hline 5 0083 ive & 14 & 17 a 26 anos & 1 a 5 SM & 5 & 4 & 3 & 2 & 1 \\
\hline 6084 & 1 & Sem Resposta & 6 a $10 \mathrm{SM}$ & 5 & 4 & 3 & 2 & 1 \\
\hline
\end{tabular}




\begin{tabular}{|c|c|c|c|c|c|c|c|c|}
\hline Wha & 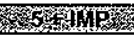 & 1 & 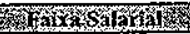 & P & Gescrin & Fom & 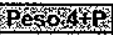 & 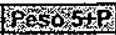 \\
\hline 0085 & 5 & 17 a 26 anos & 6 a $10 \mathrm{SM}$ & 5 & 4 & 3 & 2 & 1 \\
\hline 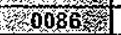 & 3 & 27 a 36 anos & 26 ou mais SM & 5 & 4 & 3 & 2 & 1 \\
\hline 2008D & 18 & 17 a 26 anos & 1 a $5 \mathrm{SM}$ & 5 & 4 & 3 & 2 & 1 \\
\hline 0008 & 14 & 17 a 26 anos & 1 a $5 \mathrm{SM}$ & 5 & 4 & 3 & 2 & 1 \\
\hline 30089 & 1 & 17 a 26 anos & 1 a 5 SM & 5 & 4 & 3 & 2 & 1 \\
\hline $0090 \%$ & 13 & 17 a 26 anos & 26 ou mais SM & 5 & 4 & 3 & 2 & 1 \\
\hline 00913 & 13 & 17 a 26 anos & 6 a $10 \mathrm{SM}$ & 5 & 4 & 3 & 2 & 1 \\
\hline 20092 & 4. & 17 a 26 anos & $6 a 10 \mathrm{SM}$ & 5 & 4 & 3 & 2 & 1 \\
\hline 0093 & 7 & 17 a 26 anos & 6 a $10 S M$ & $\overline{5}$ & 4 & 3 & 2 & 1 \\
\hline 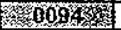 & 14 & 17 a 26 anos & $11 \mathrm{a} 15 \mathrm{SM}$ & 5 & 4 & 3 & 2 & 1 \\
\hline 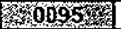 & 9 & 17 a 26 anos & 26 ou mais SM & 5 & 4 & 3 & 2 & 1 \\
\hline 19006 & 13 & 17 a 26 anos & 6 a $10 \mathrm{SM}$ & 5 & 4 & 3 & 2 & 1 \\
\hline 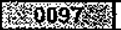 & 14 & 17 a 26 anos & 6 a $10 \mathrm{SM}$ & 5 & 4 & 3 & 2 & 1 \\
\hline 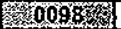 & 14 & 17 a 26 anos & 6 a $10 \mathrm{SM}$ & 5 & 4 & 3 & 2 & 1 \\
\hline 䇣得0099 & 17 & 27 a 36 anos & 1a $5 \mathrm{SM}$ & 5 & 4 & 3 & 2 & 1 \\
\hline 15000 & 17 & 17 a 26 anos & $6 \mathrm{a} 10 \mathrm{SM}$ & 5 & 4 & 3 & 2 & 1 \\
\hline 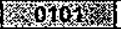 & 14 & 17 a 26 anos & 6 a $10 \mathrm{sM}$ & 5 & 4 & 3 & 2 & $T$ \\
\hline So102 & 18 & 17 a 26 anos & $1 \mathrm{a} 5 \mathrm{SM}$ & 5 & 4 & 3 & 2 & $i$ \\
\hline 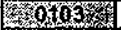 & 6 & 17 a 26 anos & 1 a $5 \mathrm{SM}$ & 5 & 4 & 3 & 2 & 1 \\
\hline 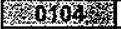 & & 17 a 26 anos & 1 a $5 \mathrm{SM}$ & 5 & 4 & 3 & 2 & 1 \\
\hline 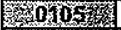 & & 17 a 26 anos & 26 ou mais SM & $\overline{5}$ & 4 & 3 & 2 & 1 \\
\hline 第 $8006 \%$ & 5 & 17 a 26 anos & 6 a $10 \mathrm{SM}$ & 5 & 4 & $\sqrt{3}$ & 2 & 1 \\
\hline 䈘 & 3 & 17 a 26 anos & 11 a $15 \mathrm{SM}$ & 5 & 4 & 3 & 2 & 7 \\
\hline 0108 & 11 & 17 a 26 anos & 16 a $20 \mathrm{SM}$ & 5 & 4 & 3 & 2 & 7 \\
\hline 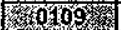 & 13 & 17 a 26 anos & 1 a $5 \mathrm{SM}$ & 5 & 4 & 3 & 2 & 1 \\
\hline 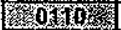 & 4 & 17 a 26 anos & 16 a 20 SM & 5 & 4 & 3 & 2 & 1 \\
\hline ras & 4 & 17 a 26 anos & 1 a $5 \mathrm{SM}$ & 5 & 4 & 3 & 2 & 1 \\
\hline 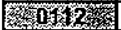 & 18 & 17 a 26 anos & 6 a $10 \mathrm{SM}$ & 5 & 4 & 3 & 2 & 1 \\
\hline 泫 & 7 & 17 a 26 anos & 11 a $15 \mathrm{SM}$ & 5 & 4 & 3 & 2 & 1 \\
\hline 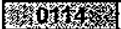 & 9 & 17 a 26 anos & 1 a 5 SM & 5 & 4 & 3 & 2 & 1 \\
\hline 栵 & 18 & 17 a 26 anos & 1 a $5 \mathrm{SM}$ & 5 & 4 & 3 & 2 & 1 \\
\hline 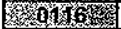 & 10 & 27 a 36 anos & 1 a $5 \mathrm{SM}$ & 5 & 4 & 3 & 2 & 1 \\
\hline 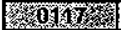 & 5 & 27 a 36 anos & 11 a $15 \mathrm{SM}$ & 5 & 4 & 3 & 2 & $\overline{1}$ \\
\hline 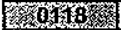 & 13 & 17 a 26 anos & 11 a 15 SM & 5 & 4 & 3 & 2 & 1 \\
\hline 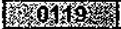 & 6 & 17 a 26 anos & 1 a $5 \mathrm{SM}$ & 5 & 4 & 3 & 2 & 1 \\
\hline 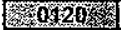 & 18 & 17 a 26 anos & 6 a $10 \mathrm{SM}$ & 5 & 4 & 3 & 2 & 1 \\
\hline 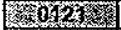 & 4 & 27 a 36 anos & 6 a $10 \mathrm{SM}$ & 5 & 4 & 3 & 2 & 1 \\
\hline in & 5 & 17 a 26 anos & 1 a $5 \mathrm{SM}$ & 5 & 4 & $\overline{3}$ & 2 & 1 \\
\hline 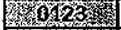 & 18 & 17 a 26 anos & 1 a $5 \mathrm{SM}$ & 5 & 4 & 3 & 2 & 1 \\
\hline X & 6 & 17 a 26 anos & 1 a $5 \mathrm{SM}$ & 5 & 4 & 3 & 2 & 1 \\
\hline 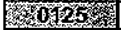 & 10 & 27 a 36 anos & 6 a $10 \mathrm{SM}$ & 5 & 4 & 3 & 2 & 1 \\
\hline 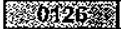 & 10 & 17 a 26 anos & $1 \mathrm{a} 5 \mathrm{SM}$ & 5 & 4 & 3 & 2 & 1 \\
\hline 筑 & 6 & 17 a 26 anos & 26 ou mais SM & 5 & 4 & 3 & 2 & 1 \\
\hline 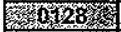 & 18 & 17 a 26 anos & $6 a 10 \mathrm{SM}$ & 5 & 4 & 3 & 2 & 1 \\
\hline 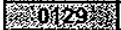 & 15 & 17 a 26 anos & 6 a $10 \mathrm{SM}$ & 5 & 4 & 3 & 2 & 1 \\
\hline 200400 & 18 & 17 a 26 anos & 6 a $10 \mathrm{SM}$ & 5 & 4 & $\overline{3}$ & 2 & 1 \\
\hline 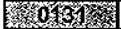 & & 17 a 26 anos & 26 ou mais SM & 5 & 4 & 3 & $\overline{2}$ & 1 \\
\hline 20132 & 7 & 17 a 26 anos & 6 a $10 \mathrm{SM}$ & 5 & 4 & 3 & 2 & 1 \\
\hline 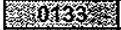 & 8 & 17 a 26 anos & 6 a $10 \mathrm{SM}$ & 5 & 4 & 3 & 2 & 1 \\
\hline 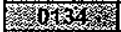 & 17 & 27 a 36 anos & 11 a $15 \mathrm{SM}$ & 5 & 4 & 3 & 2 & 1 \\
\hline 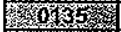 & 8 & 17 a 26 anos & 6 a $10 \mathrm{SM}$ & 5 & 4 & 3 & 2 & 1 \\
\hline 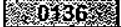 & 7 & 17 a 26 anos & 6 a $10 \mathrm{SM}$ & 5 & 4 & 3 & 2 & 1 \\
\hline bo & 2 & Sem Resposta & 6 a $10 \mathrm{SM}$ & 5 & 4 & 3 & 2 & 1 \\
\hline r & & 17 a 26 anos & 1 a 5 SM & 5 & 4 & 3 & 2 & 1 \\
\hline 䓠0139 & 2 & 17 a 26 anos & 11 a $15 \mathrm{SM}$ & 5 & 4 & 3 & 2 & 1 \\
\hline S O & & 17 a 26 anos & 6 a $10 \mathrm{SM}$ & 5 & 4 & 3 & 2 & 1 \\
\hline 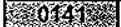 & 14 & 17 a 26 anos & 1 a 5 SM & 5 & 4 & 3 & 2 & 1 \\
\hline 䇣烈 & 6 & 27 a 36 anos & 6 a $10 \mathrm{SM}$ & 5 & 4 & 3 & 2 & 1 \\
\hline 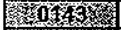 & 3 & 17 a 26 anos & 21 a $25 \mathrm{SM}$ & 5 & 4 & 3 & 2 & 1 \\
\hline 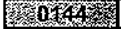 & 17 & 17 a 26 anos & 11 a $15 \mathrm{SM}$ & 5 & 4 & 3 & 2 & 1 \\
\hline 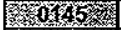 & 4 & 17 a 26 anos & 6 a $10 \mathrm{SM}$ & 5 & 4 & 3 & 2 & 1 \\
\hline ren & 7 & 17 a 26 anos & $6 a 10 \mathrm{SM}$ & 5 & 4 & 3 & 2 & 1 \\
\hline 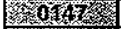 & 13 & 47 a 56 anos & 11 a $15 \mathrm{SM}$ & 5 & 4 & 3 & 2 & 1 \\
\hline 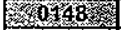 & 15 & 17 a 26 anos & 1 a 5 SM & 5 & 4 & 3 & 2 & 1 \\
\hline - & 4 & 17 a 26 anos & 1 a $5 \mathrm{SM}$ & 5 & 4 & 3 & 2 & 1 \\
\hline 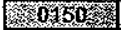 & 1 & 17 a 26 anos & 1 a $5 \mathrm{SM}$ & 5 & 4 & 3 & 2 & 1 \\
\hline 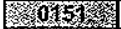 & 3 & 17 a 26 anos & 1 a 5 SM & 5 & 4 & 3 & 2 & 1 \\
\hline 0152 & 4 & 27 a 36 anos & 11 a $15 \mathrm{SM}$ & 5 & 4 & 3 & 2 & 1 \\
\hline 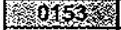 & & 17 a 26 anos & 1 a 5 SM & 5 & 4 & 3 & 2 & 1 \\
\hline ris & 5 & 17 a 26 anos & 26 ou mais SM & 5 & 4 & 3 & 2 & 1 \\
\hline 经 & 18 & 27 a 36 anos & 11 a $15 \mathrm{SM}$ & 5 & 4 & 3 & 2 & 1 \\
\hline 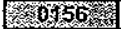 & 1 & 27 a 36 anos & 6 a $10 \mathrm{sM}$ & 5 & 4 & 3 & 2 & 1 \\
\hline 0 & 17 & 17 a 26 anos & 26 ou mais SM & 5 & 4 & 3 & 2 & 1 \\
\hline 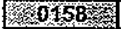 & 17 & 17 a 26 anos & 1 a $5 S M$ & 5 & 4 & 3 & 2 & 1 \\
\hline 疹䇣0159, & 2 & 17 a 26 anos & 6 a $10 \mathrm{SM}$ & 5 & 4 & 3 & 2 & 1 \\
\hline 0160 & 4 & 17 a 26 anos & $6010 \mathrm{sM}$ & 5 & 4 & 3 & 2 & 1 \\
\hline 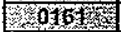 & 7 & 27 a 36 anos & 26 ou mais SM & 5 & 4 & 3 & 2 & 1 \\
\hline 0162 & 11 & 27 a 36 anos & 6 a $10 \mathrm{SM}$ & 5 & 4 & 3 & 2 & 1 \\
\hline W 0163 . & 2 & 27 a 36 anos & 1 a $5 S M$ & 5 & 4 & 3 & 2 & 1 \\
\hline 等 01614 & 1 & 27 a 36 anos & 6 a $10 \mathrm{SM}$ & 5 & 4 & 3 & 2 & 1 \\
\hline 0165 . & 3 & 17 a 26 anos & $1 \mathrm{a} 5 \mathrm{SM}$ & 5 & 4 & 3 & 2 & 1 \\
\hline 120166 & 18 & 17 a 26 anos & $1 \mathrm{a} 5 \mathrm{SM}$ & 5 & 4 & 3 & 2 & 1 \\
\hline 0167 & 10 & 17 a 26 anos & 11 a $15 \mathrm{SM}$ & 5 & 4 & 3 & 2 & 1 \\
\hline 0168 & 13 & 17 a 26 anos & 6 a $10 \mathrm{SM}$ & 5 & 4 & 3 & 2 & 1 \\
\hline
\end{tabular}




\begin{tabular}{|c|c|c|c|c|c|c|c|c|}
\hline STO & 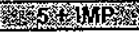 & 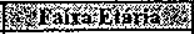 & M & B eso 140 & Resoris & PESos & 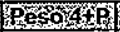 & 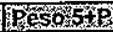 \\
\hline \% 0169 ; & 14 & 17 a 26 anos & $1 \mathrm{a} 5 \mathrm{SM}$ & 5 & 4 & 3 & 2 & 1 \\
\hline X179 & 18 & 17 a 26 anos & ia $5 \mathrm{SM}$ & 5 & 4 & 3 & 2 & 1 \\
\hline 筑 0174 & 15 & 17 a 26 anos & 26 ou mais $S M$ & 5 & 4 & 3 & 2 & 1 \\
\hline 6012 & 17 & 17 a 26 anos & 6 a $10 \mathrm{SM}$ & 5 & 4 & 3 & 2 & 1 \\
\hline 0173 & 14 & 37 a 46 anos & 26 ou mais SM & 5 & 4 & 3 & 2 & 1 \\
\hline 0 & 2 & 17 a 26 anos & 6 a $10 \mathrm{SM}$ & 5 & 4 & 3 & 2 & 1 \\
\hline 09175 & 5 & 17 a 26 anos & 6 a $10 \mathrm{SM}$ & 5 & 4 & 3 & 2 & 1 \\
\hline 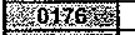 & 18 & 17 a 26 anos & 16 a $20 \mathrm{SM}$ & 5 & 4 & 3 & 2 & 1 \\
\hline 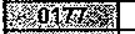 & & 17 a 26 anos & 1a $5 \mathrm{SM}$ & 5 & 4 & 3 & 2 & 1 \\
\hline S & 18 & 17 a 26 anos & 26 ou mais SM & 5 & 4 & 3 & 2 & 1 \\
\hline W & 6 & 47 a 56 anos & 11 a $15 \mathrm{SM}$ & 5 & 4 & 3 & 2 & 1 \\
\hline $60180 \leq x$ & 13 & 17 a 26 anos & 6 a $10 \mathrm{SM}$ & 5 & 4 & 3 & 2 & 1 \\
\hline 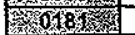 & 4 & 27 a 36 anos & 6 a $10 \mathrm{SM}$ & 5 & 4 & 3 & 2 & 1 \\
\hline 82018 & 9 & 17 a 26 anos & 1 a $5 \mathrm{SM}$ & 5 & 4 & 3 & 2 & 1 \\
\hline X 0183 S & 3 & 27 a 36 anos & 6 a $10 \mathrm{SM}$ & 5 & 4 & 3 & 2 & 1 \\
\hline 顽 & 6 & 17 a 26 anos & 6 a $10 \mathrm{SM}$ & 5 & 4 & 3 & 2 & 1 \\
\hline 36 & 5 & 17 a 26 anos & 6 a $10 \mathrm{SM}$ & 5 & 4 & 3 & 2 & 1 \\
\hline 01865 & 4 & 17 a 26 anos & 1 a $5 \mathrm{SM}$ & 5 & 4 & 3 & 2 & 1 \\
\hline 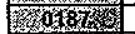 & 4 & 27 a 36 anos & 26 ou mais SM & 5 & 4 & 3 & 2 & 1 \\
\hline 0188 - & 18 & 17 a 26 anos & 6 a $10 \mathrm{SM}$ & 5 & 4 & 3 & 2 & 1 \\
\hline 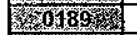 & 12 & 17 a 26 anos & 6 a $10 \mathrm{SM}$ & 5 & 4 & 3 & 2 & 1 \\
\hline 0 & 7 & 17 a 26 anos & 6 a $10 \mathrm{SM}$ & 5 & 4 & 3 & 2 & 1 \\
\hline W6196\% & 4 & 17 a 26 anos & 26 ou mais SM & 5 & 4 & 3 & 2 & 1 \\
\hline 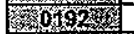 & 6 & 17 a 26 anos & 26 ou mais SM & 5 & 4 & 3 & 2 & 1 \\
\hline Exis & 17 & 17 a 26 anos & $1 \mathrm{a} 5 \mathrm{SM}$ & 5 & 4 & 3 & 2 & 1 \\
\hline 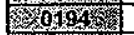 & 15 & 17 a 26 anos & 26 ou mais SM & 5 & 4 & 3 & 2 & 1 \\
\hline 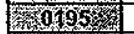 & 18 & 17 a 26 anos & 16 a $20 \mathrm{SM}$ & 5 & 4 & 3 & 2 & 1 \\
\hline 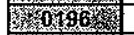 & 1 & 17 a 26 anos & 26 ou mais $S M$ & 5 & 4 & 3 & 2 & 1 \\
\hline 6 $0101 \%$ & 6 & 17 a 26 anos & 11 a $15 \mathrm{SM}$ & 5 & 4 & 3 & 2 & 1 \\
\hline x $0198<$ & 17 & 17 a 26 anos & 6 a $10 \mathrm{SM}$ & 5 & 4 & 3 & 2 & 1 \\
\hline Kar & 16 & 17 a 26 anos & 11 a $15 \mathrm{SM}$ & 5 & 4 & 3 & 2 & 1 \\
\hline 3.03 & 13 & 17 a 26 anos & 11 a $15 \mathrm{SM}$ & 5 & 4 & 3 & 2 & 1 \\
\hline 0202 & & 17 a 26 anos & 6 a $10 \mathrm{SM}$ & 5 & 4 & 3 & 2 & 1 \\
\hline 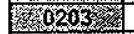 & 11 & 17 a 26 anos & 26 ou mais SM & 5 & 4 & 3 & 2 & 1 \\
\hline 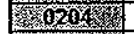 & 2 & 17 a 26 anos & $6 a 10 \mathrm{SM}$ & 5 & 4 & 3 & 2 & 1 \\
\hline - 62105 & 13 & 17 a 26 anos & $1 \mathrm{a} 5 \mathrm{SM}$ & 5 & 4 & 3 & 2 & 1 \\
\hline 资 & 2 & 17 a 26 anos & 26 ou mais SM & 5 & 4 & 3 & 2 & 1 \\
\hline 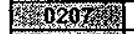 & 18 & 17 a 26 anos & 6 a $10 \mathrm{SM}$ & 5 & 4 & 3 & 2 & 1 \\
\hline S 0208 & 1 & 47 a 56 anos & 6 a $10 S M$ & 5 & 4 & 3 & 2 & 1 \\
\hline 0209 & 4 & 27 a 36 anos & 6 a $10 \mathrm{SM}$ & 5 & 4 & 3 & 2 & 1 \\
\hline 6020,0 & 1 & 17 a 26 anos & $1 \mathrm{a} 5 \mathrm{SM}$ & 5 & 4 & 3 & 2 & 1 \\
\hline 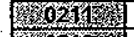 & 18 & 17 a 26 anos & 26 ou mais SM & 5 & 4 & 3 & 2 & 1 \\
\hline r & 7 & 27 a 36 anos & 1 a 5 SM & 5 & 4 & 3 & 2 & 1 \\
\hline 3. & 5 & 17 a 26 anos & 26 ou mais $S M$ & 5 & 4 & 3 & 2 & 1 \\
\hline $307 / 4$ & 18 & 17 a 26 anos & 26 ou mais SM & 5 & 4 & 3 & 2 & 1 \\
\hline 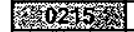 & 17 & 17 a 26 anos & 11 a $15 \mathrm{SM}$ & 5 & 4 & 3 & 2 & 1 \\
\hline 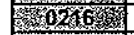 & 1 & 17 a 26 anos & 26 ou mais SM & 5 & 4 & 3 & 2 & 1 \\
\hline 40217 t & 10 & 17 a 26 anos & 1 a $5 \mathrm{SM}$ & 5 & 4 & 3 & 2 & 1 \\
\hline W & 3 & 17 a 26 anos & 26 ou mais SM & 5 & 4 & 3 & 2 & 1 \\
\hline - 0219 & 14 & 17 a 26 anos & 26 ou mais $S M$ & 5 & 4 & 3 & 2 & 1 \\
\hline (6220 & 3 & 17 a 26 anos & 11 a $15 \mathrm{SM}$ & 5 & 4 & 3 & 2 & 1 \\
\hline 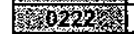 & 2 & 17 a 26 anos & 1 a $5 \mathrm{SM}$ & 5 & 4 & 3 & 2 & 7 \\
\hline 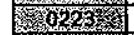 & 4 & 17 a 26 anos & 1 a $5 \mathrm{SM}$ & 5 & 4 & 3 & 2 & 1 \\
\hline 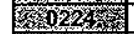 & 8 & 27 a 36 anos & 6 a $10 S M$ & 5 & 4 & 3 & 2 & 1 \\
\hline-2022538 & 3 & 17 a 26 anos & 1 a $5 \mathrm{SM}$ & 5 & 4 & 3 & 2 & 1 \\
\hline 3026 & 4 & 17 a 26 anos & 1 a $5 \mathrm{SM}$ & 5 & 4 & 3 & 2 & 1 \\
\hline S 102 & 7 & 47 a 56 anos & 11 a $15 \mathrm{SM}$ & 5 & 4 & 3 & 2 & 1 \\
\hline 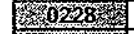 & 2 & 37 a 46 anos & 6 a $10 \mathrm{SM}$ & 5 & 4 & 3 & 2 & 1 \\
\hline 80290 & 5 & 27 a 36 anos & $6 a 10 \mathrm{SM}$ & 5 & 4 & 3 & 2 & 1 \\
\hline 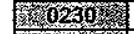 & 8 & 17 a 26 anos & 1 a $5 \mathrm{SM}$ & 5 & 4 & 3 & 2 & 1 \\
\hline X & 10 & 27 a 36 anos & 1 a $5 S M$ & 5 & 4 & 3 & 2 & 1 \\
\hline 3239 & 3 & 17 a 26 anos & 11 a $15 \mathrm{SM}$ & 5 & 4 & 3 & 2 & 1 \\
\hline-0233 & 17 & 17 a 26 anos & 1 a $5 \mathrm{SM}$ & 5 & 4 & 3 & 2 & 1 \\
\hline 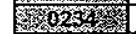 & 6 & 17 a 26 anos & 1 a $5 \mathrm{SM}$ & 5 & 4 & 3 & 2 & 1 \\
\hline G & 6 & 37 a 46 anos & 6 a $10 \mathrm{SM}$ & 5 & 4 & 3 & 2 & 1 \\
\hline 23023\% & 11 & 17 a 26 anos & 1 a $5 \mathrm{SM}$ & 5 & 4 & 3 & 2 & 1 \\
\hline 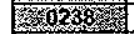 & 18 & 17 a 26 anos & 1 a 5 SM & 5 & 4 & 3 & 2 & 1 \\
\hline 经 & 11 & 17 a 26 arjos & 1 a $5 \mathrm{SM}$ & 5 & 4 & 3 & 2 & 1 \\
\hline - 0244 & 17 & 17 a 26 anos & t a $5 \mathrm{SM}$ & 5 & 4 & 3 & 2 & 1 \\
\hline $0.6 \mathrm{~s}$ & 14 & 17 a 26 anos & 6 a $10 \mathrm{SM}$ & 5 & 4 & 3 & 2 & 1 \\
\hline 3. & 18 & 17 a 26 anos & 1 a 5 SM & 5 & 4 & 3 & 2 & 1 \\
\hline-0240 & 7 & 17 a 26 anos & 6 a $10 \mathrm{SM}$ & 5 & 4 & 3 & 2 & 1 \\
\hline OE & 17 & 27 a 36 anos & 1 a $5 \mathrm{SM}$ & 5 & 4 & 3 & 2 & 1 \\
\hline 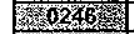 & 18 & 17 a 26 anos & 6 a $10 \mathrm{SM}$ & 5 & 4 & 3 & 2 & 1 \\
\hline 4024,5 & 13 & 27 a 36 anos & 1 a $5 \mathrm{SM}$ & 5 & 4 & 3 & 2 & 1 \\
\hline 0248 & & 27 a 36 anos & 1 a $5 \mathrm{SM}$ & 5 & 4 & 3 & 2 & $i$ \\
\hline 徨 0249 & 13 & 27 a 36 anos & 6 a $10 \mathrm{SM}$ & 5 & 4 & 3 & 2 & 1 \\
\hline 0250 & 1 & 27 a 36 anos & 1 a $5 \mathrm{SM}$ & 5 & 4 & 3 & 2 & 1 \\
\hline 0251 - & 7 & 17 a 26 anos & 6 a $10 \mathrm{SM}$ & 5 & 4 & 3 & 2 & 1 \\
\hline $025 \mathrm{Z}$ & 1 & 27 a 36 anos & 26 ou mais $S M$ & 5 & 4 & 3 & 2 & 1 \\
\hline 0253 & 18 & 17 a 26 anos & 6 a $10 \mathrm{SM}$ & 5 & 4 & 3 & 2 & 1 \\
\hline 0254 & & 17 a 26 anos & 26 ou mais $S M$ & 5 & 4 & 3 & 2 & 1 \\
\hline$\leq 0255$ & 5 & 17 a 26 anos & $6 a 10 \mathrm{SM}$ & 5 & 4 & 3 & 2 & 1 \\
\hline 5 & 14 & 27 a 36 anos & 6 a $10 \mathrm{SM}$ & 5 & 4 & 3 & 2 & 1 \\
\hline
\end{tabular}




\begin{tabular}{|c|c|c|c|c|c|c|c|c|}
\hline 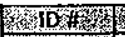 & 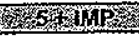 & H & W & RESO IPP & $\mathrm{EesO} 2+\mathrm{P}$ & PResos & Pessing & Prsions \\
\hline 0256 & 14 & 17 a 26 anos & $6 a 10 \mathrm{SM}$ & 5 & 4 & 3 & 2 & 1 \\
\hline 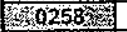 & 12 & 27 a 36 anos & 1 a 5 SM & 5 & 4 & 3 & 2 & $i$ \\
\hline 0259 & 17 & 17 a 26 anos & $6 \mathrm{a} 10 \mathrm{SM}$ & 5 & 4 & 3 & 2 & 1 \\
\hline 36260 & 10 & 17 a 26 anos & 6 a $10 \mathrm{SM}$ & 5 & 4 & 3 & 2 & $i$ \\
\hline 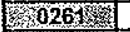 & 1 & 27 a 36 anos & 1 a $5 \mathrm{SM}$ & 5 & 4 & 3 & 2 & 1 \\
\hline 302623 & 5 & 17 a 26 anos & 11 a $15 \mathrm{SM}$ & 5 & 4 & 3 & 2 & 1 \\
\hline 02636 & & 27 a 36 anos & 6 a $10 \mathrm{SM}$ & 5 & 4 & 3 & 2 & 1 \\
\hline $60264<$ & 10 & 27 a 36 anos & 6 a $10 \mathrm{SM}$ & 5 & 4 & 3 & 2 & 1 \\
\hline 02655 & 18 & 17 a 26 anos & 26 ou mais SM & 5 & 4 & 3 & 2 & 1 \\
\hline 0267 23: & 7 & 27 a 36 anos & $6 a 10 \mathrm{SM}$ & 5 & 4 & 3 & 2 & 1 \\
\hline 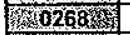 & 2 & 17 a 26 anos & t a 5 SM & 5 & 4 & 3 & 2 & 1 \\
\hline $0269 \mathrm{x}$ & 1 & 27 a 36 anos & 6 a $10 \mathrm{SM}$ & 5 & 4 & 3 & 2 & 1 \\
\hline 0200 & 14 & 17 a 26 anos & 11 a $15 \mathrm{SM}$ & 5 & 4 & 3 & 2 & 1 \\
\hline 30240 & 13 & 17 a 26 anos & 6 a $10 \mathrm{SM}$ & 5 & 4 & 3 & 2 & 1 \\
\hline 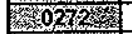 & 10 & 17 a 26 anos & 6 a $10 \mathrm{SM}$ & 5 & 4 & 3 & 2 & 1 \\
\hline 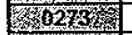 & 6 & 17 a 26 anos & 1 a $5 \mathrm{SM}$ & 5 & 4 & 3 & 2 & 1 \\
\hline 然 0274 & 14 & 17 a 26 anos & 16 a $20 \mathrm{SM}$ & 5 & 4 & 3 & 2 & 1 \\
\hline 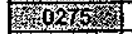 & 6 & 17 a 26 anos & 6 a $10 \mathrm{SM}$ & 5 & 4 & 3 & 2 & 1 \\
\hline 50276 & 3 & 17 a 26 anos & 26 ou mais SM & 5 & 4 & 3 & 2 & 1 \\
\hline 落2 & 14 & 17 a 26 anos & 1 a 5 SM & 5 & 4 & 3 & 2 & 1 \\
\hline S & 10 & 17 a 26 anos & 6 a $10 \mathrm{sM}$ & 5 & 4 & 3 & 2 & 1 \\
\hline 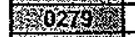 & 12 & 17 a 26 anos & 1 a $5 \mathrm{SM}$ & 5 & 4 & 3 & 2 & 1 \\
\hline 0280 & 12 & 17 a 26 anos & 11 a $15 \mathrm{SM}$ & 5 & 4 & 3 & 2 & 1 \\
\hline 40285 & 11 & 17 a 26 anos & 26 ou mais SM & 5 & 4 & 3 & 2 & 1 \\
\hline 2028 & 1 & 17 a 26 anos & 26 ou mais SM & 5 & 4 & 3 & 2 & 1 \\
\hline $02833^{2}$ & 13 & 17 a 26 anos & 1 a 5 SM & 5 & 4 & 3 & 2 & 1 \\
\hline 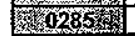 & 5 & 17 a 26 anos & 6 a $10 \mathrm{sM}$ & 5 & 4 & 3 & 2 & 1 \\
\hline 8 & 13 & 27 a 36 anos & $6 \mathrm{a} 10 \mathrm{SM}$ & 5 & 4 & 3 & 2 & 1 \\
\hline S & 5 & 17 a 26 anos & $1 \mathrm{a} 5 \mathrm{SM}$ & 5 & 4 & 3 & 2 & 1 \\
\hline S 0286 ; & 17 & 17 a 26 anos & $11 \mathrm{a} 15 \mathrm{SM}$ & 5 & 4 & 3 & 2 & 1 \\
\hline 3.0289 & 6 & 27 a 36 anos & 6 a $10 \mathrm{SM}$ & 5 & 4 & 3 & 2 & 1 \\
\hline 302900 & & 17 a 26 anos & 26 ou mais SM & 5 & 4 & 3 & 2 & 1 \\
\hline C. & & 27 a 36 anos & 1 a $5 \mathrm{SM}$ & 5 & 4 & 3 & 2 & 1 \\
\hline 0292 & 17 & 17 a 26 anos & 1 a $5 \mathrm{SM}$ & 5 & 4 & 3 & 2 & 1 \\
\hline 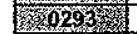 & 18 & 17 a 26 anos & 26 ou mais SM & 5 & 4 & 3 & 2 & 1 \\
\hline K3. & 8 & 47 a 56 anos & 6 a $10 \mathrm{SM}$ & 5 & 4 & 3 & 2 & 1 \\
\hline 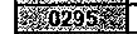 & & 17 a 26 anos & 26 ou mais SM & 5 & 4 & 3 & 2 & 1 \\
\hline 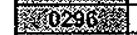 & & 17 a 26 anos & 26 ou mais $S M$ & 5 & 4 & 3 & 2 & 1 \\
\hline 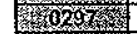 & 3 & 17 a 26 anos & 1 a $5 \mathrm{SM}$ & 5 & 4. & 3 & 2 & $i$ \\
\hline 0298 & 9 & 17 a 26 anos & 6 a $10 \mathrm{SM}$ & 5 & 4 & 3 & 2 & 1 \\
\hline 30290 & 1 & 17 a 26 anos & 26 ou mais $S M$ & 5 & 4 & 3 & 2 & 1 \\
\hline $0300 \%$ & 3 & 17 a 26 anos & 11 a $15 \mathrm{SM}$ & 5 & 4 & 3 & 2 & 1 \\
\hline 3) & 5 & 17 a 26 anos & 26 ou mais SM & 5 & 4 & 3 & 2 & 1 \\
\hline 私 63002 & 13 & 17 a 26 anos & 26 ou mais SM & 5 & 4 & 3 & 2 & $i$ \\
\hline 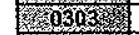 & 11 & 17 a 26 anos & 26 ou mais SM & 5 & 4 & 3 & 2 & 1 \\
\hline 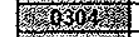 & 4 & 17 a 26 anos & 26 ou mais SM & 5 & 4 & 3 & 2 & 1 \\
\hline M 0305 & 14 & 17 a 26 anos & 11 a $15 \mathrm{SM}$ & 5 & 4 & 3 & 2 & 1 \\
\hline 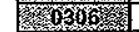 & 12 & 17 a 26 anos & 26 ou mais SM & 5 & 4 & 3 & 2 & 1 \\
\hline 20307 & 9 & 17 a 26 anos & 26 ou mais SM & 5 & 4 & 3 & 2 & 1 \\
\hline 1 & 12 & 17 a 26 anos & 26 ou mais SM & 5 & 4 & 3 & 2 & 1 \\
\hline 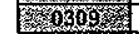 & 7 & 17 a 26 anos & 26 ou mais SM & 5 & 4 & 3 & 2 & 1 \\
\hline Wo 030 & 15 & 17 a 26 anos & 26 ou mais SM & 5 & 4 & 3 & 2 & 1 \\
\hline (5) & 7 & 17 a 26 anos & 11 a $15 \mathrm{SM}$ & 5 & 4 & 3 & 2 & 1 \\
\hline 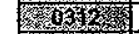 & 6 & 17 a 26 anos & 11 a $15 \mathrm{SM}$ & 5 & 4 & 3 & 2 & 1 \\
\hline 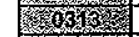 & 15 & 17 a 26 anos & 6 a $10 \mathrm{SM}$ & 5 & 4 & 3 & 2 & 1 \\
\hline S & 4 & 17 a 26 anos & $11 \mathrm{a} 15 \mathrm{SM}$ & 5 & 4 & 3 & 2 & 1 \\
\hline 0310 & 5 & 17 a 26 anos & 6 a $10 \mathrm{SM}$ & 5 & 4 & 3 & 2 & 1 \\
\hline 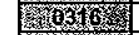 & 11 & 17 a 26 anos & 26 ou mais $S M$ & 5 & 4 & 3 & 2 & 1 \\
\hline 50315 & 11 & 17 a 26 anos & 26 ou mais SM & 5 & 4 & 3 & 2 & 1 \\
\hline K & 13 & 17 a 26 anos & 26 ou mais $S M$ & 5 & 4 & 3 & 2 & 1 \\
\hline 4 & & 17 a 26 anos & 11 a $15 \mathrm{SM}$ & 5 & 4 & 3 & 2 & 1 \\
\hline$\gamma 43201$ & & 17 a 26 anos & 11 a $15 \mathrm{SM}$ & 5 & 4 & 3 & 2 & 1 \\
\hline 6ris & 10 & 17 a 26 anos & 26 ou mais SM & 5 & 4 & 3 & 2 & 1 \\
\hline 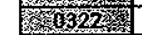 & 7 & 17 a 26 anos & 11 a15 SM & 5 & 4 & 3 & 2 & 1 \\
\hline S6 0326 & 14 & 17 a 26 anos & 26 ou mais SM & 5 & 4 & 3 & 2 & 1 \\
\hline 3ro3 & 7 & 17 a 26 anos & 6 a $10 \mathrm{SM}$ & 5 & 4 & 3 & 2 & 1 \\
\hline$x_{23} 20325$ & 2 & 37 a 46 anos & $2 \uparrow$ a $25 \mathrm{SM}$ & 5 & 4 & 3 & 2 & 1 \\
\hline V & 13 & 17 a 26 anos & i a $5 \mathrm{SM}$ & 5 & 4 & 3 & 2 & 1 \\
\hline 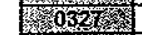 & 13 & 17 a 26 anos & 26 ou mais SM & 5 & 4 & 3 & 2 & 1 \\
\hline $0328<1$ & 1 & 17 a 26 anos & 6 a $10 \mathrm{SM}$ & 5 & 4 & 3 & 2 & 1 \\
\hline 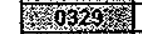 & 2 & 17 a 26 anos & 26 ou mais SM & 5 & 4 & 3 & 2 & 1 \\
\hline 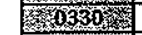 & 12 & 17 a 26 anos & 11 a $15 \mathrm{SM}$ & 5 & 4 & 3 & 2 & 1 \\
\hline 稵 0334 & 8 & 17 a 26 anos & 6 a $10 \mathrm{sM}$ & 5 & 4 & 3 & 2 & 1 \\
\hline 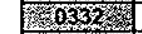 & 4 & 17 a 26 anos & 21 a $25 \mathrm{SM}$ & 5 & 4 & 3 & 2 & 1 \\
\hline 60333 & 3 & 17 a 26 anos & 11 a $15 \mathrm{SM}$ & 5 & 4 & 3 & 2 & 1 \\
\hline 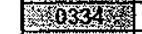 & 14 & 17 a 26 anos & 26 ou mais SM & 5 & 4 & 3 & 2 & 1 \\
\hline S & 6 & 17 a 26 anos & 26 ou mais $S M$ & 5 & 4 & 3 & 2 & 1 \\
\hline 0336 & 14 & 17 a 26 anos & $11 \mathrm{a} 15 \mathrm{SM}$ & 5 & 4 & 3 & 2 & 1 \\
\hline 03373 & & 17 a 26 anos & 1 a $55 \mathrm{M}$ & 5 & 4 & 3 & 2 & 1 \\
\hline 0338 \% & 12 & 17 a 26 anos & 11 a $15 \mathrm{SM}$ & 5 & 4 & 3 & 2 & 1 \\
\hline 0339 & 8 & 17 a 26 anos & 6 a $10 \mathrm{SM}$ & 5 & 4 & 3 & 2 & 1 \\
\hline 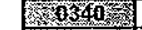 & 14 & 17 a 26 anos & 26 ou mais SM & 5 & 4 & 3 & 2 & 1 \\
\hline S 0341 r & 13 & 17 a 26 anos & 11 a $15 \mathrm{sM}$ & 5 & 4 & 3 & 2 & 1 \\
\hline 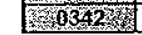 & 12 & 17 a 26 anos & 26 ou mais SM & 5 & 4 & 3 & 2 & 1 \\
\hline
\end{tabular}




\begin{tabular}{|c|c|c|c|c|c|c|c|c|}
\hline W & 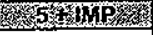 & 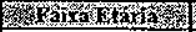 & 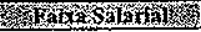 & PEs & $2 \cos 20242$ & 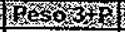 & P & 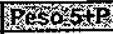 \\
\hline 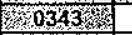 & & 17 a 26 anos & 11 a $15 \mathrm{SM}$ & 5 & 4 & 3 & 2 & 1 \\
\hline 0344 - & 8 & 17 a 26 anos & 1 a $5 \mathrm{SM}$ & 5 & 4 & 3 & 2 & 1 \\
\hline $0345 \times 3$ & 18 & 27 a 36 anos & 16 a $20 \mathrm{SM}$ & 5 & 4 & 3 & 2 & 1 \\
\hline 0346 & 2 & 17 a 26 anos & $6 \mathrm{a} 10 \mathrm{SM}$ & 5 & 4 & 3 & 2 & 1 \\
\hline 503473 & 14 & 17 a 26 anos & 6 a $10 \mathrm{SM}$ & 5 & 4 & 3 & 2 & 1 \\
\hline 20348 & & 17 a 26 anos & $16 \mathrm{a} 20 \mathrm{SM}$ & 5 & 4 & 3 & 2 & 1 \\
\hline 0349 & 18 & 17 a 26 anos & 21 a $25 \mathrm{SM}$ & 5 & 4 & 3 & 2 & 1 \\
\hline K 0350 O & 11 & 17 a 26 anos & 16 a $20 \mathrm{SM}$ & 5 & 4 & 3 & 2 & 1 \\
\hline $035 \pi$ & 17 & 17 a 26 anos & 11 a $15 \mathrm{SM}$ & 5 & 4 & 3 & 2 & 1 \\
\hline ( & 1 & 17 a 26 anos & $6 \mathrm{a} 10 \mathrm{SM}$ & 5 & 4 & 3 & 2 & 1 \\
\hline 6353 & 18 & 17 a 26 anos & $6 \mathrm{a} 10 \mathrm{SM}$ & 5 & 4 & 3 & 2 & 1 \\
\hline 80354 & 17 & 17 a 26 anos & 6 a $10 \mathrm{SM}$ & 5 & 4 & 3 & 2 & 1 \\
\hline 4355 & 10 & 17 a 26 anos & 26 ou mais SM & 5 & 4 & 3 & 2 & 1 \\
\hline 60356 \% & 18 & 17 a 26 anos & 26 ou mais SM & 5 & 4 & 3 & 2 & 1 \\
\hline 0357 & 18 & 17 a 26 anos & 11 a $15 \mathrm{SM}$ & 5 & 4 & 3 & 2 & 1 \\
\hline 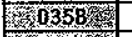 & 2 & 17 a 26 anos & 16 a $20 \mathrm{SM}$ & 5 & 4 & 3 & 2 & 1 \\
\hline 00359 & 6 & 17 a 26 anos & $1 \mathrm{a} 5 \mathrm{SM}$ & 5 & 4 & 3 & 2 & 1 \\
\hline 03030 & 13 & 17 a 26 anos & 6 a $10 \mathrm{SM}$ & 5 & 4 & 3 & 2 & 1 \\
\hline 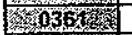 & 14 & 17 a 26 anos & 6 a 10 SM & 5 & 4 & 3 & 2 & 1 \\
\hline 0362 & 17 & 17 a 26 anos & 6 a $10 \mathrm{SM}$ & 5 & 4 & 3 & 2 & 1 \\
\hline 563634 & & 17 a 26 anos & 1 a $5 \mathrm{SM}$ & 5 & 4 & 3 & 2 & 1 \\
\hline (n) $0369 \%$ & 2 & 17 a 26 anos & 1 a $5 \mathrm{SM}$ & 5 & 4 & 3 & 2 & 1 \\
\hline 03655 & 4 & 17 a 26 anos & 1 a $5 \mathrm{SM}$ & 5 & 4 & 3 & 2 & 1 \\
\hline 0366 & 4 & 17 a 26 anos & 6 a $10 \mathrm{SM}$ & 5 & 4 & 3 & 2 & 1 \\
\hline 3xis & 15 & 27 a 36 anos & 21 a $25 \mathrm{SM}$ & 5 & 4 & 3 & 2 & 1 \\
\hline 40368 & & 17 a 26 anos & 26 ou mais SM & 5 & 4 & 3 & 2 & 1 \\
\hline Des690 & 5 & 17 a 26 anos & 26 ou mais $S M$ & 5 & 4 & 3 & 2 & 1 \\
\hline 3. & 9 & 17 a 26 anos & 1 a 5 SM & 5 & 4 & 3 & 2 & 1 \\
\hline S3 & 9 & 17 a 26 anos & 11 a $15 \mathrm{sM}$ & 5 & 4 & 3 & 2 & 1 \\
\hline tris & 7 & 17 a 26 anos & $6010 \mathrm{SM}$ & 5 & 4 & 3 & 2 & 1 \\
\hline ristos & 7 & 27 a 36 anos & 1 a $5 \mathrm{SM}$ & 5 & 4 & 3 & 2 & 1 \\
\hline 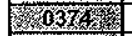 & 9 & 27 a 36 anos & 6 a $10 \mathrm{SM}$ & 5 & 4 & 3 & 2 & 1 \\
\hline 60375 & 17 & 27 a 36 anos & 26 ou mais SM & 5 & 4 & 3 & 2 & 1 \\
\hline 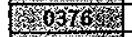 & 7 & 37 a 46 anos & 16 a $20 \mathrm{SM}$ & 5 & 4 & 3 & 2 & 1 \\
\hline 20 & 7 & 17 a 26 anos & 6 a $10 \mathrm{SM}$ & 5 & 4 & 3 & 2 & 1 \\
\hline 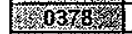 & 12 & 17 a 26 anos & 26 ou mais SM & 5 & 4 & 3 & 2 & 1 \\
\hline 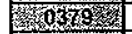 & 18 & 27 a 36 anos & 1 a $5 \mathrm{SM}$ & 5. & 4 & 3 & 2 & 1 \\
\hline 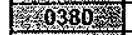 & 10 & 27 a 36 anos & 26 ou mais $S M$ & 5 & 4 & 3 & 2 & 1 \\
\hline 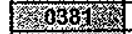 & 2 & 17 a 26 anos & 1 a $5 \mathrm{SM}$ & 5 & 4 & 3 & 2 & 1 \\
\hline 0382 & 5 & 17 a 26 anos & 26 ou mais SM & 5 & 4 & 3 & 2 & 1 \\
\hline 经 & 8 & 17 a 26 anos & 26 ou mais SM & 5 & 4. & 3 & 2 & 1 \\
\hline 3 & 7 & 17 a 26 anos & 6 a $10 \mathrm{SM}$ & 5 & 4 & 3 & 2 & 1 \\
\hline 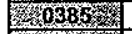 & 17 & 17 a 26 anos & 1 a $5 \mathrm{SM}$ & 5 & 4 & 3 & 2 & 1 \\
\hline 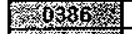 & 18 & 37 a 46 anos & 16 a $20 \mathrm{SM}$ & 5 & 4 & 3 & 2 & 1 \\
\hline 0387 & 18 & 17 a 26 anos & $11 \mathrm{a} 15 \mathrm{SM}$ & 5 & 4 & 3 & 2 & 1 \\
\hline 038 & 9 & 17 a 26 anos & 1a $5 \mathrm{SM}$ & 5 & 4 & 3 & 2 & 1 \\
\hline 0389 & & 17 a 26 anos & 6 a $10 \mathrm{SM}$ & 5 & 4 & 3 & 2 & 1 \\
\hline 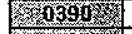 & & 17 a 26 anos & 1 a $5 \mathrm{SM}$ & 5 & 4 & 3 & 2 & 1 \\
\hline 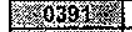 & & 27 a 36 anos & 26 ou mais SM & 5 & 4 & 3 & 2 & 1 \\
\hline 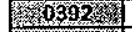 & 9 & 17 a 26 anos & 6 a $10 \mathrm{SM}$ & 5 & 4 & 3 & 2 & 1 \\
\hline 等 & 13 & 17 a 26 anos & $6 \mathrm{a} 10 \mathrm{SM}$ & 5 & 4 & 3 & 2 & 1 \\
\hline 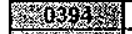 & 13 & 17 a 26 anos & 6 a $10 \mathrm{SM}$ & 5 & 4 & 3 & 2 & 1 \\
\hline K30 030 & 15 & 17 a 26 anos & 1 a $5 \mathrm{SM}$ & 5 & 4 & 3 & 2 & 1 \\
\hline S 0396 - & 4 & 17 a 26 anos & 26 ou mais SM & 5 & 4 & 3 & 2 & 1 \\
\hline S & 5 & 27 a 36 anos & 6 a $10 \mathrm{SM}$ & 5 & 4 & 3 & 2 & 1 \\
\hline 0388 & 18 & 17 a 26 anos & 6 a $10 \mathrm{SM}$ & 5 & 4 & 3 & 2 & 1 \\
\hline 20399 & 18 & 17 a 26 anos & 1 as SM & 5 & 4 & 3 & 2 & 1 \\
\hline 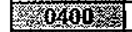 & & 17 a 26 anos & 6 a $10 S M$ & 5 & 4 & 3 & 2 & 1 \\
\hline 20401 & & 17 a 26 anos & 26 ou mais $S M$ & 5 & 4 & 3 & 2 & 1 \\
\hline 30402 & 4 & 17 a 26 anos & 6 a $10 \mathrm{SM}$ & 5 & 4 & 3 & 2 & 1 \\
\hline 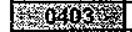 & 2 & 17 a 26 anos & 1 a $5 \mathrm{SM}$ & 5 & 4 & 3 & 2 & 1 \\
\hline 20004 & 4 & 17 a 26 anos & 1 a $5 \mathrm{SM}$ & 5 & 4 & 3 & 2 & 1 \\
\hline 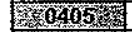 & 17 & 17 a 26 anos & 1 a 5 SM & 5 & 4 & 3 & 2 & 1 \\
\hline 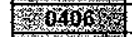 & 18 & 17 a 26 anos & 26 ou mais SM & 5 & 4 & 3 & 2 & 1 \\
\hline 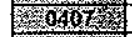 & 15 & 17 a 26 anos & $6 \mathrm{a} 10 \mathrm{SM}$ & 5 & 4 & 3 & 2 & 1 \\
\hline 0408 . & 17 & 17 a 26 anos & $6 a 10 S M$ & 5 & 4 & 3 & 2 & 1 \\
\hline 0409 \% & 5 & 17 a 26 anos & 1a5 SM & 5 & 4 & 3 & 2 & 1 \\
\hline S & 1 & 17 a 26 anos & 26 ou mais SM & 5 & 4 & 3 & 2 & 1 \\
\hline 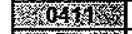 & 6 & 17 a 26 anos & 11 a $15 \mathrm{SM}$ & 5 & 4 & 3 & 2 & 1 \\
\hline 04512 & 18 & 17 a 26 anos & 1 a $5 \mathrm{SM}$ & 5 & 4 & 3 & 2 & 1 \\
\hline S 00013 & 12 & 27 a 36 anos & 1 a $5 \mathrm{SM}$ & 5 & 4 & 3 & 2 & 1 \\
\hline Sogy 4 & 12 & 17 a 26 anos & 26 ou mais SM & 5 & 4 & 3 & 2 & 1 \\
\hline 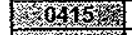 & 18 & 37 a 46 anos & 1 a $5 \mathrm{SM}$ & 5 & 4 & 3 & 2 & 1 \\
\hline 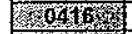 & 4 & 17 a 26 anos & 1 a $5 \mathrm{SM}$ & 5 & 4 & 3 & 2 & 1 \\
\hline 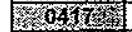 & & 17 a 26 anos & 26 ou mais $S M$ & 5 & 4 & 3 & 2 & 1 \\
\hline 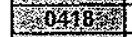 & 18 & 17 a 26 anos & 6 a $10 \mathrm{SM}$ & 5 & 4 & 3 & 2 & 1 \\
\hline 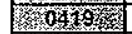 & 14 & 17 a 26 anos & 1 a $5 \mathrm{SM}$ & 5 & 4 & 3 & 2 & 1 \\
\hline K 0420 & 5 & 17 a 26 anos & 6a $10 \mathrm{SM}$ & 5 & 4 & 3 & 2 & 1 \\
\hline W 0427 & 11 & 17 a 26 anos & 26 ou mais $S M$ & 5 & 4 & 3 & 2 & 1 \\
\hline 60522 & 7 & 27 a 36 anos & 26 ou mais SM & 5 & 4 & 3 & 2 & 1 \\
\hline $20423 \%$ & 13 & 17 a 26 anos & 1 a $5 \mathrm{SM}$ & 5 & 4 & 3 & 2 & 1 \\
\hline 0424 得 & 3 & 17 a 26 anos & 1 a $5 \mathrm{SM}$ & 5 & 4 & 3 & 2 & 1 \\
\hline 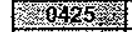 & 18 & 27 a 36 anos & 1 a $5 \mathrm{SM}$ & 5 & 4 & 3 & 2 & 1 \\
\hline 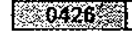 & & 17 a 26 anos & $6 a 10 \mathrm{SM}$ & 5 & 4 & 3 & 2 & 1 \\
\hline
\end{tabular}




\begin{tabular}{|c|c|c|c|c|c|c|c|c|}
\hline Ka & 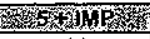 & 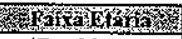 & 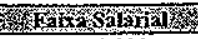 & Pes; & YPESOZ & 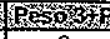 & 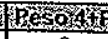 & 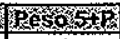 \\
\hline 0427 \% & 14 & 17 a 26 anos & 1 a $5 \mathrm{SM}$ & 5 & 4 & 3 & 2 & 1 \\
\hline Y 0428 & 7 & 17 a 26 anos & 11 a $15 \mathrm{SM}$ & 5 & 4 & 3 & 2 & 1 \\
\hline 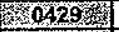 & 13 & 27 a 36 anos & $6 a 10 \mathrm{SM}$ & 5 & 4 & 3 & 2 & 1 \\
\hline 404303 & 4 & 17 a 26 anos & 11 a $15 \mathrm{SM}$ & 5 & 4 & 3 & 2 & 1 \\
\hline 04315 & 1 & 17 a 26 anos & 1 a 5 SM & 5 & 4 & 3 & 2 & 1 \\
\hline 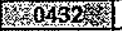 & 16 & 17 a 26 anos & 1 a 5 SM & 5 & 4 & 3 & 2 & 1 \\
\hline 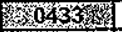 & 7 & 17 a 26 anos & 1 a 5 SM & 5 & 4 & 3 & 2 & 1 \\
\hline 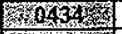 & 2 & 17 a 26 anos & 1 a $5 S M$ & 5 & 4 & 3 & 2 & 1 \\
\hline 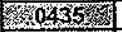 & 14 & 17 a 26 anos & 1 a 5 SM & 5 & 4 & 3 & 2 & 1 \\
\hline 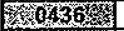 & 9 & 27 a 36 anos & 26 ou mais SM & 5 & 4 & 3 & 2 & 1 \\
\hline 604373 & 15 & 17 a 26 anos & 26 ou mais SM & 5 & 4 & 3 & 2 & 1 \\
\hline 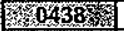 & 6 & 27 a 36 anos & 16 a $20 \mathrm{SM}$ & 5 & 4 & 3 & 2 & 1 \\
\hline 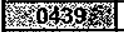 & 13 & 17 a 26 anos & 1 a $5 S M$ & 5 & 4 & 3 & 2 & 1 \\
\hline KO & & 17 a 26 anos & 6 a $10 \mathrm{SM}$ & 5 & 4 & 3 & 2 & 1 \\
\hline 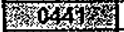 & 12 & 17 a 26 anos & $6 a 10 \mathrm{SM}$ & 5 & 4 & 3 & 2 & 1 \\
\hline 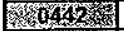 & 1 & 17 a 26 anos & 1 a $5 \mathrm{SM}$ & 5 & 4 & 3 & 2 & 1 \\
\hline 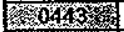 & 17 & 17 a 26 anos & 1 a $5 \mathrm{SM}$ & 5 & 4 & 3 & 2 & 1 \\
\hline 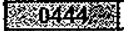 & 1 & 17 a 26 anos & 26 ou mais SM & 5 & 4 & 3 & 2 & 1 \\
\hline 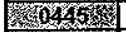 & 6 & 17 a 26 anos & 1 a $5 \mathrm{SM}$ & 5 & 4 & 3 & 2 & 1 \\
\hline 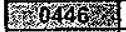 & 18 & 17 a 26 anos & 1 a $5 \mathrm{SM}$ & 5 & 4 & 3 & 2 & 1 \\
\hline 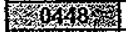 & 7 & 17 a 26 anos & 26 ou mais SM & 5 & 4 & 3 & 2 & 1 \\
\hline - & & 17 a 26 anos & 26 ou mais SM & 5 & 4 & 3 & 2 & 1 \\
\hline 50400 & 12 & 17 a 26 anos & 6 a $10 \mathrm{SM}$ & 5 & 4 & 3 & 2 & 1 \\
\hline $5_{3}^{2}$ & 4 & 17 a 26 anos & 6 a $10 \mathrm{SM}$ & 5 & 4 & 3 & 2 & 1 \\
\hline 3. & 1 & 17 a 26 anos & 1 a $5 \mathrm{SM}$ & 5 & 4 & 3 & 2 & 1 \\
\hline Wotst & 18 & 27 a 36 anos & 6 a $10 \mathrm{SM}$ & 5 & 4 & 3 & 2 & 1 \\
\hline 0455 & 4 & 27 a 36 anos & $6 \mathrm{a} 10 \mathrm{sm}$ & 5 & 4 & 3 & 2 & 1 \\
\hline 2. & 7 & 17 a 26 anos & 1 a $5 \mathrm{SM}$ & 5 & 4 & 3 & 2 & 1 \\
\hline 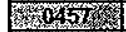 & & 17 a 26 anos & 6 a $10 \mathrm{SM}$ & 5 & 4 & 3 & 2 & 1 \\
\hline 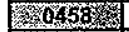 & 3 & 17 a 26 anos & 26 ou mais SM & 5 & 4 & 3 & 2 & 1 \\
\hline 滘 & 18 & 17 a 26 anos & 26 ou mais SM & 5 & 4 & 3 & 2 & 1 \\
\hline 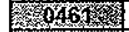 & 15 & 17 a 26 anos & 11 a $15 \mathrm{SM}$ & 5 & 4 & 3 & 2 & 1 \\
\hline 50162 & 2 & 17 a 26 anos & 26 ou mais $S M$ & 5 & 4 & 3 & 2 & 1 \\
\hline 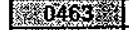 & 7 & 17 a 26 anos & 26 ou mais SM & 5 & 4 & 3 & 2 & 1 \\
\hline 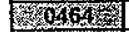 & 3 & 17 a 26 anos & 26 ou mais $S M$ & 5 & 4 & 3 & 2 & 1 \\
\hline 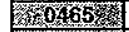 & 6 & 17 a 26 anos & 6 a $10 \mathrm{SM}$ & 5 & 4 & 3 & 2 & 1 \\
\hline 56066 & 6 & 17 a 26 anos & 1 a $5 \mathrm{SM}$ & 5 & 4 & 3 & 2 & 1 \\
\hline 0 & 14 & 17 a 26 anos & 6 a $10 \mathrm{SM}$ & 5 & 4 & 3 & 2 & 1 \\
\hline 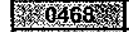 & 13 & 17 a 26 anos & 1a $5 \mathrm{SM}$ & 5 & 4 & 3 & 2 & 1 \\
\hline 6469 & 1 & 17 a 26 anos & 26 ou mais SM & 5 & 4 & 3 & 2 & 1 \\
\hline 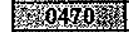 & 14 & 27 a 36 anos & s a $5 \mathrm{SM}$ & 5 & 4 & 3 & 2 & 1 \\
\hline $2_{2}^{2}$ & 15 & 17 a 26 anos & 6 a $10 \mathrm{SM}$ & 5 & 4 & 3 & 2 & 1 \\
\hline 204 & 9 & 17 a 26 anos & 11 a $15 \mathrm{SM}$ & 5 & 4 & 3 & 2 & 1 \\
\hline 60483 & 8 & 17 a 26 anos & 6 a $10 \mathrm{SM}$ & 5 & 4 & 3 & 2 & 1 \\
\hline 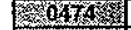 & 6 & 17 a 26 anos & 6 a $10 \mathrm{SM}$ & 5 & 4 & 3 & 2 & 1 \\
\hline 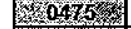 & 3 & 17 a 26 anos & 6 a $10 \mathrm{SM}$ & 5 & 4 & 3 & 2 & 1 \\
\hline 046 & 6 & 17 a 26 anos & 1 a $5 \mathrm{SM}$ & 5 & 4 & 3 & 2 & 1 \\
\hline 40472 & 9 & 17 a 26 anos & 26 ou mais $S M$ & 5 & 4 & 3 & 2 & 1 \\
\hline 3n & 5 & 17 a 26 anos & 1 a $5 \mathrm{SM}$ & 5 & 4 & 3 & 2 & 1 \\
\hline 烈 0479 & 1 & 17 a 26 anos & 1a $5 \mathrm{SM}$ & 5 & 4 & 3 & 2 & 1 \\
\hline 40 & 18 & 17 a 26 anos & 26 ou mais SM & 5 & 4 & 3 & 2 & 1 \\
\hline 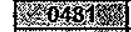 & 13 & 17 a 26 anos & 6 a $10 \mathrm{SM}$ & 5 & 4 & 3 & 2 & 1 \\
\hline 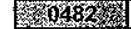 & & 17 a 26 anos & 26 ou mais SM & 5 & 4 & 3 & 2 & 1 \\
\hline 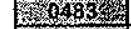 & 18 & 17 a 26 anos & 26 ou mais SM & 5 & 4 & 3 & 2 & 1 \\
\hline (2) & 18 & 27 a 36 anos & 1 a $5 \mathrm{SM}$ & 5 & 4 & 3 & 2 & 1 \\
\hline - & 17 & 17 a 26 anos & 1 a 5 SM & 5 & 4 & 3 & 2 & 1 \\
\hline 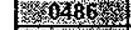 & 17 & 17 a 26 anos & 1 a 5 SM & 5 & 4 & 3 & 2 & 1 \\
\hline 6433 & 10 & 17 a 26 anos & 1 a $5 \mathrm{SM}$ & 5 & 4 & 3 & 2 & 1 \\
\hline 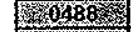 & 15 & 27 a 36 anos & 1 a 5 SM & 5 & 4 & 3 & 2 & 1 \\
\hline 0480 & 12 & 17 a 26 anos & 1 a $5 \mathrm{SM}$ & 5 & 4 & 3 & 2 & 1 \\
\hline 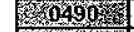 & 12 & 17 a 26 anos & 26 ou mais SM & 5 & 4 & 3 & 2 & 1 \\
\hline 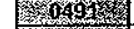 & 1 & 17 a 26 anos & 26 ou mais $\mathrm{SM}$ & 5 & 4 & 3 & 2 & 1 \\
\hline 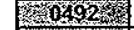 & 15 & 17 a 26 anos & 26 ou mais SM & 5 & 4 & 3 & 2 & 1 \\
\hline 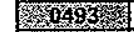 & 9 & 17 a 26 anos & 26 ou mais SM & 5 & 4 & 3 & 2 & 1 \\
\hline Sorot & 18 & 17 a 26 anos & 1 a $5 \mathrm{SM}$ & 5 & 4 & 3 & 2 & 1 \\
\hline 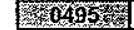 & 2 & 17 a 26 anos & 26 ou mais SM & 5 & 4 & 3 & 2 & 1 \\
\hline 60 & 6 & 17 a 26 anos & 6 a $10 \mathrm{SM}$ & 5 & 4 & 3 & 2 & 1 \\
\hline 0497 & 8 & 27 a 36 anos & 1 a $5 \mathrm{SM}$ & 5 & 4 & 3 & 2 & 1 \\
\hline 0408 & 18 & 17 a 26 anos & 11 a $15 \mathrm{SM}$ & 5 & 4 & 3 & 2 & 1 \\
\hline (5) & 15 & 17 a 26 anos & 26 ou mais SM & 5 & 4 & 3 & 2 & 1 \\
\hline 0500 & 1 & 17 a 26 anos & 11 a $15 \mathrm{SM}$ & 5 & 4 & 3 & 2 & 1 \\
\hline 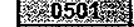 & 17 & 17 a 26 anos & 26 ou mais SM & 5 & 4 & 3 & 2 & 1 \\
\hline 0508 & 18 & 17 a 26 anos & 1 a $5 \mathrm{SM}$ & 5 & 4 & 3 & 2 & 1 \\
\hline 0503 & 1 & 27 a 36 anos & 6 a $10 \mathrm{sM}$ & 5 & 4 & 3 & 2 & 1 \\
\hline - & 1 & 17 a 26 anos & i a 5 SM & 5 & 4 & 3 & 2 & 1 \\
\hline 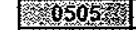 & 11 & 27 a 36 anos & 1 a $5 \mathrm{SM}$ & 5 & 4 & 3 & 2 & 1 \\
\hline ras & 18 & 17 a 26 anos & 1 a $5 \mathrm{SM}$ & 5 & 4 & 3 & 2 & 1 \\
\hline 0.507 & 16 & 17 a 26 anos & 6 a to sim & 5 & 4 & 3 & 2 & 1 \\
\hline 0508 淁 & 5 & 17 a 26 anos & 1 a $5 \mathrm{SM}$ & 5 & 4 & 3 & 2 & 1 \\
\hline 0502 & 12 & 17 a 26 anos & 6 a $10 S M$ & 5 & 4 & 3 & 2 & 1 \\
\hline 05105 & 17 & 17 a 26 anos & 11 a $15 \mathrm{SM}$ & 5 & 4 & 3 & 2 & 1 \\
\hline 0517 & 18 & 17 a 26 anos & 6 a $10 \mathrm{sM}$ & 5 & 4 & 3 & 2 & 1 \\
\hline 5 & 9 & 17 a 26 anos & 1 a $5 S M$ & 5 & 4 & 3 & 2 & 1 \\
\hline 6513 & 17 & 27 a 36 anos & 1 a $5 \mathrm{SM}$ & 5 & 4 & 3 & 2 & 1 \\
\hline
\end{tabular}




\begin{tabular}{|c|c|c|c|c|c|c|c|c|}
\hline 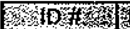 & 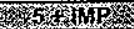 & 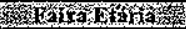 & 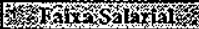 & Ps & Resoiziti & 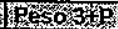 & Pes oy p & Res \\
\hline 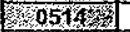 & 7 & 27 a 36 anos & 6 a $10 \mathrm{SM}$ & 5 & 4 & 3 & 2 & 1 \\
\hline 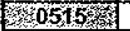 & 4 & 17 a 26 anos & 1 a $5 \mathrm{SM}$ & 5 & 4 & 3 & 2 & 1 \\
\hline 30516 & 14 & 17 a 26 anos & 26 ou mais SM & 5 & 4 & 3 & 2 & 1 \\
\hline $051 \mathrm{r}$ & 3 & 17 a 26 anos & 6 a $10 \mathrm{SM}$ & 5 & 4 & 3 & 2 & 1 \\
\hline 0518 . & 1 & 17 a 26 anos & 11 a $15 \mathrm{SM}$ & 5 & 4 & 3 & 2 & 1 \\
\hline 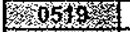 & & 17 a 26 anos & 6 a $10 \mathrm{SM}$ & 5 & 4 & 3 & 2 & 1 \\
\hline 0520 & 1 & 17 a 26 anos & $1 \mathrm{a} 5 \mathrm{SM}$ & 5 & 4 & 3 & 2 & 1 \\
\hline 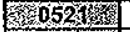 & & 17 a 26 anos & 26 ou mais $S M$ & 5 & 4 & 3 & 2 & 1 \\
\hline 0522 & 18 & 17 a 26 anos & 1 a 5 SM & 5 & 4 & 3 & 2 & 1 \\
\hline 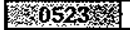 & & 17 a 26 anos & 26 ou mais SM & 5 & 4 & 3 & 2 & 1 \\
\hline 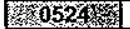 & 7 & 17 a 26 anos & 26 ou mais SM & 5 & 4 & 3 & 2 & 1 \\
\hline 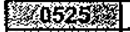 & 17 & 17 a 26 anos & 26 ou mais SM & 5 & 4 & 3 & 2 & 1 \\
\hline 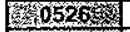 & 1 & 17 a 26 anos & 1 a $5 S M$ & 5 & 4 & 3 & 2 & 1 \\
\hline 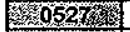 & 1 & 17 a 26 anos & 1 a $5 \mathrm{SM}$ & 5 & 4 & 3 & 2 & $i$ \\
\hline 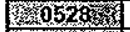 & 9 & 17 a 26 anos & 1 a $5 \mathrm{SM}$ & 5 & 4 & 3 & 2 & 1 \\
\hline 0529 & 2 & 17 a 26 anos & 26 ou mais SM & 5 & 4 & 3 & 2 & 1 \\
\hline 4. 0530 & 7 & 17 a 26 anos & 26 ou mais SM & 5 & 4 & 3 & 2 & 1 \\
\hline 0534 & 6 & 17 a 26 anos & 1 a 5 SM & 5 & 4 & 3 & 2 & 1 \\
\hline 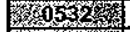 & 18 & 27 a 36 anos & 26 ou mais SM & 5 & 4 & 3 & 2 & 1 \\
\hline ( & & 17 a 26 anos & 26 ou mais SM & 5 & 4 & 3 & 2 & 1 \\
\hline 053 ; & 6 & 27 a 36 anos & 1 a $5 \mathrm{SM}$ & 5 & 4 & 3 & 2 & 1 \\
\hline 0535 & 15 & 17 a 26 anos & 1 a $5 \mathrm{SM}$ & 5 & 4 & 3 & 2 & 1 \\
\hline K⿸厂 & 14 & 17 a 26 anos & 1 a 5 SM & 5 & 4 & 3 & 2 & 1 \\
\hline 053 & 3 & 27 a 36 anos & 6 a $10 \mathrm{SM}$ & 5 & 4 & 3 & 2 & $i$ \\
\hline 1358 & 18 & 17 a 26 anos & 1 a 5 SM & 5 & 4 & 3 & 2 & 1 \\
\hline 65 39 , & 14 & 27 a 36 anos & 6 a $10 \mathrm{SM}$ & 5 & 4 & 3 & 2 & 1 \\
\hline 3540 & 2 & 17 a 26 anos & 26 ou mais SM & 5 & 4 & 3 & 2 & 1 \\
\hline 䈘os & 4 & 37 a 46 anos & 1 a $5 \mathrm{SM}$ & 5 & 4 & 3 & 2 & 1 \\
\hline 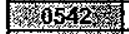 & 11 & 17 a 26 anos & 16 a $20 \mathrm{SM}$ & 5 & 4 & 3 & 2 & 1 \\
\hline 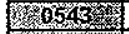 & & 17 a 26 anos & 26 ou mais SM & 5 & 4 & 3 & 2 & 1 \\
\hline 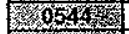 & 7 & 17 a 26 anos & 1 a $5 \mathrm{SM}$ & 5 & 4 & 3 & 2 & 1 \\
\hline 䇣 0545 & 18 & 17 a 26 anos & 26 ou mais SM & 5 & 4 & 3 & 2 & 1 \\
\hline 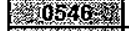 & & 17 a 26 anos & 26 ou mais SM & 5 & 4 & 3 & 2 & 1 \\
\hline 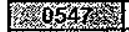 & 13 & 17 a 26 anos & 26 ou mais SM & 5 & 4 & 3 & 2 & 1 \\
\hline - & 18 & 17 a 26 anos & 1 as SM & 5 & 4 & 3 & 2 & 1 \\
\hline 0550 & 5 & 17 a 26 anos & 6 a $10 \mathrm{SM}$ & 5 & 4 & 3 & 2 & 1 \\
\hline 烈 & 13 & 17 a 26 anos & 1 a $5 \mathrm{SM}$ & 5 & 4 & 3 & 2 & 1 \\
\hline 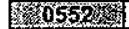 & 18 & 17 a 26 anos & 26 ou mais SM & 5 & 4 & 3 & 2 & 1 \\
\hline mo55 & & 17 a 26 anos & 6 a $10 \mathrm{SM}$ & 5 & 4 & 3 & 2 & 1 \\
\hline 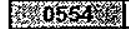 & 13 & 27 a 36 anos & 26 ou mais $S M$ & 5 & 4 & 3 & 2 & 1 \\
\hline 4055s & & Sem Resposta & 26 ou mais SM & 5 & 4 & 3 & 2 & 1 \\
\hline 26 0556 & 17 & 17 a 26 anos & 11 a $15 \mathrm{SM}$ & 5 & 4 & 3 & 2 & 1 \\
\hline 0557 䈣 & 6 & 27 a 36 anos & 1 a $5 \mathrm{SM}$ & 5 & 4 & 3 & 2 & 1 \\
\hline 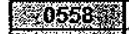 & 1 & 27 a 36 anos & 26 ou mais SM & 5 & 4 & 3 & 2 & 1 \\
\hline 60560 & 13 & 17 a 26 anos & 26 ou mais SM & 5 & 4 & 3 & 2 & 1 \\
\hline S 05615 & 9 & 17 a 26 anos & 16 a $20 \mathrm{SM}$ & 5 & 4 & 3 & 2 & 1 \\
\hline 10562 & 7 & 17 a 26 anos & 6 a $10 \mathrm{SM}$ & 5 & 4 & 3 & 2 & 1 \\
\hline 0568 & 13 & 17 a 26 anos & 6 a $10 S M$ & 5 & 4 & 3 & 2 & 1 \\
\hline 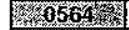 & 18 & 17 a 26 anos & 26 ou mais SM & 5 & 4 & 3 & 2 & 1 \\
\hline 26.5. & 18 & 17 a 26 anos & 1 a $5 \mathrm{SM}$ & 5 & 4 & 3 & 2 & 1 \\
\hline 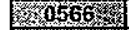 & 14 & 17 a 26 anos & 26 ou mais $S M$ & 5 & 4 & 3 & 2 & 1 \\
\hline 䇥 $050 \%$ & 14 & 17 a 26 anos & 16 a $20 \mathrm{SM}$ & 5 & 4 & 3 & 2 & 1 \\
\hline res68 & 14 & 17 a 26 anos & 1 a $5 \mathrm{SM}$ & 5 & 4 & 3 & 2 & 1 \\
\hline 0569 - & 6 & 17 a 26 anos & 16 a $20 \mathrm{SM}$ & 5 & 4 & 3 & 2 & 1 \\
\hline 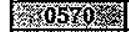 & 11 & 17 a 26 anos & 26 ou mais SM & 5 & 4 & 3 & 2 & 1 \\
\hline 0,2 & 1 & 17 a 26 anos & 6 a $10 \mathrm{SM}$ & 5 & 4 & 3 & 2 & 1 \\
\hline mo5 30 & 14 & 27 a 36 anos & 16 a $20 \mathrm{SM}$ & 5 & 4 & 3 & 2 & 1 \\
\hline 205133 & 15 & 17 a 26 anos & 6 a $10 S M$ & 5 & 4 & 3 & 2 & 1 \\
\hline 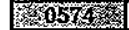 & 10 & 17 a 26 anos & 6 a $10 \mathrm{SM}$ & 5 & 4 & 3 & 2 & 1 \\
\hline 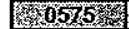 & 11 & 17 a 26 anos & 6 a $10 \mathrm{SM}$ & 5 & $\overline{4}$ & 3 & 2 & 1 \\
\hline 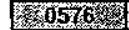 & 5 & 17 a 26 anos & 26 ou mais SM & 5 & 4 & 3 & 2 & 1 \\
\hline 057 x & 12 & 17 a 26 anos & $135 \mathrm{SM}$ & 5 & 4 & 3 & 2 & 1 \\
\hline 6 & 9 & 17 a 26 anos & 26 ou mais SM & 5 & 4 & 3 & 2 & 7 \\
\hline E 0579 & 3 & 17 a 26 anos & 16 a $20 \mathrm{SM}$ & 5 & 4 & 3 & 2 & 1 \\
\hline 0580 & 12 & 27 a 36 anos & 26 ou mais SM & 5 & 4 & 3 & 2 & 1 \\
\hline - & 11 & 17 a 26 anos & 6 a $10 \mathrm{SM}$ & 5 & 4 & 3 & $\overline{2}$ & 1 \\
\hline 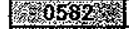 & 18 & 17 a 26 anos & 11 a $15 \mathrm{SM}$ & 5 & 4 & 3 & 2 & $T$ \\
\hline 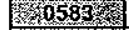 & 10 & 17 a 26 anos & 26 ou mais SM & 5 & 4 & 3 & 2 & 1 \\
\hline $5_{5}$ & 4 & 17 a 26 anos & 26 ou mais SM & 5 & 4 & 3 & 2 & 1 \\
\hline 10585 & 6 & 27 a 36 anos & 6 a $10 \mathrm{SM}$ & 5 & 4 & 3 & 2 & 1 \\
\hline 50586 . & 14 & 17 a 26 anos & 6 a $10 \mathrm{SM}$ & 5 & 4 & 3 & 2 & 1 \\
\hline S & 17 & 27 a 36 anos & 11 a $15 \mathrm{SM}$ & 5 & 4 & 3 & 2 & 1 \\
\hline $0588 \mathrm{~g}$ & 14 & 17 a 26 anios & 26 ou mais SM & 5 & 4 & 3 & 2 & 1 \\
\hline 10589 & & 17 a 26 anos & 26 ou mais SM & 5 & 4 & 3 & 2 & -1 \\
\hline 0590 & 1 & 37 a 46 anos & 26 ou mais SM & 5 & 4 & 3 & 2 & 1 \\
\hline 15991 & 2 & 27 a 36 anos & $6310 \mathrm{SM}$ & 5 & 4 & 3 & 2 & 1 \\
\hline 10592 & 8 & 27 a 36 anios & 1 a $5 \mathrm{SM}$ & 5 & 4 & 3 & 2 & 1 \\
\hline 0593 & 1 & 17 a 26 anos & 1 a 5 SM & 5 & 4 & 3 & 2 & 1 \\
\hline 0594 樂 & 5 & 17 a 26 anos & $1 \mathrm{a} 5 \mathrm{SM}$ & 5 & 4 & 3 & 2 & 1 \\
\hline 0559 & 7 & 17 a 26 anos & 1 a $5 \mathrm{SM}$ & 5 & 4 & 3 & 2 & 1 \\
\hline 0596 & 13 & 27 a 36 anos & 1 a $5 \mathrm{SM}$ & 5 & 4 & 3 & 2 & $i$ \\
\hline$y_{3} 6597$ & 13 & 17 a 26 anos & 6 a $10 \mathrm{SM}$ & 5 & 4 & 3 & 2 & 1 \\
\hline S & 5 & 17 a 26 anos & 1 a $5 S M$ & 5 & 4 & 3 & 2 & 1 \\
\hline 邆 & $t$ & 17 a 26 anos & $1 \mathrm{aSSM}$ & 5 & 4 & 3 & 2 & 1 \\
\hline
\end{tabular}




\begin{tabular}{|c|c|c|c|c|c|c|c|c|}
\hline r & 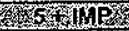 & 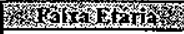 & W & $\mathrm{P}$ - & PDSO & hosons & Pesoly & RSSOLAR \\
\hline 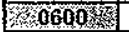 & 18 & 17 a 26 anos & $6 a 10 \mathrm{SM}$ & 5 & 4 & 3 & 2 & 1 \\
\hline 060 S & & 17 a 26 anos & 26 ou mais SM & 5 & 4 & 3 & 2 & 1 \\
\hline 0602 & 13 & 17 a 26 anos & 6 a $10 \mathrm{SM}$ & 5 & 4 & 3 & 2 & 1 \\
\hline 00603 & 1 & 17 a 26 anos & 1 a $5 \mathrm{SM}$ & 5 & 4 & 3 & 2 & 1 \\
\hline W 0606 & 13 & 17 a 26 anos & 6 a $10 \mathrm{SM}$ & 5 & 4 & 3 & 2 & 1 \\
\hline 察观605 & 2 & 17 a 26 anos & 1 a $5 \mathrm{SM}$ & 5 & 4 & 3 & 2 & 1 \\
\hline 6506 & 3 & 17 a 26 anos & 1 a 5 SM & 5 & 4 & 3 & 2 & 1 \\
\hline 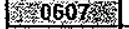 & 3. & 17 a 26 anos & 6 a $10 \mathrm{SM}$ & 5 & 4 & 3 & 2 & 1 \\
\hline 0608 & 18 & 27 a 36 anos & 1 a $5 \mathrm{SM}$ & 5 & 4 & 3 & 2 & 1 \\
\hline 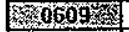 & 17 & 37 a 46 anos & 1 a $5 \mathrm{SM}$ & 5 & 4 & 3 & 2 & 1 \\
\hline 30610 & 8 & Sem Resposta & 26 ou mais SM & 5 & 4 & 3 & 2 & 1 \\
\hline 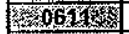 & 18 & 17 a 26 anos & 1 a $5 \mathrm{SM}$ & 5 & 4 & 3 & 2 & 1 \\
\hline 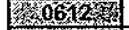 & & 17 a 26 anos & 1 a $5 \mathrm{SM}$ & 5 & 4 & 3 & 2 & 1 \\
\hline 36. & 9 & 27 a 36 anos & 1 a5 SM & 5 & 4 & 3 & 2 & 1 \\
\hline 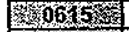 & 8 & 17 a 26 anos & 1 a $5 \mathrm{SM}$ & 5 & 4 & 3 & 2 & 1 \\
\hline S6 06165 & 18 & 27 a 36 anos & 11 a $15 \mathrm{SM}$ & 5 & 4 & 3 & 2 & 1 \\
\hline 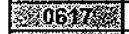 & 1 & 17 a 26 anos & 6 a $10 \mathrm{SM}$ & 5 & 4 & 3 & 2 & 1 \\
\hline 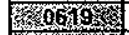 & 3 & 27 a 36 anos & 26 ou mais SM & 5 & 4 & 3 & 2 & 1 \\
\hline 306200 & 2 & 17 a 26 anos & ta $5 \mathrm{SM}$ & 5 & 4 & 3 & 2 & 1 \\
\hline 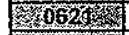 & 5 & 27 a 36 anos & 6 a $10 S M$ & 5 & 4 & 3 & 2 & 1 \\
\hline 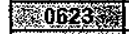 & 14 & 27 a 36 anos & 6 a $10 \mathrm{SM}$ & 5 & 4 & 3 & 2 & 1 \\
\hline 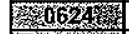 & 2 & 17 a 26 anos & 1 a $5 \mathrm{SM}$ & 5 & 4 & 3 & 2 & 1 \\
\hline $0, B_{2} 5$ & 2 & 17 a 26 anos & 1. $5 \mathrm{SM}$ & 5 & 4 & 3 & 2 & 1 \\
\hline 606265 & 18 & 47 a 56 anos & 21 a 25 SM & 5 & 4 & 3 & 2 & 1 \\
\hline S & 18 & 17 a 26 anos & 6 a $10 \mathrm{SM}$ & 5 & 4 & 3 & 2 & 1 \\
\hline S 0628 & 17 & 27 a 36 anos & 1 . $5 \mathrm{SM}$ & 5 & 4 & 3 & 2 & 1 \\
\hline S. & 18 & 27 a 36 anos & 6 a $10 \mathrm{SM}$ & 5 & 4 & 3 & 2 & 1 \\
\hline 的 & 2 & 17 a 26 anos & 6 a $10 \mathrm{SM}$ & 5 & 4 & 3 & 2 & 1 \\
\hline 60632 & 18 & 17 a 26 anos & 16 a $20 \mathrm{SM}$ & 5 & 4 & 3 & 2 & 1 \\
\hline S & 1 & 17 a 26 anos & 1 a $5 \mathrm{SM}$ & 5 & 4 & 3 & 2 & 1 \\
\hline 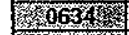 & 18 & 27 a 36 anos & 1 a $5 \mathrm{SM}$ & 5 & 4 & 3 & 2 & 1 \\
\hline - & 3 & 27 a 36 anos & 11 a $15 \mathrm{SM}$ & 5 & 4 & 3 & 2 & 1 \\
\hline 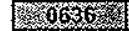 & 18 & 37 a 46 anos & 6 a $10 \mathrm{SM}$ & 5 & 4 & 3 & 2 & 1 \\
\hline 5063 & 4 & 27 a 36 anos & 6 a $10 \mathrm{SM}$ & 5 & 4 & 3 & 2 & 1 \\
\hline 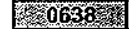 & 13 & 27 a 36 anos & 1 a $5 \mathrm{SM}$ & 5 & 4 & 3 & 2 & 1 \\
\hline 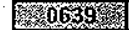 & 4 & 27 a 36 anos & 1 a $5 \mathrm{SM}$ & 5 & 4 & 3 & 2 & 1 \\
\hline 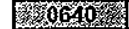 & 4 & 17 a 26 anos & 6 a $10 \mathrm{SM}$ & 5 & 4 & 3 & 2 & $t$ \\
\hline 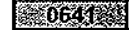 & 15 & 17 a 26 anos & 1 a $5 \mathrm{SM}$ & 5 & 4 & 3 & 2 & 1 \\
\hline 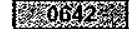 & 11 & 17 a 26 anos & $6 a 10 \mathrm{SM}$ & 5 & 4 & 3 & 2 & 1 \\
\hline 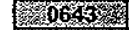 & 12 & 17 a 26 anos & 6 a $10 \mathrm{SM}$ & 5 & 4 & 3 & 2 & 1 \\
\hline 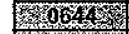 & 18 & 17 a 26 anos & 1 a5 SM & 5 & 4 & 3 & 2 & 1 \\
\hline 20 045 & 9 & 17 a 26 anos & 6 a $10 \mathrm{SM}$ & 5 & 4 & 3 & 2 & 1 \\
\hline - 0646 & 14 & 17 a 26 anos & 6 a $10 S M$ & 5 & 4 & 3 & 2 & 1 \\
\hline 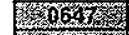 & 7 & 17 a 26 anos & 11 a $15 \mathrm{SM}$ & 5 & 4 & 3 & 2 & 1 \\
\hline 留 & 11 & 17 a 26 anos & 1 a $5 S M$ & 5 & 4 & 3 & 2 & 1 \\
\hline 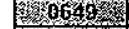 & 4 & 27 a 36 anos & 6 a $10 \mathrm{SM}$ & 5 & 4 & 3 & 2 & 1 \\
\hline 20650 & 12 & 17 a 26 anos & 11 a $15 \mathrm{SM}$ & 5 & 4 & 3 & 2 & 1 \\
\hline (66510 & 14 & 17 a 26 anos & 26 ou mais SM & 5 & 4 & 3 & 2 & 1 \\
\hline 0.522 & 18 & 17 a 26 anos & $6 \mathrm{a} 10 \mathrm{sM}$ & 5 & 4 & 3 & 2 & 1 \\
\hline 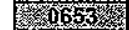 & 6 & 17 a 26 anos & 11 a $15 \mathrm{SM}$ & 5 & 4 & 3 & 2 & 1 \\
\hline (4) & 5 & 17 a 26 anos & 6a $10 \mathrm{SM}$ & 5 & 4 & 3 & 2 & 4 \\
\hline 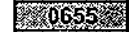 & 7 & 17 a 26 anos & 11 a $15 \mathrm{SM}$ & 5 & 4 & 3 & 2 & 1 \\
\hline 0656 & 1 & 17 a 26 anos & 26 ou mais SM & 5 & 4 & 3 & 2 & 1 \\
\hline 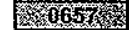 & 15 & 17 a 26 anos & 1 a 5 SM & 5 & 4 & 3 & 2 & $T$ \\
\hline 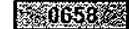 & 13 & 17 a 26 anos & 26 ou mais SM & 5 & 4 & 3 & 2 & 1 \\
\hline 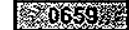 & 2 & 17 a 26 anos & 6 a $10 \mathrm{SM}$ & 5 & 4 & 3 & 2 & 1 \\
\hline 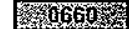 & 4 & 17 a 26 anos & 6 a $10 \mathrm{SM}$ & 5 & 4 & 3 & 2 & 1 \\
\hline 4066 & 13 & 17 a 26 anos & 16 a $20 \mathrm{SM}$ & 5 & 4 & 3 & 2 & 1 \\
\hline (50652 & 18 & 17 a 26 anos & 1a5SM & 5 & 4 & 3 & 2 & 1 \\
\hline 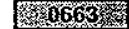 & 4 & 17 a 26 anos & 11 a $15 \mathrm{SM}$ & 5 & 4 & 3 & 2 & 1 \\
\hline 0 & 13 & 17 a 26 anos & 26 ou mais SM & 5 & 4 & 3 & 2 & 1 \\
\hline 6065 & 9 & 17 a 26 anos & 6 a $10 \mathrm{SM}$ & 5 & 4 & 3 & 2 & 1 \\
\hline 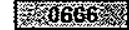 & 3 & 17 a 26 anos & 6 a $10 \mathrm{SM}$ & 5 & 4 & 3 & 2 & 1 \\
\hline 6 & 18 & 17 a 26 anos & $1 \mathrm{a} 5 \mathrm{SM}$ & 5 & 4 & 3 & 2 & 1 \\
\hline - & 18 & 17 a 26 anos & 6 a $10 \mathrm{SM}$ & 5 & 4 & 3 & 2 & 1 \\
\hline 15069 & 10 & 17 a 26 anos & 26 ou mais SM & 5 & 4 & 3 & 2 & 1 \\
\hline 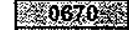 & 6 & 17 a 26 anos & $11 \mathrm{a} 15 \mathrm{SM}$ & 5 & 4 & 3 & 2 & 1 \\
\hline 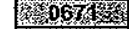 & 3 & 17 a 26 anos & 6 a $10 \mathrm{SM}$ & 5 & 4 & 3 & 2 & 1 \\
\hline S & 15 & 17 a 26 anos & 1 a $5 \mathrm{SM}$ & 5 & 4 & 3 & 2 & 1 \\
\hline 0678 & 2 & 17 a 26 anos & 1a 5 SM & 5 & 4 & 3 & 2 & 1 \\
\hline 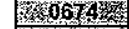 & 17 & 17 a 26 anos & 26 ou mais SM & 5 & 4 & 3 & 2 & 1 \\
\hline 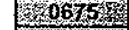 & 4 & 17 a 26 anos & 6 a $10 \mathrm{SM}$ & 5 & 4 & 3 & 2 & 1 \\
\hline 0676 & 10 & 17 a 26 anos & ta5 SM & 5 & 4 & 3 & 2 & 1 \\
\hline 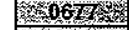 & 12 & 17 a 26 anos & 26 ou mais SM & 5 & 4 & 3 & 2 & 1 \\
\hline 0678 & 18 & 17 a 26 anos & 26 ou mais $S M$ & 5 & 4 & 3 & 2 & 1 \\
\hline W679 & 12 & 17 a 26 anos & 1 a $5 S M$ & 5 & 4 & 3 & 2 & 1 \\
\hline-06812 & 13 & 17 a 26 anos & 11 a 15 SM & 5 & 4 & 3 & 2 & 1 \\
\hline $0068 \%$ & 5 & 17 a 26 anos & 26 ou mais $S M$ & 5 & 4 & 3 & 2 & 1 \\
\hline 00683 & 4 & 27 a 36 anos & 16 a $20 \mathrm{SM}$ & 5 & 4 & 3 & 2 & 1 \\
\hline 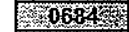 & & 17 a 26 anos & 1 a $5 S M$ & 5 & 4 & 3 & 2 & 1 \\
\hline 3605\% & 17 & 17 a 26 anos & 1 a 5 SM & 5 & 4 & 3 & 2 & 1 \\
\hline 0686 & 11 & 17 a 26 anos & 1 a $5 \mathrm{SM}$ & 5 & 4 & 3 & 2 & 1 \\
\hline 06876 & 13 & 17 a 26 anos & 26 ou mais $\mathrm{SM}$ & 5 & 4 & 3 & 2 & 1 \\
\hline 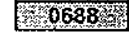 & 1 & 17 a 26 anos & 1. $5 \mathrm{SM}$ & 5 & 4 & 3 & 2 & 1 \\
\hline
\end{tabular}




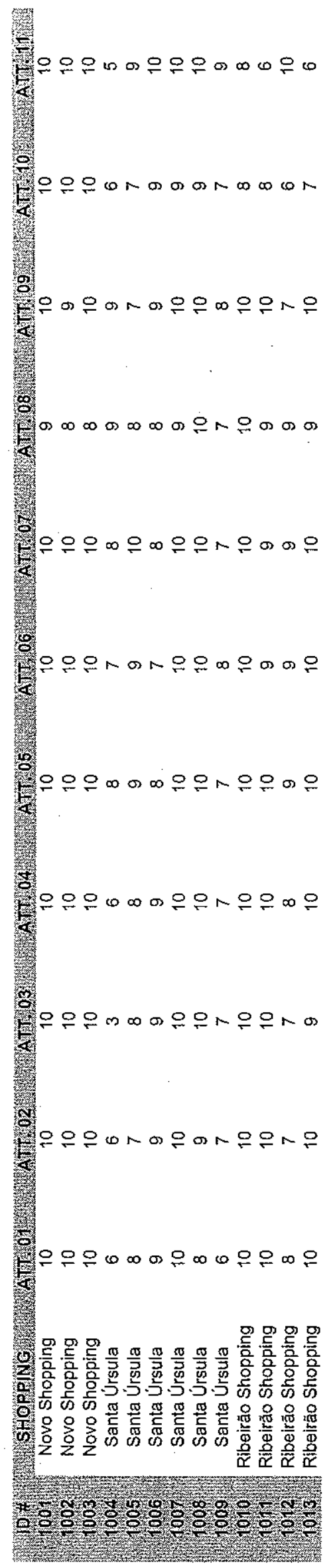




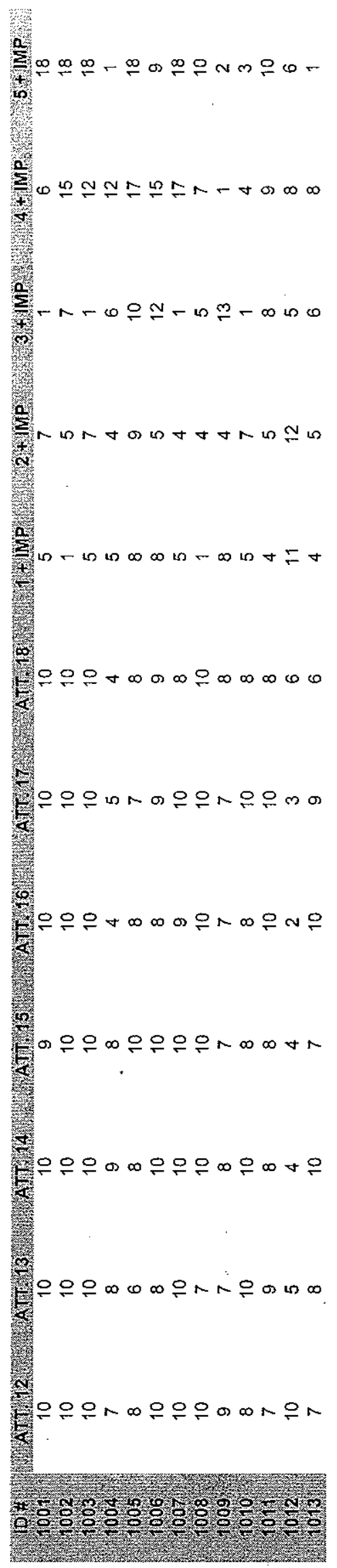

